TECHNICAL REPORT STANDARD TITLE PAGE

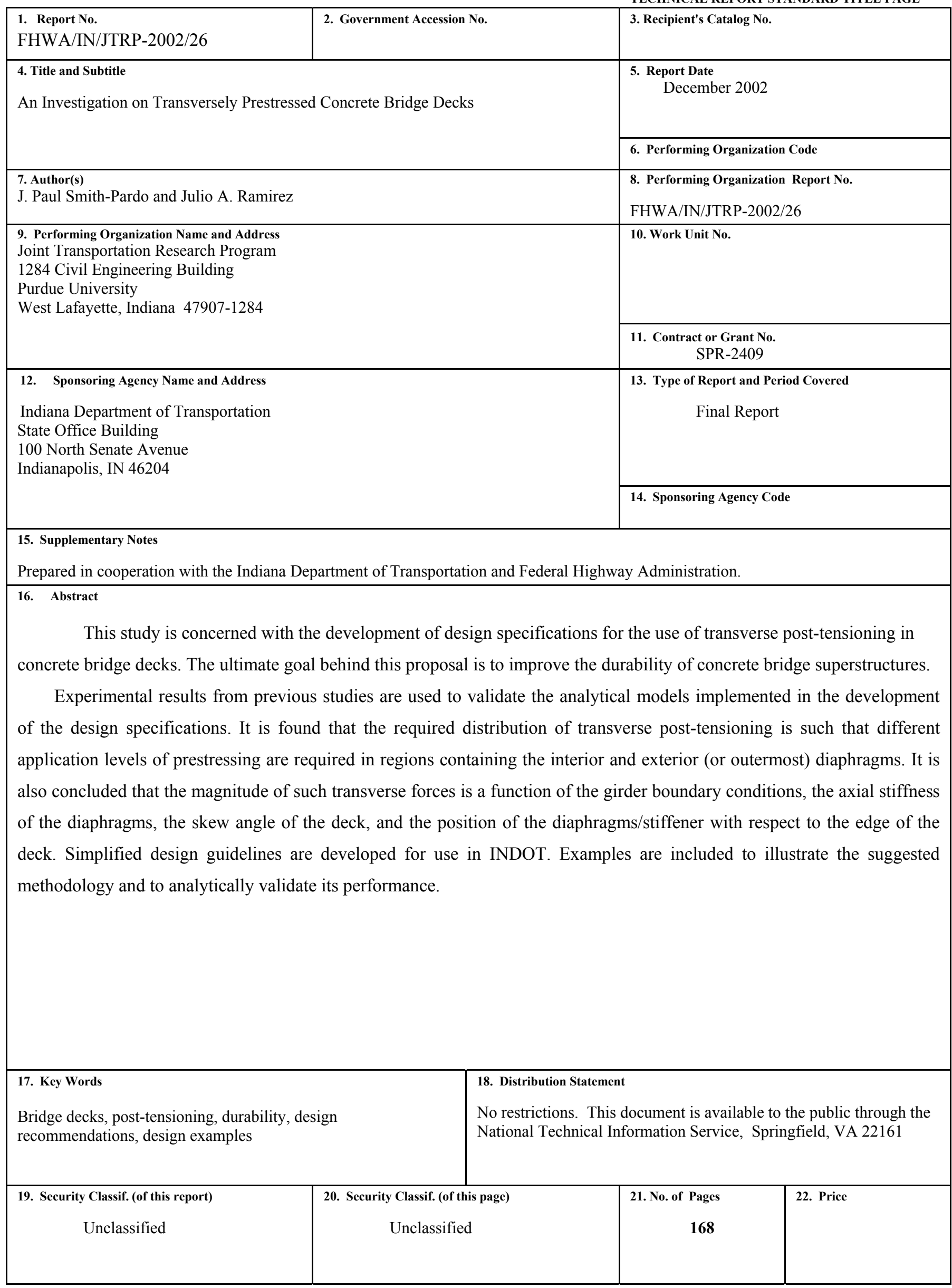




\section{TECHNICAL Summary}

INDOT Research

Technology Transfer and Project Implementation Information

\section{An Investigation on Transversely Prestressed Concrete Bridge Decks}

\section{Introduction}

The conceptual idea of transverse posttensioning bridge superstructures was first implemented during the sixties in Europe as an empirical-based practice. The technique, applicable to cell-box girder bridges exclusively, was intended to (Almustafa, 1983):

- Maximize the length of cantilever overhangs

- Minimize the number of webs

- Improve the connection between longitudinal girders

- Provide better and less congested reinforcement layout at pier locations

Analytical and experimental evidence on the behavior of transversely post-tensioned decks only became available in the mid eighties when a multiphase project was carried out at the University of Texas at Austin (Poston et. al (1984, 1985, 1987, 1989)). The outcome of the Texas Study was a series of design specifications for the use of transverse post-tensioning in concrete bridge decks.

The design specifications developed in this study constitute a more general version of the existing recommendations (Texas recommendations). Improvements include:

(i) General support conditions for girders are possible,

(ii) The effect of the interaction between outermost diaphragms and the boundary conditions of the girder on the distribution of transverse stresses is taken into account,

(iii) The suggested specifications provide the user with more options during the design procedure.
The objective of this research project was to develop general design guidelines for the application of deck edge transverse posttensioning required to meet desirable levels of compression stresses on the top surface of concrete bridge decks. The desired level of compression induced by the transverse posttensioning must be enough to limit the level of tensile stresses at service on the top surface of the deck. Transverse stresses induced by live and dead load are superimposed to the stresses induced by the applied post-tensioning under the assumption of linear elastic behavior. The actual calculation of the transverse stresses induced by live and dead load is beyond the scope of this study.

The investigation is limited to the study of the effect of transverse post-tensioning on slab and deck-on-girder concrete bridges. A recent survey of the Indiana Department of Transportation (INDOT) indicates that about $80 \%$ of the concrete bridge lettings in Indiana during the last 1.5 years (February 2000 to September 2001) are slabs and deck-on-girder. Therefore, the suggested design aids should cover the largest percentage of concrete bridges in Indiana.

The work conducted in this research project is presented in two volumes. The first volume includes information such as: (i) a detailed description of the state-of-the art in the use of the methodology of transverse posttensioning, (ii) an evaluation of alternative modeling techniques using commercial Finite Elements programs, (iii) a preliminary evaluation of the relevant variables. The second volume presents the results from parametric 
studies using SAP2000 and their consequent design implications. This allowed the formulation of detailed design aids and recommendations for the use of transverse post-tensioning.

\section{Findings}

In this study emphasis has been placed on developing general design guidelines for the application of deck edge transverse posttensioning required to meet desirable levels of compression stresses on the top surface of concrete bridge decks. It is found that the required distribution of transverse posttensioning is such that different application levels of prestressing are required in regions containing the interior and exterior (or outermost) diaphragms. It is also concluded that the magnitude of such transverse forces is mainly a function of the girder's boundary conditions, the axial stiffness of the diaphragms, the skew angle of the deck, and the position of the diaphragms/stiffener with respect to the edge of the deck.

Additional findings from this study include:

- Different modeling schemes for a particular deck-on-girder structure subjected to transverse forces only (test model of the Texas study) were found to produce results reasonably similar to the experimental values. Average ratios of calculated to experimentally inferred stresses ranged from 1.10 to 1.15 .

- The influence of the diaphragm position was approximated evaluated considering a T-section having an increasing flange width as the diaphragm is placed closer to mid-span. From this model, it can be seen that the restraining effect of exterior diaphragms is more significant than the effect of interior diaphragms.
- Except for very short spans, the effect of every diaphragm in the superstructure can be taken as independent of the corresponding effect of companion diaphragms. The restraining action of a particular diaphragm is localized in a region of the deck containing such element. Subsequently, prescribing different levels of post-tensioning at different diaphragm regions is possible.

- The use of transverse post-tensioning in integral bent spans is limited in terms of efficiency. The post-tensioning is found to be ineffective in regions close to the integral support. Practically, a scheme of transverse post-tensioning to limit the size of such "ineffective region" can be proposed.

- The parametric study suggests that the methodology of transverse posttensioning is not practical for integralend bridges having skew angles larger than $20^{\circ}$. For such cases the transverse post-tensioning may induce tensile stresses on top of the deck.

- For steel-girder-integral-bent spans, the transverse post-tensioning should be used only if the outermost diaphragm/stiffener is placed not less than $6 \mathrm{ft}$ away from the end of the girder. Otherwise the required transverse force may be excessive.

\section{Implementation}

The data required to use the proposed design guidelines include; diaphragm size and type (concrete or steel), definition of boundary conditions for the girders, position of the outermost diaphragm with respect to the ends of the girders and, deck skew angle. The user has the choice of selecting the widths of the diaphragm regions.
The most practical (and easiest) implementation of the suggested methodology consists in considering only two categories for the boundary conditions of the girders; nonintegral or integral ends. The first case corresponds to girders' ends supported on either rocker or elastomeric bearings, whereas the second case corresponds to integral-abutment 
ends. Two sets of design aids are available depending on the type of girders for the superstructure under consideration; concrete or steel. The user has the alternative of using more general deign guidelines but this requires a more precise definition of the boundary conditions for the girders. In all cases, the suggested distribution of transverse post-tensioning is such that different application levels of prestressing are required in regions containing the interior and exterior (or outermost) diaphragms.

In the case of skew decks, the proposed methodology requires placing the post- tensioning ducts oriented parallel to the skewed edge of the deck. The design specifications are limited to deck skew angles smaller $30^{\circ}$ for nonintegral ends, and $20^{\circ}$ for integral ends.

For steel-girder-integral-bent spans, transverse post-tensioning should be used only if the outermost diaphragm/stiffener is placed not less than $6 \mathrm{ft}$ away from the end of the girder.

The developed design specifications can also be applicable to slab bridges. In this case the user has to consider slab bridges as particular case of deck-on-girder bridges where the area of transverse concrete elements is zero.

\section{Contacts}

For more information:

Prof. Julio Ramirez

Principal Investigator

School of Civil Engineering

Purdue University

West Lafayette IN 47907

Phone: (765) 494-2716

Fax: (765) 496-1105

\author{
Indiana Department of Transportation \\ Division of Research \\ 1205 Montgomery Street \\ P.O. Box 2279 \\ West Lafayette, IN 47906 \\ Phone: (765) 463-1521 \\ Fax: (765) 497-1665
}

\section{Purdue University}

Joint Transportation Research Program

School of Civil Engineering

West Lafayette, IN 47907-1284

Phone: (765) 494-9310

Fax: (765) 496-1105 
Final Report

FHWA/IN/JTRP-2002/26

\title{
AN INVESTIGATION ON TRANSVERSELY PRESTRESSED CONCRETE BRIDGE DECKS
}

\author{
by \\ Julio A. Ramirez \\ Principal Investigator \\ Professor of Civil Engineering \\ and \\ J. Paul Smith-Pardo \\ Graduate Research Assistant \\ School of Civil Engineering \\ Purdue University
Joint Transportation Research Program
Project No. C-36-51ZZ
File No. 7-4-52
SPR-2409
Conducted in Cooperation with the Indiana Department of Transportation and the Federal Highway Administration

The contents of this report reflect the views of the authors, who are responsible for the facts and the accuracy of the data presented herein. The contents do not necessarily reflect the official views or policies of the Indiana Department of Transportation or the Federal Highway Administration at the time of publication. This report does not constitute a standard, specification, or regulation.

\author{
Purdue University \\ West Lafayette, IN 47907
}

December 2002 


\section{Table of Contents}

$1 \quad$ Introduction........................................................ 1

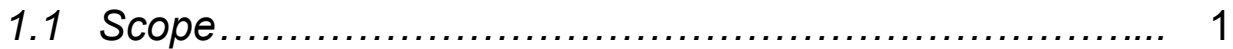

1.2 Problem Statement........................................ 2

1.3 Objective................................................. 2

2 Modeling of Transversely Post-tensioned Deck-on-Girder

Bridges.............................................................. 3

2.1 Alternative Modeling Techniques........................... 3

2.2 Comparison of Results from F.E Analyses and Laboratory Work...................................... 4

2.3 Comparison with Results from Alternate Software.......... 6

3 Identification of Relevant Variables.............................. 30

3.1 Introduction............................................. 30

3.2 Effect of Girders........................................ 31

3.3 Effect of Boundary Conditions............................. 32

3.4 Effect of Spacing of Post-tensioning ........................ 32

3.5 Effect of Deck Thickness.................................. 33

3.6 Effect of Diaphragms................................... 33

$4 \quad$ Parametric Study.................................................... 58

4.1 Notation .................................................. 58

4.2 Base Case and Range of Variables......................... 59

4.3 Minimum and Average Transverse Stress on Different

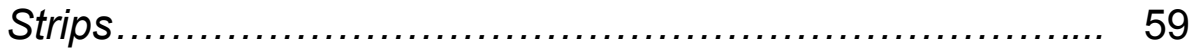




\section{Table of Contents}

$5 \quad$ General Design Provisions.................................... 85

5.1 Recommended Post-tensioning Scheme for Skew Bridges. 85

5.2 Required Post-tensioning Distribution for Base Case Structure ................................................. 86

5.3 Required Post-tensioning Distribution for Any Case Included in the Parametric Study ............................ 88

5.4 Required Post-tensioning Distribution for Integral Bent Bridges............................................... 91

5.5 Required Post-tensioning Distribution for Slab Bridges...... 94

5.6 Estimation of $K_{s}$ for Non-Integral Ends...................... 94

5.7 Design Recommendations for End Spans of Multi-span Integral-Bent Bridges................................... 96

5.8 Maximum Post-tensioning Spacing ......................... 96

5.9 Durability Considerations................................... 97

5.10 Post-tensioning Sequence................................. 99

\section{Simplified Design Procedure for Use in INDOT}

-Detailed Description-........................................ 118

6.1 Deck on Concrete Girder Bridges, Design Aid Set 1

(Figures 6.2- 6.4) ......................................................... 118

6.2 Deck on Steel Girder Bridges, Design Aid Set 2

(Figures 6.5- 6.7) ...................................................... 120 


\section{Table of Contents}

$7 \quad$ Examples and Verification of Design Guidelines.................. 129

7.1 Design Example 1: Nonskew Bridge, Non-integral Girders' Ends

7.2 Design Example 2: End Span of a Multi-Span Integral-Bent Steel Girder Bridge.......................................... 132

7.3 Design Example 3: End Span of a Multi-Span Integral-Bent Skewed Concrete Girder Bridge............................. 136

8 Summary and Implementation..................................... 149

8.1 Summary of Study and Findings.......................... 149

8.2 Conclusions.............................................. 150

8.3 Implementation........................................ 152

$9 \quad$ Future Work........................................................ 154

Appendix A: References................................................. 155

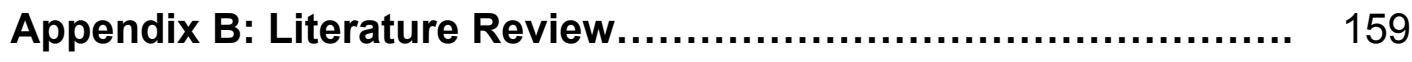




\section{List of Figures}

Figure 2.1 Test Model in the Experimental Study at the University of

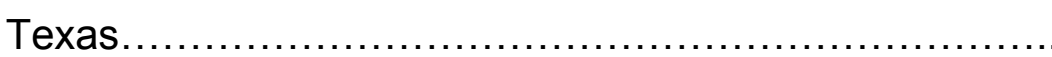

Figure 2.2 Locations of Strain Gages for All-Diaphragm Case of

Texas Study.

Figure 2.3 Locations of Strain Gages for End-Diaphragm Case of

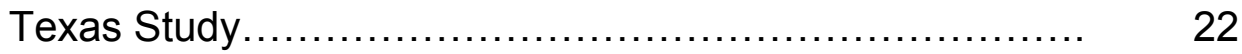

Figure 2.4 (a) 2D Modeling of Test Structure. All-diaphragm Case...... 23

Figure 2.4 (b) 3D-Type I Modeling of Test Structure. All-diaphragm

Case .................................................. 23

Figure 2.4 (c) 3D-Type II Modeling of Test Structure. All-diaphragm

Case.

Figure 2.4 (d) 3D-Type III Modeling of Test Structure. All-diaphragm

Case.

Figure 2.5 (a) 2D Modeling of Test Structure. End-diaphragm

Case......

Figure 2.5 (b) 3D-Type I Modeling of Test Structure. End-diaphragm

Case.

Figure 2.5 (c) 3D-Type II Modeling of Test Structure. End-diaphragm

Case.

26

Figure 2.5 (d) 3D-Type III Modeling of Test Structure. End-diaphragm

Case.

Figure 2.6 Finite Elements in the Model with ANSYS 5.7; slabs as

Shells, and diaphragms and girders as solid brick

elements.

Figure 2.7 Contour plots for the distribution of transverse stresses.

All-diaphragm case of the Texas Study....

Figure 2.8 Contour plots for the distribution of transverse stresses.

End-diaphragm case of the Texas Study .................... 29

Figure 3.1 Base Case Structure. 


\section{List of Figures}

Figure 3.2 Distribution of Transverse Stresses for Base Case

Structure

Figure3.3 Effect of the Girder Spacing.............................. 40

Figure 3.4 Isolated Effect of Girder (no diaphragms) ................... 41

Figure 3.5 Effect of Boundary Conditions............................. 42

Figure 3.6 Effect of Transverse Post-Tensioning Spacing................ 43

Figure 3.7 Effect of Deck Thickness.................................. 44

Figure 3.8 Effect of Diaphragms..................................... 45

Figure 3.9 Definition of Locations, and Lines 1 and 2 .................. 46

Figure 3.10 (a) Transverse Stresses Along Line 1 for

Different Diaphragm Sizes.......................... 47

Figure 3.10 (b) Transverse Stresses Along Line 2 for

Different Diaphragm Sizes............... 48

Figure 3.11 (a) Transverse Stresses Along Line 1 for

Different Diaphragm Sizes. Exterior Diaphragm

Only....................................................

Figure 3.11 (b) Transverse Stresses Along Line 2 for

Different Diaphragm Sizes. Exterior Diaphragm

Only

Figure 3.12 (a) Transverse Stresses Along Line 1 for

Different Diaphragm Sizes. Interior Diaphragm

Only

Figure 3.12 (b) Transverse Stresses Along Line 2 for

Different Diaphragm Sizes. Interior Diaphragm

Only

Figure 3.13 (a) Transverse Stresses Along Line 1 for

Different Diaphragm Locations... 


\section{List of Figures}

Figure 3.13 (b) Transverse Stresses Along Line 2 for

Different Diaphragm Locations..................

Figure 3.14 Top Fiber Stresses in a T-Beam as a Function of Flange Width for a Unit Stress on the Flange...... 55

Figure 3.15 Minimum Stress on Line 1 as a Function of

Diaphragm Location..................................... 56

Figure 3.16 Flange Width of an Equivalent T-Beam as a Function of

Diaphragm Position....................................... 57

Figure 4.1 Notation for Parametric Study .................................... $\quad 65$

Figure 4.2 Base Case Structure for Parametric Study.................. 66

Figure 4.3 (a) Minimum Stress at Different Strips as a Function of Number of Diaphragms.

Figure 4.3 (b) Average Stress at Different Strips as a Function of Number of Diaphragms................................ 68

Figure 4.4 (a) Minimum Stress at Different Strips as a Function of Diaphragm Aspect Ratio.................................

Figure 4.4 (b) Average Stress at Different Strips as a Function of Diaphragm Aspect Ratio.

Figure 4.5 (a) Minimum Stress at Different Strips as a Function of Skew Angle............................................

Figure 4.5 (b) Average Stress at Different Strips as a Function of

Skew Angle.

Figure 4.6 (a) Minimum Stress at Different Strips as a Function of Horizontal Restriction at Girders Ends.....

Figure 4.6 (b) Average Stress at Different Strips as a Function of Horizontal Restriction at Girders Ends. 


\section{List of Figures}

Figure 4.7 (a) Minimum Stress at Different Strips as a Function of Concrete Diaphragm Area.................................

Figure 4.7 (b) Average Stress at Different Strips as a Function of Concrete Diaphragm Area..................................

Figure 4.8 (a) Minimum Stress at Different Strips as a Function of Steel Diaphragm Area.....................................

Figure 4.8 (b) Average Stress at Different Strips as a Function of Steel Diaphragm Area

Figure 4.9 (a) Minimum Stress at Different Strips as a Function of Diaphragm Position.

Figure 4.9 (b) Average Stress at Different Strips as a Function of Diaphragm Position.

Figure 4.10 (a) Minimum Stress at Strip 1 as a Function of Concrete Diaphragm Area and Degree of Restraint at Girders' Ends.

Figure 4.10 (b) Minimum Stress at Strip 3 as a Function of Concrete Diaphragm Area and Degree of Restraint at Girders' Ends.

Figure 4.11 (a) Minimum Stress at Strip 1 as a Function of Steel

Diaphragm Area and Degree of Restraint at Girders'

Ends

Figure 4.11 (b) Minimum Stress at Strip 3 as a Function of Steel

Diaphragm Area and Degree of Restraint at Girders'

Ends.

Figure 5.1 Suggested Distribution of Transverse Post-Tensioning.......

Figure 5.2(a) Required Combination of Diaphragm Region Width and

Extra-PT Force Factor to Have $\sigma_{\min }=0.8$ at Exterior Diaphragm Region. Base Case Structure 


\section{List of Figures}

Figure 5.2(b) Required Combination of Diaphragm Region Width and

Extra-PT Force Factor to Have $\sigma_{\min }=1.0$ at Interior

Diaphragm Region. Base Case Structure.

102

Figure 5.3(a) Extra Post-Tensioning Force Factor at Exterior

Diaphragm

103

Figure 5.3(b) Extra Post-Tensioning Force Factor at Interior

Diaphragm

104

Figure 5.4(a) Extra Post-Tensioning Force Factor at Exterior

Diaphragm Region

105

Figure 5.4(b) Extra Post-Tensioning Force Factor at Interior

Diaphragm Region

106

Figure 5.5 Factor Modifying $\alpha_{\mathrm{e}}$ to Account for Exterior Diaphragm

Position.

107

Figure 5.6 Correction Factor for Skew Angle. Exterior Diaphragm

Region Only.

108

Figure 5.7 Post-tensioning Scheme for Integral-Bent-Concrete-Girder

Bridges.

109

Figure 5.8 Extra Post-tensioning Force Factor at End Regions of

Concrete Girder Integral Abutment Bridges.

Figure 5.9 Post-tensioning Scheme for Integral-Bent-Steel-Girder

Bridges...

Figure 5.10(a) Extra Post-tensioning Force Factor at End Regions of Steel Girder Integral Abutment Bridges. Exterior

Diaphragm Located at $4 \mathrm{ft}$ from End of Deck

Figure 5.10(b) Extra Post-tensioning Force Factor at End Regions of Steel Girder Integral Abutment Bridges. Exterior

Diaphragm Located at $6 \mathrm{ft}$ from End of Deck 


\section{List of Figures}

Figure 5.10(c) Extra Post-tensioning Force Factor at End Regions of Steel Girder Integral Abutment Bridges. Exterior Diaphragm Located at $8 \mathrm{ft}$ from End of Deck............ 114

Figure 5.10(d) Extra Post-tensioning Force Factor at End Regions of Steel Girder Integral Abutment Bridges. Exterior Diaphragm Located at $10 \mathrm{ft}$ from End of Deck.......... 115

Figure 5.11 Derivation of Value of $\mathrm{K}_{\mathrm{s}}$ for Elastomeric Bearings 116

Figure 5.12 Maximum Spacing of Post-tensioning Forces ............... 117

Figure 6.1 General Design Scheme.................................. 122

Plot Set 1. Design Aids for Concrete Girder Bridges..................... 123

Plot Set 2. Design Aids for Concrete Steel Bridges..................... 126

Figure 7.1 Overall View of Bridge Span of Example 1................. 140

Figure 7.2 Required Distribution of Transverse Post-tensioning for

Example 1 141

Figure 7.3 Distribution of Normalized Transverse Stresses on the

Deck of Example 1 (Analysis using SAP2000) 142

Figure 7.4 Overall View of Bridge Span of Example 2................... 143

Figure 7.5 Required Distribution of Transverse Post-tensioning for

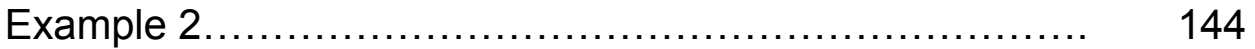

Figure 7.6 Distribution of Normalized Transverse Stresses on the

Deck of Example 2 (Analysis using SAP2000)................ 145

Figure 7.7 Overall View of Bridge Span of Example 3................. 146

Figure 7.8 Required Distribution of Transverse Post-tensioning for

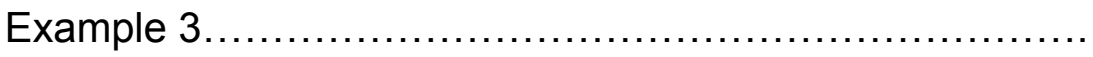

Figure 7.9 Distribution of Normalized Transverse Stresses on the

Deck of Example 3 (Analysis using SAP2000).............. 148

Figure B.1 Diaphragm Region in a Skewed Bridge Deck............... 168 


\section{List of Tables}

Table 2.1 (a) Comparison of Slab Experimental Transverse Stresses and Values from a 2D FE Model. All Diaphragm Case.......

Table 2.1 (b) Comparison of Slab Experimental Transverse Stresses and Values from a 3D Type I FE Model. All Diaphragm Case.

Table 2.1 (c) Comparison of Slab Experimental Transverse Stresses and Values from a 3D Type II FE Model. All Diaphragm Case.

Table 2.1 (d) Comparison of Slab Experimental Transverse Stresses and Values from a 3D Type III FE Model. All Diaphragm Case.

Table 2.2 (a) Comparison of Slab Experimental Transverse Stresses and Values from a 2D FE Model. End Diaphragm Case...

Table 2.2 (b) Comparison of Slab Experimental Transverse Stresses and Values from a 3D Type I FE Model. End Diaphragm Case.

Table 2.2 (c) Comparison of Slab Experimental Transverse Stresses and Values from a 3D Type II FE Model. End Diaphragm Case.

Table 2.2 (d) Comparison of Slab Experimental Transverse Stresses and Values from a 3D Type III FE Model. End Diaphragm Case.

Table 2.3 Comparison of Experimental Transverse Stresses and Values from ANSYS 5.7. All Diaphragm Case

Table 2.4 Comparison of Experimental Transverse Stresses and Values from ANSYS 5.7. End Diaphragm Case..............

Table 2.5 Comparison of Results from ANSYS 5.7 and Results from Sap2000. All Diaphragm Case. 


\section{List of Tables}

Table 2.6 Comparison of Results from ANSYS 5.7 and Results from

Sap2000. End Diaphragm Case............................. 19

Table 4.1 Set of Cases Considered in the Parametric Study............. 64 


\section{1- Introduction}

This study is devoted to the development of preliminary design specifications for the use of transverse post-tensioning as an alternative to delay the onset of deterioration of concrete bridge decks associated with corrosion of the reinforcement. It has been extensively recognized in the literature that flexural cracking accelerates the process of corrosion initiation (Weyers, R.E. et al. (1998), Dagher, H. J. and Kulendran, S. (1992), Suzuki, K. et al. (1990), Beeby A. W. (1981), and Beeby, A. W. (1979)). Poston, R. W. (1984) and by Poston et al. (1985) showed the beneficial effect of using of transverse postensioning as a mechanism to delay the deterioration process of concrete bridge decks associated with corrosion of the reinforcement. A first attempt to develop the corresponding design specifications was made during the first half decade of the eighties at the University of Texas at Austin (see Appendix B). The proposed design specifications in this report use the Texas proposals as the starting point and include suggested improvements.

\subsection{Scope}

The research conducted during the study described in this report is limited to the study of the effect of transverse post-tensioning on slab and, deck-on-girder bridges (includes AASHTO I-beam and Bulb-tee beam bridges). A recent survey of the Indiana Department of Transportation (INDOT) indicates that about $80 \%$ of the concrete bridge lettings in Indiana during the last 1.5 years (February 2000 to September 2001) are slabs and, deck-on-girder types. The suggested design aids should cover the largest percentage of concrete bridges in Indiana. 


\subsection{Problem Statement}

Given a deck-on-girder bridge superstructure under a uniform compression stress applied at the edges of the deck, how are the transverse stresses distributed on the deck?.

It is also important to isolate the effects that are key contributors to the final distribution of the deck transverse stresses resulting from the application of edge post-tensioning forces.

\subsection{Objective}

The objective of this study is to develop design guidelines for the application of deck edge transverse post-tensioning required to meet desirable levels of compression stresses on the top surface of concrete bridge decks. The desired level of compression induced by the transverse post-tensioning must be enough to limit the level of tensile stresses at service on the top surface of the deck. Transverse stresses induced by live and dead load are superimposed to the stresses induced by the applied post-tensioning under the assumption of linear elastic behavior. The actual calculation of the transverse stresses induced by live and dead load is beyond the scope of this study. 


\section{2- Modeling of Transversely Post-tensioned Deck-on-Girder}

\section{Bridges}

\subsection{Alternative Modeling Techniques}

Modeling techniques for deck-on-girder superstructures range from closed-form solutions for particular cases (Westergaard (1930), Duberg et al. (1960), Cao and Shing (1999)) to numerical solutions (Chen, Siess, and Newmark (1975)), and more recently to F.E Modeling techniques. F.E modeling alternatives include:

- 2D models (see for example, Mabsout, 1999): deck, girders, and diaphragms are on the same plane. This implies that in regions of the deck containing the diaphragm, there is a concentration of stiffness. Then for transversely stressed bridge decks this means that the induced transverse stresses decrease in proportion to the magnitude of such extra stiffness. With this type of analysis, the eccentricity effect of the transverse post-tensioning associated with the presence of the diaphragm(s) is not taken into account.

- 3D Models: deck, girders, and diaphragms are placed on different planes. The effect of the eccentricity of the diaphragms with respect to the applied transverse post-tensioning force is taken into account. The reduction in the transverse stresses due to added axial stiffness from the diaphragm is somewhat alleviated by the compression at the top of the slab associated with the eccentric post-tensioning forces. For modeling deck-on-girder bridges, three distinctive alternatives are typically found in the literature (Bishara and Elmir (1990), Bishara et al. (1993), Mabsout et al. (1997), Chan and Chan (1999)). 3D F.E modeling alternatives, referred here as Types I through III, are described next: 
- Type I: Girders and diaphragms are modeled as frame elements rigidly connected to the deck.

- Type II : Flanges and webs of girders are modeled as frame elements and diaphragms as shell elements. Adjacent elements are rigidly connected to each other.

- Type III : Top flange of girders and diaphragms are modeled as frame elements rigidly connected to the deck. Bottom flange and web of girders are modeled as frame and shell elements.

\subsection{Comparison of Results from F.E Analyses and Laboratory Work}

An approximate half scale model deck-on-girder bridge superstructure was tested at the University of Texas (Almustafa, 1983, Mora, 1983, Poston, 1984, Ralls, 1984, Phipps, 1985). Figure 2.1 depicts the relevant geometric characteristics of the test. The applied transverse stress at the edge of the deck was about $0.6 \mathrm{ksi}$, except in $1.8 \mathrm{ft}$-wide regions around the diaphragms where the applied stress was about $1.2 \mathrm{ksi}$. Two test categories were carried out; (i) the first test corresponded to the case where the superstructure had both interior and exterior diaphragms, this was referred to as all-diaphragm case, (ii) the second test category corresponded to the case where interior diaphragms were removed from the superstructure, this was referred to as end-diaphragm case. Only half of the deck was transversely posttensioned during each test.

Mid-depth stresses were reported in this experimental program as the average of the top and bottom surface stresses at each location of the deck. Stresses were inferred from strain gages readings assuming linear response of concrete. Figures 2.2 shows several locations where top and bottom transverse stresses were experimentally obtained (Ralls 
(1984), Almustafa, (1983)) for the all-diaphragm case. Figure 2.3 on the other hand, shows several locations where mid-depth stresses where inferred for the end-diaphragm case. In the experimental phase of the Texas Study, stresses were obtained at locations in addition to the ones indicated in Figures 2.2 and 2.3, however, they are not clearly shown in the reports available (Almustafa (1983), Mora (1983), Ralls (1984), Poston et al. (1985)). The experimental values are compared to the transverse stresses obtained from modeling the test structure using SAP2000 (2D and 3D F.E models).

For the all-diaphragm case, Figures 2.4 (a) through (d) show the resulting transverse stresses at the top of the deck according to $2 \mathrm{D}$, and 3D types I through III F.E analyses. Figures 2.5 (a) through (d) show the results for the end-diaphragm case.

Tables 2.1 (a) through (d) show the comparison of the experimental transverse stresses and the analytical values obtained using 2D, and 3D Types I through III models respectively. The comparison is carried out at every specific strain gage location indicated in Figure 2.2 for the all-diaphragm case. Tables 2.2 (a) through (d) show the comparison for the end-diaphragm case (see Figure 2.3 for locations). The following observations can be made from Tables 2.1 and 2.2:

\section{All-diaphragm case:}

- The average difference between the experimental and the calculated top transverse stresses is $14 \%$ using $3 \mathrm{D} \mathrm{F.E}$ modeling and $16 \%$ using $2 \mathrm{D}$ modeling. However, the maximum difference can be as high as $40 \%$ in both cases.

- The difference between the calculated and the experimental mid-depth transverse stresses is approximately $10 \%$ on average, with a maximum of $20 \%$. There is not significant 
difference in the calculated values using either $2 \mathrm{D}$ or $3 \mathrm{D}$ modeling.

End-diaphragm case:

- The average difference between experimental and calculated mid-depth transverse stresses is $10 \%$ regardless of the modeling technique

- The maximum difference between experimental and calculated mid-depth stresses is $43 \%$ using $2 \mathrm{D}$ modeling and $36 \%$ using $3 \mathrm{D}$ modeling.

\subsection{Comparison with Results from Alternate Software}

The half scale deck-on-girder superstructure described in Section 2.2 was also modeled using the Finite Element program ANSYS, version 5.7. Because the program allows the use of brick elements to model girders and diaphragms, the definition of rigid elements to connect the deck to the diaphragms and to the girders is not longer necessary. The deck was modeled again with shell elements. A deficiency of this modeling scheme is that solid elements only allow the definition of three translations at each node whereas shell elements allow both three translations and three rotations. This implies that there exist incompatibilities of deformations at the deck-girder (and deckdiaphragm) interfaces.

Comparisons of the experimental transverse stresses and the results obtained using ANSYS 5.7 are shown in Tables 2.3 and 2.4. It is noticed from these tables that for the all-diaphragm case (Table 2.3), a better prediction of the experimental values is obtained using ANSYS (12\% error on average for top transverse stresses) than using SAP2000 (14\% error on average for top transverse stresses when using 3D modeling). For the end-diaphragm case, the prediction of experimental 
values using ANSYS is less accurate (14\% on average for mid-depth transverse stresses) than using SAP2000 (10\% on average for middepth transverse stresses).

Tables 2.6 and 2.7 show a comparison of the results from ANSYS 5.7 and SAP2000. It is noticed that the difference between the results from ANSYS and the results from SAP2000 is about $10 \%$ only on average for both the all-diaphragm and the end-diaphragm case.

The similarity of the results obtained using these two F.E programs can also be observed from the contour plots representing the distribution of transverse stresses on the deck shown in Figure 2.7 for the all-diaphragm case and Figure 2.8 for the end-diaphragm case. 
Table 2.1 (a): Comparison of Slab Experimental Transverse Stresses and Values from a 2D FE model. All-Diaphragm Case

\begin{tabular}{|c|c|c|c|c|c|c|c|c|c|}
\hline \multirow{2}{*}{$\begin{array}{l}\text { Location } \\
\text { (see Fig. } 2.2 \text { ) }\end{array}$} & \multicolumn{2}{|c|}{ Experimental, ksi } & \multirow[b]{2}{*}{ Middle } & \multicolumn{2}{|c|}{ 2D, ksi } & \multirow[b]{2}{*}{ Middle } & \multicolumn{2}{|c|}{$\%$ Error, 2D Modeling } & \multirow[b]{2}{*}{ Middle } \\
\hline & Top & Bottom & & Top & Bottom & & Top & Bottom & \\
\hline 1 & 1.00 & 0.60 & 0.80 & 0.87 & 0.95 & 0.91 & 13 & 58 & 14 \\
\hline 2 & 0.98 & & & 0.82 & & & 16 & & \\
\hline 3 & 0.82 & 0.91 & 0.87 & 0.78 & 0.71 & 0.75 & 5 & 22 & 14 \\
\hline 4 & 0.67 & 1.00 & 0.84 & 0.82 & 0.82 & 0.82 & 22 & 18 & 2 \\
\hline 5 & 0.67 & & & 0.76 & & & 13 & & \\
\hline 6 & 0.70 & & & 0.79 & & & 13 & & \\
\hline 7 & 0.70 & 1.10 & 0.90 & 0.75 & 0.78 & 0.77 & 7 & 29 & 15 \\
\hline 8 & 0.76 & 0.57 & 0.67 & 0.76 & 0.86 & 0.81 & 0 & 51 & 22 \\
\hline 9 & 1.56 & 0.90 & 1.23 & 0.94 & 1.10 & 1.02 & 40 & 22 & 17 \\
\hline 10 & 0.95 & 0.37 & 0.66 & 0.59 & 0.60 & 0.60 & 38 & 62 & 10 \\
\hline 11 & 0.69 & 0.50 & 0.60 & 0.64 & 0.68 & 0.66 & 7 & 36 & 11 \\
\hline 12 & 0.67 & & & 0.75 & & & 12 & & \\
\hline 13 & 0.82 & & & 0.76 & & & 7 & & \\
\hline 14 & 0.69 & 0.59 & 0.64 & 0.68 & 0.68 & 0.68 & 1 & 15 & 6 \\
\hline 15 & 0.59 & & & 0.67 & & & 14 & & \\
\hline 16 & 0.56 & 0.70 & 0.63 & 0.75 & 0.60 & 0.68 & 34 & 14 & 7 \\
\hline 17 & 0.86 & 0.43 & 0.65 & 0.59 & 0.60 & 0.60 & 31 & 40 & 8 \\
\hline 18 & 0.94 & 0.57 & 0.76 & 0.85 & 0.95 & 0.90 & 10 & 67 & 19 \\
\hline 19 & 0.51 & & & 0.64 & & & 25 & & \\
\hline 20 & 0.55 & 0.51 & 0.53 & 0.61 & 0.54 & 0.58 & 11 & 6 & 8 \\
\hline 21 & 0.46 & 0.57 & 0.52 & 0.56 & 0.56 & 0.56 & 22 & 2 & 9 \\
\hline 22 & 0.55 & & & 0.65 & & & 18 & & \\
\hline 23 & 0.52 & & & 0.66 & & & 27 & & \\
\hline 24 & 0.57 & 0.38 & 0.48 & 0.60 & 0.39 & 0.50 & 5 & 3 & 4 \\
\hline 25 & 0.48 & & & 0.58 & & & 21 & & \\
\hline 26 & 0.44 & 0.40 & 0.42 & 0.46 & 0.46 & 0.46 & 5 & 15 & 10 \\
\hline 27 & 0.62 & & & 0.52 & & & 16 & & \\
\hline & & & & & & $\begin{array}{c}\text { mean } \\
\max \\
\min \end{array}$ & $\begin{array}{c}16 \\
40 \\
0\end{array}$ & $\begin{array}{c}\text { mean } \\
\max \\
\min \end{array}$ & $\begin{array}{c}11 \\
22 \\
0\end{array}$ \\
\hline
\end{tabular}


Table 2.1 (b): Comparison of SlabExperimental Transverse Stresses and Values from a 3D-Type I FE model. All-Diaphragm Case

\begin{tabular}{|c|c|c|c|c|c|c|c|c|c|}
\hline \multirow{2}{*}{$\begin{array}{l}\text { Location } \\
\text { (see Fig. 2.2) }\end{array}$} & \multicolumn{3}{|c|}{ Experimental, ksi } & \multicolumn{3}{|c|}{ 3D Type I, ksi } & \multicolumn{2}{|c|}{$\%$ Error } & \multirow[b]{2}{*}{ Middle } \\
\hline & Top & Bottom & Middle & Top & Bottom & Middle & Top & Bottom & \\
\hline 1 & 1.00 & 0.60 & 0.80 & 1.02 & 0.88 & 0.95 & 2 & 47 & 19 \\
\hline 2 & 0.98 & & & 0.95 & & & 3 & & \\
\hline 3 & 0.82 & 0.91 & 0.87 & 0.74 & 0.80 & 0.77 & 10 & -12 & 11 \\
\hline 4 & 0.67 & 1.00 & 0.84 & 0.82 & 0.82 & 0.82 & 22 & -18 & 2 \\
\hline 5 & 0.67 & & & 0.78 & & & 16 & & \\
\hline 6 & 0.70 & & & 0.75 & & & 7 & & \\
\hline 7 & 0.70 & 1.10 & 0.90 & 0.74 & 0.80 & 0.77 & 6 & -27 & 14 \\
\hline 8 & 0.76 & 0.57 & 0.67 & 0.83 & 0.75 & 0.79 & 9 & 32 & 19 \\
\hline 9 & 1.56 & 0.90 & 1.23 & 0.97 & 1.33 & 1.15 & 38 & 48 & 7 \\
\hline 10 & 0.95 & 0.37 & 0.66 & 0.59 & 0.60 & 0.60 & 38 & 62 & 10 \\
\hline 11 & 0.69 & 0.50 & 0.60 & 0.66 & 0.65 & 0.66 & 4 & 30 & 10 \\
\hline 12 & 0.67 & & & 0.73 & & & 9 & & \\
\hline 13 & 0.82 & & & 0.74 & & & 10 & & \\
\hline 14 & 0.69 & 0.59 & 0.64 & 0.69 & 0.69 & 0.69 & 0 & 17 & 8 \\
\hline 15 & 0.59 & & & 0.65 & & & 10 & & \\
\hline 16 & 0.56 & 0.70 & 0.63 & 0.73 & 0.62 & 0.68 & 30 & -11 & 7 \\
\hline 17 & 0.86 & 0.43 & 0.65 & 0.59 & 0.60 & 0.60 & 31 & 40 & 8 \\
\hline 18 & 0.94 & 0.57 & 0.76 & 0.96 & 0.90 & 0.93 & 2 & 58 & 23 \\
\hline 19 & 0.51 & & & 0.64 & & & 25 & & \\
\hline 20 & 0.55 & 0.51 & 0.53 & 0.57 & 0.58 & 0.58 & 4 & 14 & 8 \\
\hline 21 & 0.46 & 0.57 & 0.52 & 0.56 & 0.56 & 0.56 & 22 & -2 & 9 \\
\hline 22 & 0.55 & & & 0.62 & & & 13 & & \\
\hline 23 & 0.52 & & & 0.67 & & & 29 & & \\
\hline 24 & 0.57 & 0.38 & 0.48 & 0.59 & 0.43 & 0.51 & 4 & 13 & 7 \\
\hline 25 & 0.48 & & & 0.54 & & & 13 & & \\
\hline 26 & 0.44 & 0.40 & 0.42 & 0.47 & 0.47 & 0.47 & 7 & 18 & 12 \\
\hline 27 & 0.62 & & & 0.47 & & & 24 & & \\
\hline & & & & & & mean & $\bar{~} 14$ & mean & 11 \\
\hline & & & & & & $\max$ & 38 & $\max$ & 23 \\
\hline & & & & & & $\min$ & 0 & $\min$ & 0 \\
\hline
\end{tabular}


Table 2.1 (c): Comparison of Slab Experimental Results and Values from a 3D-Type II FE model. All-Diaphragm Case

\begin{tabular}{|c|c|c|c|c|c|c|c|c|c|}
\hline \multirow{2}{*}{$\begin{array}{l}\text { Location } \\
\text { (see Fig. } 2.2 \text { ) }\end{array}$} & \multicolumn{3}{|c|}{ Experimental, ksi } & \multicolumn{3}{|c|}{ 3D Type II, ksi } & \multicolumn{2}{|c|}{$\%$ Error } & \multirow[b]{2}{*}{ Middle } \\
\hline & Top & Bottom & Middle & Top & Bottom & Middle & Top & Bottom & \\
\hline 1 & 1.00 & 0.60 & 0.80 & 0.94 & 0.95 & 0.95 & 6 & 58 & 18 \\
\hline 2 & 0.98 & & & 0.94 & & & 4 & & \\
\hline 4 & 0.67 & 1.00 & 0.84 & 0.80 & 0.80 & 0.80 & 19 & -20 & 4 \\
\hline 5 & 0.67 & & & 0.75 & & & 12 & & \\
\hline 6 & 0.70 & & & 0.73 & & & 4 & & \\
\hline 8 & 0.76 & 0.57 & 0.67 & 0.77 & 0.75 & 0.76 & 1 & 32 & 14 \\
\hline 9 & 1.56 & 0.90 & 1.23 & 1.10 & 1.20 & 1.15 & 29 & 33 & 7 \\
\hline 10 & 0.95 & 0.37 & 0.66 & 0.59 & 0.60 & 0.60 & 38 & 62 & 10 \\
\hline 11 & 0.69 & 0.50 & 0.60 & 0.67 & 0.63 & 0.65 & 3 & 26 & 9 \\
\hline 12 & 0.67 & & & 0.74 & & & 10 & & \\
\hline 13 & 0.82 & & & 0.73 & & & 11 & & \\
\hline 17 & 0.86 & 0.43 & 0.65 & 0.59 & 0.60 & 0.60 & 31 & 40 & 8 \\
\hline 18 & 0.94 & 0.57 & 0.76 & 0.81 & 1.08 & 0.95 & 14 & 89 & 25 \\
\hline 19 & 0.51 & & & 0.65 & & & 27 & & \\
\hline 20 & 0.55 & 0.51 & 0.53 & 0.58 & 0.55 & 0.57 & 5 & 8 & 7 \\
\hline 21 & 0.46 & 0.57 & 0.52 & 0.55 & 0.55 & 0.55 & 20 & -4 & 7 \\
\hline 22 & 0.55 & & & 0.60 & & & 9 & & \\
\hline 23 & 0.52 & & & 0.65 & & & 25 & & \\
\hline 24 & 0.57 & 0.38 & 0.48 & 0.59 & 0.42 & 0.51 & 4 & 11 & 6 \\
\hline 25 & 0.48 & & & 0.54 & & & 13 & & \\
\hline 26 & 0.44 & 0.40 & 0.42 & 0.46 & 0.46 & 0.46 & 5 & 15 & 10 \\
\hline 27 & 0.62 & & & 0.47 & & & 24 & & \\
\hline
\end{tabular}


Table 2.1 (d): Comparison of Slab Experimental Transverse Stresses and Values from a 3D-Type III FE model. All-Diaphragm Case

\begin{tabular}{|c|c|c|c|c|c|c|c|c|c|}
\hline \multirow{2}{*}{$\begin{array}{c}\text { Location } \\
\text { (see Fig. } 2.2 \text { ) }\end{array}$} & \multicolumn{3}{|c|}{ Experimental, ksi } & \multicolumn{3}{|c|}{ 3D Type III, ksi } & \multicolumn{2}{|c|}{$\%$ Error } & \multirow[b]{2}{*}{ Middle } \\
\hline & Top & Bottom & Middle & Top & Bottom & Middle & Top & Bottom & \\
\hline 1 & 1.00 & 0.60 & 0.80 & 1.02 & 0.89 & 0.96 & 2 & 48 & 19 \\
\hline 2 & 0.98 & & & 0.95 & & & 3 & & \\
\hline 3 & 0.82 & 0.91 & 0.87 & 0.75 & 0.80 & 0.78 & 9 & -12 & 10 \\
\hline 4 & 0.67 & 1.00 & 0.84 & 0.82 & 0.82 & 0.82 & 22 & -18 & 2 \\
\hline 5 & 0.67 & & & 0.78 & & & 16 & & \\
\hline 6 & 0.70 & & & 0.75 & & & 7 & & \\
\hline 7 & 0.70 & 1.10 & 0.90 & 0.75 & 0.80 & 0.78 & 7 & -27 & 14 \\
\hline 8 & 0.76 & 0.57 & 0.67 & 0.80 & 0.78 & 0.79 & 5 & 37 & 19 \\
\hline 9 & 1.56 & 0.90 & 1.23 & 0.90 & 1.40 & 1.15 & 42 & 56 & 7 \\
\hline 10 & 0.95 & 0.37 & 0.66 & 0.59 & 0.60 & 0.60 & 38 & 62 & 10 \\
\hline 11 & 0.69 & 0.50 & 0.60 & 0.68 & 0.64 & 0.66 & 1 & 28 & 11 \\
\hline 12 & 0.67 & & & 0.74 & & & 10 & & \\
\hline 13 & 0.82 & & & 0.74 & & & 10 & & \\
\hline 14 & 0.69 & 0.59 & 0.64 & 0.69 & 0.69 & 0.69 & 0 & 17 & 8 \\
\hline 15 & 0.59 & & & 0.65 & & & 10 & & \\
\hline 16 & 0.56 & 0.70 & 0.63 & 0.74 & 0.62 & 0.68 & 32 & -11 & 8 \\
\hline 17 & 0.86 & 0.43 & 0.65 & 0.59 & 0.60 & 0.60 & 31 & 40 & 8 \\
\hline 18 & 0.94 & 0.57 & 0.76 & 0.91 & 0.94 & 0.93 & 3 & 65 & 23 \\
\hline 19 & 0.51 & & & 0.64 & & & 25 & & \\
\hline 20 & 0.55 & 0.51 & 0.53 & 0.57 & 0.57 & 0.57 & 4 & 12 & 8 \\
\hline 21 & 0.46 & 0.57 & 0.52 & 0.56 & 0.56 & 0.56 & 22 & -2 & 9 \\
\hline 22 & 0.55 & & & 0.62 & & & 13 & & \\
\hline 23 & 0.52 & & & 0.67 & & & 29 & & \\
\hline 24 & 0.57 & 0.38 & 0.48 & 0.59 & 0.42 & 0.51 & 4 & 11 & 6 \\
\hline 25 & 0.48 & & & 0.54 & & & 13 & & \\
\hline 26 & 0.44 & 0.40 & 0.42 & 0.47 & 0.46 & 0.47 & 7 & 15 & 11 \\
\hline 27 & 0.62 & & & 0.47 & & & 24 & & \\
\hline & & & & & & mean & 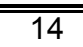 & mean & 11 \\
\hline & & & & & & $\max$ & 42 & $\max$ & 23 \\
\hline & & & & & & $\min$ & 0 & $\min$ & 0 \\
\hline
\end{tabular}


Table 2.2 (a): Comparison of Slab Experimental Transverse Stresses and Values froma 2DFE Model. End-Diaphragm Case

\begin{tabular}{|c|c|c|c|c|c|}
\hline \multirow{2}{*}{$\begin{array}{l}\text { Location } \\
\text { (see Fig. 23) }\end{array}$} & \multirow{2}{*}{$\begin{array}{c}\text { Experimental , ksi } \\
\text { Middle }\end{array}$} & \multicolumn{3}{|c|}{ 2D Modeling, ksi } & \multirow{2}{*}{$\begin{array}{l}\text { \%Error } \\
\text { Middle }\end{array}$} \\
\hline & & Top & Bottom & Middle & \\
\hline 1 & 1.01 & 0.80 & 0.82 & 0.81 & 20 \\
\hline 2 & 0.92 & 0.76 & 0.86 & 0.81 & 12 \\
\hline 3 & 0.84 & 0.81 & 0.81 & 0.81 & 4 \\
\hline 4 & 0.84 & 0.76 & 0.86 & 0.81 & 4 \\
\hline 5 & 1.79 & 0.94 & 1.11 & 1.03 & 43 \\
\hline 6 & 0.68 & 0.59 & 0.61 & 0.60 & 12 \\
\hline 7 & 0.64 & 0.62 & 0.64 & 0.63 & 2 \\
\hline 8 & 0.63 & 0.64 & 0.64 & 0.64 & 2 \\
\hline 9 & 0.63 & 0.71 & 0.56 & 0.64 & 1 \\
\hline 10 & 0.65 & 0.59 & 0.61 & 0.60 & 8 \\
\hline 11 & 0.57 & 0.55 & 0.64 & 0.60 & 4 \\
\hline 12 & 0.53 & 0.54 & 0.48 & 0.51 & 4 \\
\hline 13 & 0.54 & 0.50 & 0.50 & 0.50 & 7 \\
\hline 14 & 0.57 & 0.62 & 0.43 & 0.53 & 8 \\
\hline 15 & 0.47 & 0.51 & 0.31 & 0.41 & 13 \\
\hline 16 & 0.40 & 0.39 & 0.38 & 0.39 & 4 \\
\hline \multirow[t]{4}{*}{17} & 0.57 & 0.51 & 0.31 & 0.41 & 28 \\
\hline & & & & mean & 10 \\
\hline & & & & $\max$ & 43 \\
\hline & & & & $\min$ & 1 \\
\hline
\end{tabular}


Table 2.2 (b): Comparison of Slab Experimental Transverse Stresses and Values from a 3D-Type I FE model. End-Diaphragm Case

\begin{tabular}{|c|c|c|c|c|c|}
\hline \multirow{2}{*}{$\begin{array}{l}\text { Location } \\
\text { (see Fig. 2.3) }\end{array}$} & \multirow{2}{*}{$\begin{array}{c}\text { Experimental, ksi } \\
\text { Middle }\end{array}$} & \multicolumn{3}{|c|}{ 3D Type I, ksi } & \multirow{2}{*}{$\begin{array}{l}\text { \%Erro } \\
\text { Middle }\end{array}$} \\
\hline & & Top & Bottom & Middle & \\
\hline 1 & 1.01 & 0.85 & 0.91 & 0.88 & 13 \\
\hline 2 & 0.92 & 0.82 & 0.75 & 0.79 & 15 \\
\hline 3 & 0.84 & 0.80 & 0.80 & 0.80 & 5 \\
\hline 4 & 0.84 & 0.82 & 0.75 & 0.79 & 7 \\
\hline 5 & 1.79 & 0.95 & 1.33 & 1.14 & 36 \\
\hline 6 & 0.68 & 0.59 & 0.60 & 0.60 & 13 \\
\hline 7 & 0.64 & 0.60 & 0.65 & 0.63 & 2 \\
\hline 8 & 0.63 & 0.65 & 0.65 & 0.65 & 3 \\
\hline 9 & 0.63 & 0.68 & 0.59 & 0.64 & 1 \\
\hline 10 & 0.65 & 0.59 & 0.60 & 0.60 & 8 \\
\hline 11 & 0.57 & 0.56 & 0.63 & 0.60 & 4 \\
\hline 12 & 0.53 & 0.49 & 0.54 & 0.52 & 3 \\
\hline 13 & 0.54 & 0.50 & 0.50 & 0.50 & 7 \\
\hline 14 & 0.57 & 0.59 & 0.47 & 0.53 & 7 \\
\hline 15 & 0.47 & 0.48 & 0.35 & 0.42 & 12 \\
\hline 16 & 0.40 & 0.39 & 0.39 & 0.39 & 3 \\
\hline 17 & 0.57 & 0.48 & 0.35 & 0.42 & 27 \\
\hline & & & & $\begin{array}{c}\text { mean } \\
\max \\
\min \end{array}$ & $\begin{array}{c}10 \\
36 \\
1\end{array}$ \\
\hline
\end{tabular}


Table 2.2 (c): Comparison of Slab Experimental Transverse Stresses and Values from a 3D-Type II FE model. End-Diaphragm Case

\begin{tabular}{cccccc} 
Location & Experimental, ksi & \multicolumn{3}{c}{ 3D Type II, ksi } & \% Error \\
\cline { 3 - 5 } (see Fig. 2.3) & Middle & Top & Bottom & Middle & Middle \\
\hline 1 & 1.01 & 0.81 & 0.88 & 0.85 & 16 \\
2 & 0.92 & 0.75 & 0.76 & 0.76 & 18 \\
3 & 0.84 & 0.78 & 0.78 & 0.78 & 7 \\
4 & 0.84 & 0.75 & 0.76 & 0.76 & 10 \\
5 & 1.79 & 1.01 & 1.22 & 1.12 & 38 \\
6 & 0.68 & 0.59 & 0.60 & 0.60 & 13 \\
7 & 0.64 & 0.60 & 0.65 & 0.63 & 2 \\
8 & 0.63 & 0.64 & 0.64 & 0.64 & 2 \\
9 & 0.63 & 0.68 & 0.59 & 0.64 & 1 \\
10 & 0.65 & 0.59 & 0.60 & 0.60 & 8 \\
11 & 0.57 & 0.55 & 0.64 & 0.60 & 4 \\
12 & 0.53 & 0.49 & 0.54 & 0.52 & 3 \\
13 & 0.54 & 0.50 & 0.50 & 0.50 & 7 \\
14 & 0.57 & 0.59 & 0.47 & 0.53 & 7 \\
15 & 0.47 & 0.48 & 0.35 & 0.42 & 12 \\
16 & 0.40 & 0.39 & 0.39 & 0.39 & 3 \\
17 & 0.57 & 0.48 & 0.35 & 0.42 & 27 \\
\hline \hline
\end{tabular}


Table 2.2 (d): Comparison of Slab Experimental Transverse Stresses and Values from a 3D-Type III FE model. End-Diaphragm Case

\begin{tabular}{cccccc} 
Location & Experimental, ksi & \multicolumn{3}{c}{ 3D Type III, ksi } & \% Error \\
\cline { 3 - 5 } (see Fig. 2.3) & Middle & Top & Bottom & Middle & Middle \\
\hline 1 & 1.01 & 0.86 & 0.92 & 0.89 & 12 \\
2 & 0.92 & 0.80 & 0.77 & 0.79 & 15 \\
3 & 0.84 & 0.80 & 0.80 & 0.80 & 5 \\
4 & 0.84 & 0.80 & 0.77 & 0.79 & 7 \\
5 & 1.79 & 0.88 & 1.42 & 1.15 & 36 \\
6 & 0.68 & 0.59 & 0.60 & 0.60 & 13 \\
7 & 0.64 & 0.60 & 0.65 & 0.63 & 2 \\
8 & 0.63 & 0.65 & 0.65 & 0.65 & 3 \\
9 & 0.63 & 0.69 & 0.59 & 0.64 & 2 \\
10 & 0.65 & 0.59 & 0.60 & 0.60 & 8 \\
11 & 0.57 & 0.55 & 0.64 & 0.60 & 4 \\
12 & 0.53 & 0.49 & 0.54 & 0.52 & 3 \\
13 & 0.54 & 0.50 & 0.50 & 0.50 & 7 \\
14 & 0.57 & 0.59 & 0.47 & 0.53 & 7 \\
15 & 0.47 & 0.48 & 0.35 & 0.42 & 12 \\
16 & 0.40 & 0.39 & 0.39 & 0.39 & 3 \\
17 & 0.57 & 0.48 & 0.35 & 0.42 & 27 \\
& & & & & mean \\
\hline \hline
\end{tabular}


Table 2.3: Comparison of Experimental Transverse Stresses and Values from ANSYS 5.7 . All-Diaphragm Case of Texas Model

\begin{tabular}{|c|c|c|c|c|c|c|c|c|c|}
\hline \multirow{2}{*}{$\begin{array}{l}\text { Location } \\
\text { (see Fig. 2.2) }\end{array}$} & \multicolumn{3}{|c|}{ Experimental, ksi } & \multicolumn{3}{|c|}{ ANSYS, ksi } & \multicolumn{2}{|c|}{$\%$ Error } & \multirow[b]{2}{*}{ Middle } \\
\hline & Top & Bottom & Middle & Top & Bottom & Middle & Top & Bottom & \\
\hline 1 & 1.00 & 0.60 & 0.80 & 1.01 & 0.50 & 0.76 & 1 & 17 & 6 \\
\hline 2 & 0.98 & & & 0.93 & & & 5 & & \\
\hline 3 & 0.82 & 0.91 & 0.87 & 0.68 & 0.53 & 0.61 & 17 & 42 & 30 \\
\hline 4 & 0.67 & 1.00 & 0.84 & 0.80 & 0.60 & 0.70 & 19 & 40 & 16 \\
\hline 5 & 0.67 & & & 0.73 & & & 9 & & \\
\hline 6 & 0.70 & & & 0.78 & & & 11 & & \\
\hline 7 & 0.70 & 1.10 & 0.90 & 0.68 & 0.54 & 0.61 & 3 & 51 & 32 \\
\hline 8 & 0.76 & 0.57 & 0.67 & 0.71 & 0.66 & 0.69 & 7 & 16 & 3 \\
\hline 9 & 1.56 & 0.90 & 1.23 & 1.18 & 0.62 & 0.90 & 24 & 31 & 27 \\
\hline 10 & 0.95 & 0.37 & 0.66 & 0.61 & 0.59 & 0.60 & 36 & 59 & 9 \\
\hline 11 & 0.69 & 0.50 & 0.60 & 0.65 & 0.39 & 0.52 & 6 & 22 & 13 \\
\hline 12 & 0.67 & & & 0.69 & & & 3 & & \\
\hline 13 & 0.82 & & & 0.68 & & & 17 & & \\
\hline 14 & 0.69 & 0.59 & 0.64 & 0.64 & 0.44 & 0.54 & 7 & 25 & 16 \\
\hline 15 & 0.59 & & & 0.64 & & & 8 & & \\
\hline 16 & 0.56 & 0.70 & 0.63 & 0.69 & 0.68 & 0.69 & 23 & 3 & 9 \\
\hline 17 & 0.86 & 0.43 & 0.65 & 0.61 & 0.59 & 0.60 & 29 & 37 & 7 \\
\hline 18 & 0.94 & 0.57 & 0.76 & 0.92 & 0.52 & 0.72 & 2 & 9 & 5 \\
\hline 19 & 0.51 & & & 0.51 & & & 0 & & \\
\hline 20 & 0.55 & 0.51 & 0.53 & 0.51 & 0.36 & 0.44 & 7 & 29 & 18 \\
\hline 21 & 0.46 & 0.57 & 0.52 & 0.49 & 0.36 & 0.43 & 7 & 37 & 17 \\
\hline 22 & 0.55 & & & 0.56 & & & 2 & & \\
\hline 23 & 0.52 & & & 0.62 & & & 19 & & \\
\hline 24 & 0.57 & 0.38 & 0.48 & 0.51 & 0.46 & 0.49 & 11 & 21 & 2 \\
\hline 25 & 0.48 & & & 0.46 & & & 4 & & \\
\hline 26 & 0.44 & 0.40 & 0.42 & 0.42 & 0.33 & 0.38 & 5 & 18 & 11 \\
\hline \multirow[t]{4}{*}{27} & 0.62 & & & 0.43 & & & 31 & & \\
\hline & & & & & & mean & 12 & mean & 14 \\
\hline & & & & & & $\max$ & 36 & $\max$ & 32 \\
\hline & & & & & & $\min$ & 0 & $\min$ & 0 \\
\hline
\end{tabular}


Table 2.4 : Comparison of Slab Experimental Transverse Stresses and Values from ANSYS. End-Diaphragm Case of Texas Model

\begin{tabular}{|c|c|c|c|c|c|}
\hline \multirow{2}{*}{$\begin{array}{c}\text { Location } \\
\text { (see Fig. 2.3) }\end{array}$} & \multirow{2}{*}{$\begin{array}{c}\text { Experimental, ksi } \\
\text { Middle }\end{array}$} & \multicolumn{3}{|c|}{ ANSYS, ksi } & \multirow{2}{*}{$\begin{array}{l}\% \text { Error } \\
\text { Middle }\end{array}$} \\
\hline & & Top & Bottom & Middle & \\
\hline 1 & 1.01 & 0.86 & 0.92 & 0.87 & 14 \\
\hline 2 & 0.92 & 0.80 & 0.77 & 0.68 & 26 \\
\hline 3 & 0.84 & 0.80 & 0.80 & 0.69 & 18 \\
\hline 4 & 0.84 & 0.80 & 0.77 & 0.68 & 19 \\
\hline 5 & 1.79 & 0.88 & 1.42 & 1.05 & 41 \\
\hline 6 & 0.68 & 0.59 & 0.60 & 0.60 & 12 \\
\hline 7 & 0.64 & 0.60 & 0.65 & 0.53 & 17 \\
\hline 8 & 0.63 & 0.65 & 0.65 & 0.55 & 13 \\
\hline 9 & 0.63 & 0.69 & 0.59 & 0.70 & 11 \\
\hline 10 & 0.65 & 0.59 & 0.60 & 0.60 & 8 \\
\hline 11 & 0.57 & 0.55 & 0.64 & 0.58 & 2 \\
\hline 12 & 0.53 & 0.49 & 0.54 & 0.46 & 13 \\
\hline 13 & 0.54 & 0.50 & 0.50 & 0.45 & 17 \\
\hline 14 & 0.57 & 0.59 & 0.47 & 0.63 & 11 \\
\hline 15 & 0.47 & 0.48 & 0.35 & 0.47 & 0 \\
\hline 16 & 0.40 & 0.39 & 0.39 & 0.37 & 8 \\
\hline 17 & 0.57 & 0.48 & 0.35 & 0.51 & 11 \\
\hline & & & & $\begin{array}{c}\text { mean } \\
\max \\
\min \end{array}$ & $\begin{array}{c}14 \\
41 \\
0 \\
\end{array}$ \\
\hline
\end{tabular}


Table 2.5: Comparison of Results from ANSYS 5.7 and Results from SAP2000. All-Diaphragm Case of Texas Model

\begin{tabular}{|c|c|c|c|c|c|c|c|c|c|}
\hline \multirow{3}{*}{$\begin{array}{l}\text { Location } \\
\text { (see Fig. 2.2) }\end{array}$} & \multirow[b]{2}{*}{ ANSYS } & \multicolumn{4}{|c|}{ Transverse Stresses on top of slab, ksi } & \multicolumn{4}{|c|}{ Comparison with ANSYS, \% Difference } \\
\hline & & SA2000, 2D & Sap2000, TI & Sap2000, TII & Sap2000, TIII & SAP2000, 2D & SAP2000, TI & SAP2000, TII & SAP2000, TIII \\
\hline & 1.01 & 0.87 & 1.02 & 0.94 & 1.02 & $14 \%$ & $1 \%$ & $7 \%$ & $1 \%$ \\
\hline 2 & 0.93 & 0.82 & 0.95 & 0.94 & 0.95 & $12 \%$ & $2 \%$ & $1 \%$ & $2 \%$ \\
\hline 3 & 0.68 & 0.78 & 0.74 & 0.71 & 0.75 & $15 \%$ & $9 \%$ & $4 \%$ & $10 \%$ \\
\hline 5 & 0.73 & 0.76 & 0.78 & 0.75 & 0.78 & $4 \%$ & $7 \%$ & $3 \%$ & $7 \%$ \\
\hline 6 & 0.78 & 0.79 & 0.75 & 0.73 & 0.75 & $1 \%$ & $4 \%$ & $6 \%$ & $4 \%$ \\
\hline 7 & 0.68 & 0.75 & 0.74 & 0.71 & 0.75 & $10 \%$ & $9 \%$ & $4 \%$ & $10 \%$ \\
\hline 8 & 0.71 & 0.76 & 0.83 & 0.77 & 0.80 & $7 \%$ & $17 \%$ & $8 \%$ & $13 \%$ \\
\hline 9 & 1.18 & 0.94 & 0.97 & 1.10 & 0.90 & $20 \%$ & $18 \%$ & $7 \%$ & $24 \%$ \\
\hline 10 & 0.61 & 0.59 & 0.59 & 0.59 & 0.59 & $3 \%$ & $3 \%$ & $3 \%$ & $3 \%$ \\
\hline 11 & 0.65 & 0.64 & 0.66 & 0.67 & 0.68 & $2 \%$ & $2 \%$ & $3 \%$ & $5 \%$ \\
\hline 12 & 0.69 & 0.75 & 0.73 & 0.74 & 0.74 & $9 \%$ & $6 \%$ & $7 \%$ & $7 \%$ \\
\hline 13 & 0.68 & 0.76 & 0.74 & 0.73 & 0.74 & $12 \%$ & $9 \%$ & $7 \%$ & $9 \%$ \\
\hline 14 & 0.64 & 0.68 & 0.69 & 0.68 & 0.69 & $6 \%$ & $8 \%$ & $6 \%$ & $8 \%$ \\
\hline 15 & 0.64 & 0.67 & 0.65 & 0.64 & 0.65 & $5 \%$ & $2 \%$ & $0 \%$ & $2 \%$ \\
\hline 16 & 0.69 & 0.75 & 0.73 & 0.74 & 0.74 & $9 \%$ & $6 \%$ & $7 \%$ & $7 \%$ \\
\hline 17 & 0.61 & 0.59 & 0.59 & 0.59 & 0.59 & $3 \%$ & $3 \%$ & $3 \%$ & $3 \%$ \\
\hline 18 & 0.92 & 0.85 & 0.96 & 0.81 & 0.91 & $8 \%$ & $4 \%$ & $12 \%$ & $1 \%$ \\
\hline 19 & 0.51 & 0.64 & 0.64 & 0.65 & 0.64 & $25 \%$ & $25 \%$ & $27 \%$ & $25 \%$ \\
\hline 21 & 0.49 & 0.56 & 0.56 & 0.55 & 0.56 & $14 \%$ & $14 \%$ & $12 \%$ & $14 \%$ \\
\hline 22 & 0.56 & 0.65 & 0.62 & 0.60 & 0.62 & $16 \%$ & $11 \%$ & $7 \%$ & $11 \%$ \\
\hline 23 & 0.62 & 0.66 & 0.67 & 0.65 & 0.67 & $6 \%$ & $8 \%$ & $5 \%$ & $8 \%$ \\
\hline 24 & 0.51 & 0.6 & 0.59 & 0.59 & 0.59 & $18 \%$ & $16 \%$ & $16 \%$ & $16 \%$ \\
\hline 25 & 0.46 & 0.58 & 0.54 & 0.54 & 0.54 & $26 \%$ & $17 \%$ & $17 \%$ & $17 \%$ \\
\hline 26 & 0.42 & 0.46 & 0.47 & 0.46 & 0.47 & $10 \%$ & $12 \%$ & $10 \%$ & $12 \%$ \\
\hline \multirow[t]{3}{*}{27} & 0.43 & 0.52 & 0.47 & 0.47 & 0.47 & $21 \%$ & $9 \%$ & $9 \%$ & $9 \%$ \\
\hline & & & & & mean & $11 \%$ & $9 \%$ & $8 \%$ & $9 \%$ \\
\hline & & & & & $\max$ & $26 \%$ & $25 \%$ & $27 \%$ & $25 \%$ \\
\hline
\end{tabular}

Note:

TI: Type I F.E Model (see Section 5 of this report)

TII: Type II F.E Model

TIII: Type III F.E Model 
Table 2.6: Comparison of Results from ANSYS 5.7 and Results from SAP2000. End-Diaphragm Case of Texas Model

\begin{tabular}{|c|c|c|c|c|c|c|c|c|c|}
\hline \multirow{2}{*}{$\begin{array}{l}\text { Location } \\
\text { (see Fig. 2.3) }\end{array}$} & \multirow[b]{2}{*}{ ANSYS } & \multicolumn{4}{|c|}{ Slab Middepth Transverse Stresses, ksi } & \multicolumn{4}{|c|}{ Comparison with ANSYS, \% Difference } \\
\hline & & SA2000, 2D & Sap2000, TI & Sap2000, TII & Sap2000, TIII & SA2000, 2D & SAP2000, TI & SAP2000, TII & SAP2000, TIII \\
\hline 1 & 0.87 & 0.81 & 0.88 & 0.85 & 0.89 & $7 \%$ & $1 \%$ & $3 \%$ & $2 \%$ \\
\hline 2 & 0.68 & 0.81 & 0.79 & 0.76 & 0.79 & $19 \%$ & $15 \%$ & $11 \%$ & $15 \%$ \\
\hline 3 & 0.69 & 0.81 & 0.80 & 0.78 & 0.80 & $17 \%$ & $16 \%$ & $13 \%$ & $16 \%$ \\
\hline 4 & 0.68 & 0.81 & 0.79 & 0.76 & 0.79 & $19 \%$ & $15 \%$ & $11 \%$ & $15 \%$ \\
\hline 5 & 1.05 & 1.03 & 1.14 & 1.12 & 1.15 & $2 \%$ & $9 \%$ & $6 \%$ & $10 \%$ \\
\hline 6 & 0.60 & 0.60 & 0.60 & 0.60 & 0.60 & $0 \%$ & $1 \%$ & $1 \%$ & $1 \%$ \\
\hline 7 & 0.53 & 0.63 & 0.63 & 0.63 & 0.63 & $19 \%$ & $18 \%$ & $18 \%$ & $18 \%$ \\
\hline 8 & 0.55 & 0.64 & 0.65 & 0.64 & 0.65 & $16 \%$ & $18 \%$ & $16 \%$ & $18 \%$ \\
\hline 9 & 0.70 & 0.64 & 0.64 & 0.64 & 0.64 & $9 \%$ & $9 \%$ & $9 \%$ & $9 \%$ \\
\hline 10 & 0.60 & 0.60 & 0.60 & 0.60 & 0.60 & $0 \%$ & $1 \%$ & $1 \%$ & $1 \%$ \\
\hline 11 & 0.58 & 0.60 & 0.60 & 0.60 & 0.60 & $3 \%$ & $3 \%$ & $3 \%$ & $3 \%$ \\
\hline 12 & 0.46 & 0.51 & 0.52 & 0.52 & 0.52 & $11 \%$ & $12 \%$ & $12 \%$ & $12 \%$ \\
\hline 13 & 0.45 & 0.50 & 0.50 & 0.50 & 0.50 & $11 \%$ & $11 \%$ & $11 \%$ & $11 \%$ \\
\hline 14 & 0.63 & 0.53 & 0.53 & 0.53 & 0.53 & $17 \%$ & $16 \%$ & $16 \%$ & $16 \%$ \\
\hline 15 & 0.47 & 0.41 & 0.42 & 0.42 & 0.42 & $13 \%$ & $12 \%$ & $12 \%$ & $12 \%$ \\
\hline 16 & 0.37 & 0.39 & 0.39 & 0.39 & 0.39 & $4 \%$ & $5 \%$ & $5 \%$ & $5 \%$ \\
\hline 17 & 0.51 & 0.41 & 0.42 & 0.42 & 0.42 & $20 \%$ & $19 \%$ & $19 \%$ & $19 \%$ \\
\hline & & & & & $\begin{array}{l}\text { mean } \\
\text { max }\end{array}$ & $\begin{array}{l}11 \% \\
20 \%\end{array}$ & $\begin{array}{l}11 \% \\
19 \%\end{array}$ & $\begin{array}{l}10 \% \\
19 \%\end{array}$ & $\begin{array}{l}11 \% \\
19 \%\end{array}$ \\
\hline
\end{tabular}

Note:

TI: Type I F.E Model (see Section 5 of this report)

TII: Type II F.E Model

TIII: Type III F.E Model 


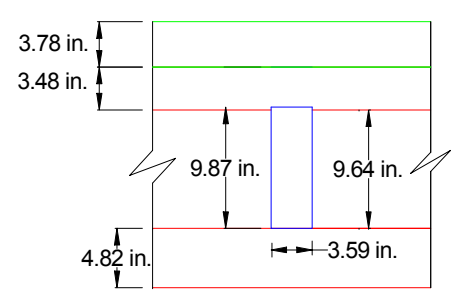

View C-C

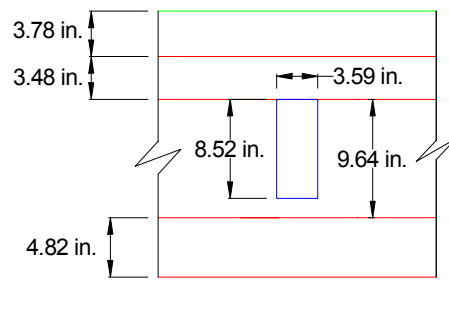

View D-D

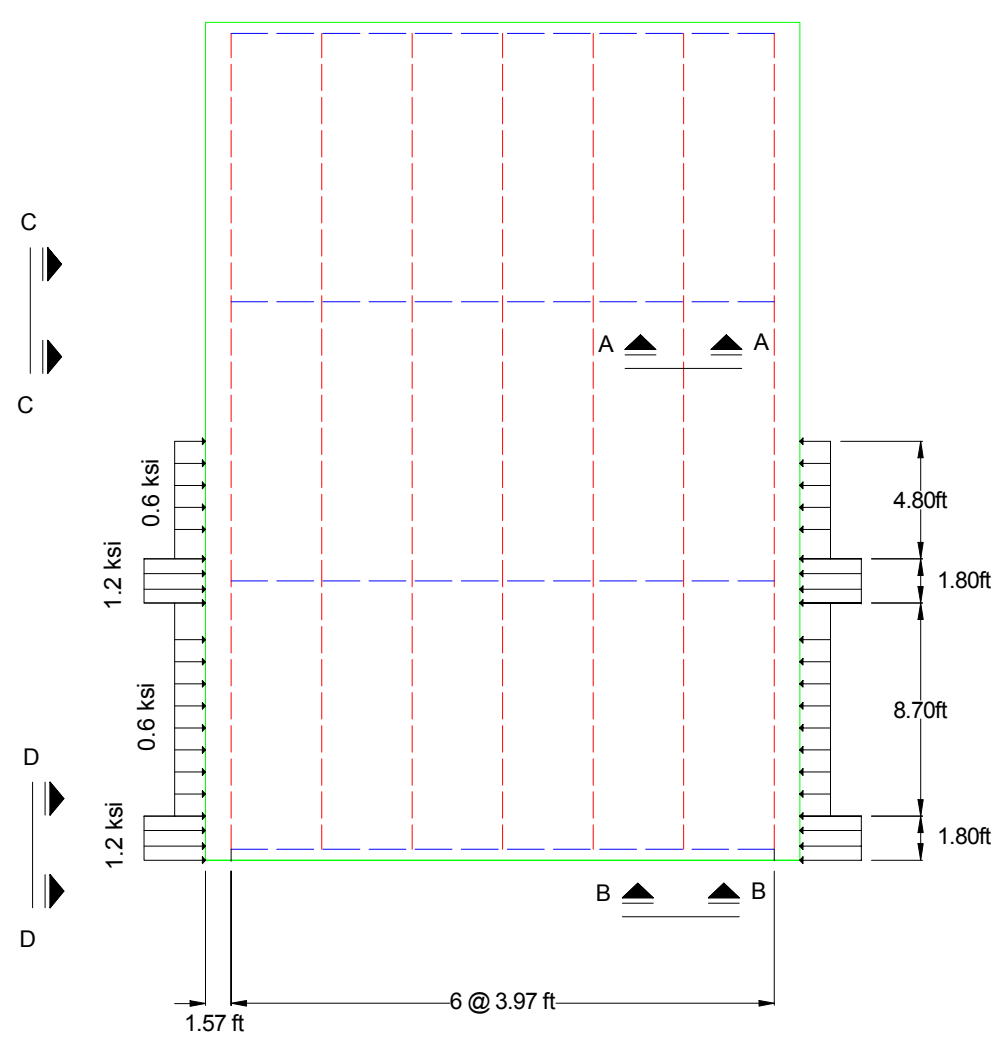

6.28 in.

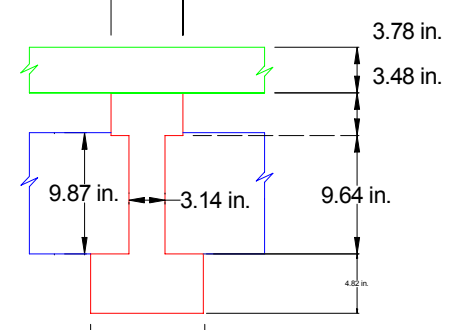

-9.87 in-

View A-A

6.28 in

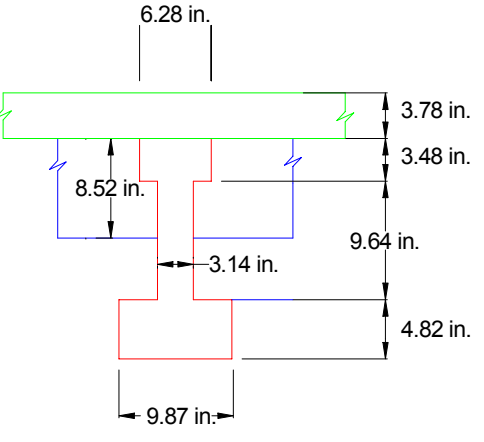

View B-B

Figure 2.1 Test Model in the Experimental Study at University of Texas 


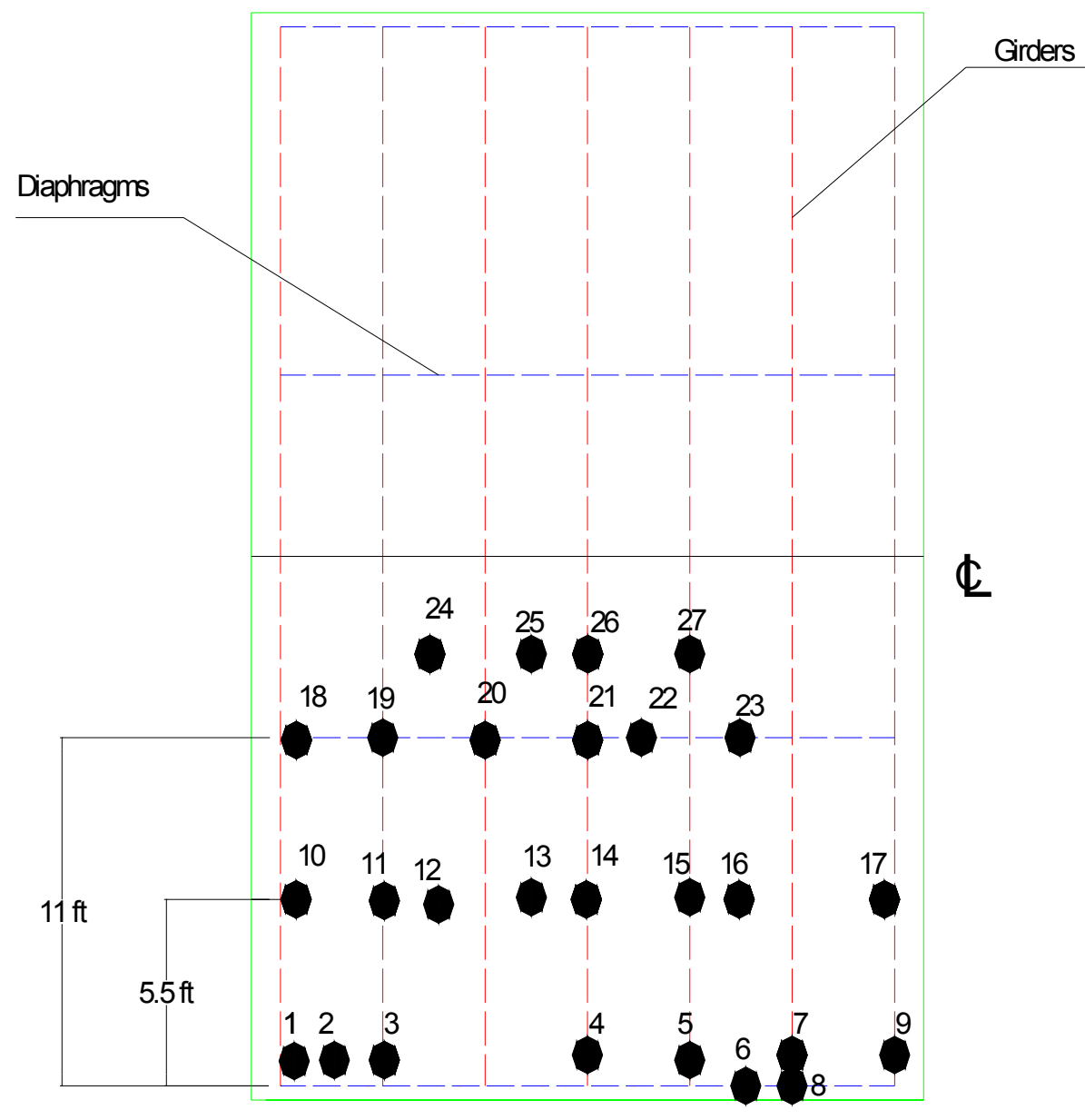

Figure 2.2 Locations of Strain Gages for All-Diaphragm Case of Texas Study 


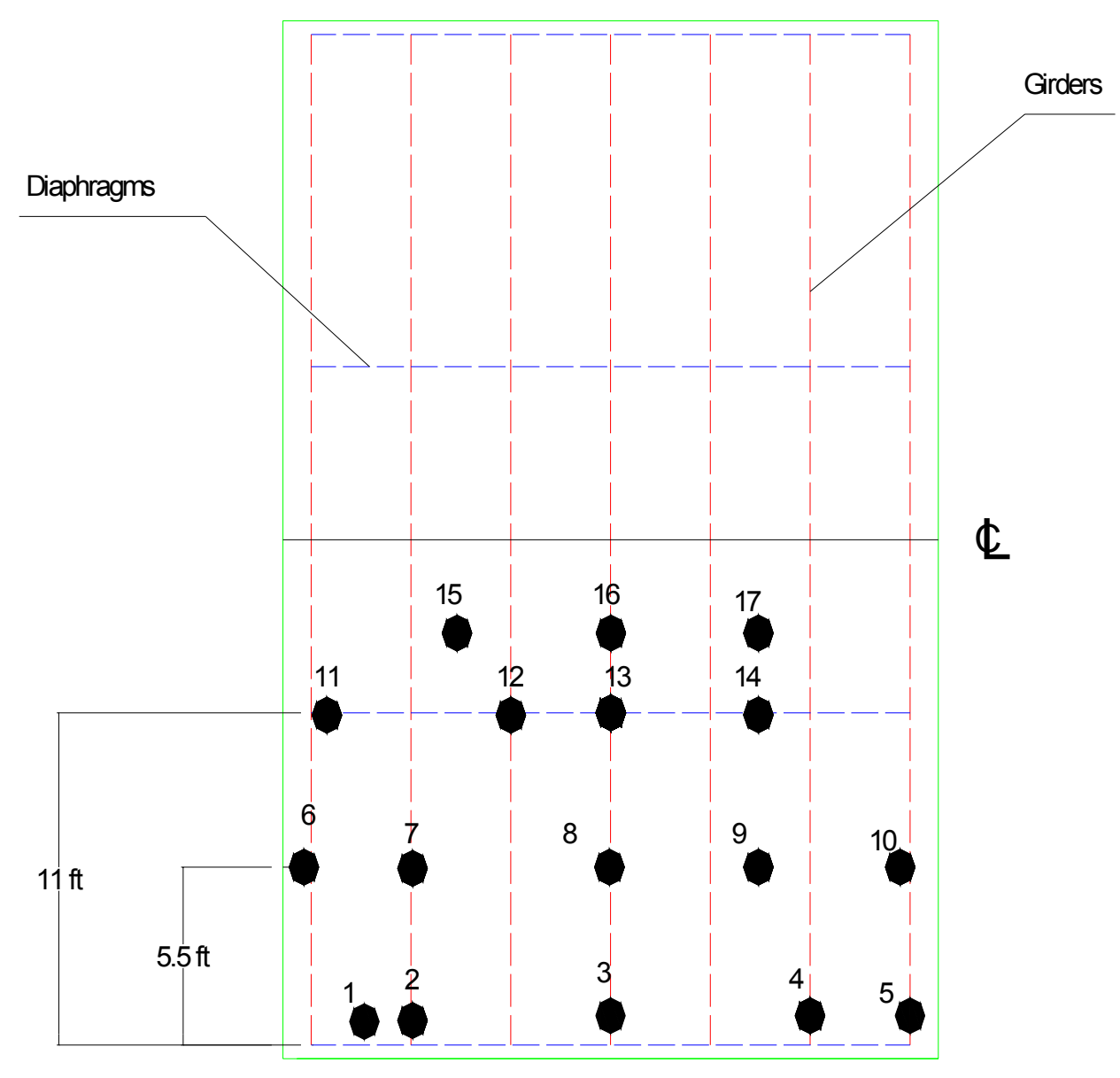

Figure 2.3 Locations of Strain Gages for End-Diaphragm Case of Texas Study 


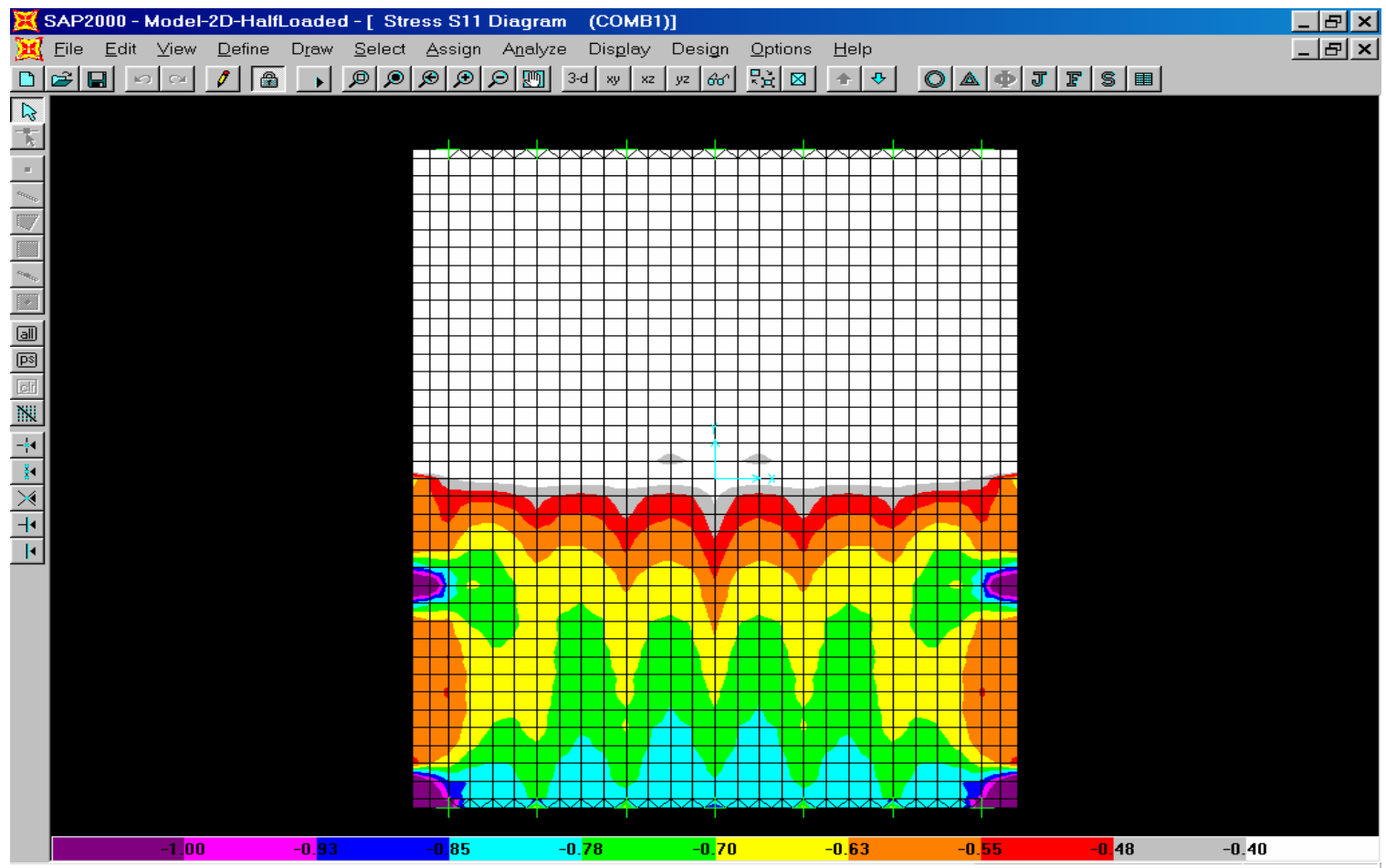

Figure 2.4 (a): 2D Modeling of Test Structure. All-diaphragm Case.

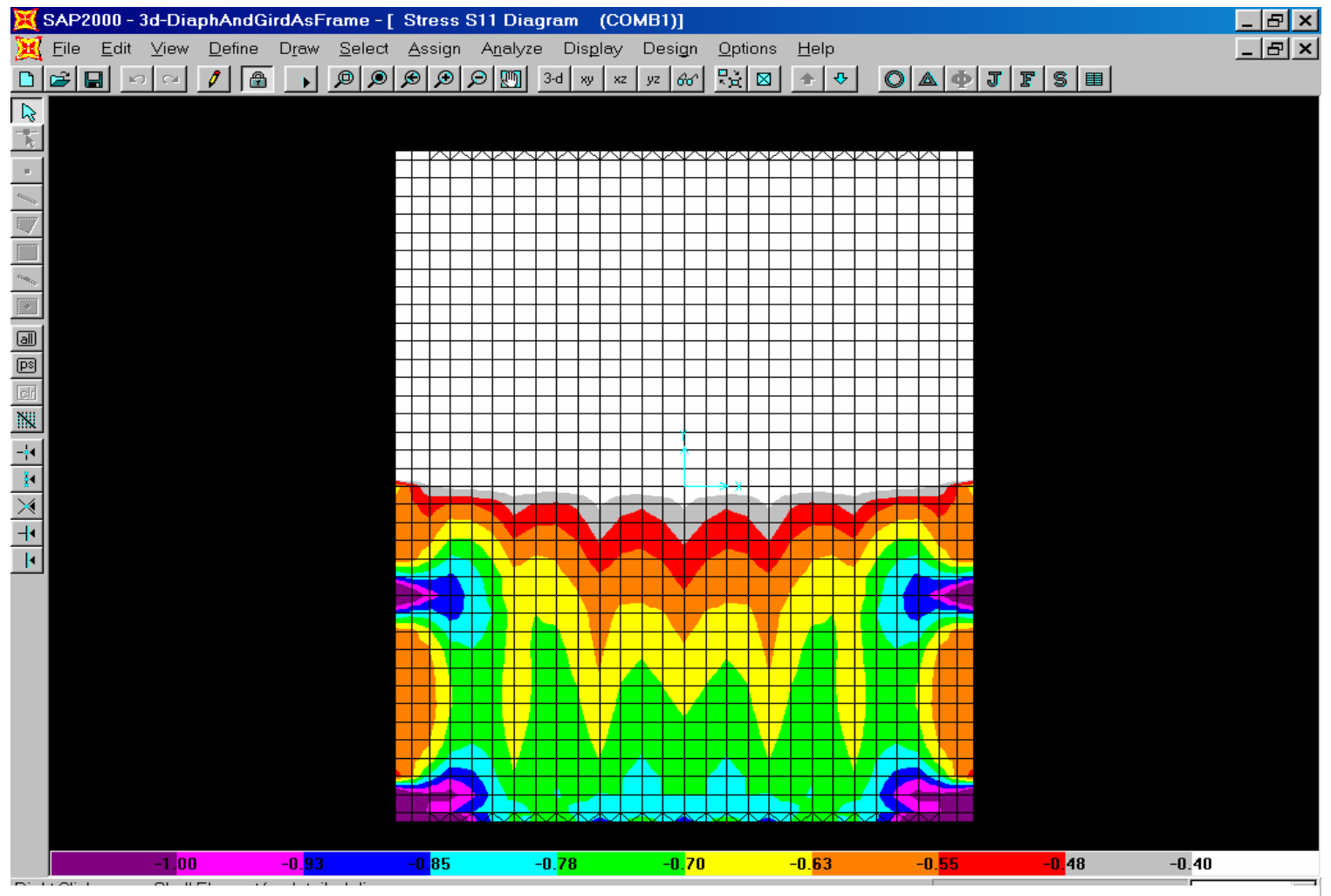

Figure 2.4 (b): 3D-Type I Modeling of Test Structure. All-diaphragm Case 


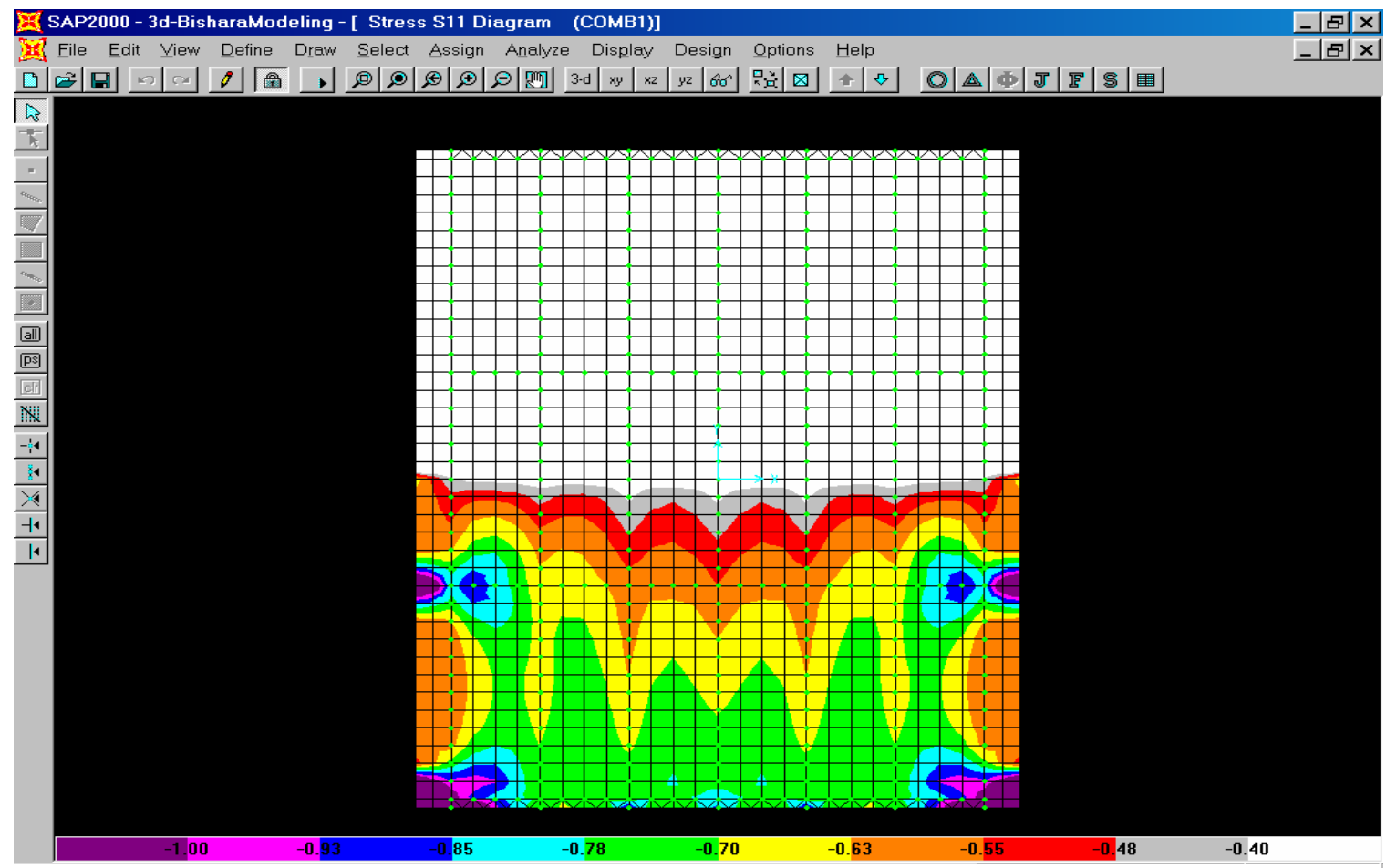

Figure 2.4 (c): 3D-Type II Modeling of Test Structure. All-diaphragm Case

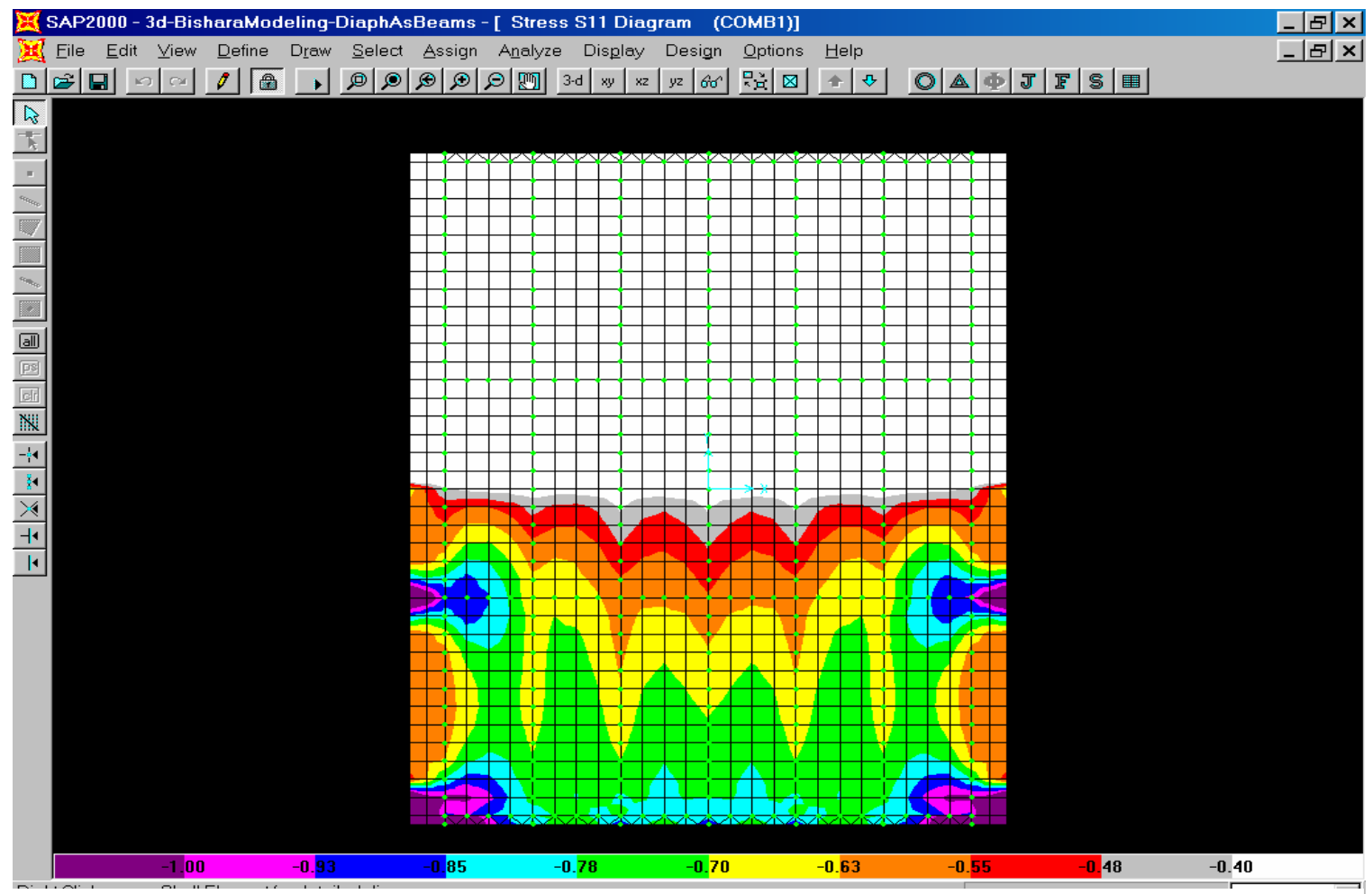

Figure 2.4 (d): 3D-Type III Modeling of Test structure. All-diaphragm Case 


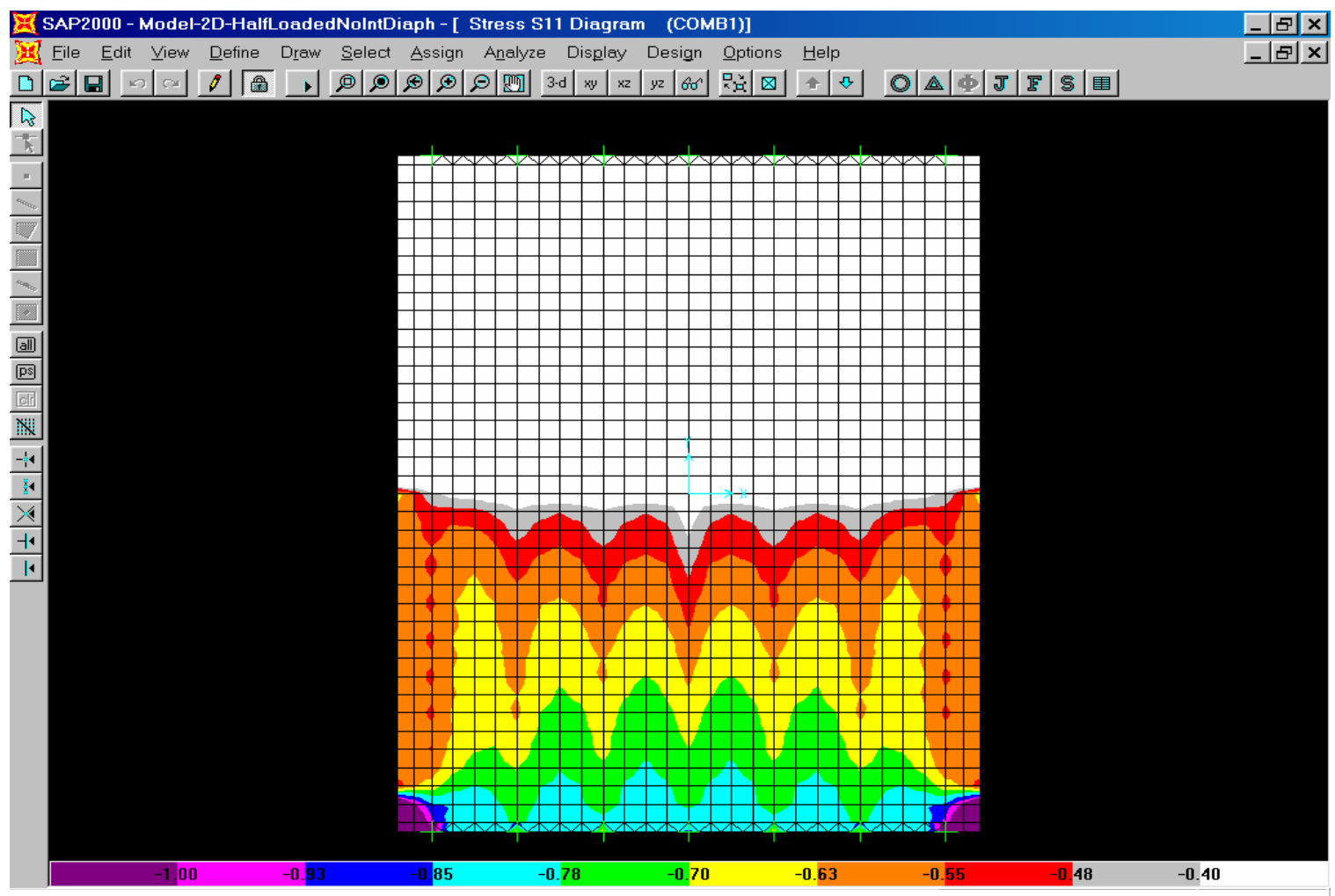

Figure 2.5 (a): 2D Modeling of Test Structure. End-diaphragm Case.

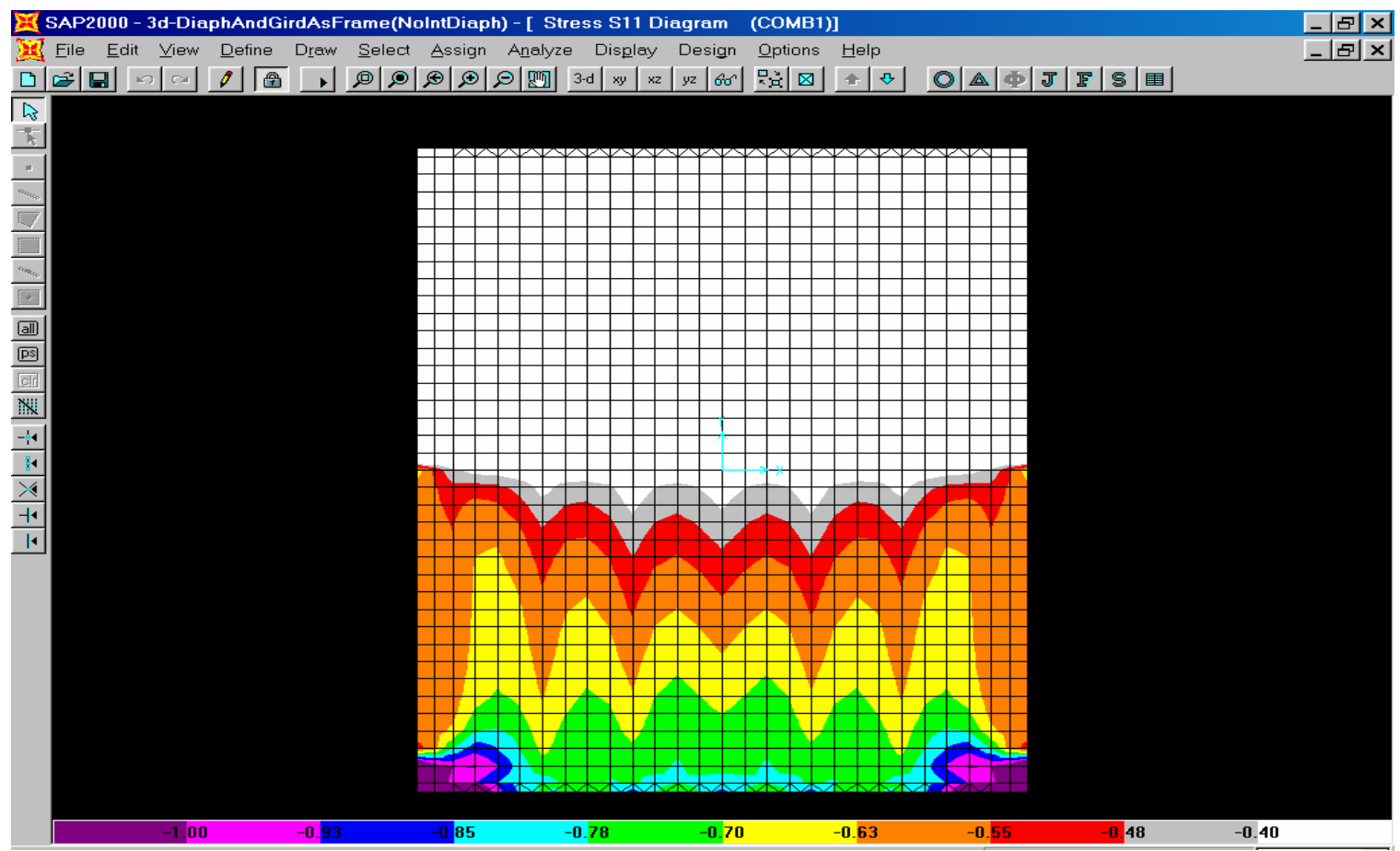

Figure 2.5 (b): 3D-Type I Modeling of Test Structure. End-diaphragm Case 


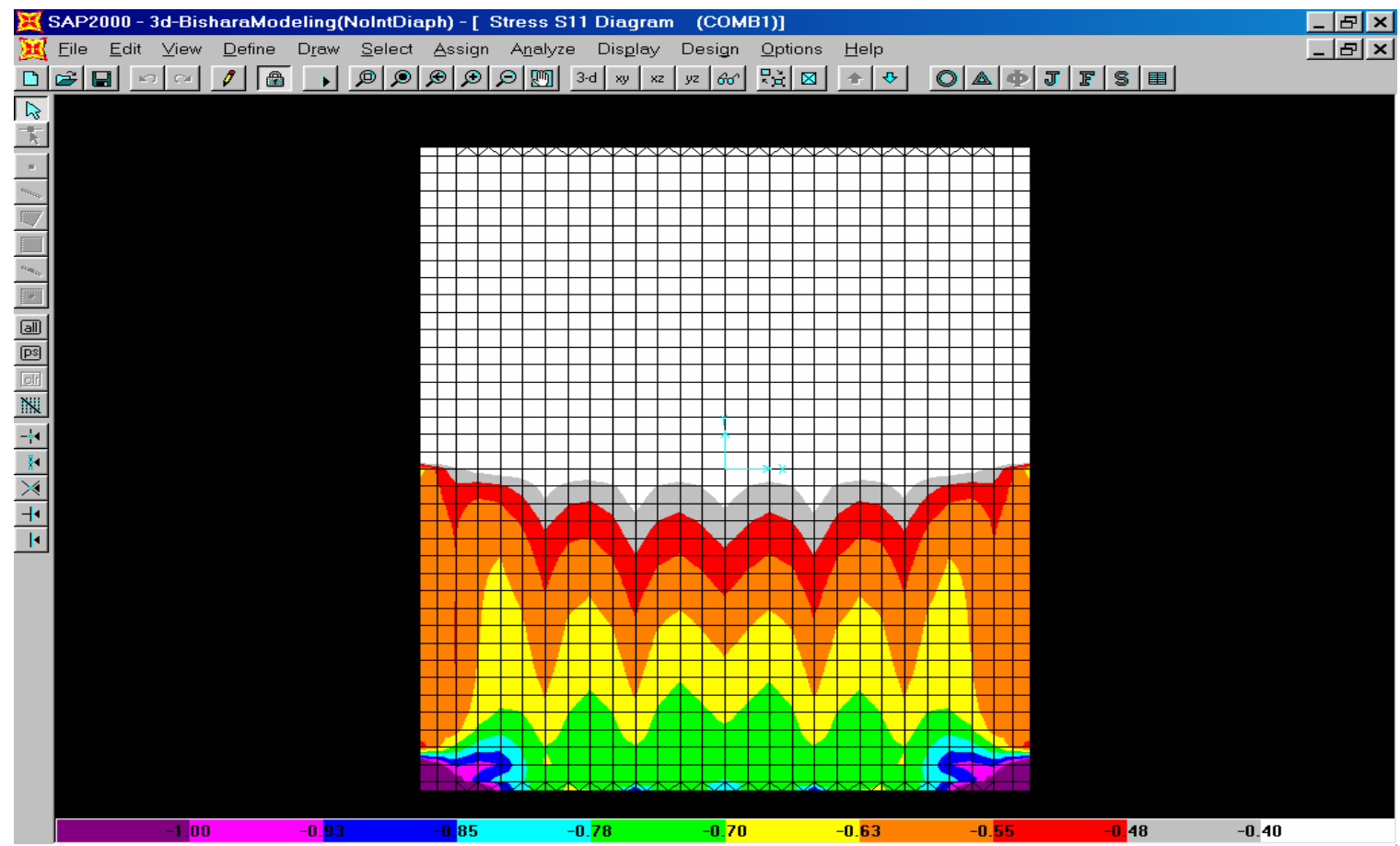

Figure 2.5 (c): 3D-Type II Modeling of Test Structure. End-diaphragm Case

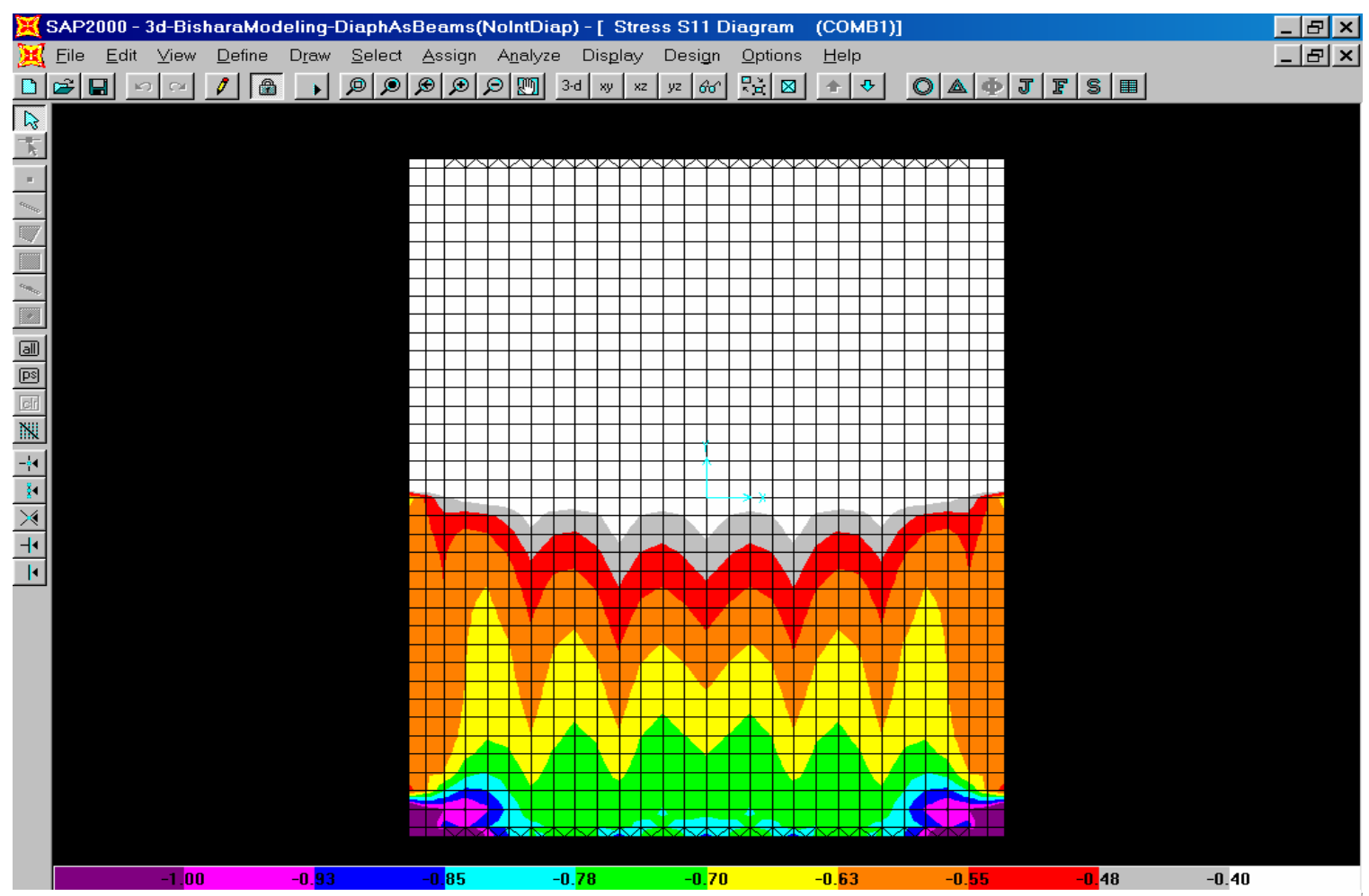

Figure $2.5(\mathrm{~d})$ : 3D-Type III Modeling of Test Structure. End-diaphragm Case 


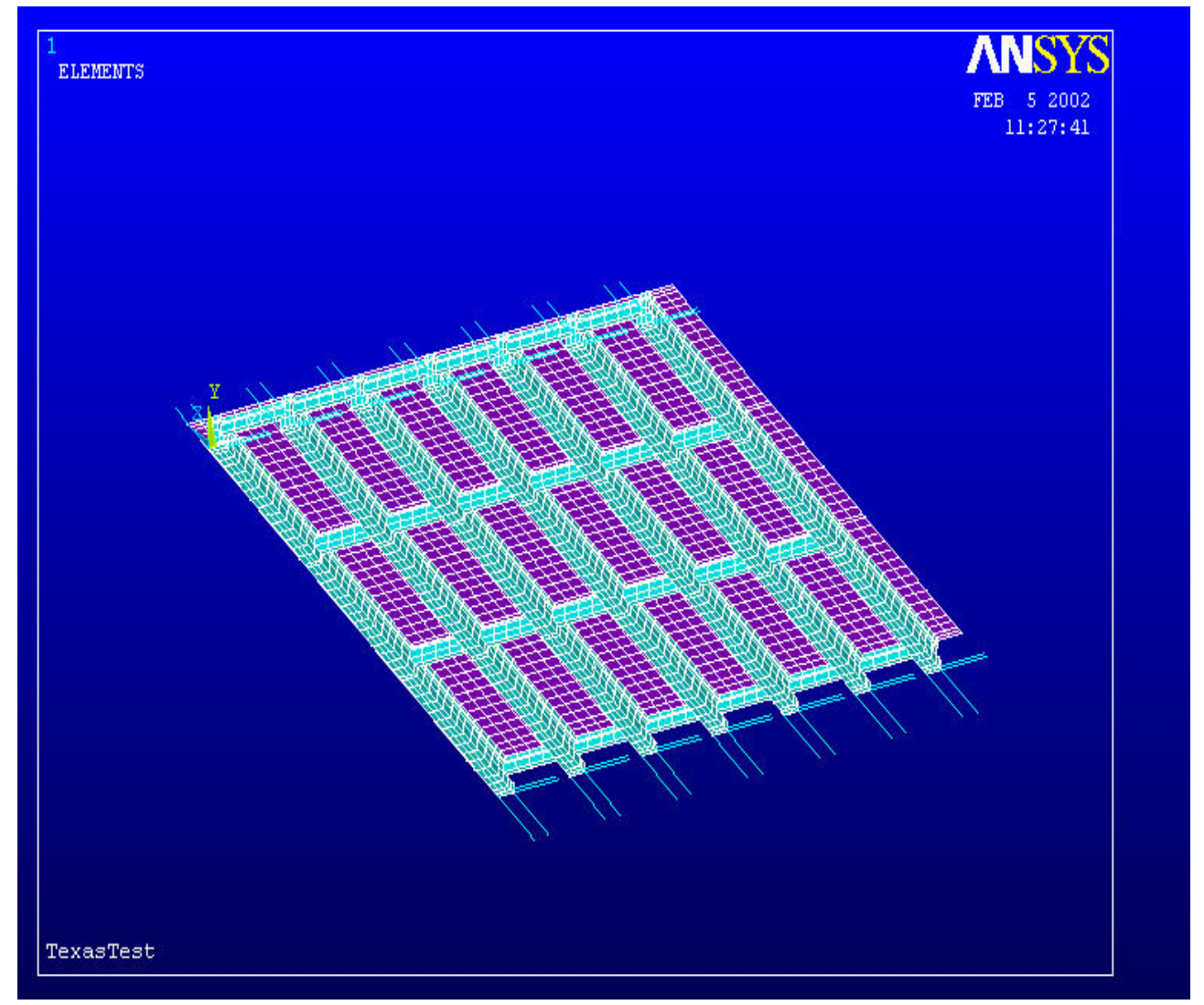

Figure 2.6: Finite Elements in the model with ANSYS 5.7: slabs as shells, and diaphragms and girders as solid brick elements 
(a)

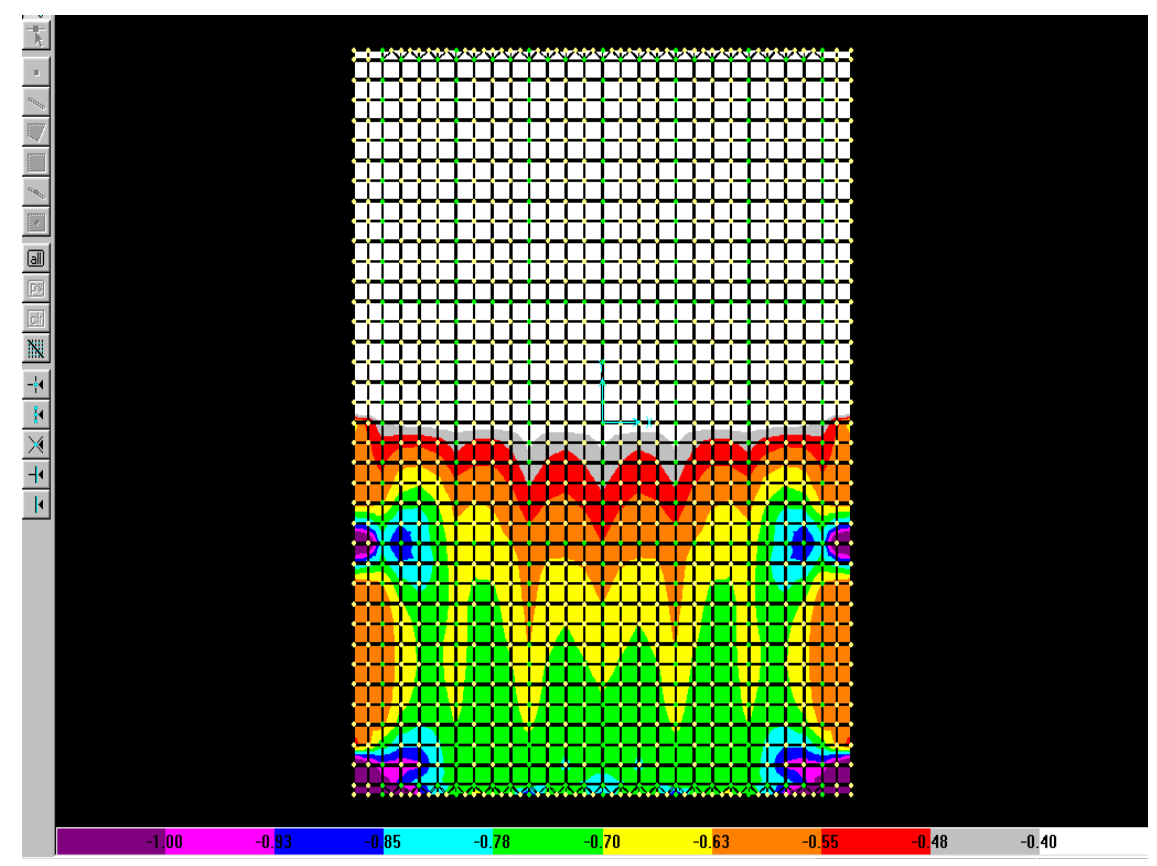

(b)

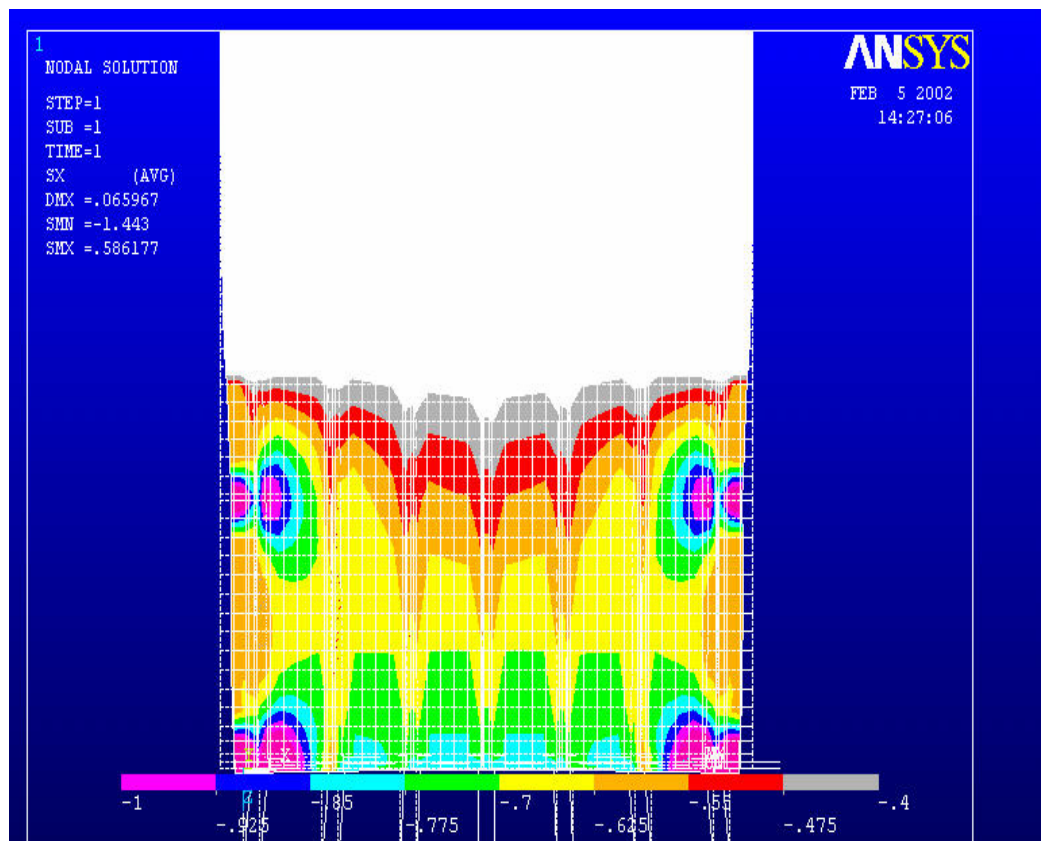

Figure 2.7: Contour plots for the distribution of transverse stresses. All-diaphragm case of the Texas Study (a) Using 3D Type III modeling in SAP2000 (diaphragms, girder webs and slab as shell elements. Flanges as frame elements)

(b) Using ANSYS 5.7 (slab as shell element, and diaphragms and girders as solid brick elements) 
(a)

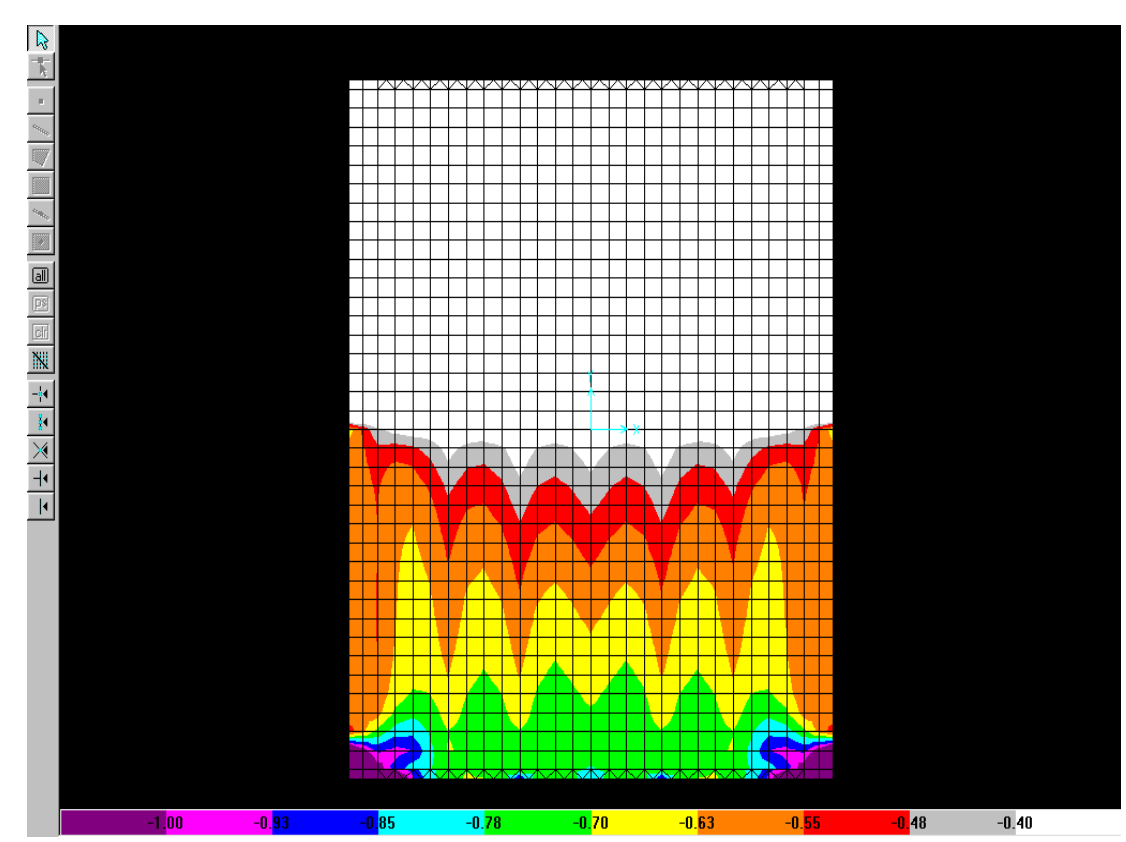

(b)

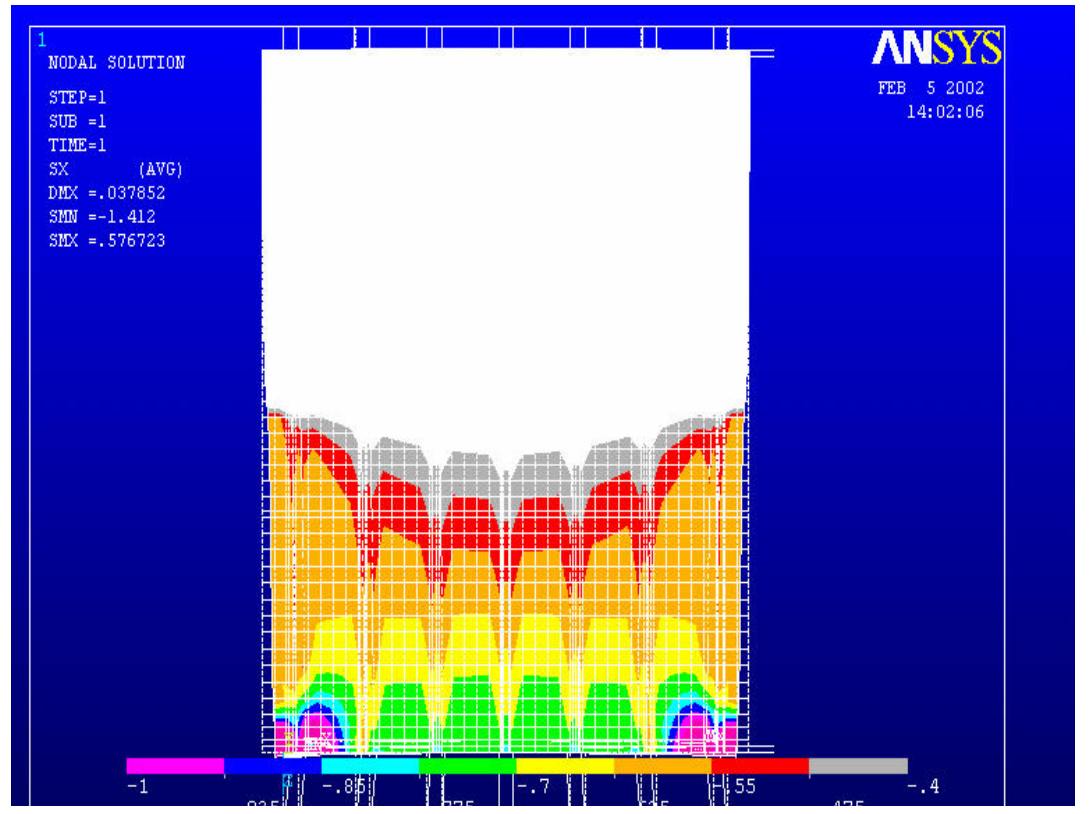

Figure 2.8: Contour plots for the distribution of transverse stresses. End-diaphragm case of the Texas Study (a) Using 3D Type III modeling in SAP2000 (diaphragms, girder webs and slab as shell elements. Flanges as frame elements)

(b) Using ANSYS 5.7 (slab as shell element, and diaphragms and girders as solid brick elements) 


\section{3- Identification of Relevant Variables}

\subsection{Introduction}

It was noted from Sections 2.2 and 2.3 that 2D and 3D models using SAP2000 and ANSYS 5.7 performed reasonably well in predicting the experimental transverse stresses on the deck of a transversely posttensioned deck-on-girder bridge. Any of these models (and computer programs) would then be adequate to represent and analyze a transversely post-tensioned bridge deck. Because the large demand of modeling needed in the parametric study, SAP2000 was selected to carry out the series of analyses.

A series of 2D analyses (and 3D when noted) using SAP2000 were carried out to identify the key variables affecting the distribution of transverse stresses on the deck. For this purpose, a base case superstructure (shown in Figure 3.1) was defined. The structure consists of a simply supported deck-on-girder bridge having a span length of $76 \mathrm{ft}$ and a width of $58 \mathrm{ft}$. Girders are AASHTO Type III spaced at $8.83 \mathrm{ft}$ and diaphragms are $8 \mathrm{in}$. width $\times 27 \mathrm{in}$. height spaced at $25.33 \mathrm{ft}$. Two exterior and, two interior diaphragms, and seven girders are included in the model. The deck is 8.25 in. thick. Support conditions consist of unreinforced elastomeric bearing pads supporting the ends of the girders. Each girder support is modeled as a rolling pin and two mutually perpendicular 10k/in-stiffness springs (to simulate the bearing pad).

In all the parametric studies, the base case structure (Figure 3.1) or a modified version of it (as specified) is subjected to an edge transverse stress of 100 units applied to the deck as concentrated forces at the corresponding nodes of the F.E mesh. Under this loading condition, the induced deck transverse stresses can be obtained as a percentage of the applied edge transverse stress. 
Figure 3.2 shows the distribution of transverse stresses for the base case structure according to 2D F.E model. The restraining effects of the diaphragms and support conditions of the girders are evident after noticing the reduction of transverse stresses in regions containing the diaphragms (especially at the ends of the deck).

\subsection{Effect of Girders}

The effect of the number of girders is examined by reducing the spacing of the girders in the base case structure to a half and to a quarter of the original $8.83 \mathrm{ft}$ (i.e., increasing the number of girders). The distribution of transverse stresses for the resulting structure, according to 2D F.E analysis, is shown in Figures 3.3(a) and (b) respectively. It can be noticed that there is not a significant change in the distribution of transverse stresses as compared to the results for the base case (Figure 3.2), suggesting that the girder spacing does not significantly affect the distribution of transverse stresses on the deck.

The isolated effect of the presence of the girders on the distribution of transverse stresses is further evaluated by removing the features representing the diaphragms in the base case structure (Figure 3.1). Figure 3.4 (a) shows the resulting distribution of transverse stresses for this case. Figure $3.4(\mathrm{~b})$, on the other hand, corresponds to the results for the hypothetical case where the girders are made of steel (and diaphragms are not present).

It can be concluded from Figures 3.3 and 3.4 that the presence of the girders alone on the superstructure does not significantly affect the distribution of transverse stresses on the deck (regardless of the individual girder stiffness). 


\subsection{Effect of Boundary Conditions}

Figure 3.5(a) shows the resulting distribution of transverse stresses for a modified version of the base case structure. In this case, one of the ends of each girder is restrained against any movement except displacement in the transverse direction, and the opposite end is restrained only against displacement in the transverse direction. Figure 3.5(b) corresponds to the case where the ends of the girders are unrestrained, but the ends of the deck are restrained in the same fashion as in the case from which Figure 3.5(a) was obtained. It is noticed that transverse stresses are significantly reduced (see bottom of Figures 3.5(a) and (b)) in regions where transverse displacements are restrained. This suggests that the boundary conditions of the girder and/or deck can play an important role in determining the distribution of the induced transverse stresses.

\subsection{Effect of Spacing of Post-tensioning}

In the previous analyses (Sections 3.2 and 3.3 ) the transverse forces representing the post-tensioning were applied at all edge nodes of the F.E mesh. The resulting distribution of transverse stresses in Figure 3.6 (a) and (b), however, correspond to the case where the concentrated loads are applied only at every other node, and at every 3 nodes (i.e., leaving 3 nodes unloaded between two consecutive loaded nodes). In both cases, the average applied edge transverse stress on the base case structure is still equal to 100 units. It is noticed that a region of reduced compression stresses appears between points of application of post-tensioning forces near the edge of the deck and that the size of such region increases as the distance between loaded nodes increases. 


\subsection{Effect of Deck Thickness}

The effect of the deck thickness is studied by modeling the upper half of the deck in the base structure as shell elements with thickness equal to 6 in. (instead of 8.25 in.). Figure 3.7 shows the distribution of transverse stress for the resulting structure. Notice that the compressive transverse stresses are slightly smaller in the thinner halfdeck, indicating that decreasing the thickness of the deck magnifies the restraining effect of the diaphragms. This can be explained by recognizing that the relative stiffness of the diaphragm becomes more significant for a thinner deck.

Because current practice in the Indiana Department of Transportation (INDOT) calls for a fixed deck thickness of 8 in. for deck-on-girder concrete bridges, this parameter will be kept constant during the development of design aids for the use of transverse posttensioning.

\subsection{Effect of Diaphragms}

\subsubsection{General}

Figure 3.8 shows the distribution of transverse stresses for a modified version of the base case structure in which the lower half of the bridge superstructure has no diaphragms. It can be seen from this figure that the elimination of the diaphragms in the lower half of the deck results in larger compressive transverse stresses. This suggests that the diaphragms have a marked influence in the distribution of transverse stresses. A more detailed study of the effects of the diaphragms is presented in the following subsections. 


\subsubsection{Effect of Diaphragm Size}

The influence of the diaphragm size on the distribution of transverse stresses is further evaluated using a 3D Type I F.E model. The distribution of transverse stresses along two reference longitudinal lines on the deck, labeled as lines 1 and 2, is presented next. Points along lines 1 and 2 are defined in terms of locations.

Locations and lines of reference are schematically indicated in Figure 3.9. Locations 1 and 13 coincide with the original position of the end and interior diaphragms in the base case structure. Adjacent locations are spaced $25.3 \mathrm{in}$. from each other. Line 1 is located over the second girder from the edge of the deck. Line 2 is located over the central girder. For a specific location, stresses in lines 1 and 2 are considered representative of the transverse distribution of transverse stresses.

Figures $3.10(\mathrm{a})$ and $3.10(\mathrm{~b})$ show the variation of the transverse stresses along lines 1 and 2 for different diaphragm sizes (keeping the same aspect ratio; $65 \mathrm{in}^{2}, 176 \mathrm{in}^{2}$, and $270 \mathrm{in}^{2}$. Transverse stresses are reported as fractions of the stresses applied at the edges of the deck. The salient findings are:

(i) Along line 1, transverse stresses decrease very rapidly as the location of exterior diaphragm is approached. A maximum stress reduction of $60 \%$ occurs at the location of the exterior diaphragms.

(ii) The reduction of transverse stresses with increasing diaphragm size is more significant at locations close to the exterior diaphragms.

(iii) The transverse stress along line 1 changes more rapidly than along line 2 .

(iv) Increasing the area of the diaphragms results in smaller transverse stresses. However, near mid-span (location 19) 
the transverse stresses remain almost equal to the applied edge stresses regardless of the size of the diaphragms.

In order to establish the difference between the effect of the exterior and interior diaphragms on the distribution of transverse stresses, two modified versions of the base case were considered; in the first case the structure had exterior diaphragms only, in the second case the structure had interior diaphragms only. Figures 3.11 and 3.12 show the variation of the transverse stresses along lines 1 and 2 for the first case (exterior diaphragm only) and for the second case (interior diaphragm only). Comparison of these figures confirms the significant difference in the restraining effect of exterior diaphragms as compared to interior diaphragms. It could be argued that the restraining effect of the exterior diaphragms as showed in Figure 3.11 is being influenced by the lateral restraint imposed by the neoprene pads at the girders' ends. However, through extensive numerical simulation it was found that small values for the spring stiffness (simulating the neoprene pads) did not appreciably change the distribution of stresses shown in this figure. The results of these simulations are not explicitly included in this report.

\subsubsection{Effect of Diaphragm Position}

It is evident from the comparison of Figures 3.11 and 3.12 that as the diaphragms are moved from the end of the deck towards midspan, their restraining effect becomes less significant.

Considering the base case structure but with only two diaphragms symmetrically located with respect to midspan, the effect of the diaphragm position can be studied. Figures 3.13 (a) and (b) show the distribution of stresses along lines 1 and 2 respectively for different locations of the diaphragms. Notice how the transverse stresses increase as the diaphragms are placed closer to midspan. 


\subsubsection{Rationalization of the Effect of Diaphragm Position}

A question that emerges from observing Figure 3.13 is why there is such difference in the restraining effect of the diaphragm, when their position is changed. A hypothesis that might explain this is that there is composite action of the deck with the diaphragm as a T-section. The flange width of such T-section increases as the diaphragms are placed closer to mid-span. It can be visualized that the "flange width" for an interior diaphragm is greater than the "flange width" for an exterior diaphragm because in the first case the diaphragm would belong to a Tshape section, whereas the second case to an L-shape section.

Consider the 8 in. $\times 27$ in. diaphragm of the base case structure (Figure 3.1) as the web of a T-section having a flange width $B_{\text {eff }}$ under a unit stress (equivalent to the transverse post-tensioning). The unit stress is transformed into a concentrated force acting in the middle of the flange. Then, the stress at the top of the composite section can be found from basic flexure theory (neglecting shear lagging) for different

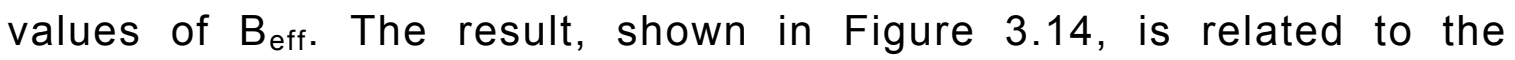
hypothesis stated above and is absolutely independent of the results obtained in the F.E analysis.

Figure 3.15 , on the other hand, shows the minimum transverse stress along line 1 (which always occur at Location 1) as a function of the location of the diaphragm. The values of minimum transverse stresses needed to construct this figure are obtained from Figure 3.13(a).

Comparison of Figures 3.14 and 3.15 indicates that the variation of the top stress (transverse) is similar with respect to both the effective width, and the diaphragm position. This similarity supports the formulated hypothesis, which can be stated as:

$\mathrm{B}_{\text {eff }}=\mathrm{K} \times$ position of diaphragm 
where, $\mathrm{K}$ is a constant.

The hypothesis is further validated by plotting in Figure $3.16, B_{\text {eff }}$ from Figure 3.14 and the diaphragm location from Figure 3.15, for given normalized stresses. The resulting relationship is very close to linear (which supports Equation (3.1)). 


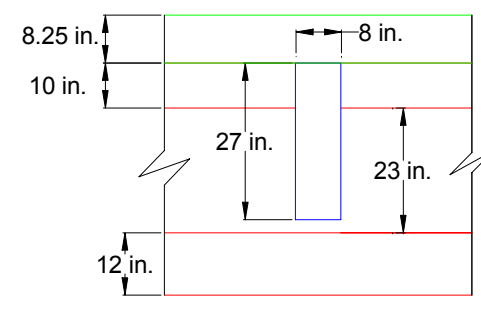

View C-C

View D-D

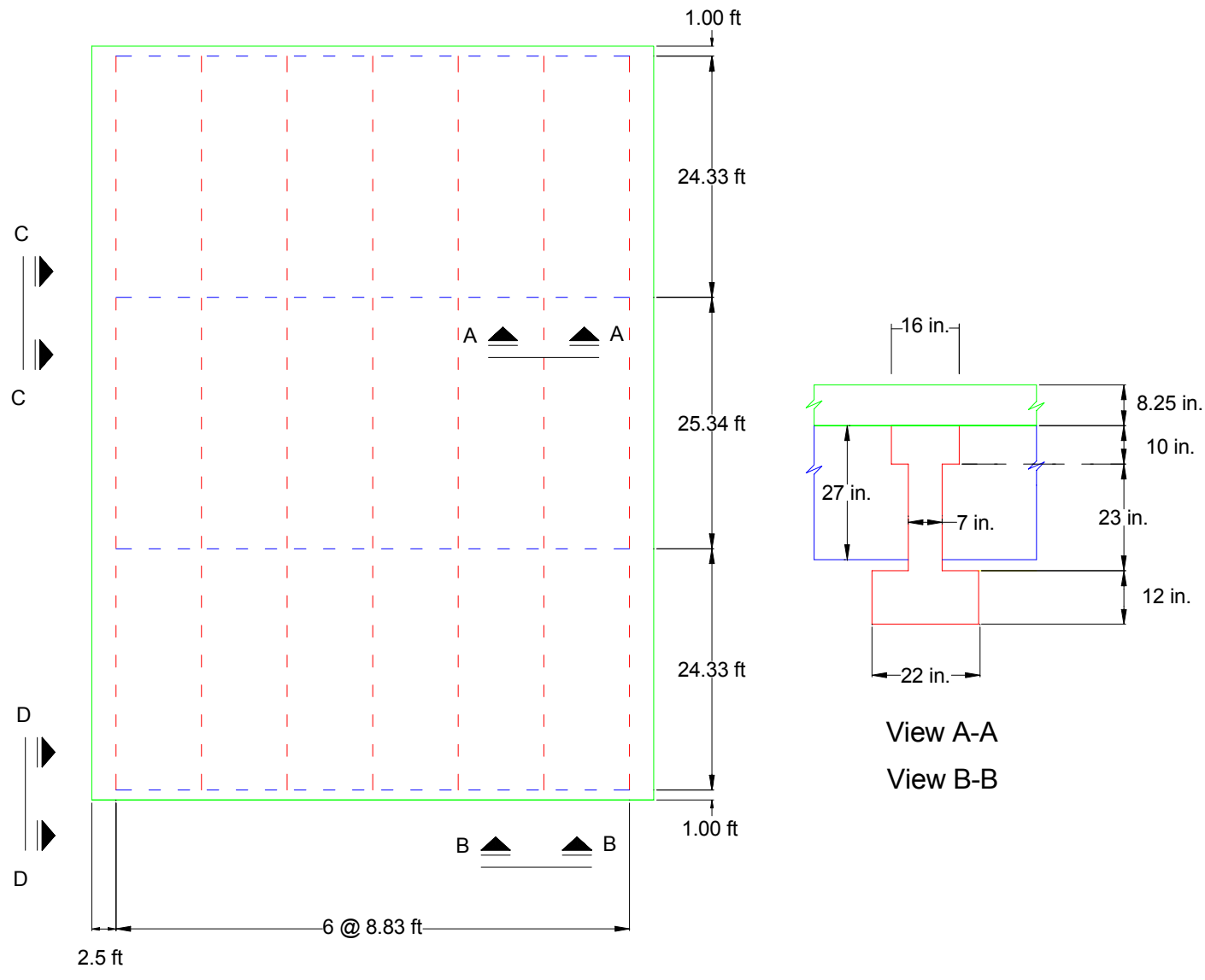

Figure 3.1 Base Case Structure 


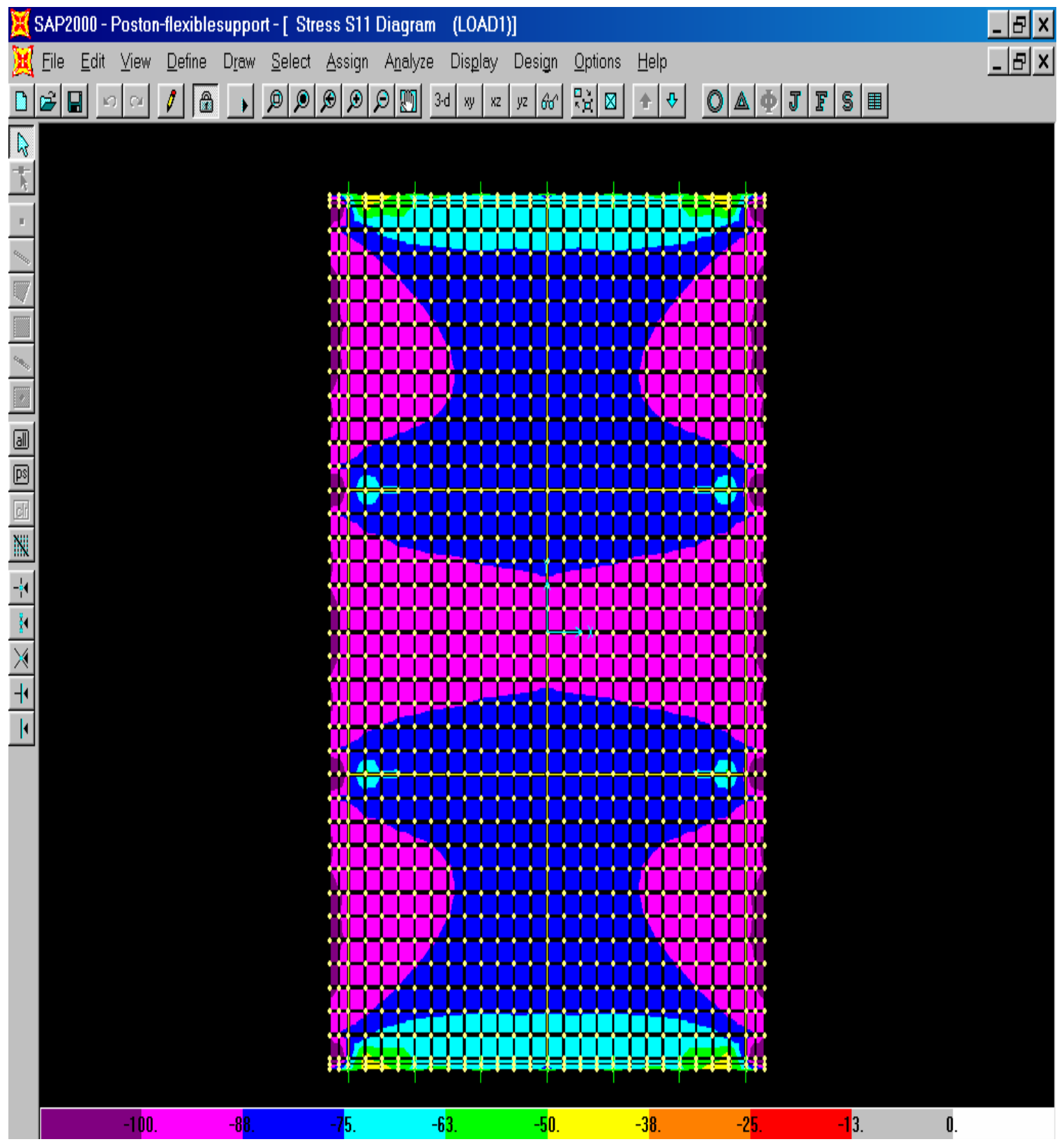

Figure 3.2- Distribution of Transverse Stresses for Base Case Structure. 


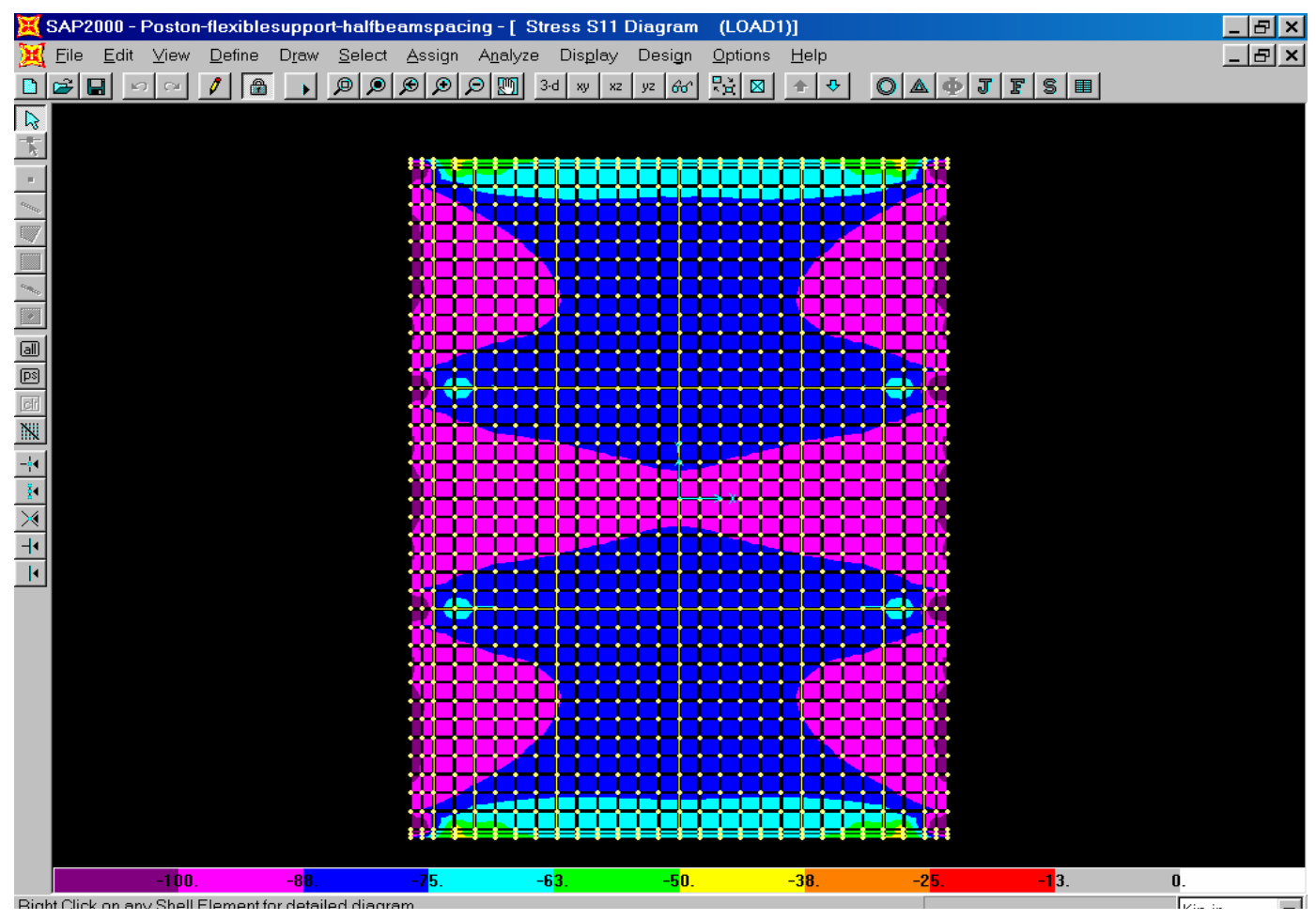

(a)

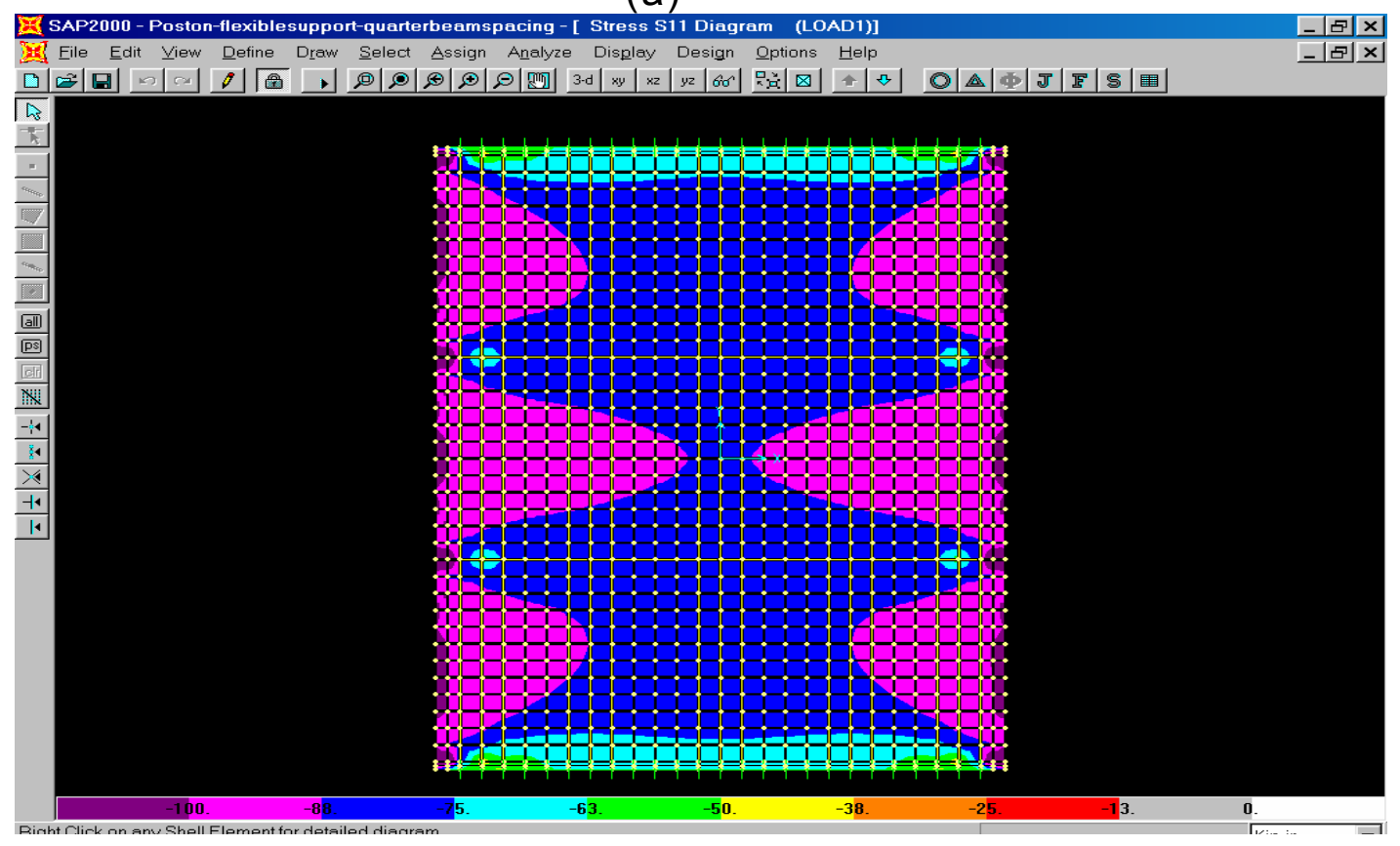

(b)

Figure3.3- Effect of the Girder Spacing.

(a) Girder spacing equal to half of that for the base case structure

(b) Girder spacing equal a quarter girder of that for the base case structure 


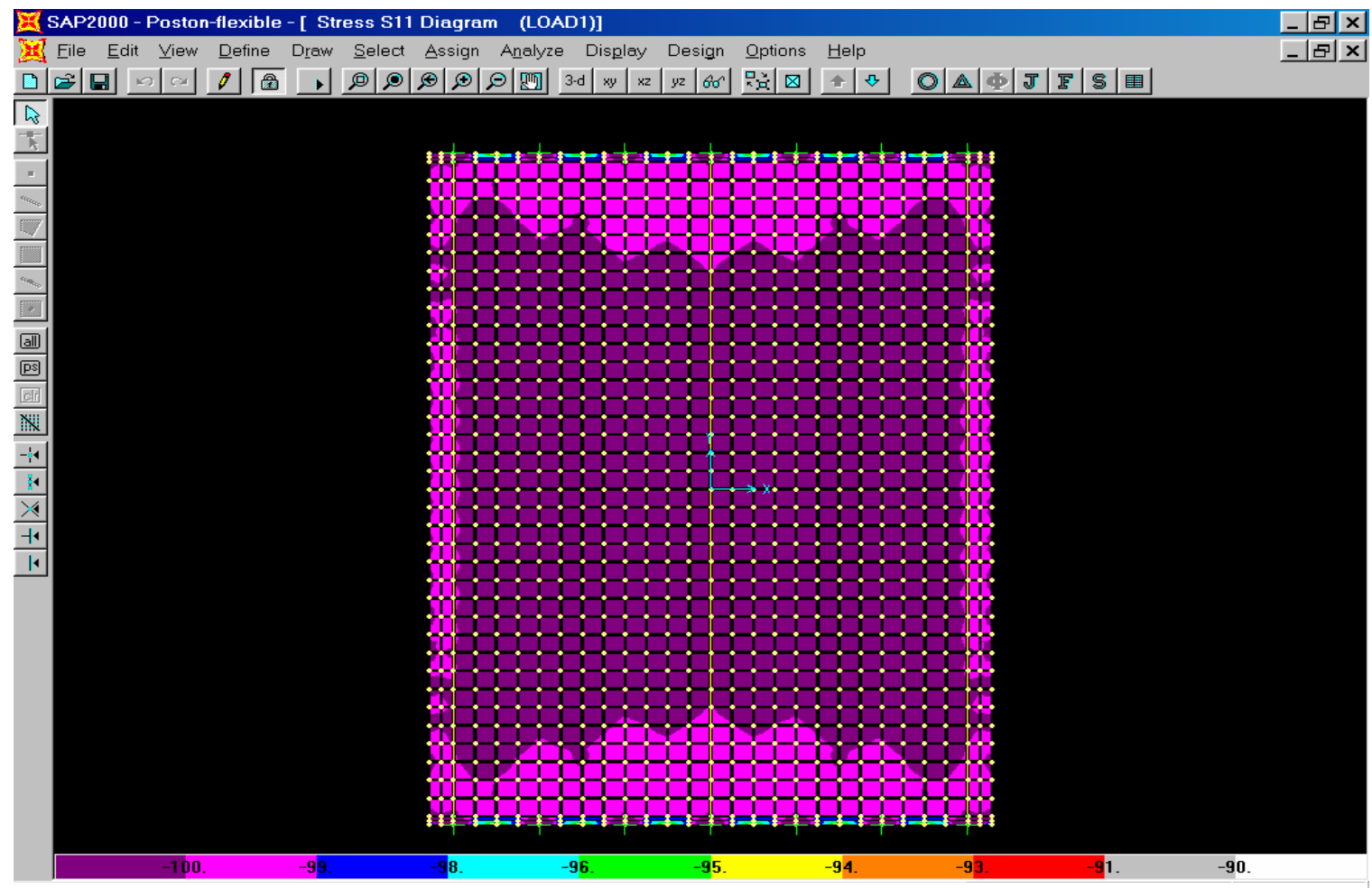

(a)

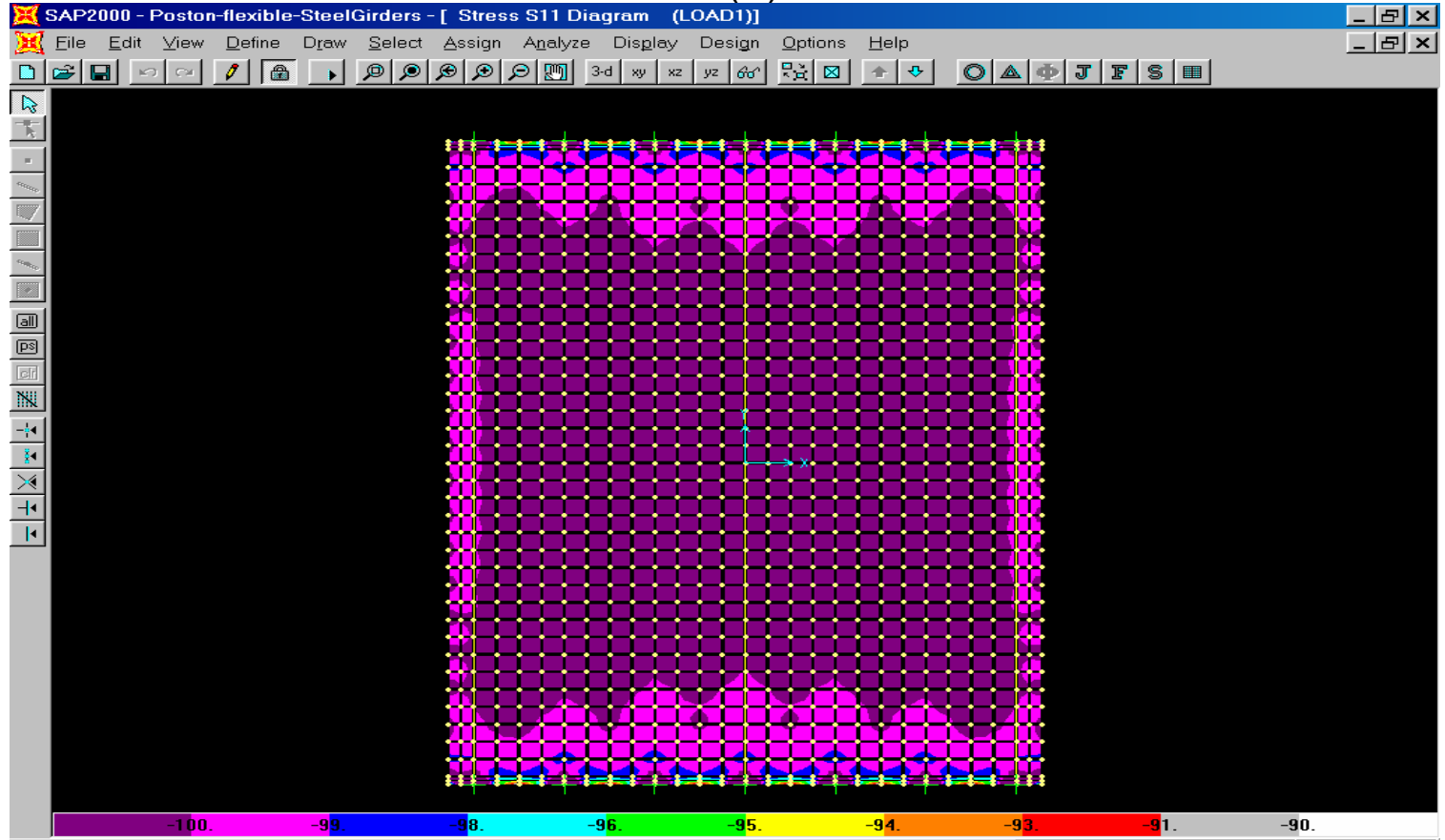

(b)

Figure 3.4 Isolated Effect of Girder (no diaphragms)

(a) Concrete Girders

(b) Steel Girders 


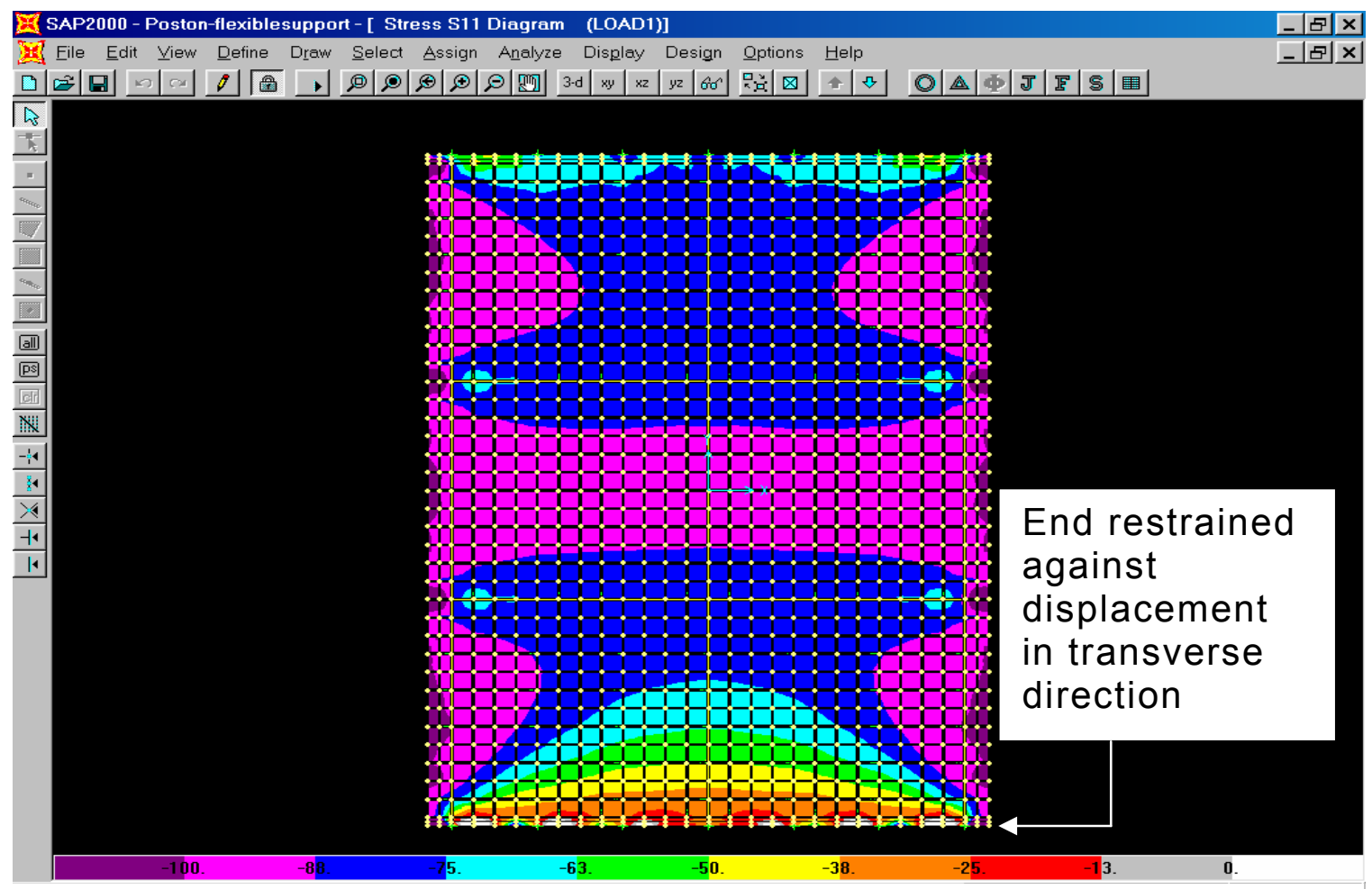

(a)

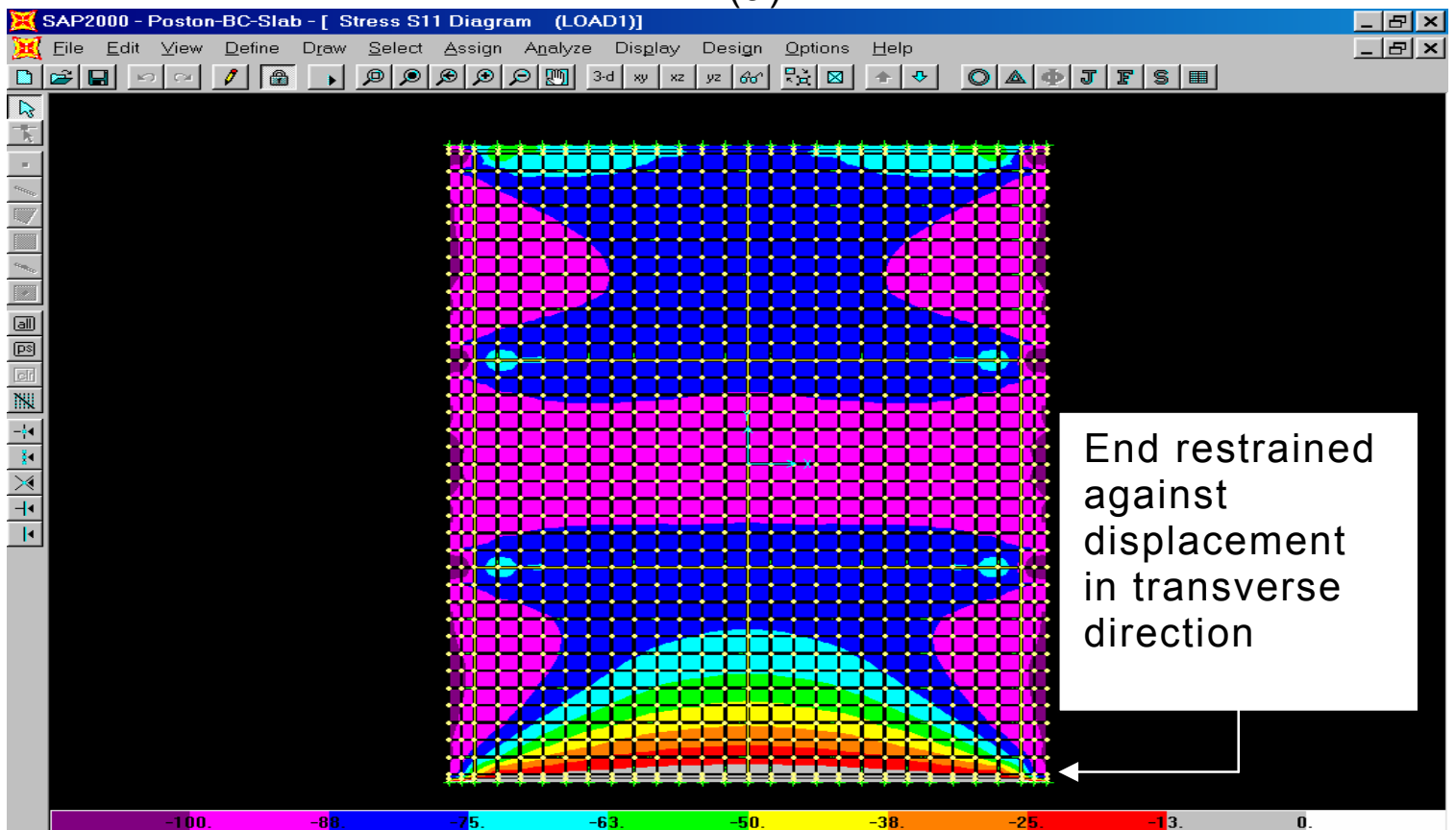

(b)

Figure 3.5 Effect of Boundary Conditions

(a) On Girders

(b) On Deck 


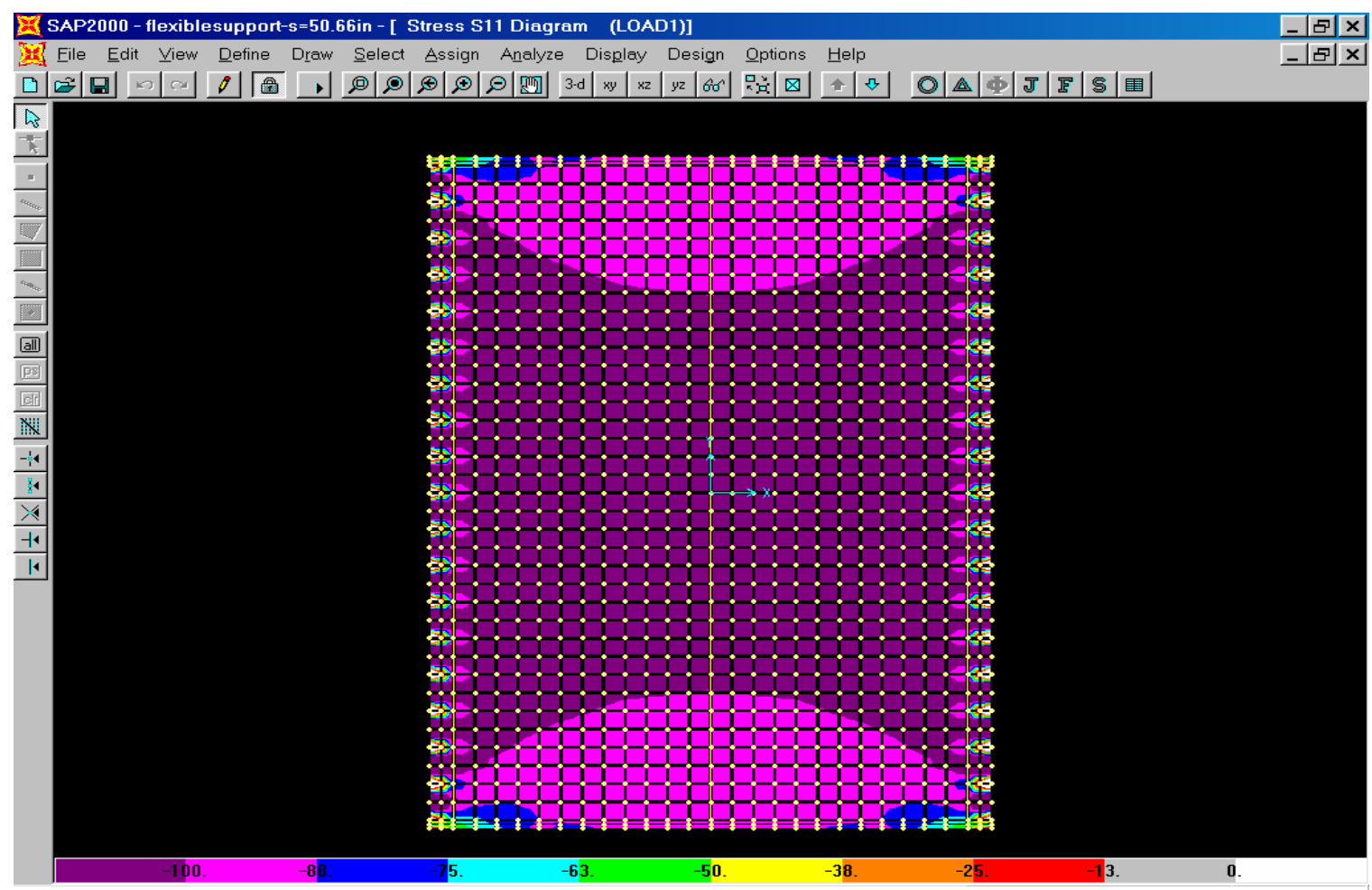

(a)

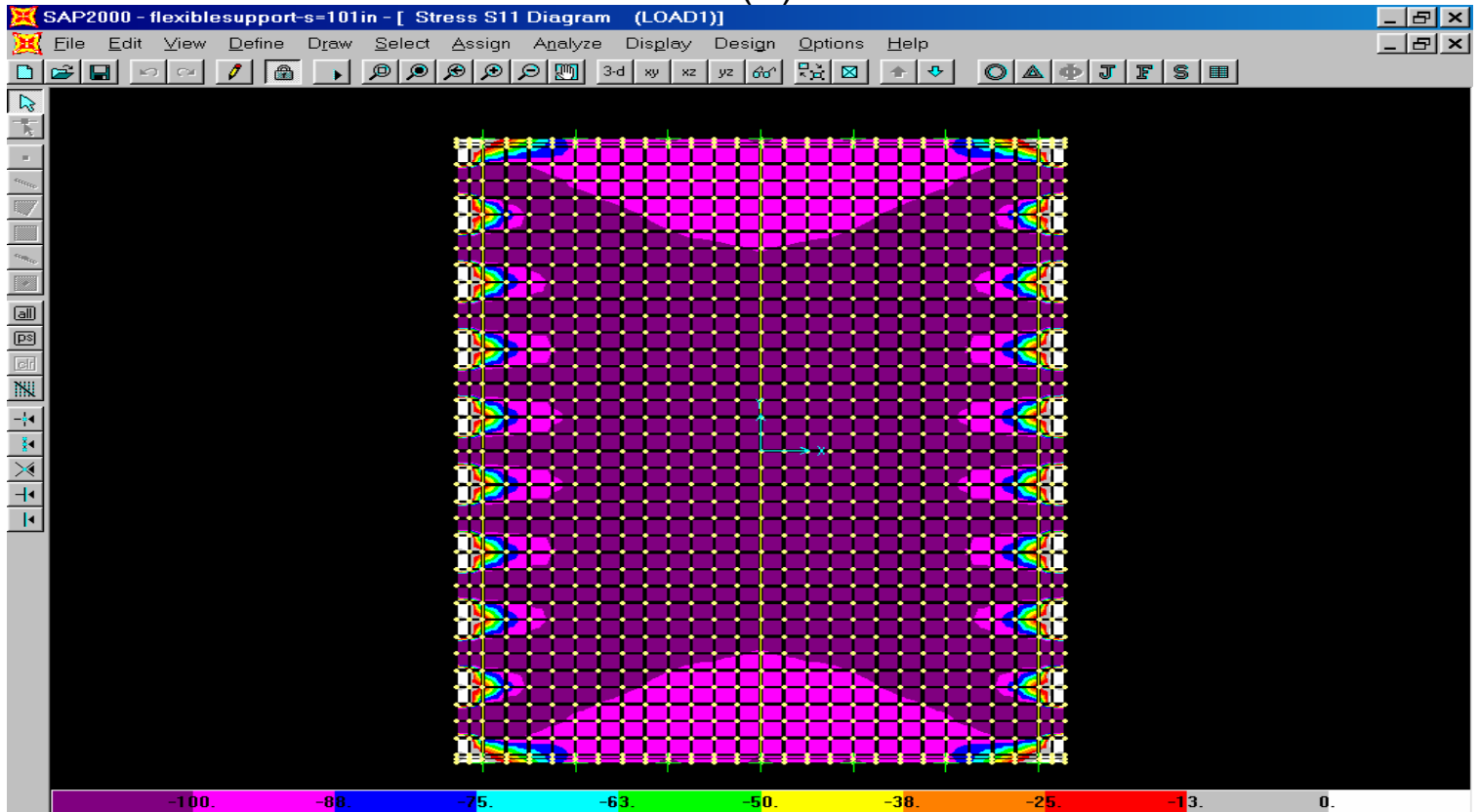

(b)

Figure 3.6 Effect of Transverse Post-Tensioning Spacing

(a) Transverse Force at Every Other Node

(b) Transverse Force at Every Four Nodes 


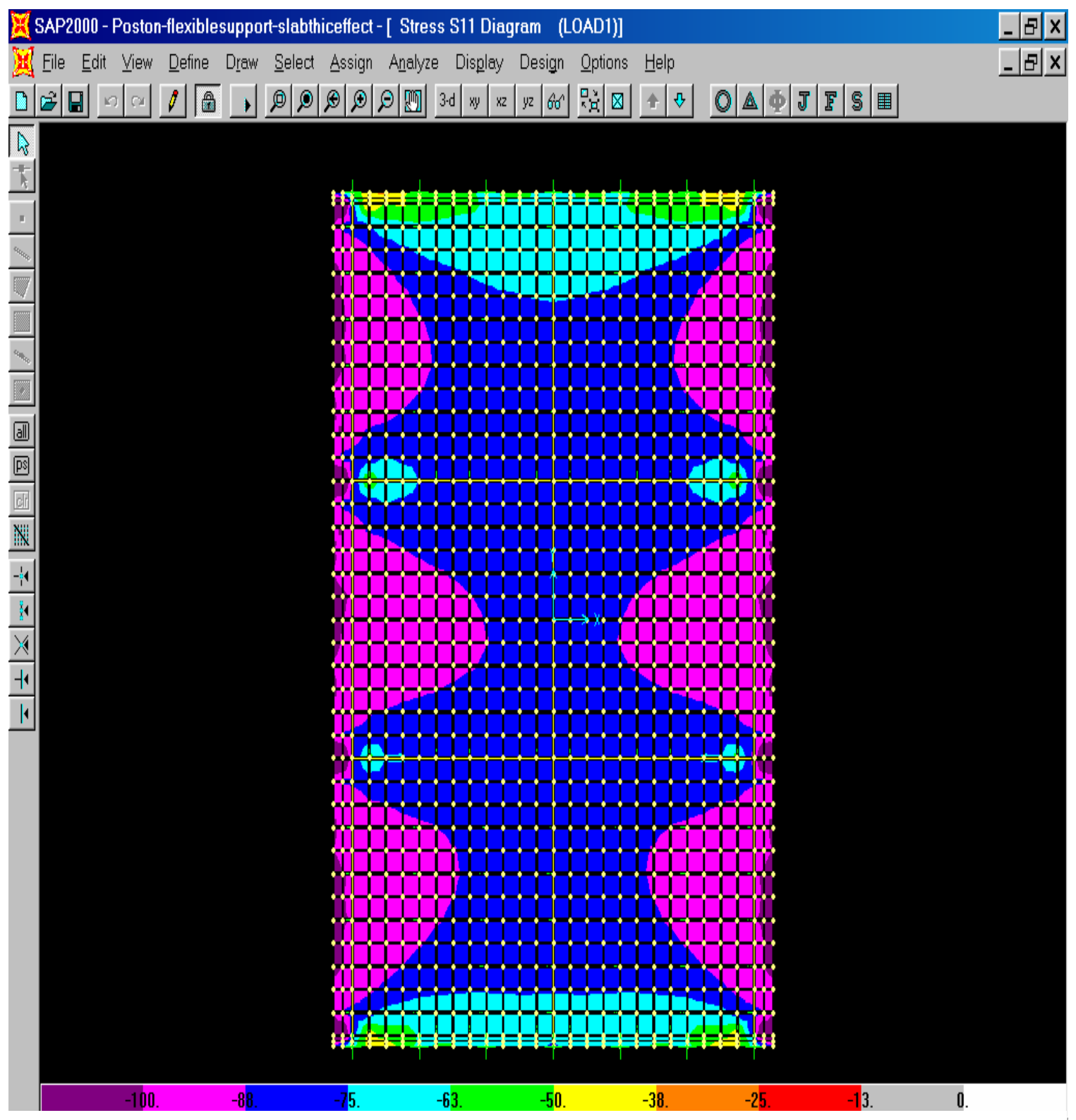

Figure 3.7 Effect of Deck Thickness 


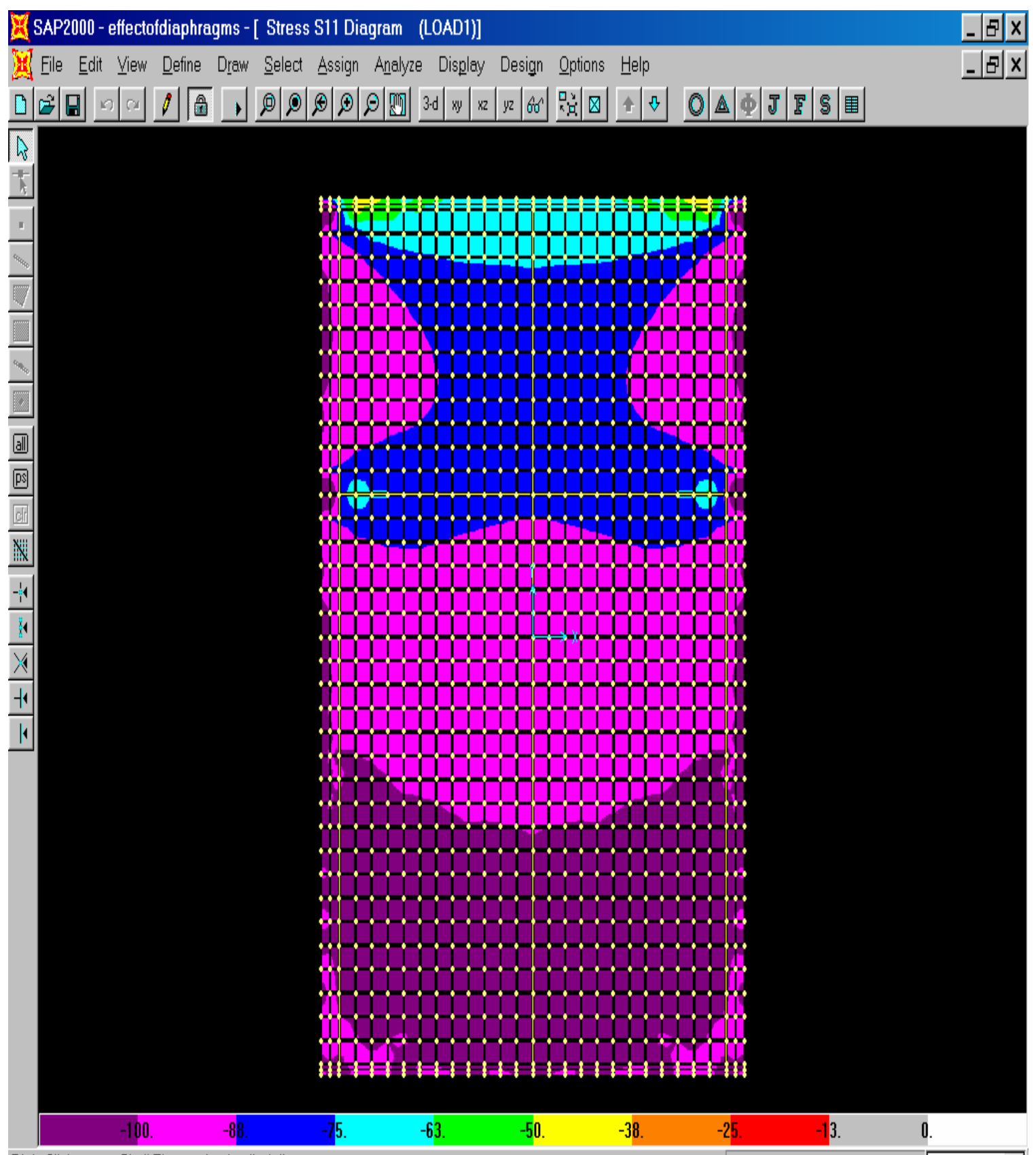

Figure 3.8 Effect of Diaphragms (bottom half does not have diaphragms) 


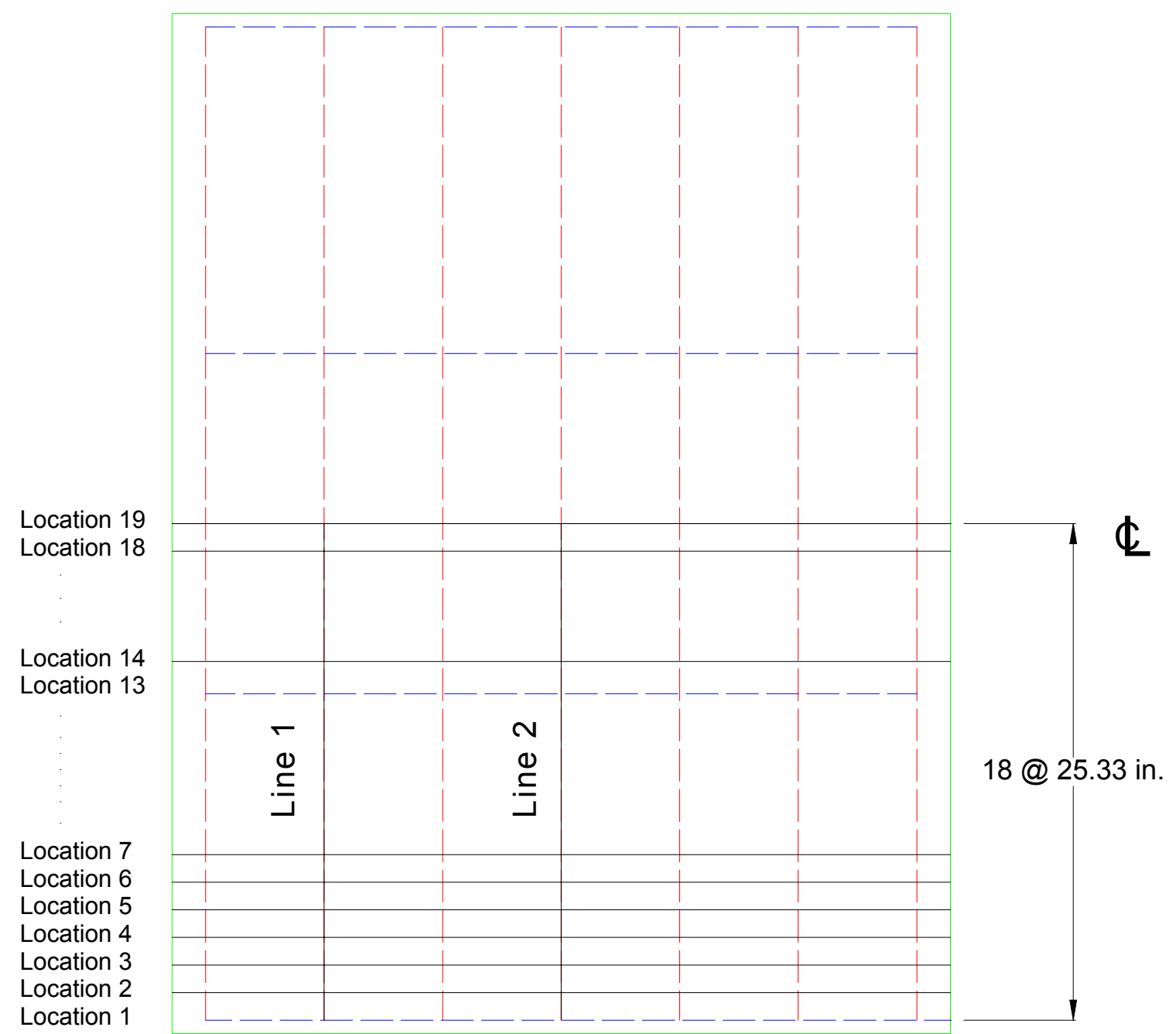

Figure 3.9 Definition of Locations, and Lines 1 and 2 


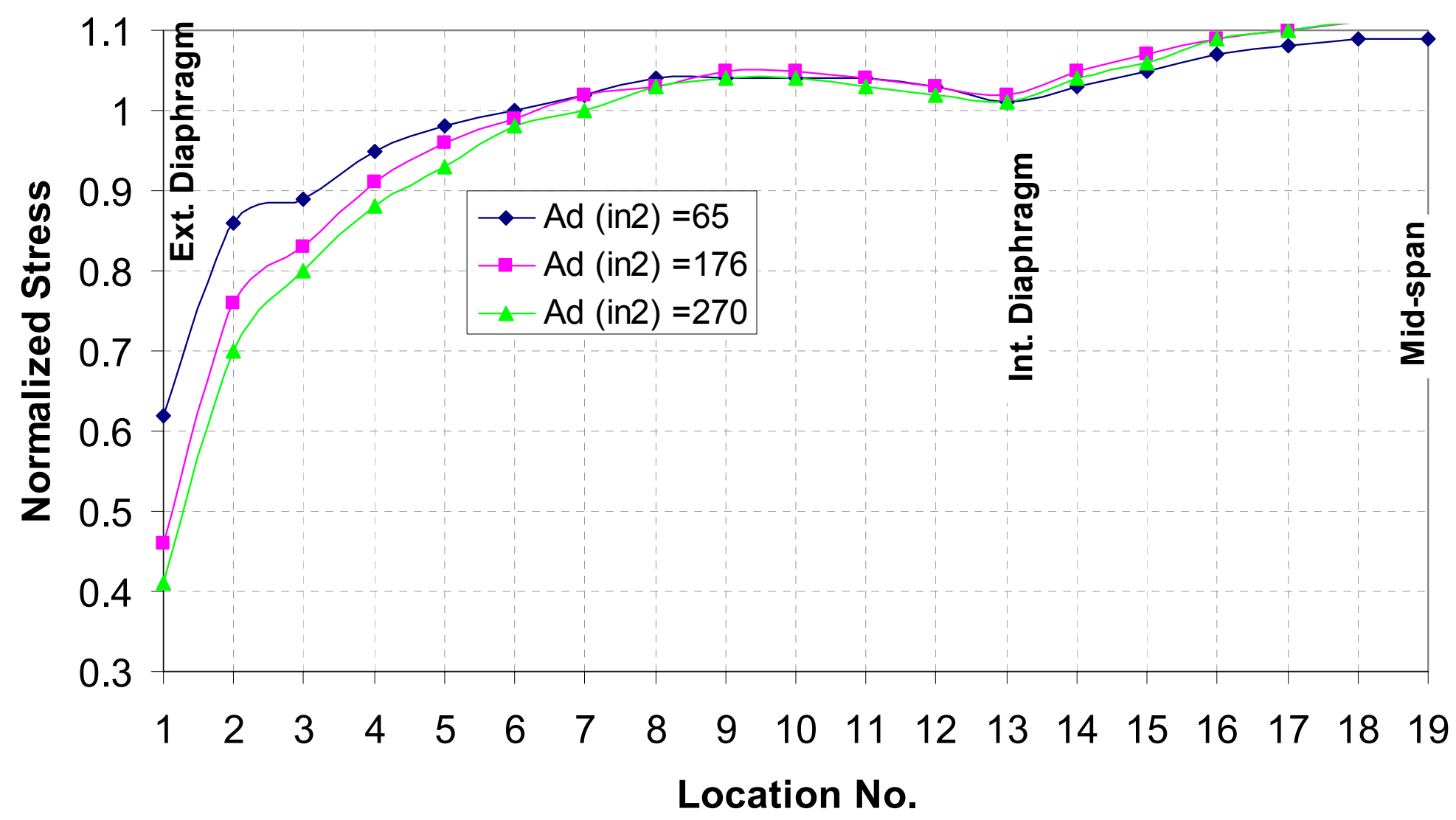

Figure 3.10 (a) Transverse Stresses Along Line 1 for Different Diaphragm Sizes 


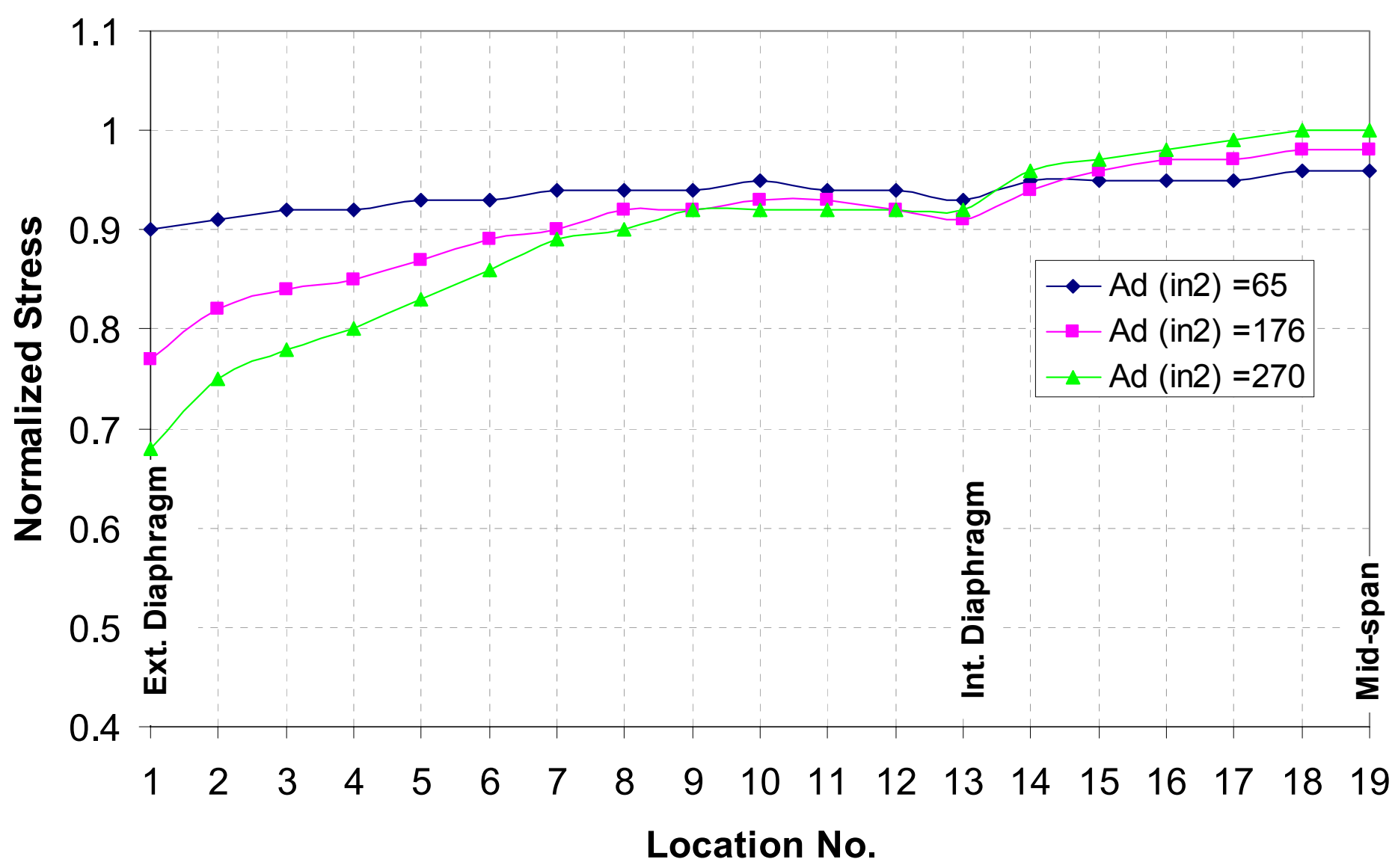

Figure 3.10 (b) Transverse Stresses Along Line 2 for Different Diaphragm Sizes 


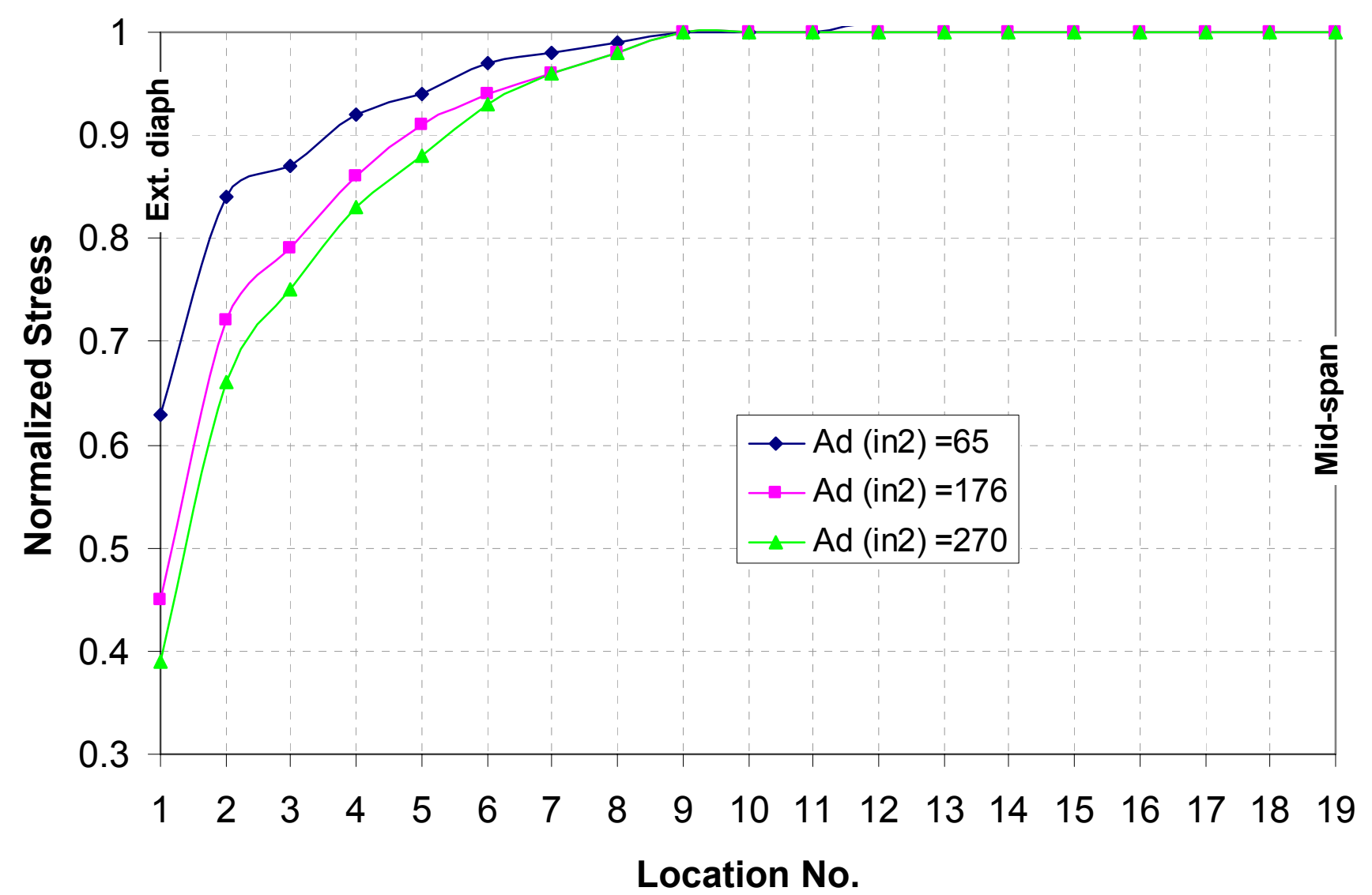

Figure 3.11(a) Transverse Stresses Along Line 1 for Different Diaphragm Sizes. Exterior Diaphragms Only 


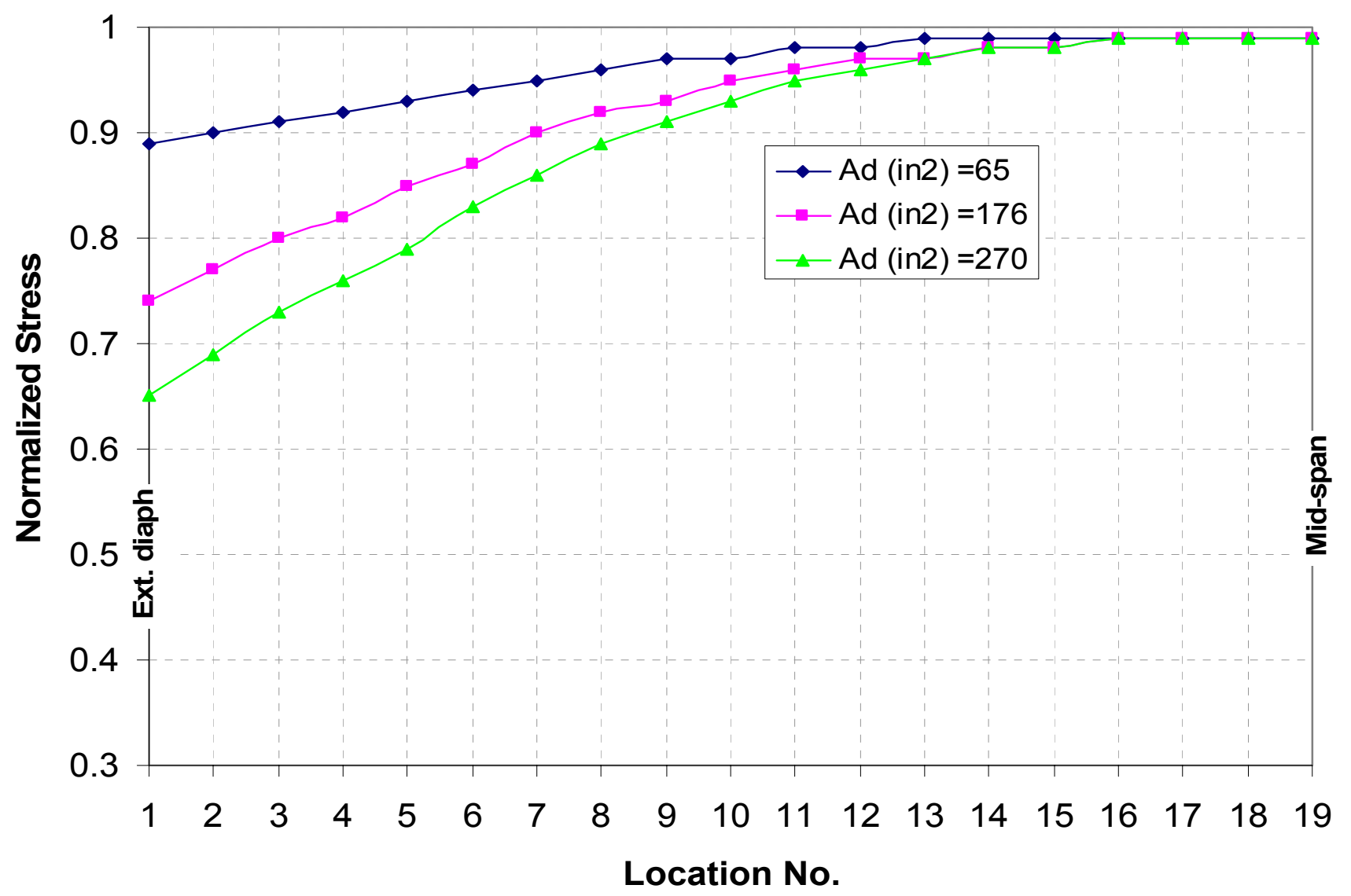

Figure 3.11(b) Transverse Stresses Along Line 2 for Different Diaphragm Sizes. Exterior Diaphragms Only 


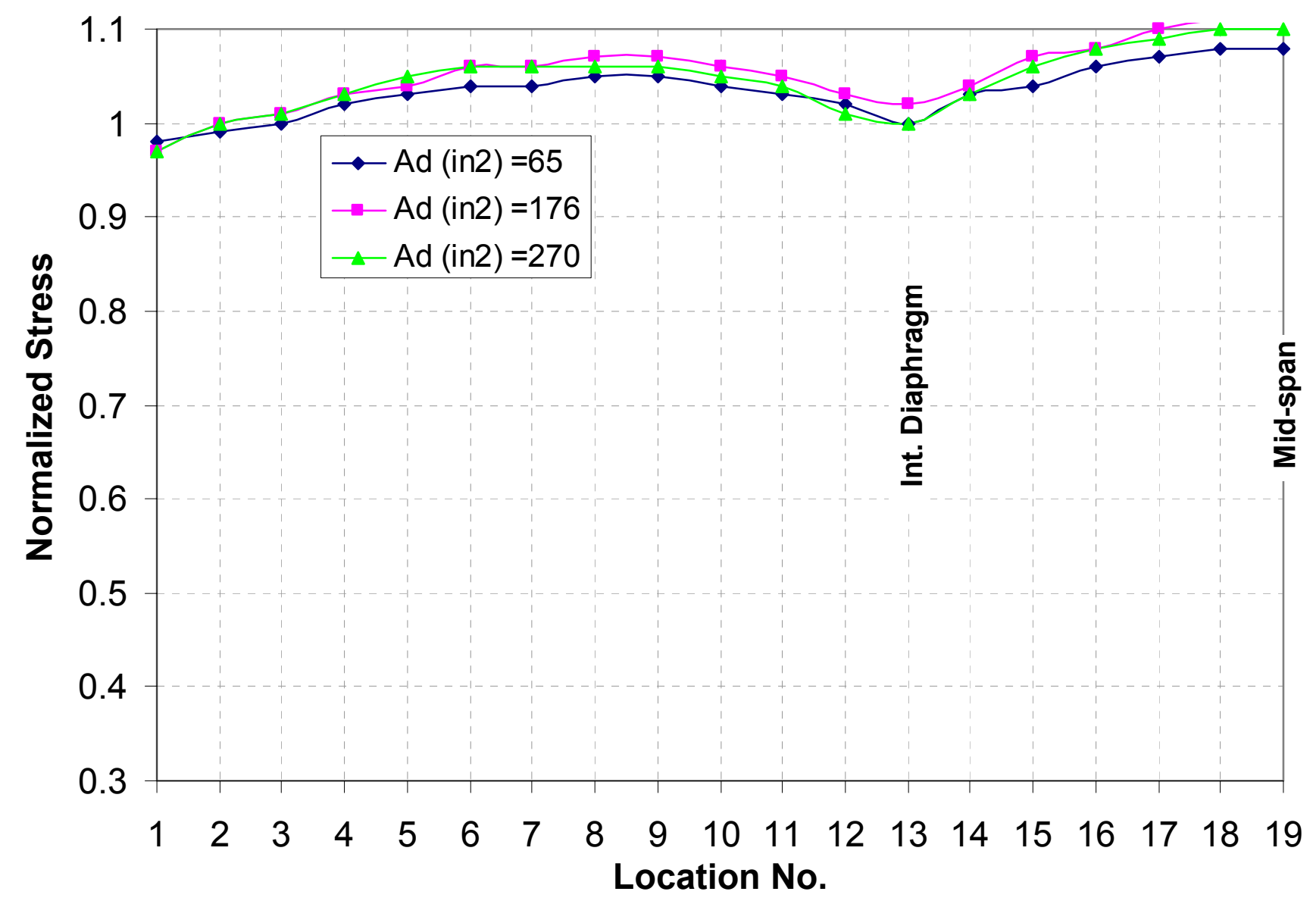

Figure 3.12(a) Transverse Stresses Along Line 1 for Different Diaphragm Sizes. Interior Diaphragms Only 


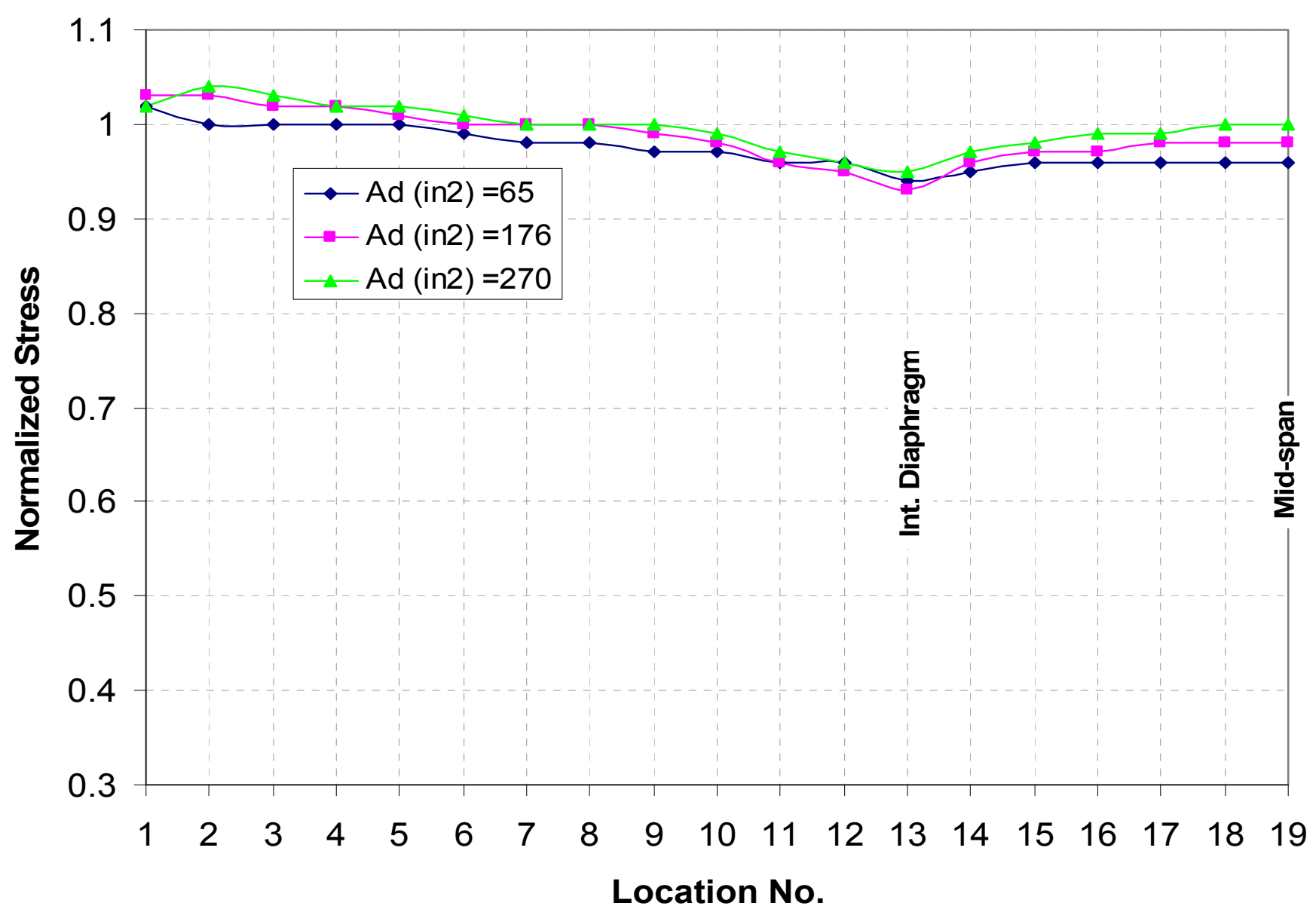

Figure 3.12(b) Transverse Stresses Along Line 2 for Different Diaphragm Sizes. Interior Diaphragms Only 


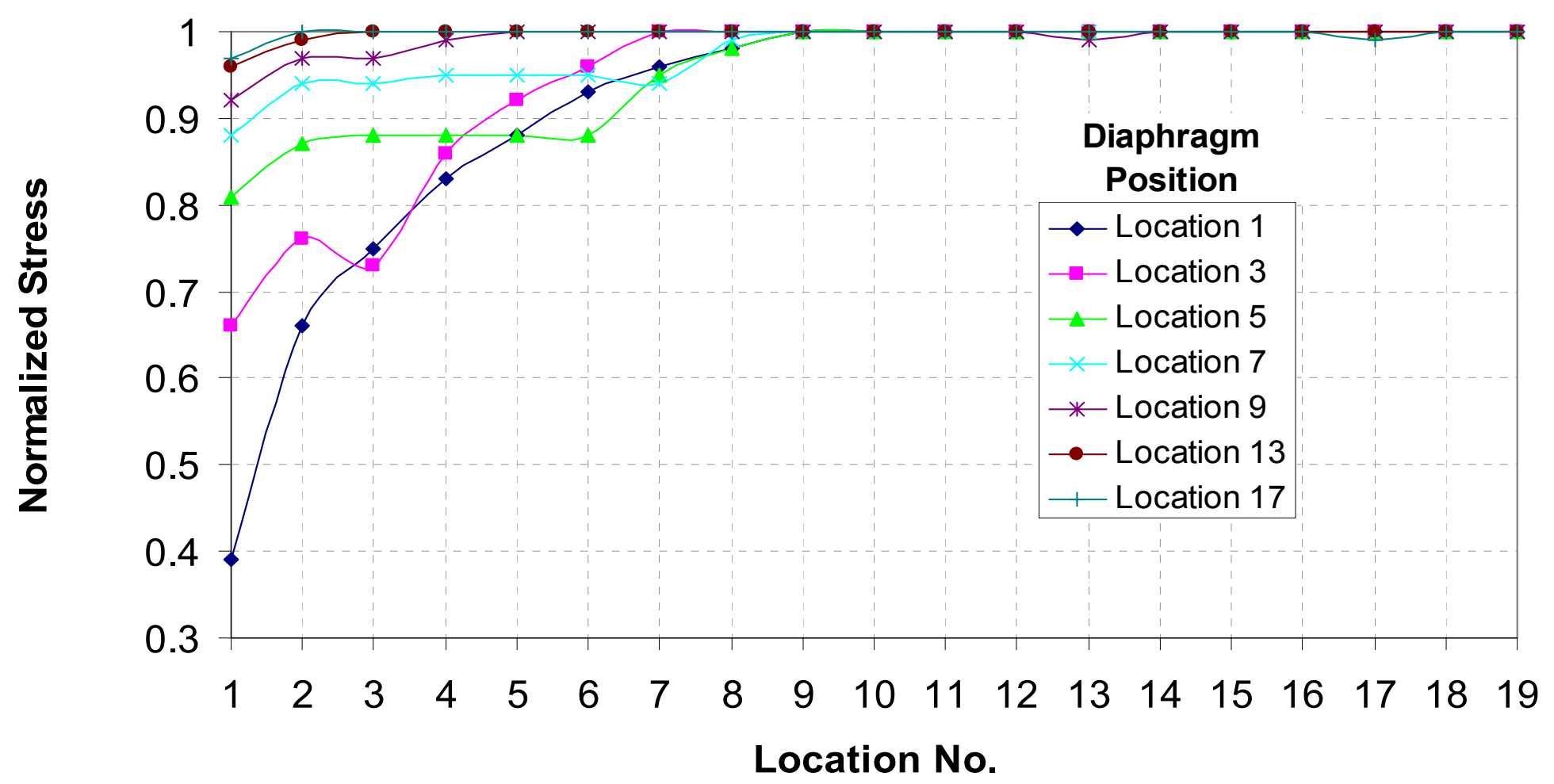

Figure 3.13 (a) Transverse Stresses Along Line 1 for Different Diaphragm Locations 


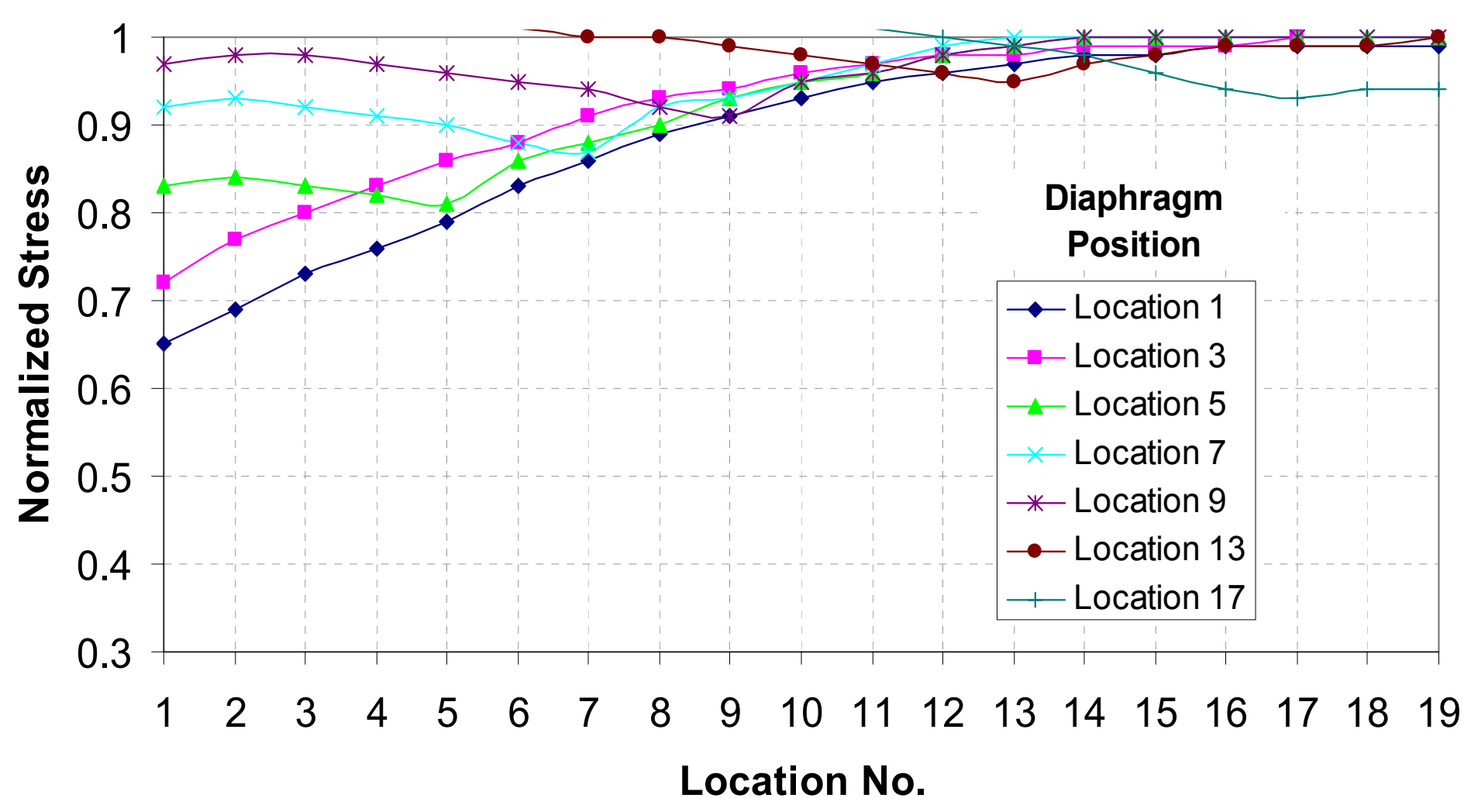

Figure 3.13 (b) Transverse Stresses Along Line 2 for Different Diaphragm Locations 


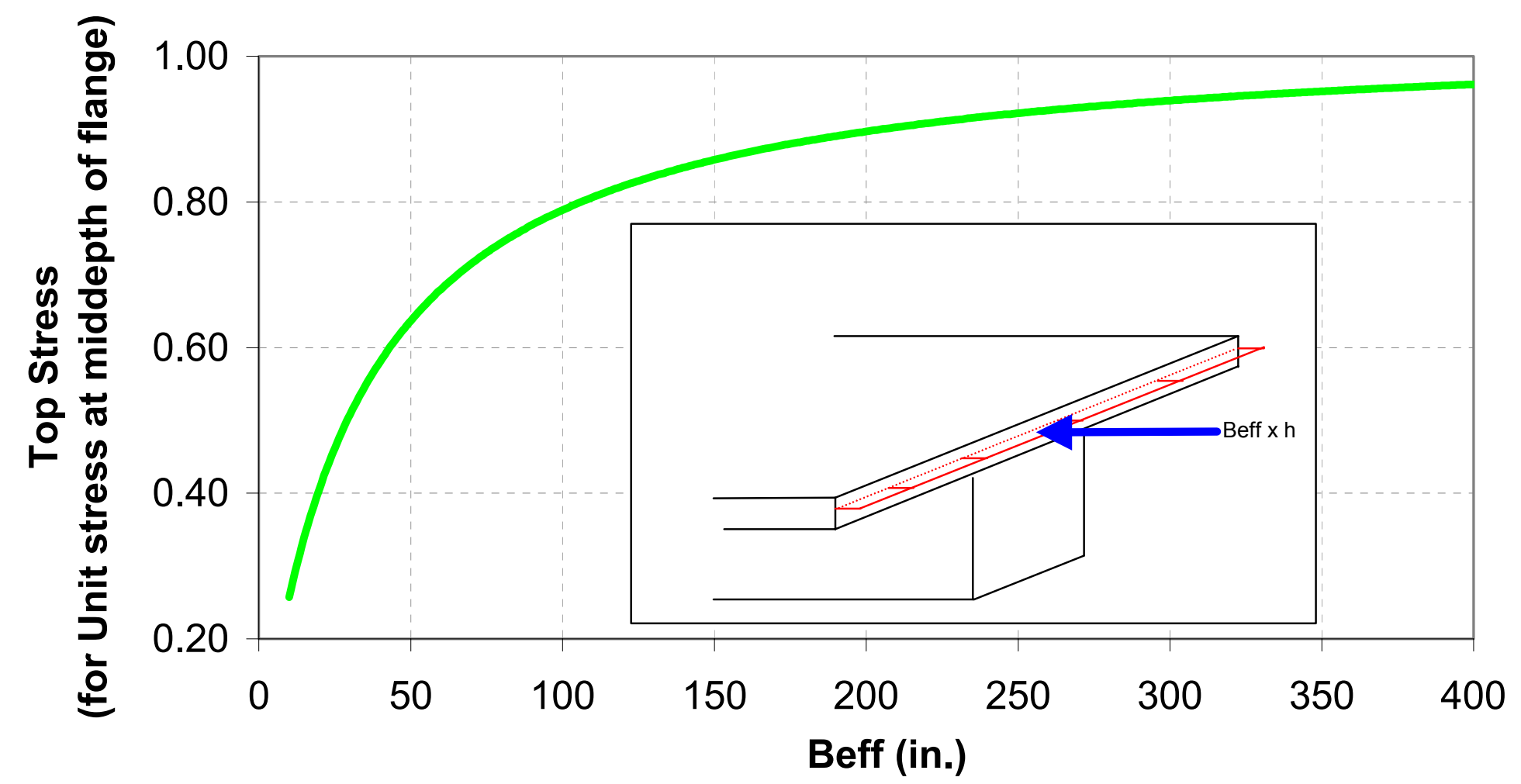

Figure 3.14 Top Fiber Stresses in a T-Beam as a Function of Flange Width for a Unit Stress on the Flange 


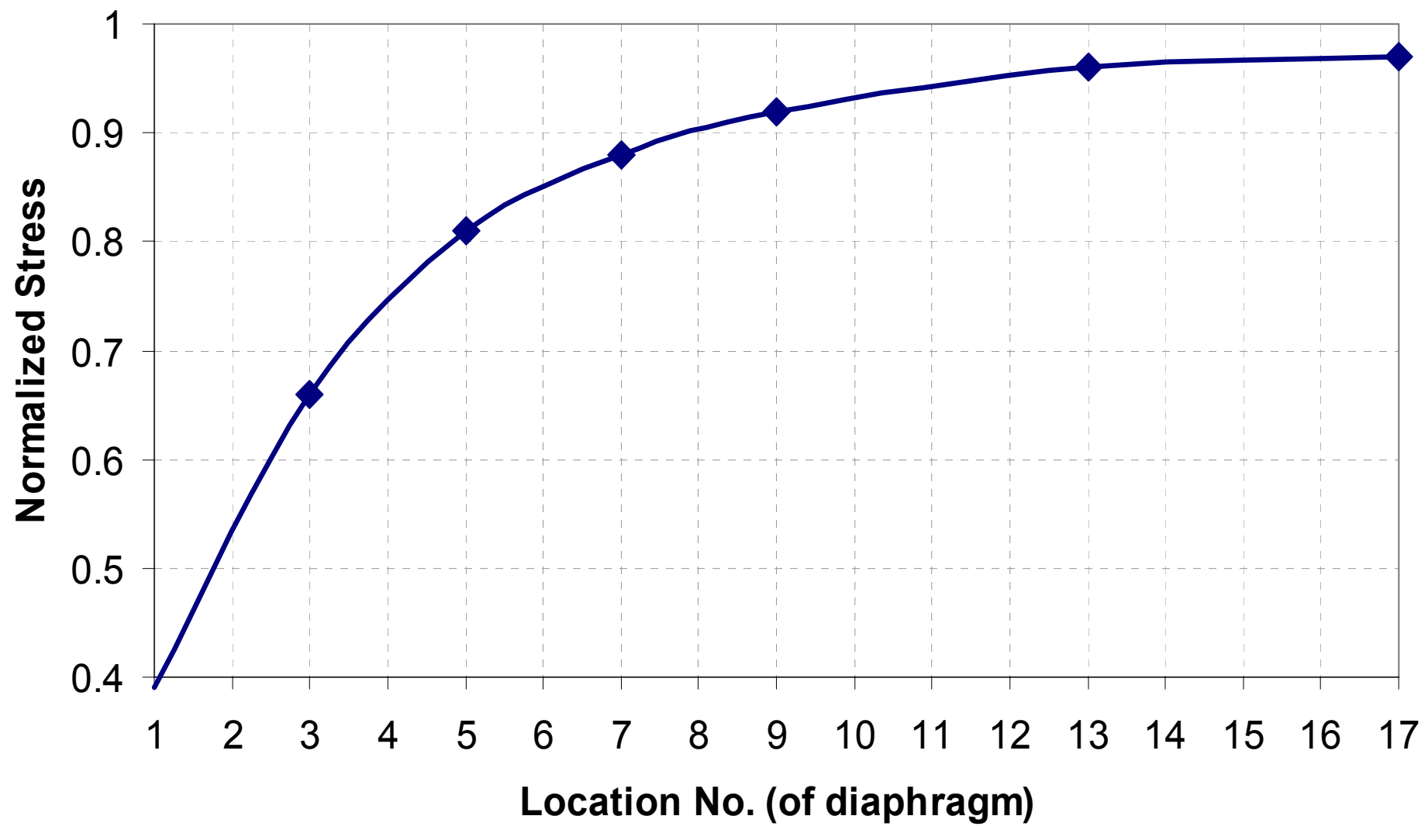

Figure 3.15 Minimum Stress on Line 1 as a Function of Diaphragm Location 


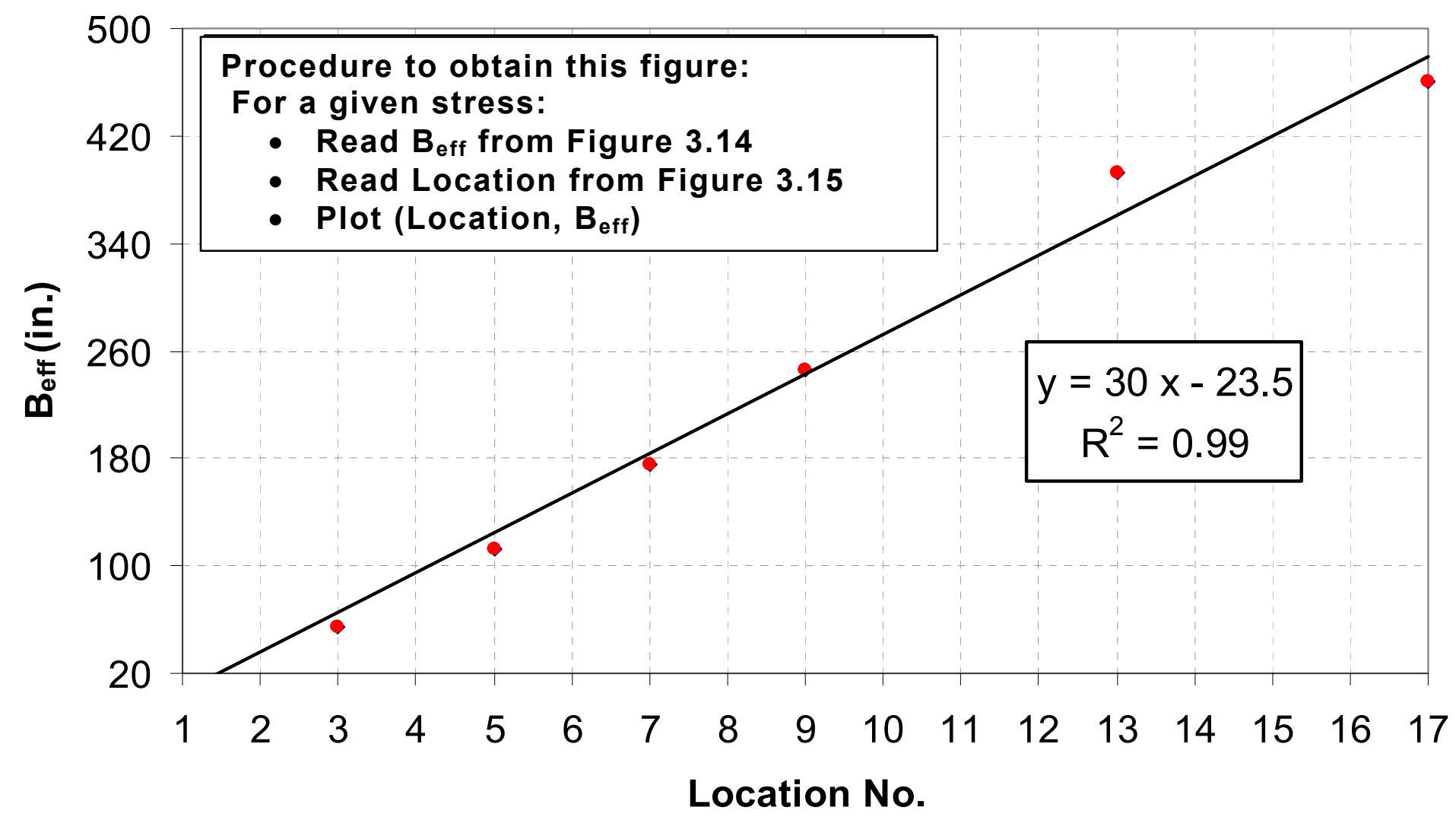

Figure 3.16 Flange Width of an Equivalent T-Beam as a Function of Diaphragm Position 


\section{4- Parametric Study}

\subsection{Notation}

In order to facilitate the description of the parametric study, it is convenient to establish the following definitions:

Diaphragm: any element of the superstructure spanning in the transverse direction; transverse girder, stiffener, and/or diaphragm itself.

Diaphragm region: transverse region on the surface of the deck over a diaphragm. The width of such region is as specified.

Exterior diaphragm region: diaphragm region corresponding to the diaphragm that is the closest to the edge of the deck. This diaphragm will be referred to as exterior diaphragm.

Interior diaphragm region: diaphragm region corresponding to any diaphragm other than the exterior diaphragm. These diaphragms will be referred to as interior diaphragms.

Intermediate region: region of the deck between consecutive diaphragm regions

$\underline{\sigma}_{\mathrm{I}}$ : transverse stress applied at the edge of the deck, simulating the transverse post-tensioning.

$\underline{\alpha}$ : extra-post-tensioning force factor for $\sigma_{\mathrm{T}}$.

Strip 1 (S1): line on the top surface of the deck along an exterior diaphragm

Strip 2 (S2): line on the top surface of the deck located in the middle of an exterior diaphragm and an adjacent interior diaphragm

Strip 3 (S3): line on the top surface of the deck along an interior diaphragm

Strip 4 (S4): line on the top surface of the deck between two consecutive interior diaphragms.

Figure 4.1 illustrates all the definitions presented above. 


\subsection{Base Case and Range of Variables}

The base case structure for the parametric study consists of a simply supported deck-on-girder bridge having a span length of $76 \mathrm{ft}$ and a width of $58 \mathrm{ft}$. Girders are AASHTO Type III spaced at $8.83 \mathrm{ft}$ and diaphragms are $10 \mathrm{in}$. width $\times 20 \mathrm{in}$. height spaced at $24.33 \mathrm{ft}$ and 25.33ft. Two exterior and two interior diaphragms, and seven girders are included in the model. The deck is 8.25 in. thick. Support conditions consist of unreinforced elastomeric bearing pads supporting the ends of the girders. Each bearing is modeled as a rolling pin and two $10 \mathrm{k} / \mathrm{in}-$ stiffness springs. The springs, placed in both the longitudinal and the transverse direction, are used to model the restraining effect of the neoprene pads on the girders. Details of the structural configuration are shown in Figure 4.2. The structure is subjected to a uniform unit compressive stress applied along the edges of the deck simulating the post-tensioning. No dead or live loads are considered in the analyses.

Variables considered in the parametric study include: size of concrete diaphragms, size of steel diaphragms, degree of restriction against longitudinal and transverse displacement at the ends of girders, aspect ratio of diaphragms, number of diaphragms, position of exterior diaphragm with respect to the edge of the deck, and skew angle of the deck. Table 4.1 summarizes all the sets of cases considered in the parametric study and the range of values for the different variables for each set.

\subsection{Minimum and Average Transverse Stress on Different Strips}

Stresses on Strips 1 through 4 (strips are defined in section 4.1) are considered to be representative of the distribution of transverse stresses in the longitudinal direction. The unit compressive stress applied at the edge of the deck allows obtaining the induced transverse stress at any joint of the finite element mesh as a proportion of the applied transverse stress. For a given case of the parametric study, the 
stresses in all the mesh joints contained in a particular strip are obtained and the minimum and average values are reported. 3D Type I F.E modeling with SAP2000 is used for the analyses.

\subsubsection{Effect of Number of Diaphragms}

The base case illustrated in Figure 4.2 is consecutively modified by changing the number of diaphragms in the superstructure. This corresponds to set case 2 in Table 4.1. In all the analyses, the diaphragms are evenly spaced.

Figures 4.3(a) and (b) show the variation of the minimum and average stress at different strips as a function of the number of diaphragms. It is noticed that there is not a significant change in the distribution of transverse stresses with the number of diaphragms. This implies that the effect of every diaphragm is approximately independent of the corresponding effect of companion diaphragms. In other words, it can be stated that the restraining action of a particular diaphragm is mainly localized in a region of the deck containing such element. This is an important conclusion because it will allow prescribing different levels of post-tensioning at different diaphragm regions in the design aids.

\subsubsection{Effect of Diaphragm Aspect Ratio}

The base case structure illustrated in Figure 4.2 is subsequently modified by changing the ratio height/width for the diaphragms. This corresponds to set Case 3 in Table 4.1.

The results from the corresponding F. E. analyses are shown in Figures 4.4 (a) and (b) where the minimum and average stresses at different strips are shown as a function of the diaphragm aspect ratio. It is noticed that the magnitude of the induced transverse stresses increases with the diaphragm aspect ratio. This is expected because a higher aspect ratio would correspond to a larger eccentricity of the applied transverse force (in compression). The effect of the aspect ratio, however, is not significant. 


\subsubsection{Effect of Skew}

The base case structure illustrated in Figure 4.2 is modified to account for bridge skew angle. This corresponds to set Case 4 in Table 4.1. The applied compressive stresses are oriented parallel to the skewed end of the deck (the transverse forces are not perpendicular to the edges of the deck). A justification for using this post-tensioning scheme is given in Section 5.1 of this report.

Figures 4.5(a) and (b) show the variation of the minimum and average transverse stresses with the bridge skew angle at Strips 1 though 4 (stripes are now parallel to the skew end of the deck). It is observed that the induced transverse stress decreases with the skew angle of the structure. The reduction can be in part associated with the fact that only the horizontal component of the applied edge compressive stress contributes to the induced transverse stresses.

\subsubsection{Effect of Boundary Conditions of Girders}

The base case illustrated in Figure 4.2 is consecutively modified by changing the level of restrain against displacement in the longitudinal and transverse direction at the ends of each girder. Such level of restraint is simulated with two mutually perpendicular springs having elastic constants equal to $\mathrm{K}_{\mathrm{s}}$. This corresponds to set Case 5 in Table 4.1 .

The minimum and average stresses as a function of $\mathrm{K}_{\mathrm{s}}$ at different strips is shown in Figures 4.6 (a) and (b). It is evident that the degree of fixity at the girders' ends significantly affects the distribution of induced transverse stresses especially in regions of the deck close to the supports. More restrained support conditions for the girders would be qualitatively equivalent to a stiffer element at the end of the deck. Such conceptual element will attract a significant portion of the applied transverse stresses. 


\subsubsection{Effect of RC Diaphragm Size}

The base case illustrated in Figure 4.2 is consecutively modified by changing the size of the diaphragms. This corresponds to set Case 6 in Table 4.1. Concrete diaphragms are modeled as elastic elements having a Young Modulus, $E_{c}=4000 \mathrm{ksi}$.

The results from the Finite Element analyses are summarized in Figures 4.7 (a) and (b). It is noticed that the minimum and average stresses at different strips significantly depend on the size of the diaphragms. Notice, for instance, that the minimum normalized stress in strip 1 (S1) changes from 0.55 for a $100 \mathrm{in}^{2}$ diaphragm size to 0.42 for a 200 in $^{2}$ diaphragm size (see Figure 4.7(a)). Evidently, a greater diaphragm will "attract" more of the induced transverse compressive stresses on the deck. The restraining effect of the diaphragms, however, is less significant at interior than at exterior diaphragm regions.

\subsubsection{Effect of Steel Diaphragm Size}

The base case illustrated in Figure 4.2 is consecutively modified by changing the size and type of diaphragms. This corresponds to set Case 7 in Table 4.1.The modulus of elasticity for the diaphragms is now equal to $29000 \mathrm{ksi}$ (instead of $4000 \mathrm{ksi}$ assumed for concrete diaphragms).

The steel diaphragm sizes considered in the analyses correspond to W14 and W16 rolled shapes (typically used in Indiana's bridges).

The results from the Finite Element analyses are summarized in Figures 4.8 (a) and (b). It is noticed (also by comparing with Figures 4.7 (a) and (b)) that the minimum and average stresses at different strips significantly depend on the axial stiffness of the diaphragms. Notice, for instance, that the minimum normalized stress in strip 1 (S1) reaches values as low as 0.22 for a $200 \mathrm{in}^{2}$ steel diaphragm (see Figure 4.8(a)). The restraining effect of the diaphragms is, however, considerably less significant at interior diaphragm regions. 


\subsubsection{Effect of Position of Exterior Diaphragm}

The base case illustrated in Figure 4.2 is consecutively modified by changing the position of the exterior diaphragm with respect to the ends of the girders. This corresponds to set Case 8 in Table 4.1.

Figures 4.9 (a) and (b) summarize the results from the analyses in terms of the minimum and average stresses at different strips. It is observed that the transverse stresses at the end of the deck are affected by the relative position of the exterior diaphragm. Notice that the minimum normalized stress in strip 1 (S1) changes from 0.4 to 0.6 when the exterior diaphragm is placed first at $6 \mathrm{in.}$ and then at $30 \mathrm{in}$. away from the edge of the deck (see Figure 4.9(a)). This phenomenon was rationalized in Section 3.6.4.

\subsubsection{Combined Effect of Diaphragm Size and Boundary Conditions of Girders}

Since the axial stiffness of the diaphragm and, the level of restrain at the girder ends, appeared to be the parameters most significantly affecting the distribution of transverse stresses on the deck, analyses of the combined effect of these parameters was deemed of relevance.

The results from the analyses are summarized in Figures 4.10(a) and (b) and, 4.11(a) and (b). The minimum transverse stress as a function of the area of concrete diaphragm at strips 1 and 3 is shown in Figures 4.10(a) and (b). In these figures, there is a family of curves for different values of $\mathrm{K}_{\mathrm{s}}$. Figures $4.11(\mathrm{a})$ and (b) also show the variation of the minimum transverse stress on Strips 1 and 3 as a function of the area of steel diaphragms.

The results from Figures 4.10 and 4.11 will be used later in the formulation of design aids. The strategy chosen is to prescribe initial values of transverse prestressing required at interior and exterior diaphragm regions as a function of: (1) $\mathrm{K}_{\mathrm{s}}$ and, (2) the diaphragm type and size and, then apply correction factors for skew angle and diaphragm position. 
Table 4.1 Set of Cases Considered in the Parametric Study

\begin{tabular}{|c|c|c|c|c|c|c|c|}
\hline \multirow[b]{2}{*}{ Case } & \multicolumn{7}{|c|}{ Variable value or range of values } \\
\hline & No. of Diaphs & $\begin{array}{l}\text { Diaph. Aspect Ratio } \\
\text { (height/width) }\end{array}$ & $\begin{array}{c}\text { Skew }_{1} \\
\text { (Degrees) }\end{array}$ & $\begin{array}{c}\mathbf{K}_{\mathbf{s}} \\
\text { (kips/in) }\end{array}$ & $\begin{array}{c}\text { RC Diaph. Size } \\
\left(\text { in }^{2}\right)\end{array}$ & $\begin{array}{c}\text { Steel Diaph. Size } \\
\left(\mathrm{in}^{2}\right)\end{array}$ & $\begin{array}{l}\text { Loc. of Ext. Diaph } \\
\text { (in) }\end{array}$ \\
\hline Base & 4 & 2 & 0 & 10 & 200 & N/A & 12 \\
\hline 1 & 3 to 7 & 2 & 0 & 10 & 200 & $\mathrm{~N} / \mathrm{A}$ & 12 \\
\hline 2 & 4 & 0.5 to 3 & 0 & 10 & 200 & $\mathrm{~N} / \mathrm{A}$ & 12 \\
\hline 3 & 4 & 2 & 0 & 10 & 200 & N/A & 12 \\
\hline 4 & 4 & 2 & 0 to 30 & 10 & 200 & $\mathrm{~N} / \mathrm{A}$ & 12 \\
\hline 5 & 4 & 2 & 0 & 1 to $10^{6}$ & 200 & $\mathrm{~N} / \mathrm{A}$ & 12 \\
\hline 6 & 4 & 2 & 0 & 10 & 32 to 450 & $\mathrm{~N} / \mathrm{A}$ & 12 \\
\hline 7 & 4 & $\mathrm{~N} / \mathrm{A}_{2}$ & 0 & 10 & $\mathrm{~N} / \mathrm{A}$ & 10 to 240 & 12 \\
\hline 8 & 4 & 2 & 0 & 10 & 200 & $\mathrm{~N} / \mathrm{A}$ & 6 to 48 \\
\hline
\end{tabular}

Notes:

1: transverse force representing the post-tensioning is applied in the direction of the skew

2: Steel diaphragms are W14 and W16 rolled elements

Ks: stiffness of springs representing the degree of restrain against displacement in transverse and longitudinal direction:

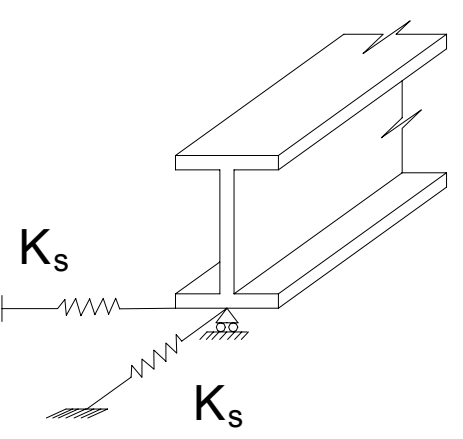




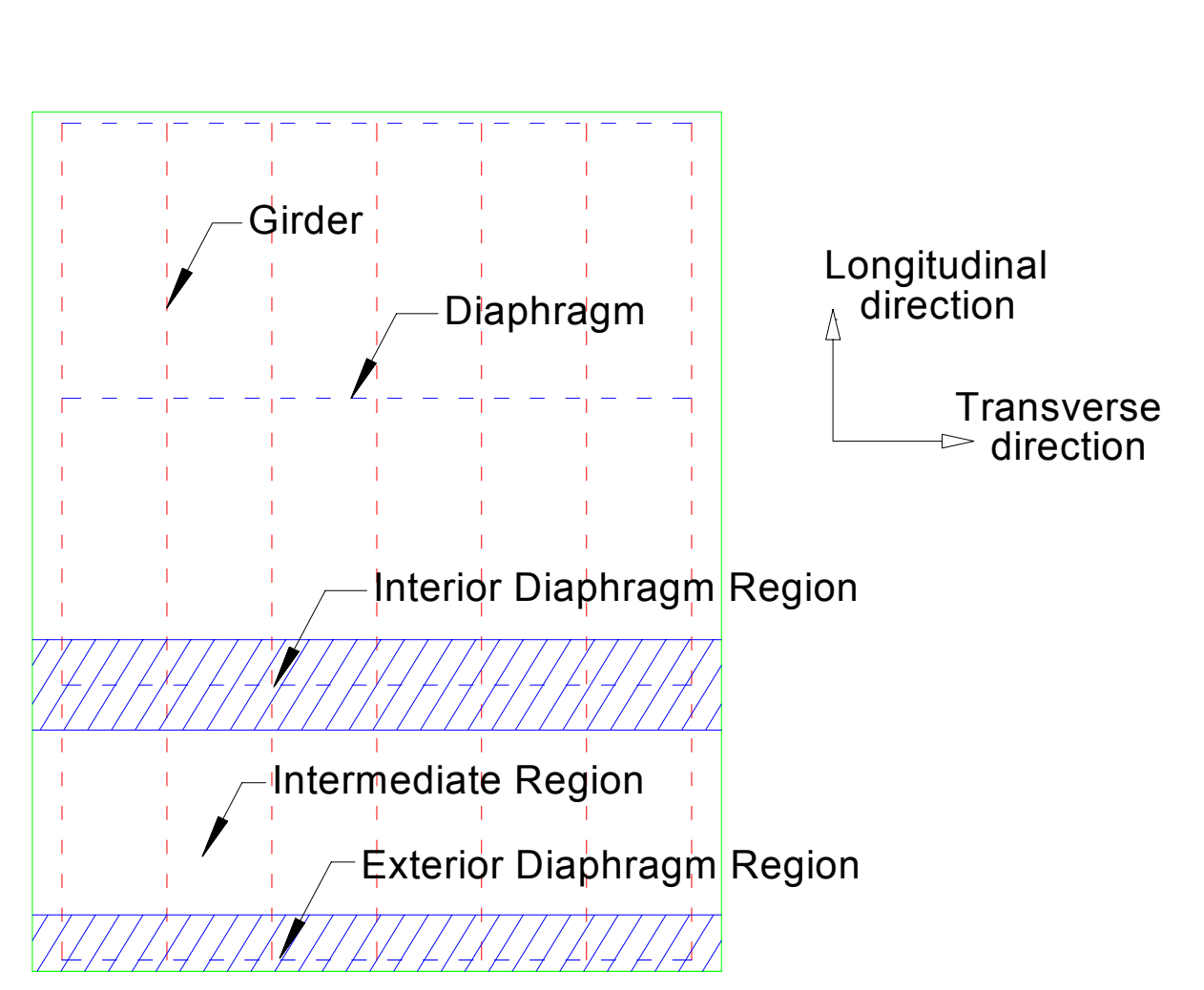

(a) Definition of Deck Regions

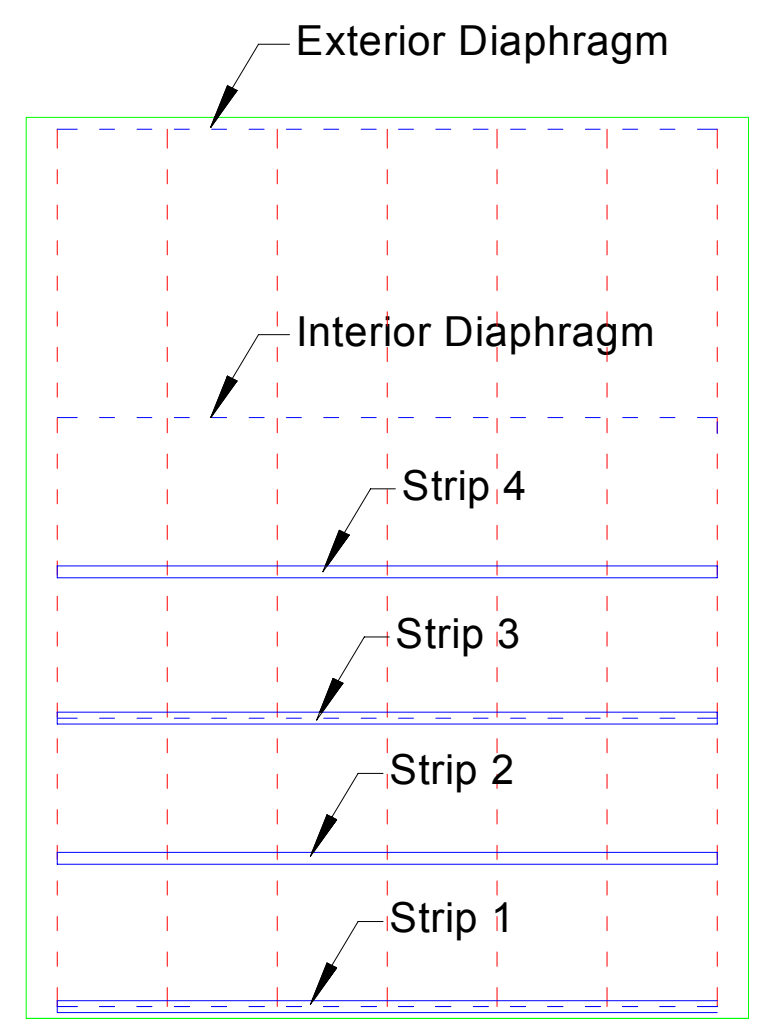

(b) Definition of Strips

Figure 4.1 Notation for Parametric Study 


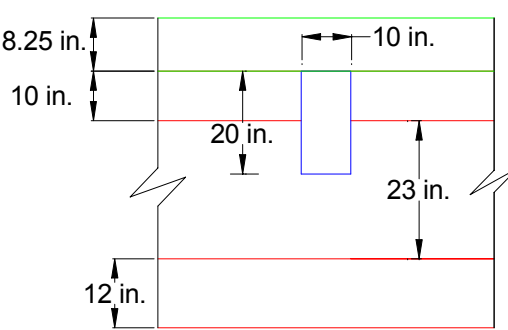

View C-C

View D-D

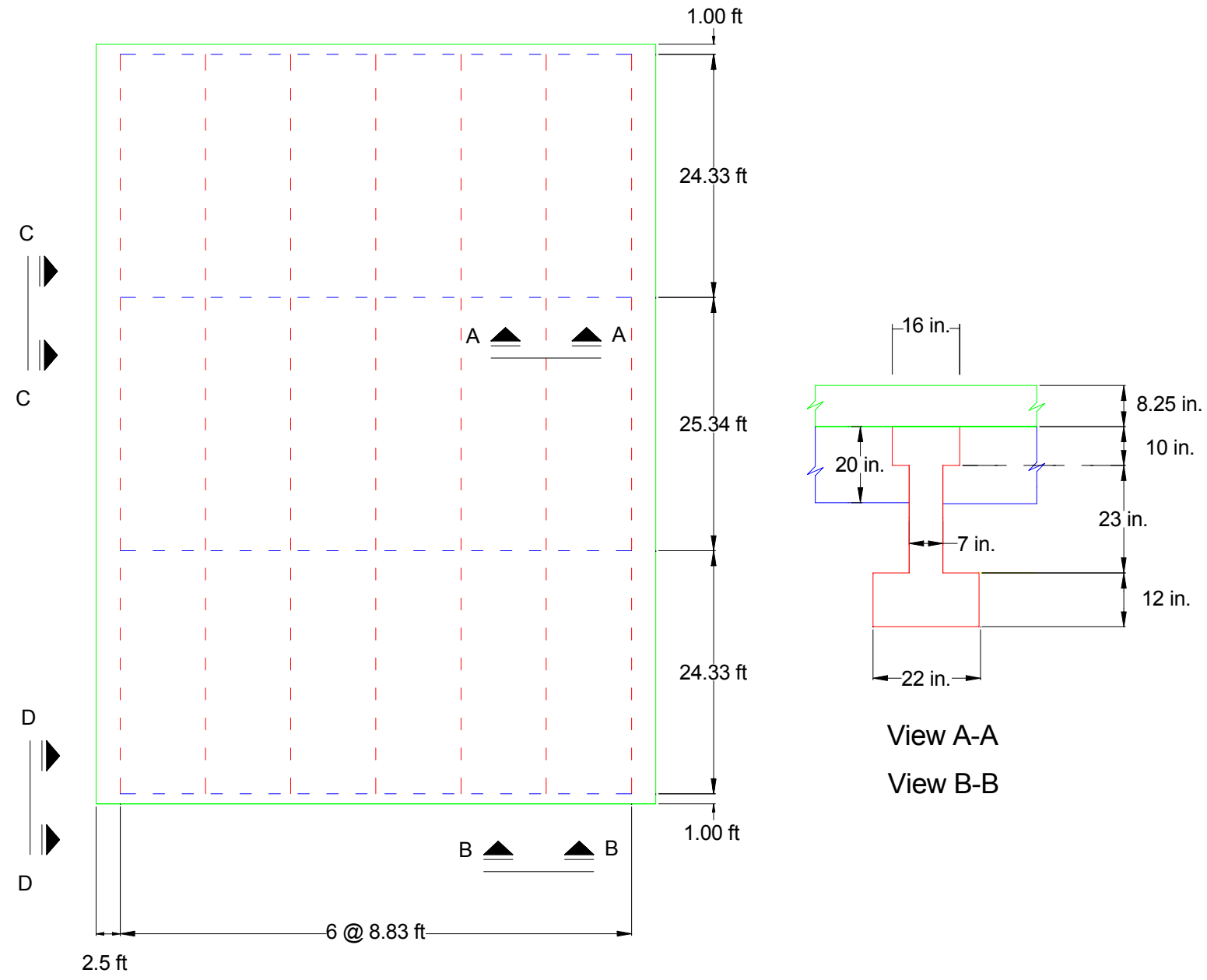

Figure 4.2 Base Case Structure for Parametric Study 


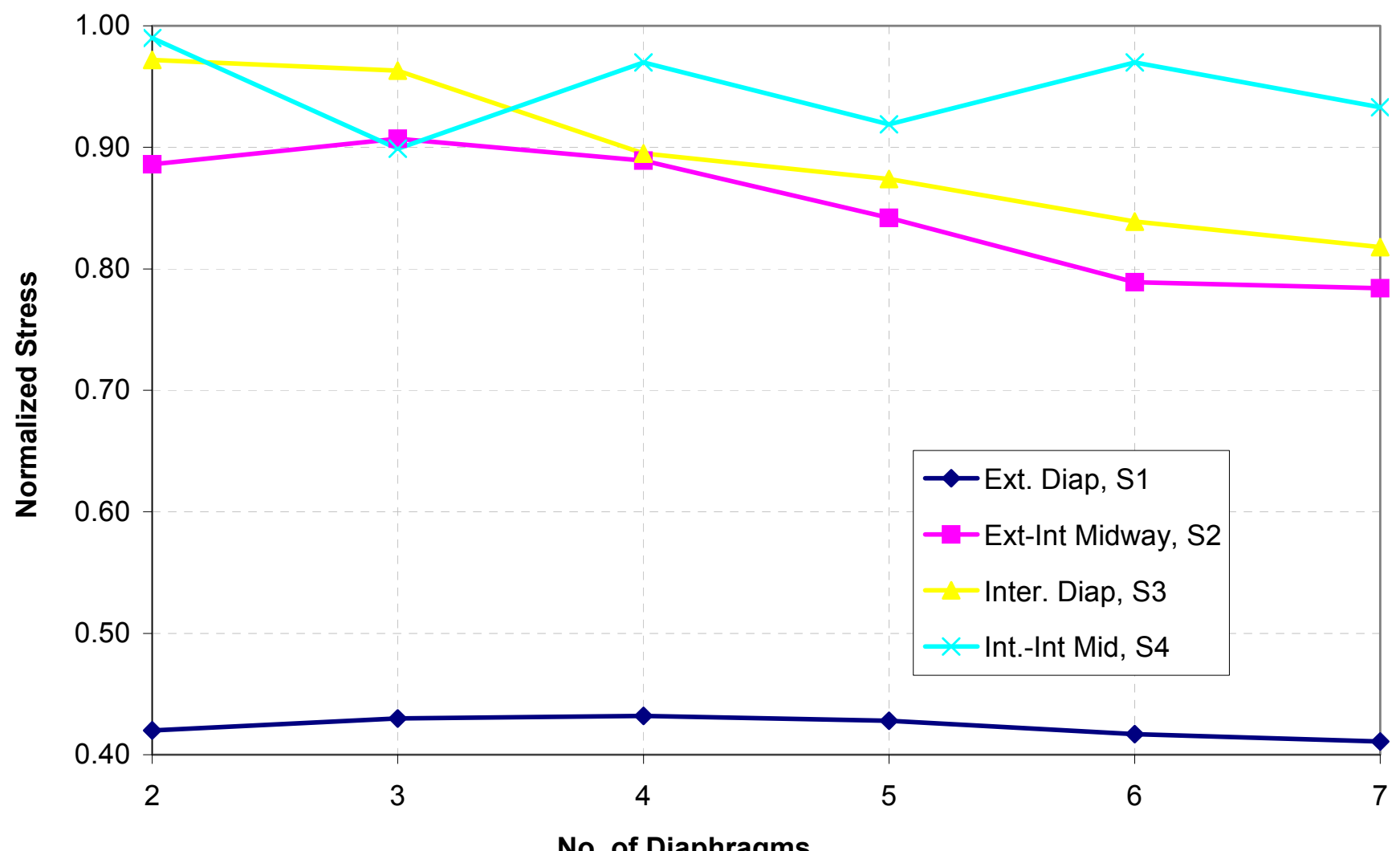

No. of Diaphragms

Figure 4.3(a) Minimum Stress at Different Strips as a Function of Number of Diaphragms 


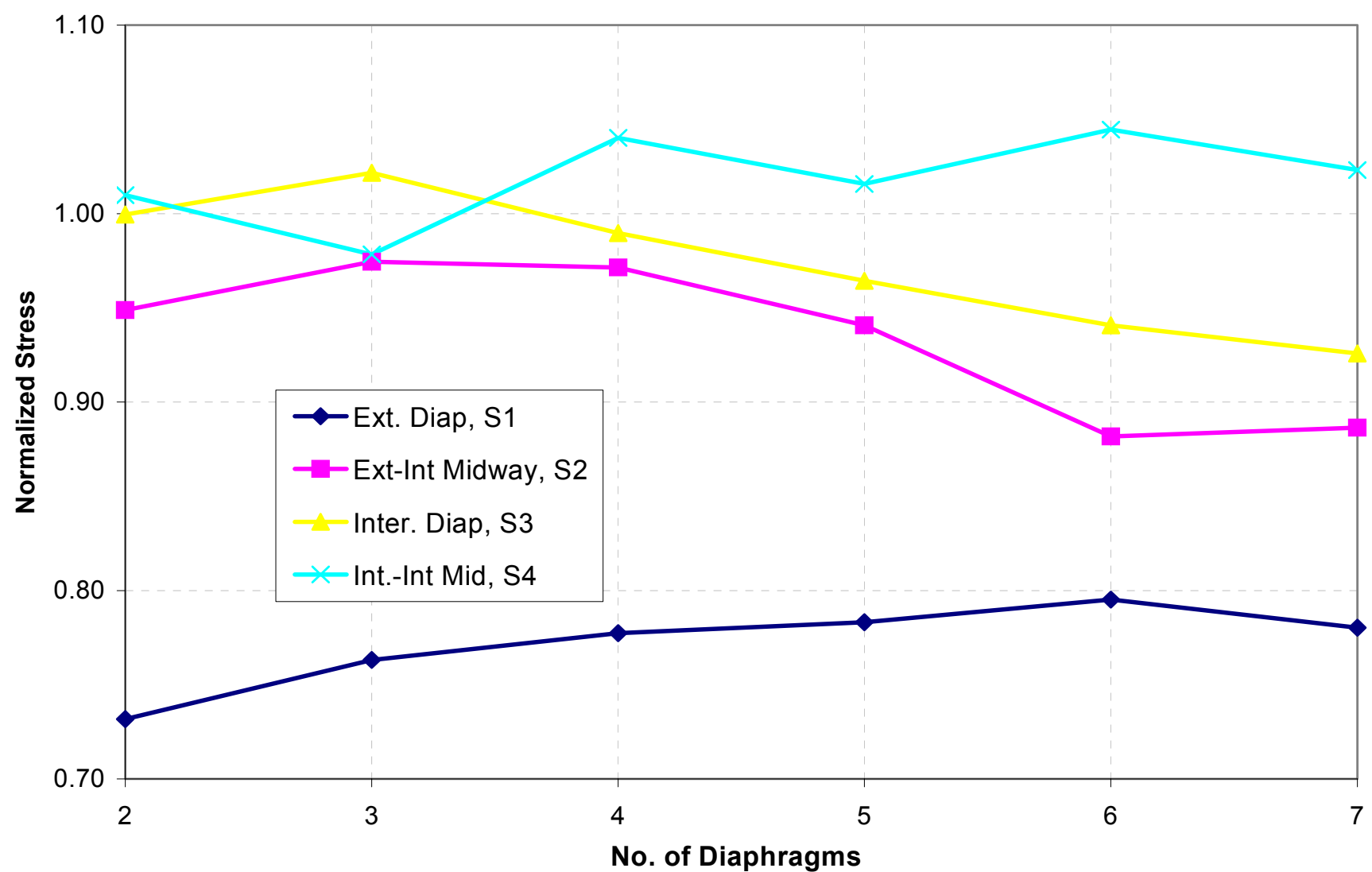

Figure 4.3(b) Average Stress at Different Strips as a Function of Number of Diaphragms 


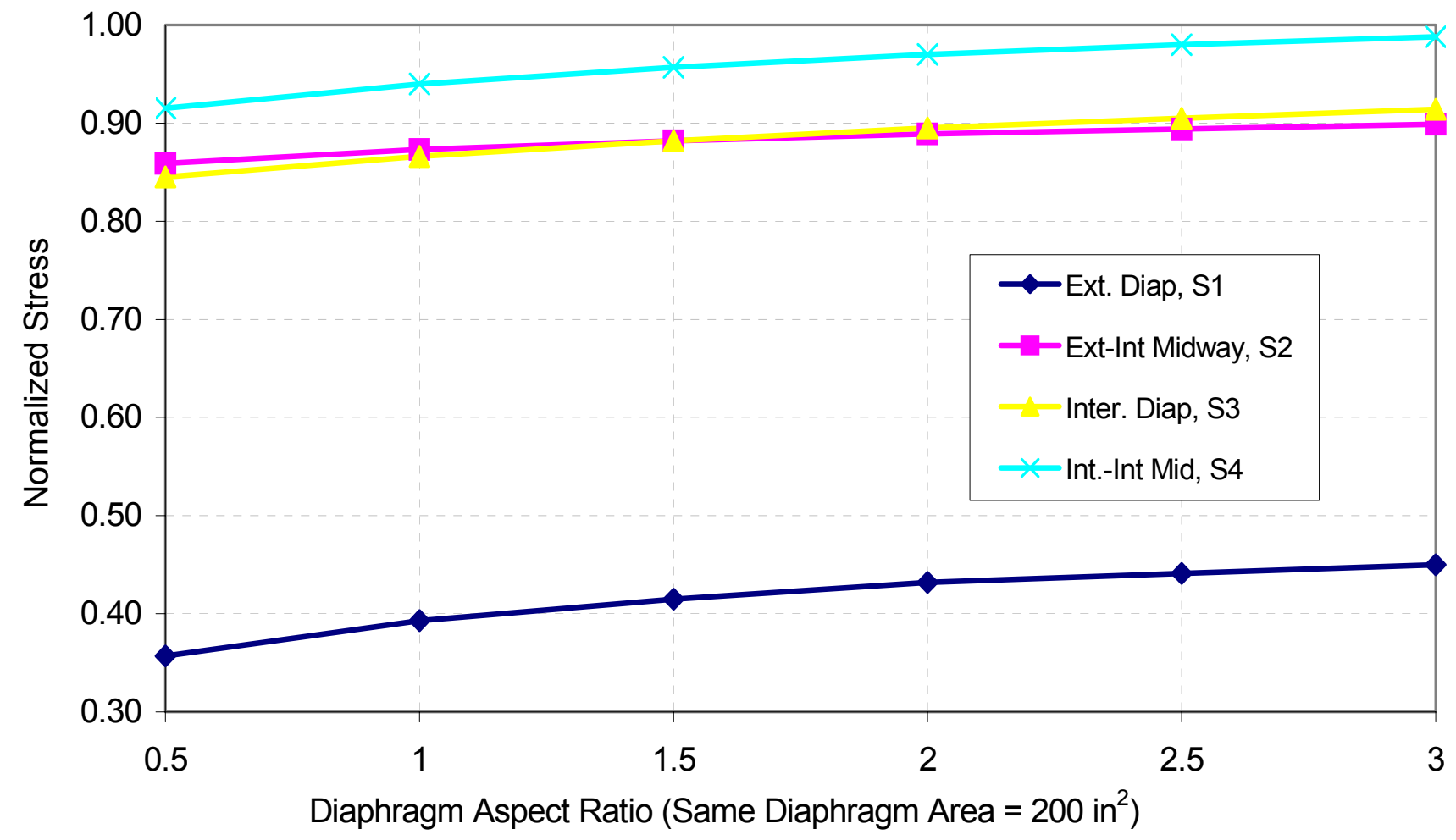

Figure 4.4 (a) Minimum Stress at Different Strips as a Function of Diaphragm Aspect Ratio 


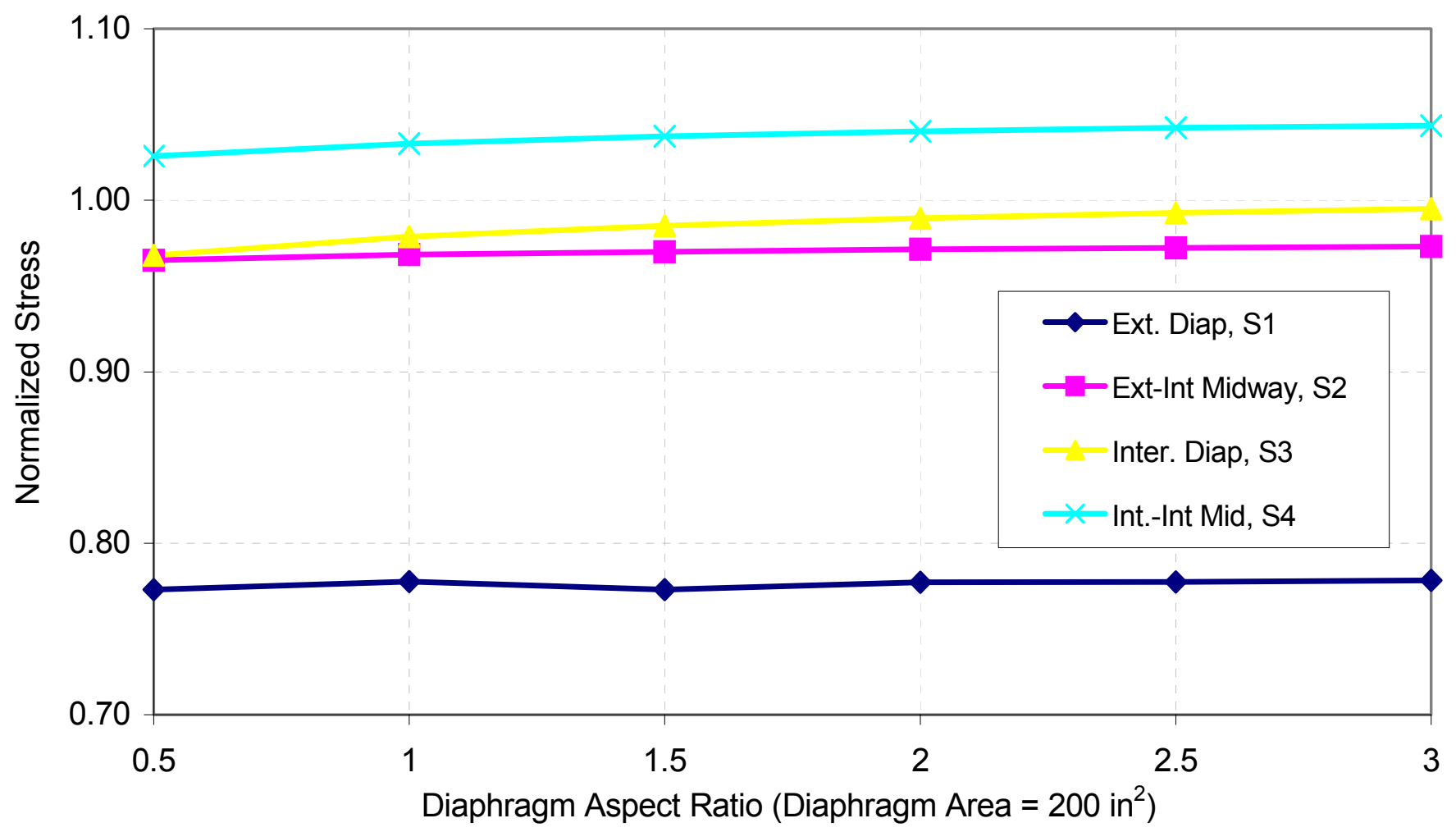

Figure 4.4 (b) Average Stress at Different Strips as a Function of Diaphragm Aspect Ratio 


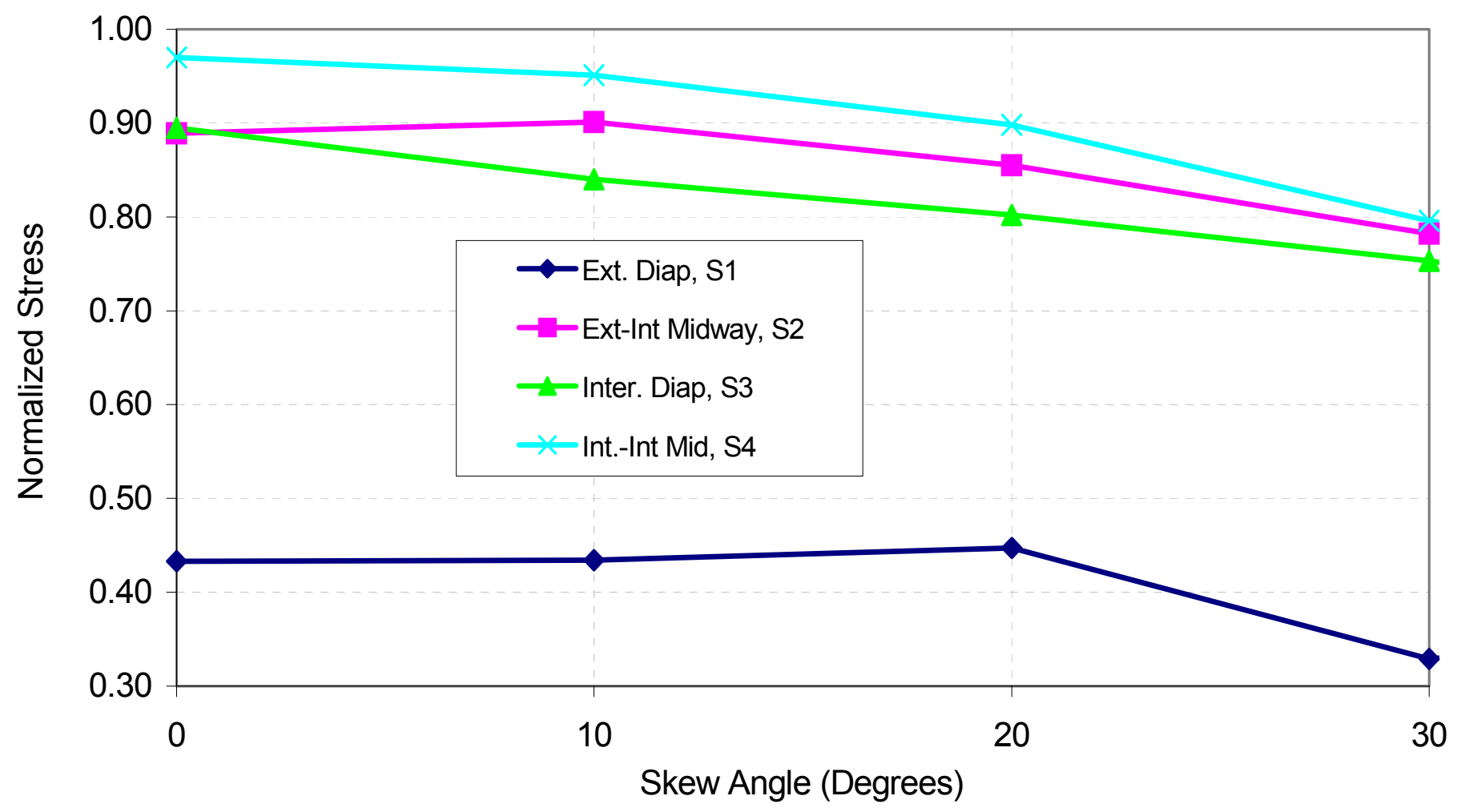

Figure 4.5(a) Minimum Stress at Different Strips as a Function of Skew Angle 


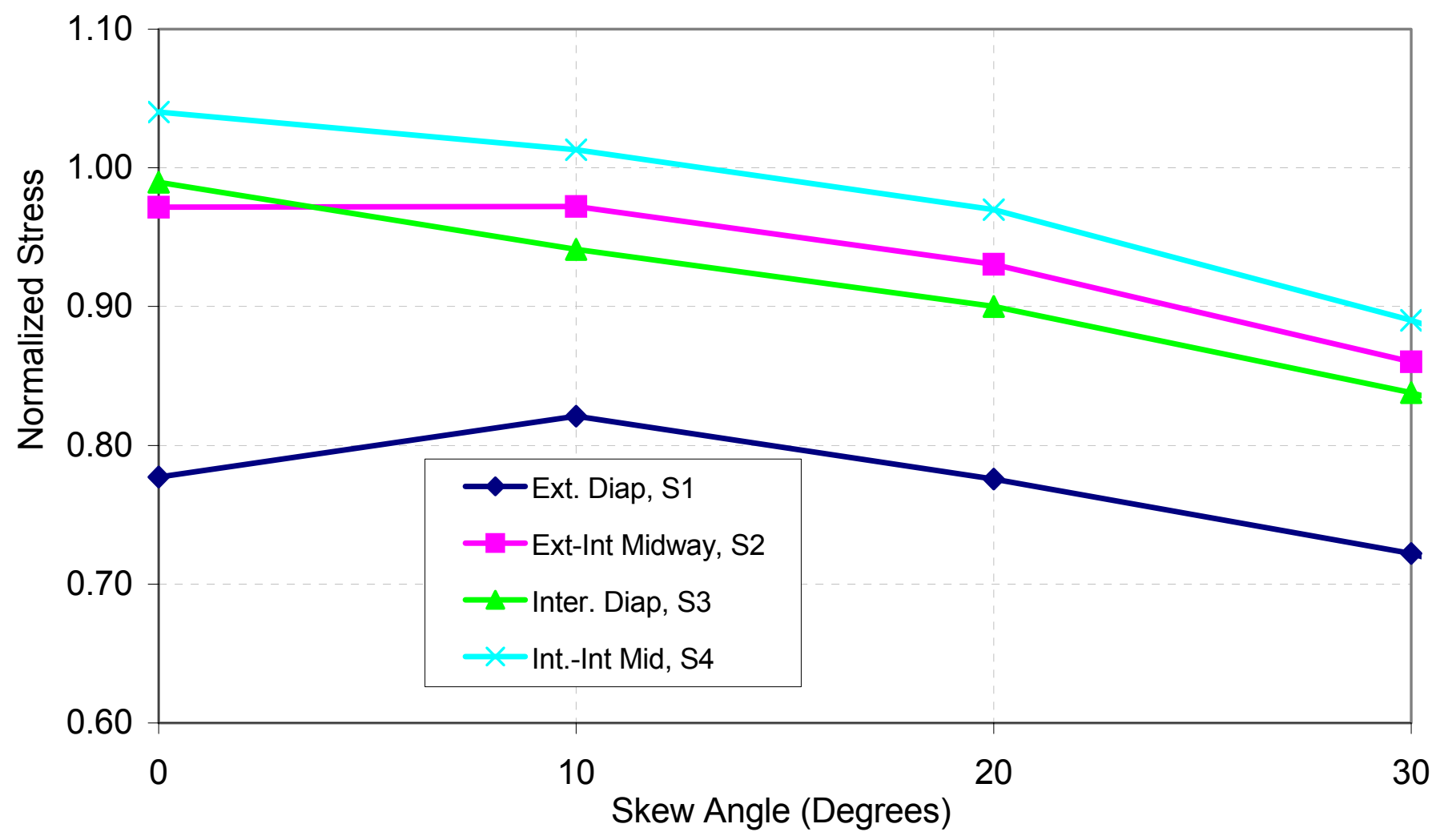

Figure 4.5(b) Average Stress at Different Strips as a Function of Skew Angle 


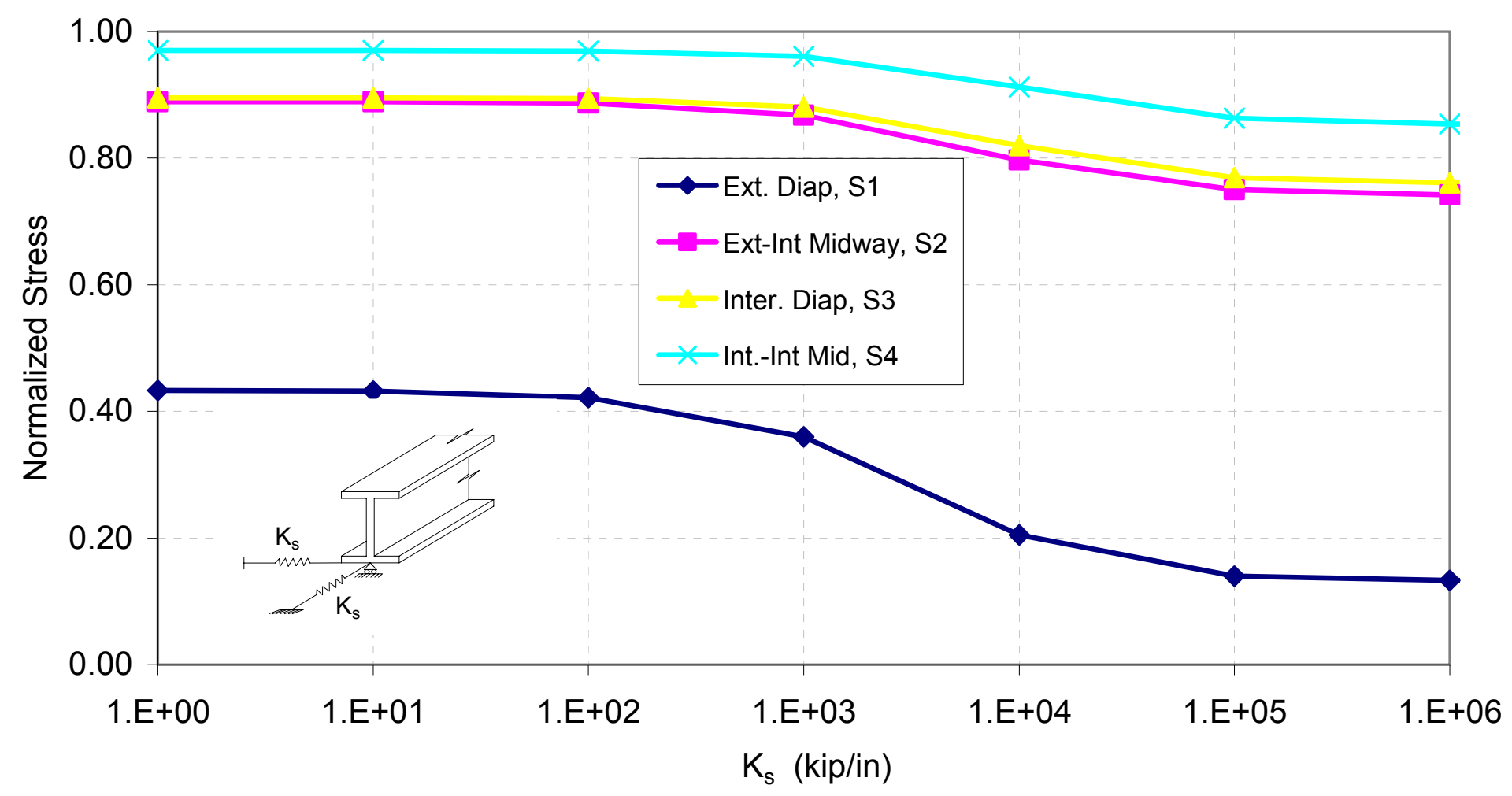

Figure 4.6 (a) Minimum Stress at Different Strips as a Function of Degree of Horizontal Restriction at Girders Ends 


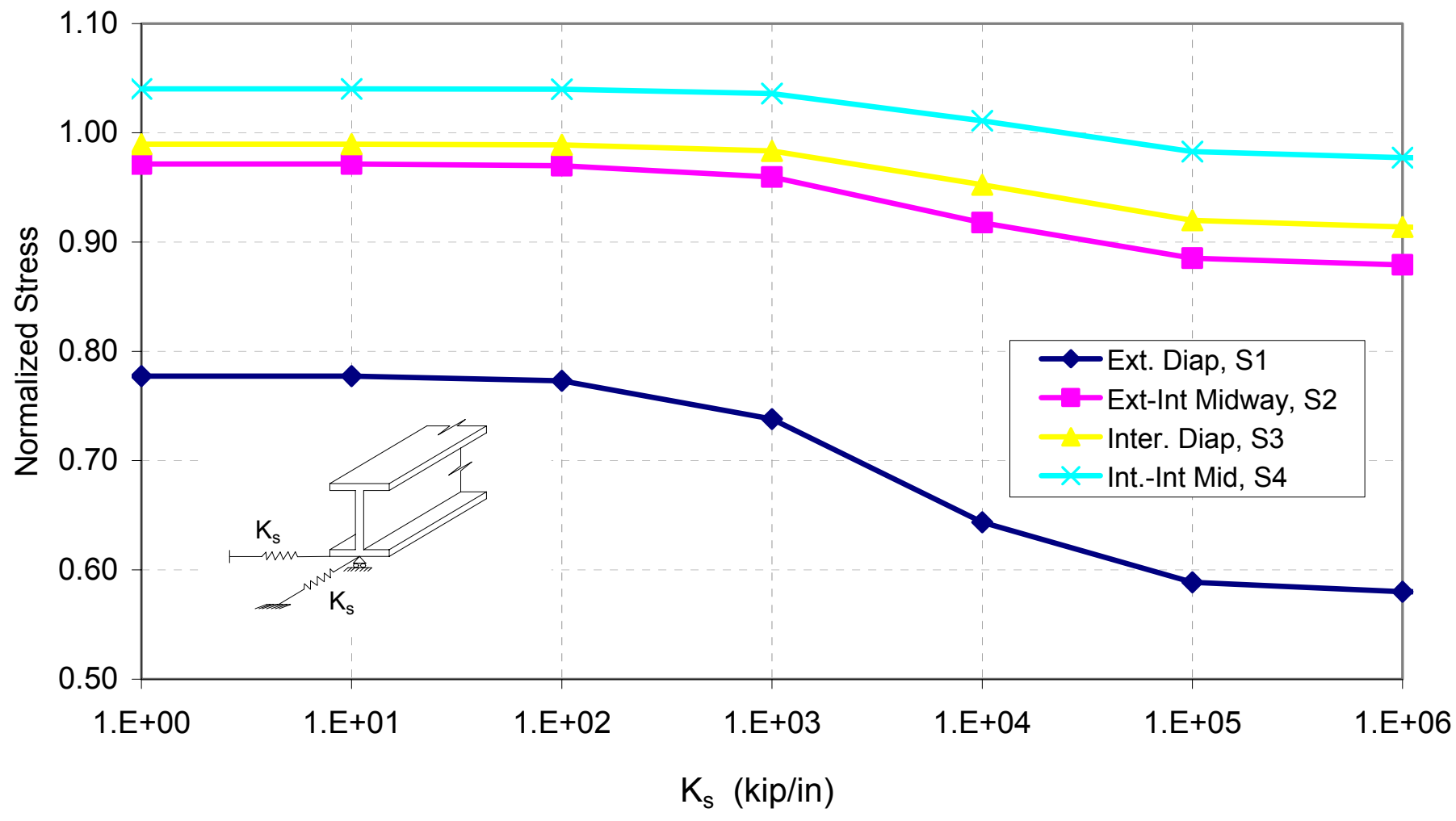

Figure 4.6 (b) Average Stress at Different Strips as a Function of Degree of Horizontal Restriction at Girders Ends 


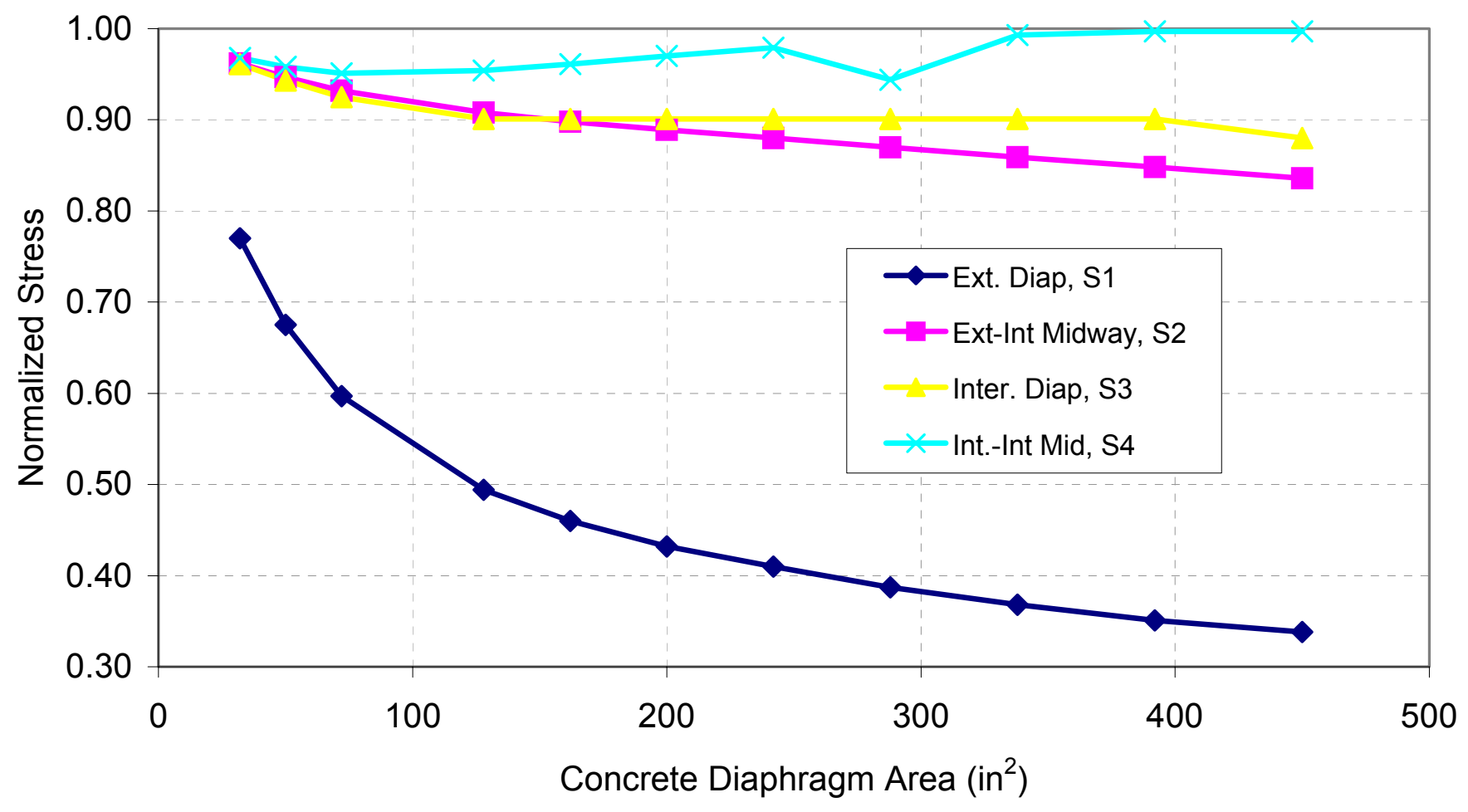

Figure 4.7 (a) Minimum Stress at Different Strips as a Function of Concrete Diaphragm Area 


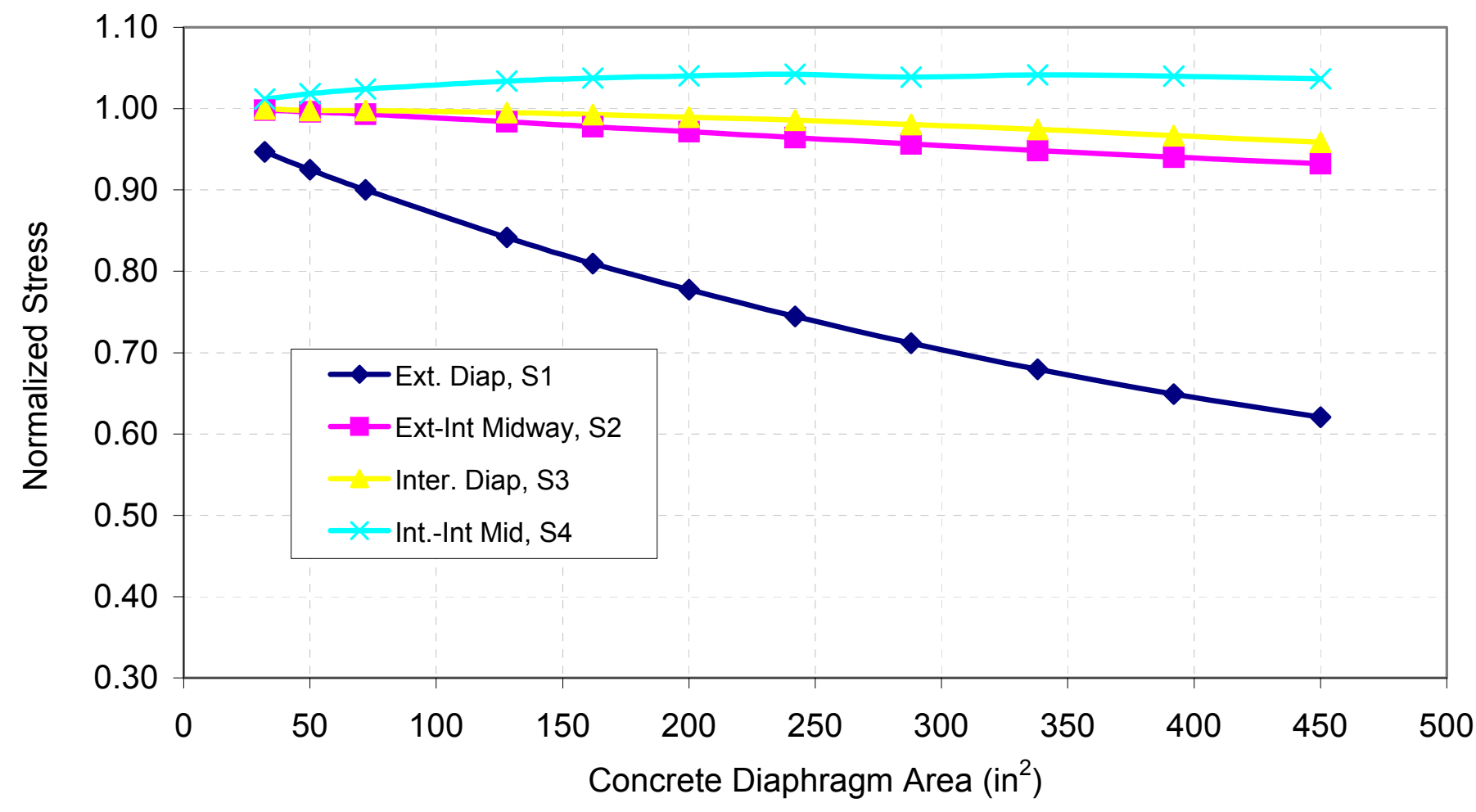

Figure 4.7 (b) Average Stress at Different Strips as a Function of Concrete Diaphragm Area 


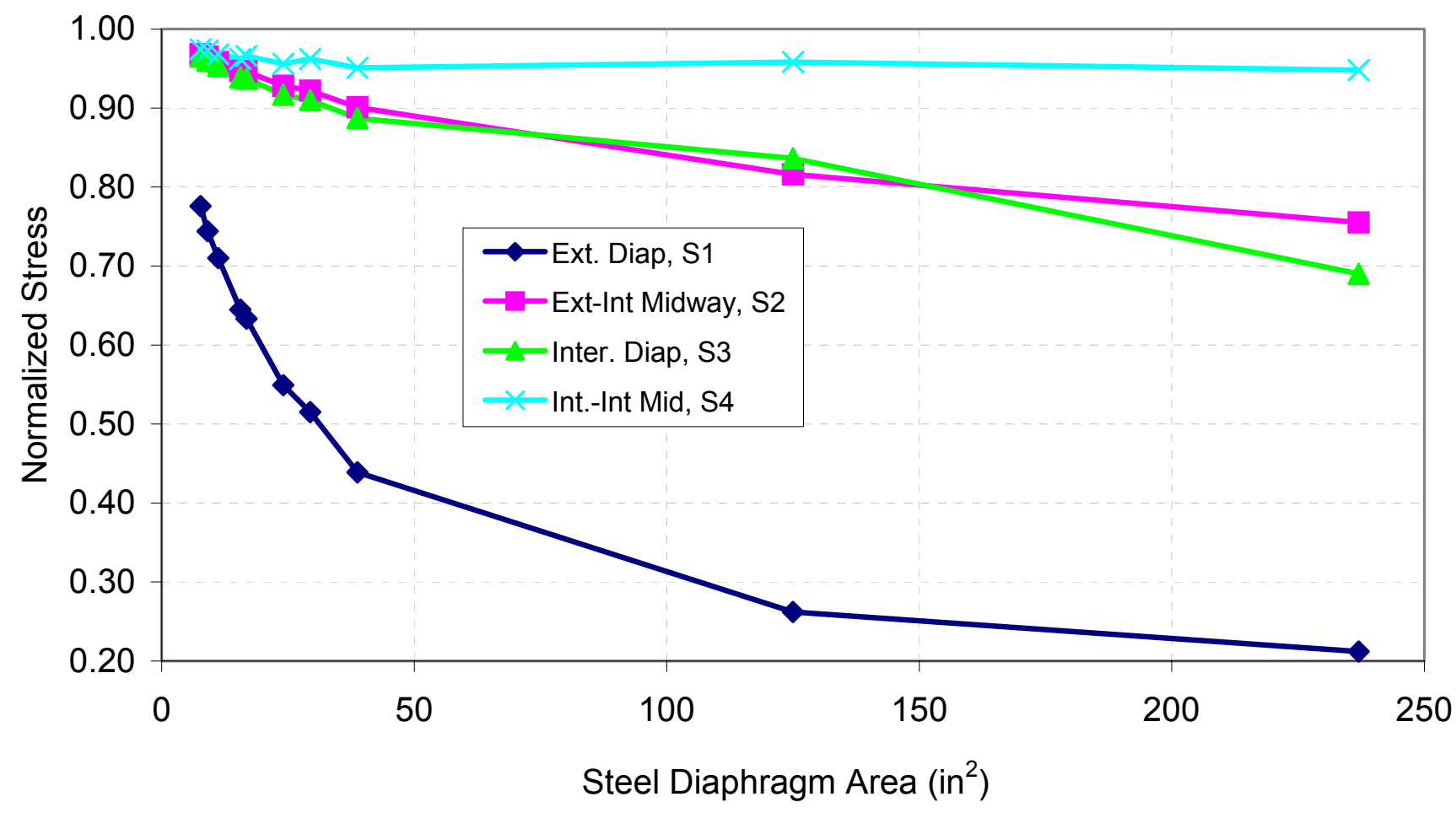

Figure 4.8(a) Minimum Stress at Different Strips as a Function of Steel Diaphragm Area 


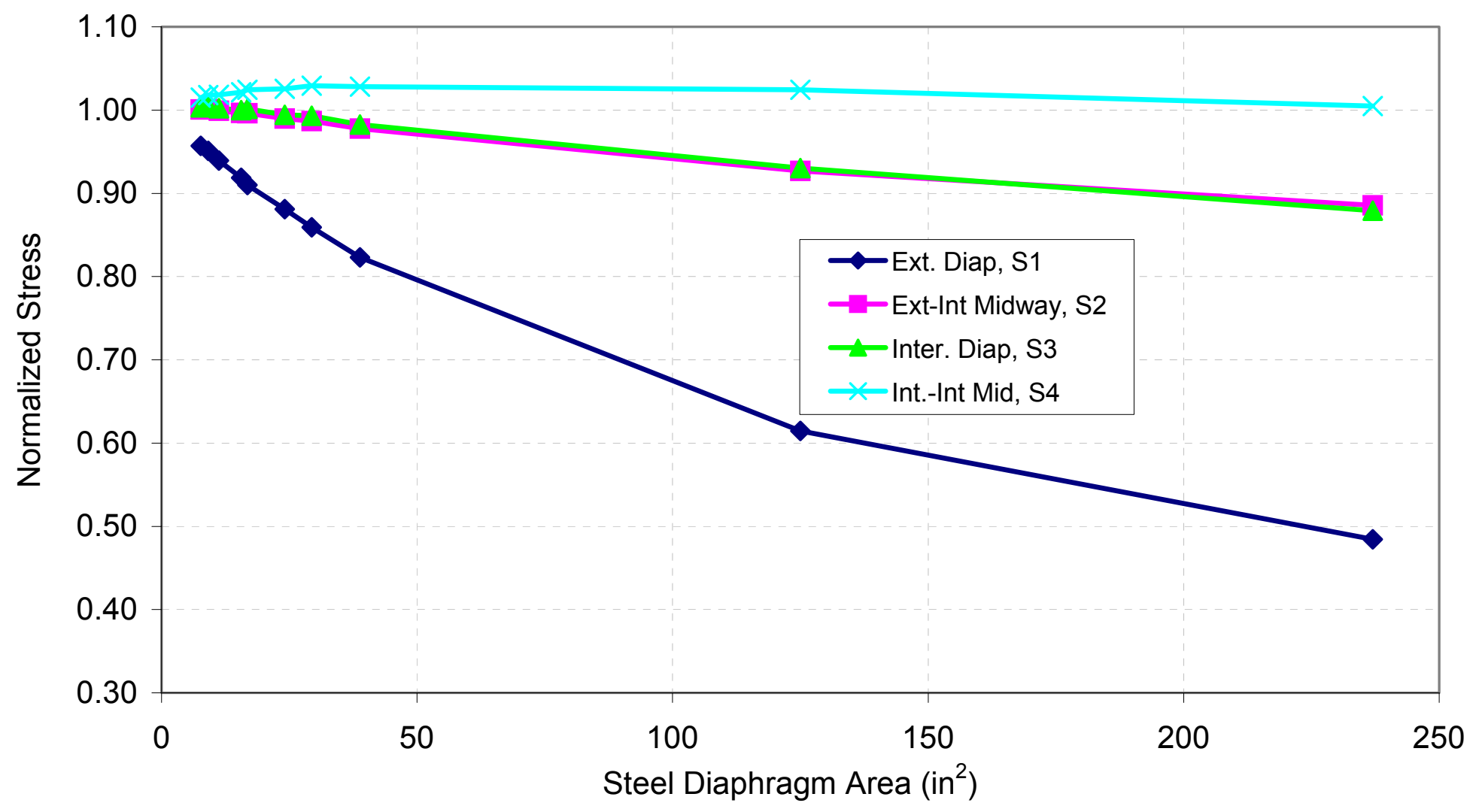

Figure 4.8(a) Average Stress at Different Strips as a Function of Steel Diaphragm Area 


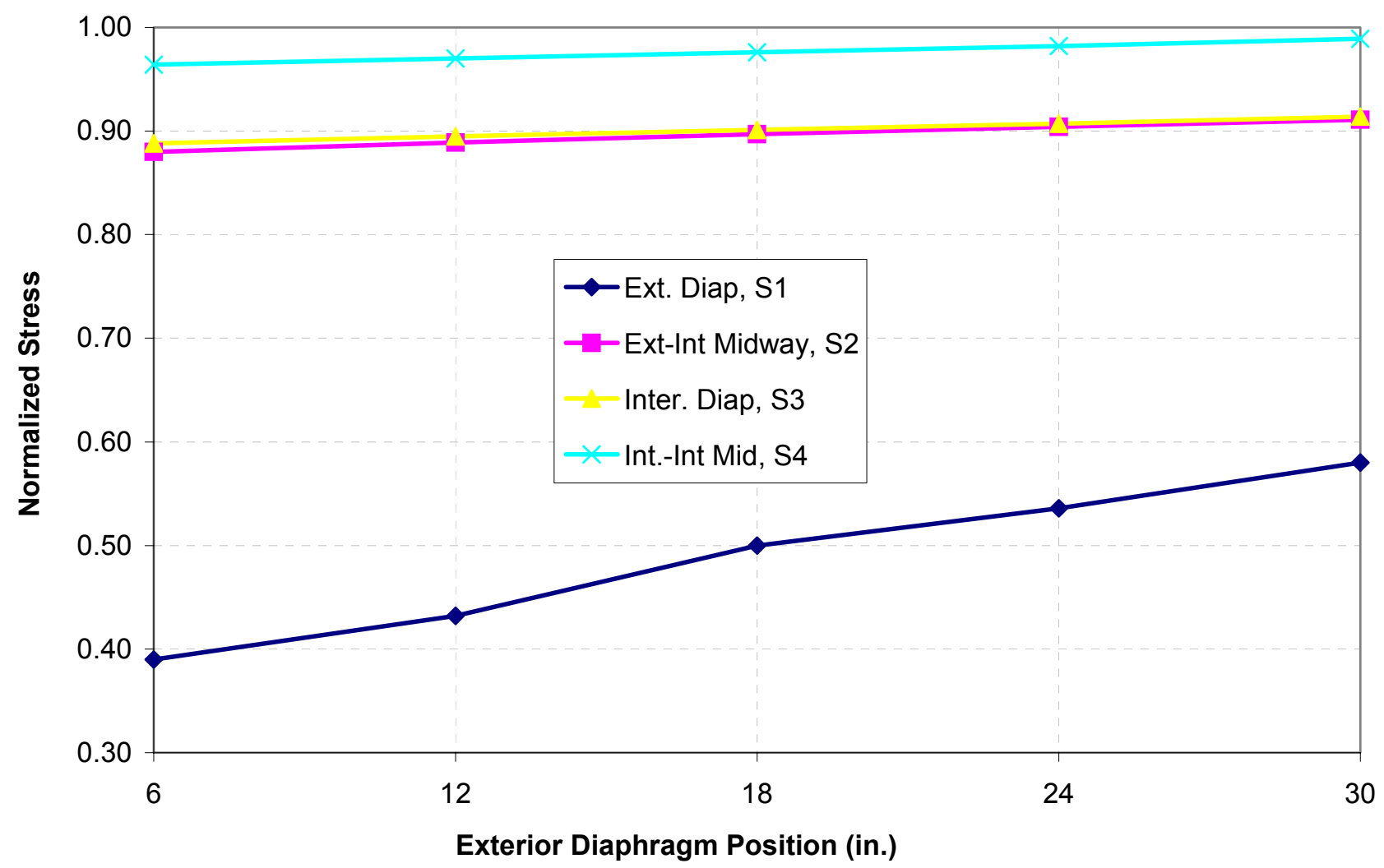

Figure 4.9(a) Minimum Stress at Different Strips as a Function of Diaphragm Position 


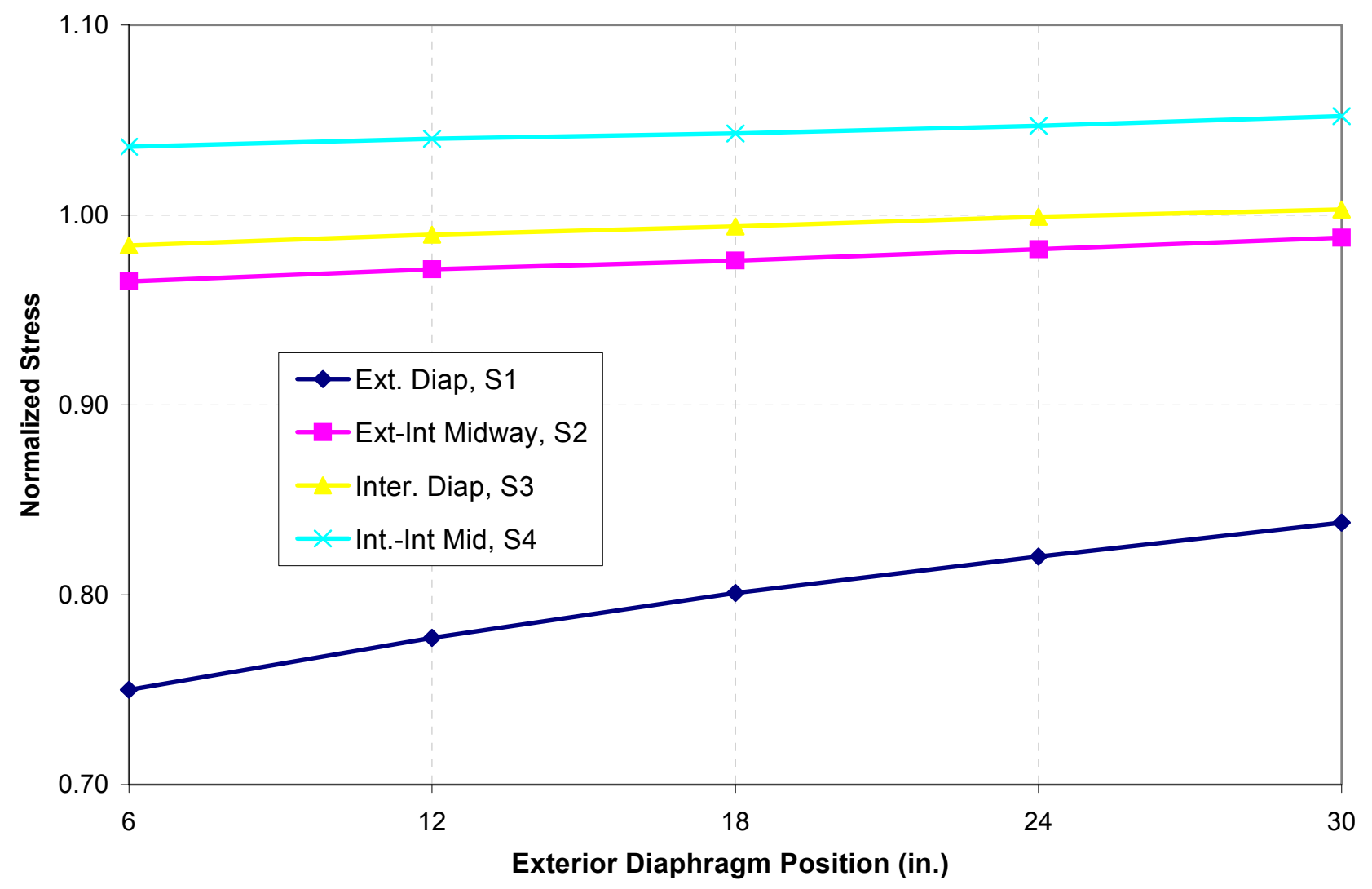

Figure 4.9(b) Average Stress at Different Stripes as a Function of Diaphragm Position 


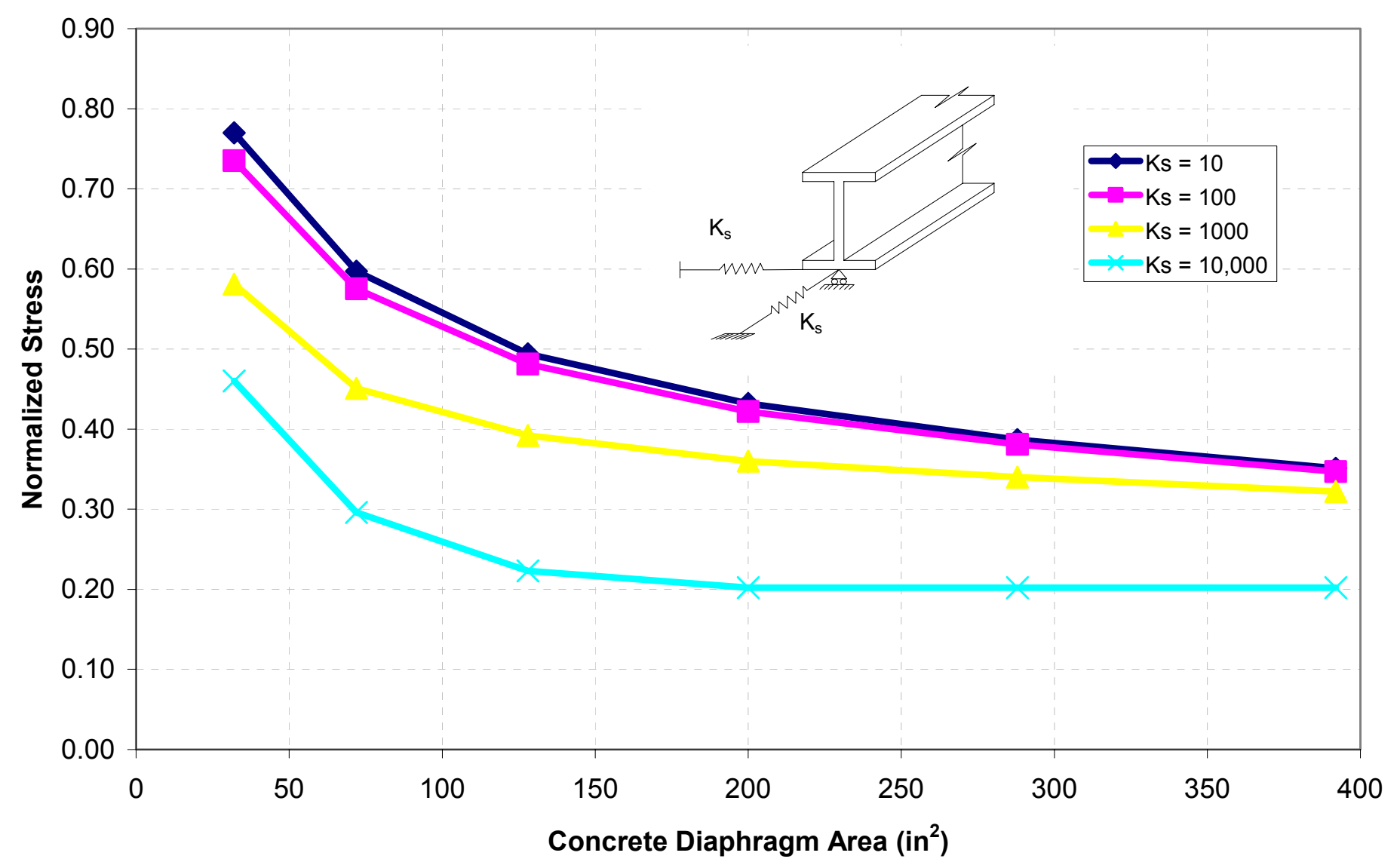

Figure 4.10 (a) Minimum Stress at Strip 1 as a Function of Concrete Diaphragm Area and Degree of Restraint at Girders' Ends 


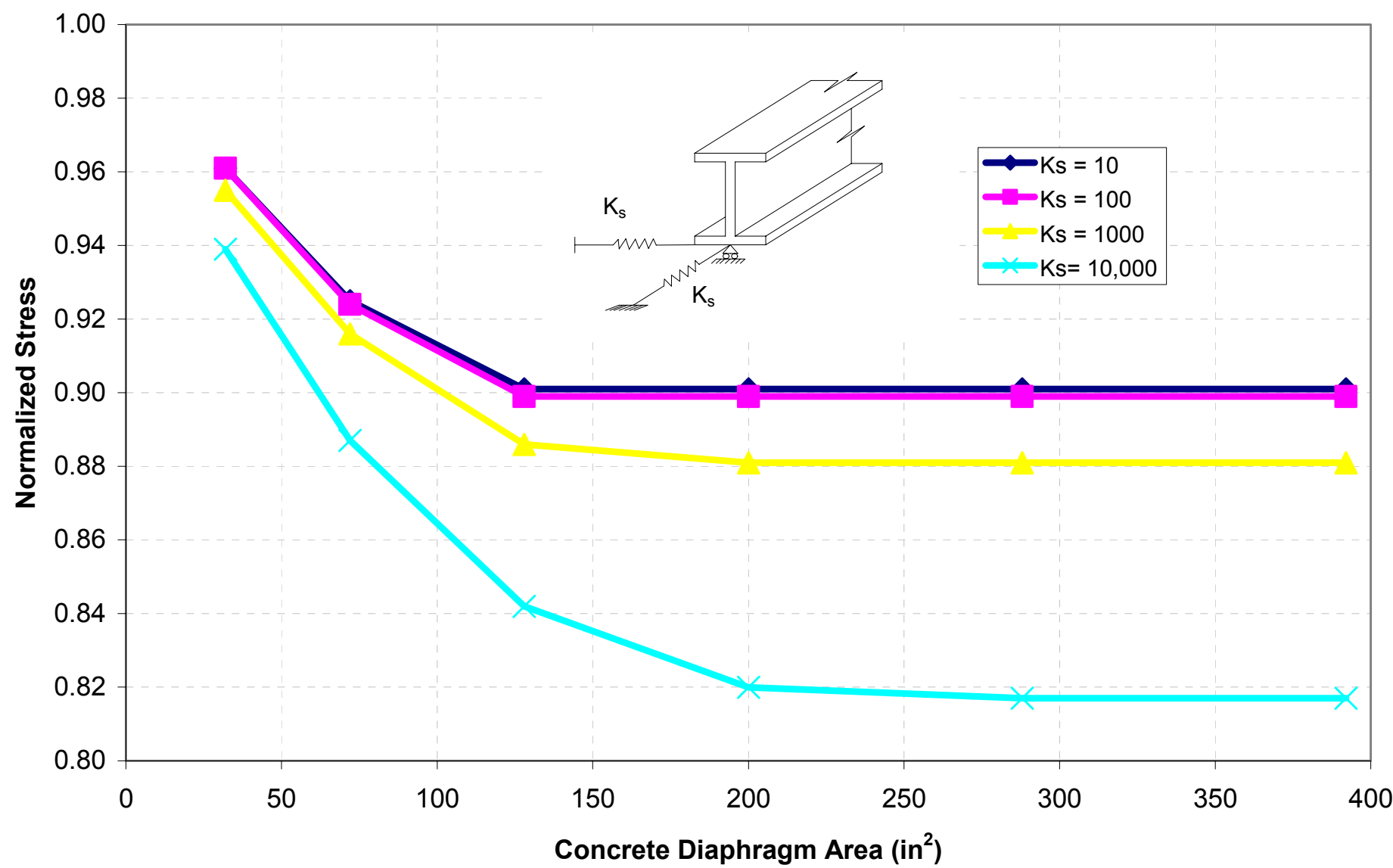

Figure 4.10 (b) Minimum Stress at Strip 3 as a Function of Concrete Diaphragm Area and Degree of Restraint at Girders' Ends 


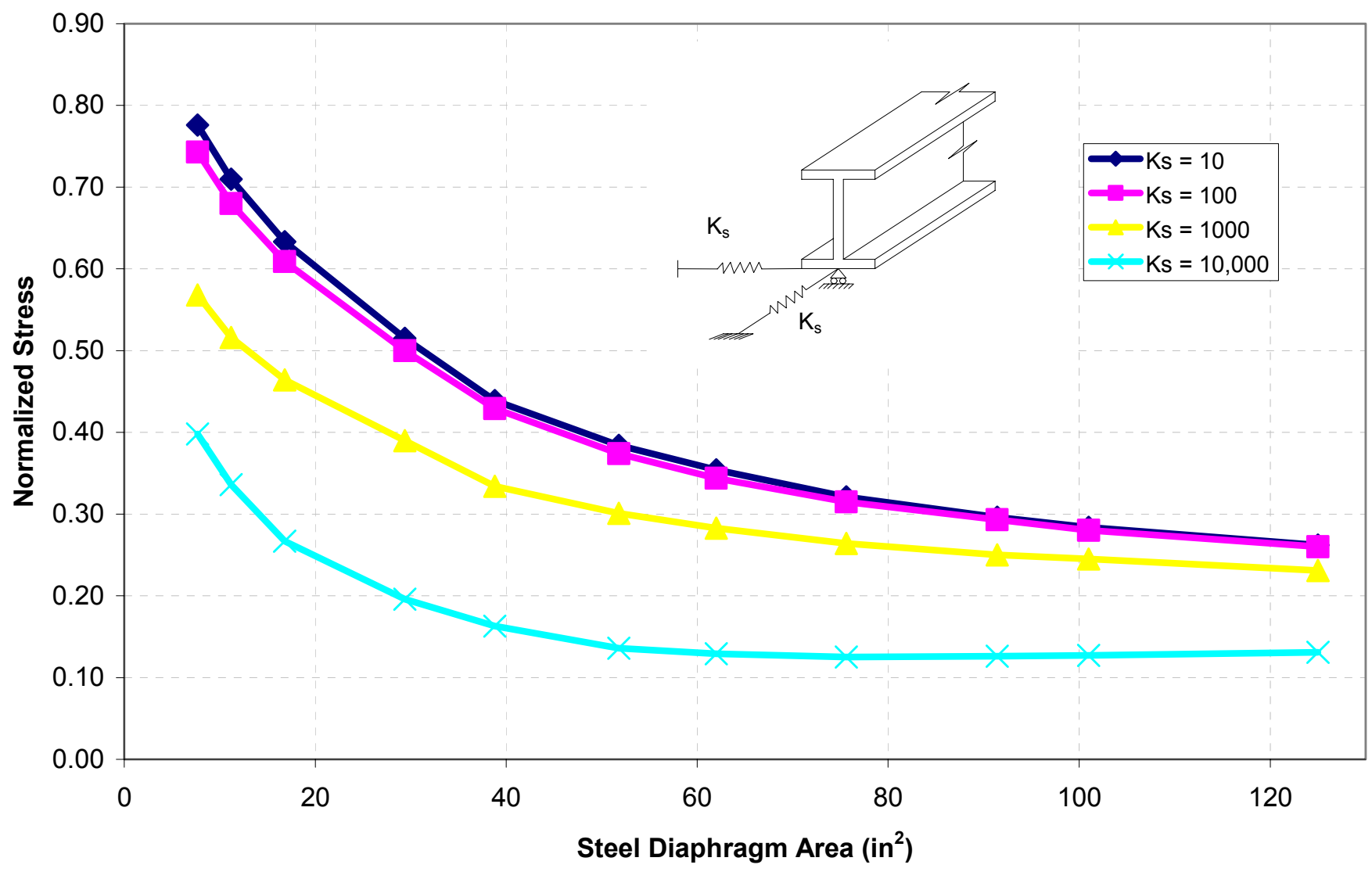

Figure 4.11 (a) Minimum Stress at Strip 1 as a Function of Steel Diaphragm Area and Degree of Restraint at Girders' Ends 


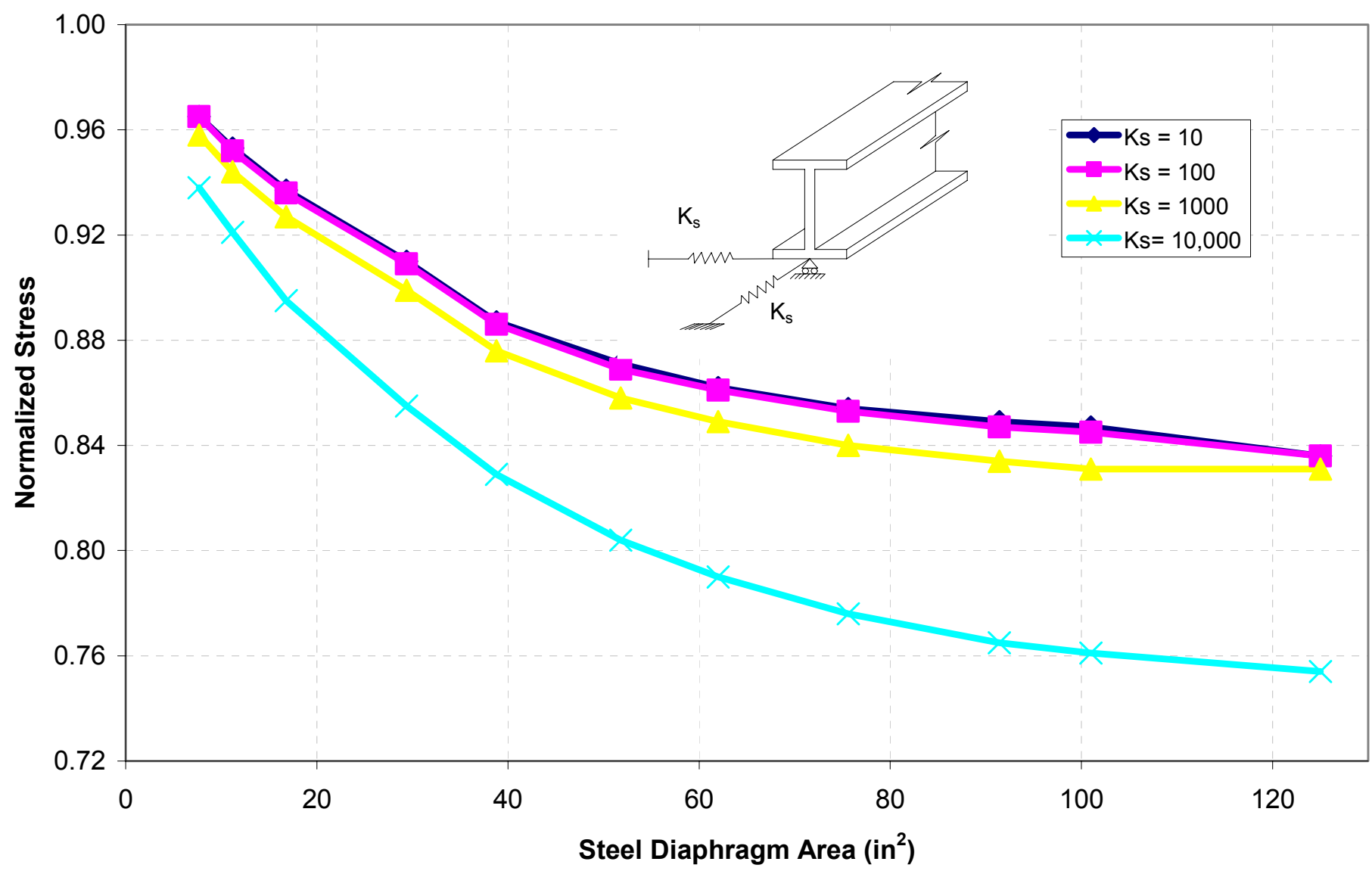

Figure 4.11 (b) Minimum Stress at Strip 3 as a Function of Steel Diaphragm Area and Degree of Restraint at Girders' Ends 


\section{5- General Design Provisions}

\subsection{Recommended Post-tensioning Scheme for Skew Bridges}

Three possible alternatives for the use of transverse post-tensioning in skewed bridges are: (i) tendons oriented parallel to the direction of the skewed edge of the deck, or (ii) tendons oriented perpendicular to the direction of the girders, or (iii) a combination of alternatives (i) and (ii), i.e., tendons are placed perpendicular to the girders at the interior of the deck, and in a "fan arrangement" in regions near the acute corners.

The use of tendons oriented perpendicular to the girders (alternative (ii)) may be impractical for several reasons; tendons would be very short in regions close to the acute corners of the deck, anchorage problems would occur at the skewed edges (and congestion would happen where two panels meet), more tendons would be needed as compared to alternatives (i) and (iii).

The specification of a fan arrangement (alternative (iii)) is difficult and impractical during construction; such excessive detailing would not correspond to the level of precision achieved in the analyses. In addition, congestion would occur at pier locations in the skewed edge of the deck due to the presence of multiple anchorages from adjacent panels.

The use of tendons oriented parallel to the skewed edge of the deck (alternative (i)) seems more plausible. The most salient shortcoming of this post-tensioning scheme is that only the horizontal component of the applied force contributes to the induced transverse stresses in the deck (approximately). It is recommended, therefore, to use post-tensioning tendons oriented parallel to the deck and limit the application of this methodology to bridges with skews smaller than $30^{\circ}$. This limitation on the maximum skew angle as far as this report is in line with the results 
of a recent survey by the Indiana Department of Transportation (INDOT), which indicates that about $75 \%$ of the skewed concrete bridge lettings in Indiana during February 2000 to September 2001 have skew angles less or equal to $30^{\circ}$.

\subsection{Required Post-tensioning Distribution for Base Case Structure}

\subsubsection{Geometrical Distribution}

It is noticed from Figures 4.3 to 4.11 that the minimum (and average) stress at the exterior diaphragm region is considerable less than the one at the interior diaphragm region. Because of the premise of localized restraining effects from each individual diaphragm (Section 4.3.1), it is reasonable to suggest a different level of transverse stress to be applied at: (i) intermediate regions, (ii) exterior diaphragm regions, and (iii) interior diaphragm regions. Consequently, applied transverse stresses, $\sigma_{T}$, are set equal to: (i) one $\left(\sigma_{T}=1\right)$ in intermediate regions, (ii) $\alpha_{e}\left(\sigma_{T}=\alpha_{e}\right)$ in exterior diaphragm regions and, (iii) $\alpha_{i}\left(\sigma_{T}\right.$ $\left.=\alpha_{i}\right)$ in interior diaphragm regions. Clearly, $\alpha_{e}>\alpha_{i}>1$ should always be obtained. The suggested distribution of post-tensioning is schematically shown in Figure 5.1. It is evident that a more elaborated distribution could be proposed but the level of precision in the analyses does not justify such detailing. Moreover, a more detailed distribution of the post-tensioning may not be practical during construction.

Notice from Figure 5.1 that the applied transverse stresses are already normalized by the required level of compressive stress at service (which depends on the dead and live loads). If the desired level of compression to be obtained from post-tensioning was known, then the actual post-tensioning scheme needed (in terms of applied stresses) would be equal to distribution shown in Figure 5.1 multiplied by such required level of compression stress. 


\subsubsection{Magnitude of Required Post-tensioning Forces}

It is also noticed from Figures 4.3 to 4.9 that at the exterior diaphragm region the minimum transverse stress is considerably smaller than the average transverse stress. In strip 1, the minimum and the average values may differ even by a factor of two. This suggests that at the end diaphragm region, the minimum transverse stress occurs in a localized zone of the deck. This can also be noticed from the contour maps presented in Chapter 3 in which the distribution of transverse stresses on the deck is shown. Clearly, it would be conservative to formulate design aids producing a minimum normalized transverse stress equal to one.

In contrast, at interior diaphragm regions the minimum and the average transverse stress are not significantly different as can be noticed from Figures 4.3 to 4.9. This suggests that the distribution of transverse stresses is more uniform at the interior diaphragm regions.

Based on these observations, the criterion for formulating the design aids is to produce a minimum normalized transverse stress equal to 1.0 at interior diaphragm regions and equal to 0.8 at exterior diaphragm regions.

The values of $\alpha_{e}$ and $\alpha_{i}$ needed to produce a minimum normalized stress of 0.8 at exterior diaphragm regions and 1.0 at interior diaphragm regions for the base case structure are shown in Figure 5.2 (a) and (b). These values of $\alpha_{e}$ and $\alpha_{i}$ were obtained by iterative Type I Finite Element analyses using SAP2000. Figure 5.2, itself, would be a design aid applicable to the base case structure (Figure 4.2) only. Notice that the user has the alternative of defining the desired width of the diaphragm region, which gives more flexibility in the design process. 


\subsection{Required Post-tensioning Distribution for Any Case Included in the Parametric Study}

The schematic distribution of the transverse post-tensioning is preserved as shown in Figure 5.1. For a particular structure, corresponding to the base case, the values of $\alpha_{e}$ and $\alpha_{i}$ are readily available from Figure 5.2. On the other hand, the information gathered in such parametric study (Figures 4.3 to 4.11 ) must be sufficient to "predict" the magnitude of the minimum (and average) normalized transverse stress in the exterior or interior diaphragm region, $\sigma_{\min }$, ext or $\sigma_{\min }$, int, for the case where a uniform unit transverse stress is applied at the edges of the deck. The question remains, however, as how to extend the available design aids from the base case structure to all the cases included in the parametric study (see Table 4.1).

In order to address such fundamental question, the following expression is hypothesized:

$\alpha \times \sigma_{\min }=$ constant

where, $\alpha$ is the extra-post-tensioning force factor in any diaphragm region (exterior or interior) needed to make the minimum normalized transverse stress, $\sigma_{\mathrm{min}, \text { ext }}$ or $\sigma_{\mathrm{min}, \text { int }}$ (as obtained in Figures 4.3 to 4.11 ) equal to 0.8 or 1.0 .

Equation (5.1) makes intuitive sense; the smaller the minimum normalized transverse stress at a given diaphragm region (for a uniform unit transverse stress applied at the edges of the deck), the larger the extra transverse force that needs to be applied in such region in order to increase such minimum to a specified value $(0.8$ or 1.0$)$. 


\subsubsection{Design Aids Accounting for Girders' Boundary Conditions and}

\section{Diaphragms' Axial Stiffness}

Assuming that $\sigma_{\min }$ ext and $\sigma_{\min }$, int, can be obtained by any means, and because $\alpha_{e}$ and $\alpha_{i}$ are known for the base case, the extra-posttensioning force factors $\alpha_{e}$ and $\alpha_{l}$, for any case included in the parametric study can be obtained as (using Equation 5.1):

$\left(\alpha_{e, i}\right)_{\text {any case }}=\left(\alpha_{e, i}\right)_{\text {base case }} \times \frac{\left(\sigma_{\text {min,ext or int }}\right)_{\text {base case }}}{\left(\sigma_{\text {min,ext or int }}\right)_{\text {any case }}}$

The minimum stress at any diaphragm region, $\sigma_{\min }$, will depend on many variables, however, it was noticed in Chapter 4 that the most influencing parameters were the diaphragm size and type (or axial stiffness), and the boundary conditions for the girders.

It is initially assumed that $\sigma_{\min }$ depends on the combined effect of the boundary conditions of the girders and, the diaphragm axial stiffness only. Figures 4.10 and 4.11 , therefore, can be used to find the ratio: $\frac{\left(\sigma_{\text {min,ext or int }}\right)_{\text {base case }}}{\left(\sigma_{\text {min,ext or int }}\right)_{\text {any case }}}$, which in turns equals $\frac{\left(\alpha_{e, i}\right)_{\text {any case }}}{\left(\alpha_{e, i}\right)_{\text {base case }}}$.

Following this procedure, the design aids given in Figures 5.3 (a) and (b) and, 5.4 (a) and (b) are obtained. Notice that the discrete results were "smoothed" using least square techniques in order to make the design aids available for any "intermediate case" contained in the ranges of values included in the parametric study.

According to the parametric study (Chapter 4), additional parameters influencing the distribution of transverse stresses are: the position of the exterior diaphragm with respect to the end of the deck, and the skew angle. In order to account for the effects of such variables, correction factors are suggested as discussed in the following subsections. It is assumed that the correction factors for skew 
angle and, exterior diaphragm position are independent from each other so that they can be applied separately.

\subsubsection{Correction Factor for Exterior Diaphragm Position}

The position of the exterior diaphragm with respect to the end of the girders has an appreciable effect on the distribution of transverse stresses in the exterior diaphragm region only. Therefore, any correction of the existing design aids (Section 5.3.1) to account for the position of the exterior diaphragm will be applied to exterior diaphragm regions only.

The base case structure (Figure 4.2) is consecutively modified by varying the position of the exterior diaphragm. Exterior diaphragms are located at 6 in., 12 in., 18 in., 24 in., 30 in., and 36 in. from the end of the deck. For each case, an iterative procedure was required in the finite element analyses in order to find the required $\alpha_{e}$ to produce $\sigma_{\text {min,ext }}=0.8$. This $\alpha_{\mathrm{e}}$ is then compared to the one obtained from Figure 5.3 and the modification factor is obtained (taken the ratio of $\alpha_{e}$ 's).

It can be noticed that the magnitude of the correction factor for exterior diaphragm position depended also on the boundary conditions of the girders, thus the procedure was repeated for different values of $\mathrm{K}_{\mathrm{s}}$. The resulting family of correction factors for diaphragm position is shown in Figure 5.5. These curves were smoothed using least square techniques to allow the use of the design aids for any diaphragm position between 6 in. and 36 in.

\subsubsection{Correction Factor Skew Angle}

\section{At Interior Diaphragm Regions and Intermediate Diaphragm Regions}

For interior diaphragms as well as intermediate diaphragm regions the correction factor for skew angle was simply suggested as the secant of the angle. 


\section{At Exterior Diaphragm Regions}

In order to find the correction factor for $\alpha_{e}$ accounting for the effect of skew angle, the following procedure was used:

The base case structure is consecutively modified by changing the skew angle of the superstructure. $0^{\circ}, 10^{\circ}, 20^{\circ}$, and $30^{\circ}$ were considered in the analyses. For each case iterative finite element analyses are required to find the required $\alpha_{e}$ producing $\sigma_{\min , \text { ext }}=0.8$. This $\alpha_{e}$ is then compared to the one obtained from Figure 5.3 and the modification factor is obtained (taken the ratio of $\alpha_{e}$ 's). Because it was noticed that the magnitude of the correction factor for skew angle depended also on the girders' boundary conditions, the procedure was repeated for different values of $K_{s}$. The resulting family of correction factors for skew angle is shown in Figure 5.6. The resulting curves were smoothed using least square techniques to allow the use of the design aids for skew angles between $0^{\circ}$ and $30^{\circ}$.

\subsection{Required Post-tensioning Distribution for Integral Bent Bridges}

Integral bent bridges are considered as a separate category in the formulation of design aids. For modeling purposes, the girders ends are considered as clamped. Induced compressive transverse stresses near the ends are always small, regardless of the extra-post-tensioning force applied at the end region of the deck. The design criterion has to be reformulated because achieving a minimum normalized transverse stress equal to 0.8 is no longer practical. The adopted criterion is to prescribe $\alpha_{e}$ such that there is only a small "ineffective stripe" at the end of the deck where the normalized transverse stresses are less than 0.8. In other words, everywhere on the deck's surface except in this ineffective end stripe the induced normalized transverse stresses are more than 0.8 . The width of the ineffective stripe is arbitrarily selected as $3 \mathrm{ft}$ (measured from the end of the girders). Different design aids are 
formulated for concrete-girder as compared to steel-girder integral bridges. The reason for this is that steel girder superstructures commonly have exterior diaphragms (stiffeners) at the ends whereas concrete girders do not have such elements.

\subsubsection{Concrete-Girders-Integral-Bent Bridges}

Typically, concrete-girder-integral-bent bridges have not transverse elements near the abutments. The suggested post-tensioning scheme for this case is shown in Figure 5.7. For skew bridges, the posttensioning bars/ducts should be placed parallel to the skewed edge.

The definition of the exterior diaphragm region is inadequate (there is not exterior diaphragm). Such region is now referred to as end region. Iterative Finite Element analyses with SAP2000 were carried out to find the required extra-post-tensioning factor, $\alpha_{e}$, to have an ineffective end stripe of $3 \mathrm{ft}$-width.

Widths of end regions considered in the analyses included: $5 \mathrm{ft}, 7 \mathrm{ft}$, $9 \mathrm{ft}$, and $13 \mathrm{ft}$. The resulting values of $\alpha_{e}$ for different widths of end regions are shown in Figure 5.8. Note that the "discrete" results were smoothened using least square techniques. The analyses suggested that the post-tensioning scheme shown in Figure 5.7 is applicable for integral bent bridges with skew angles of 20 degrees or less. For skew angles of more than 20 degrees the transverse post-tensioning might even generate tension stresses on top of the deck.

For interior diaphragm regions the width of the diaphragm region and the extra-post-tensioning force factor, $\alpha_{i}$, can be approximately obtained using $\mathrm{K}_{\mathrm{s}}=10,000 \mathrm{kip} / \mathrm{in}$ and Figures 5.2(b) and 5.3(b).

Again, for intermediate diaphragm regions as well as interior diaphragm regions the correction factor for skew angle was suggested as the secant of the angle. 


\subsubsection{Steel-Girder-Integral-Bent Bridges}

Steel-girder-integral-bent bridges usually have transverse elements near the abutments (either diaphragms or stiffeners). Design aids for this case should take into account both: the size of the exterior diaphragm and its position with respect to the end of the deck. The suggested post-tensioning scheme is shown in Figure 5.9. The exterior diaphragm region is arbitrarily defined, as a transverse stripe that extends from the end of the deck to $3 \mathrm{ft}$ beyond the position of the exterior diaphragm. For a given exterior diaphragm size and position, iterative uses of Finite Element analyses with SAP2000 are carried out to find the required extra-post-tensioning factor, $\alpha_{e}$, to have an ineffective end stripe (where $\sigma<0.8$ ) of $3 \mathrm{ft}$-width.

Figure 5.10 (a) to (d) show the required extra-post-tensioning force factor at the exterior diaphragm region, $\alpha_{e}$, for different sizes of the exterior diaphragm, and different positions of the diaphragms with respect to the end of the girders; $4 \mathrm{ft}, 6 \mathrm{ft}, 8 \mathrm{ft}, 10 \mathrm{ft}$ respectively. The analyses suggest that the post-tensioning scheme shown in Figure 5.9 is applicable for integral bent bridges with skew angles of 20 degrees or less. For skew angles of more than 20 degrees the transverse posttensioning might even generate tension stresses on top of the deck. It is again suggested to place the post-tensioning bars/ducts parallel to the skewed edge. It is also noticed that it is impractical to locate the exterior diaphragms at less than $6 \mathrm{ft}$ from the end of the girders, as excessive extra-post-tensioning force factors are required. This is true especially for large values of the skew angle.

For interior diaphragm regions, the width of the diaphragm region and the extra-post-tensioning force factor, $\alpha_{i}$, can be approximately obtained using $\mathrm{K}_{\mathrm{s}}=10,000 \mathrm{kip} / \mathrm{in}$ and Figures 5.2(b) and 5.4(b).

Again, for intermediate diaphragm regions as well as interior diaphragm regions the correction factor for skew angle was suggested as the secant of the angle. 


\subsection{Required Post-tensioning Distribution for Slab Bridges}

Slab bridges can be considered as a particular case of deck-ongirder bridges where the area of transverse concrete elements is zero (and there are not girders). The design aids presented in Sections 5.2 and 5.3 can be used to find $\alpha_{e}$ for the end regions of the slab. A very small area of concrete diaphragms should be hypothetically considered, however, $\alpha_{e}$ should be always more than 1.0.

\subsection{Estimation of $K_{s}$ for Non-Integral Ends}

Typically, girder ends are either: (i) supported on elastomeric bearings or rocker bearings, (ii) embedded into end-bents (integral-bent bridges), or (iii) a combination of both (one girder end is integral and the other end is supported on neoprene pads or rocker bearings). Design aids for integral-end bent are already available from Section 5.3. If elastomeric bearings are used to support the girders, then the restraining effect of the neoprene pads needs to be estimated. Referring to Figure 5.11, and letting $A_{p}$ be the area of the pad and $h_{p}$ its thickness, the magnitude of $K_{s}$ is given by (see derivation in Figure 5.11):

$K_{s}=G \times A_{p} / h_{p}$

where, $G$ is the modulus of elasticity in shear of the elastomeric bearing

Values of $G$ can be found in the related-literature $(\mathrm{PCl}$ Design Handbook (1999), Bridge Design Manual (1975), Pfeifer and Iverson (1985)). The current Bridge Design Manual of the Indiana Department of Transportation (INDOT), for example, suggests values of $G$ between 50 and 300 psi for plain pads (depending on the temperature). Pfeifer and 
Iverson (1985) suggest values of $G$ between 500 and 3000 psi for reinforced pads (and 100 to 215 psi for unreinforced pads).

On the other hand, standard sizes of elastomeric bearings are commonly used. For deck-on-girder bridges INDOT, for example uses four standard pad sizes; the smallest one is $7 \times 14 \mathrm{in}$. and, 2.4 in. thick, whereas the largest one is $10 \times 24 \mathrm{in}$. and $3.2 \mathrm{in}$. thick.

The INDOT's standard elastomeric pads' range of values of $K_{s}$ is as follows (using Equation 5.3):

- For unreinforced pads

$$
\begin{aligned}
& \mathrm{K}_{\mathrm{s}, \min }=2.0 \mathrm{kip} / \mathrm{in} . \quad \text { (smallest pad and } \mathrm{G}=50 \mathrm{psi} \text { ) } \\
& \mathrm{K}_{\mathrm{s}, \max }=27 \mathrm{kip} / \mathrm{in} \quad \text { (largest pad and } \mathrm{G}=360 \mathrm{psi} \text { ) }
\end{aligned}
$$

- For reinforced pads

$$
\begin{array}{ll}
\mathrm{K}_{\mathrm{s}, \min }=20 \mathrm{kip} / \mathrm{in} . & \text { (smallest pad and } \mathrm{G}=500 \mathrm{psi}) \\
\mathrm{K}_{\mathrm{s}, \max }=230 \mathrm{kip} / \mathrm{in} & \text { (largest pad and } \mathrm{G}=3000 \mathrm{psi})
\end{array}
$$

Note in the design aids that the extra-post-tensioning force factors, $\alpha_{e}$ and $\alpha_{i}$, are not sensitive to values of $K_{s}<200 \mathrm{kips} / \mathrm{in}$. Then, for elastomeric pads (either unreinforced or reinforced), a conservative value of $K_{s}=200 \mathrm{kips} / \mathrm{in}$ can be used.

No values of $K_{s}$ are available for rocker bearings according to the literature review conducted as part of this study. As a first approximation, it is suggested to use the same value of $K_{s}=200 \mathrm{kips} / \mathrm{in}$ for this case. If the user wants to be conservative, however, he/she might consider the girder ends as integral. More research is needed to estimate the $\mathrm{K}_{\mathrm{s}}$ for rocker bearings.

The approximations presented above significantly simplify the design procedure described in Section 5.3. Simplified design aids for use in INDOT are presented in Chapter 6. 


\subsection{Design Recommendations for End Spans of Multi-span Integral- Bent Bridges}

For multi-span integral-bent bridges, the end spans of the superstructure will have girders supported on elastomeric or rocker bearings in one end and integral in the other end. Based on the results of the parametric study, unless the span under consideration is very short, the distribution of transverse stresses in one end should not be significantly affected by the boundary conditions at the opposite end. It is then recommended to use $\alpha_{e}$ for integral-bent bridges at the integral end, and to use $\alpha_{e}$ for $K_{s}=200 \mathrm{kip} / \mathrm{in}$, as suggested previously for nonintegral ends, at the opposite end. At interior diaphragm regions conservatively use $\alpha_{i}$ for integral end-bent (i.e, use $K_{s}=10,000 \mathrm{kip} / \mathrm{in}$ ).

\subsection{Maximum Post-tensioning Spacing}

There is a region between adjacent points of application of posttensioning forces at the deck's edge in which transverse stresses are not effectively transmitted (see Section 3.4). The size of such region increases with the spacing between post-tensioning forces. Loads perpendicular to the plane of the deck should be avoided in this ineffectively stressed region.

An expression for the maximum spacing of the transverse posttensioning forces was derived by Poston et. al. (1985):

$S_{p, \max }=3(x-a+12$ in. $)$

where:

$S_{p, \max }$ is the maximum transverse post-tensioning spacing, 
$a$ is the distance from the edge of the deck to the bearing plate of the bearing anchorage plate (see Figure 5.12(a)), and

$x$ is the distance, in the transverse direction, from the edge of the deck to the inside face of the curb or rail (Figure 5.12(a)).

Equation (5.4) was obtained based on the assumption that the ineffective stressed region has the shape of an equilateral triangle of side $S_{p}$. This assumption, illustrated in Figure 5.12(b), was first suggested by Phipps (1985).

Maximum spacing of the post-tensioning forces is also limited by the occurrence of shear lag in the deck. ACl provisions ( $\mathrm{ACl}$ 318-2002, Section 18.12.4), in this case, limit the maximum spacing to the lesser of 8 times the deck thickness or $5 \mathrm{ft}$. Thus, the maximum spacing of transverse post-tensioning is given by Equation (5.5):

$S_{p, \max }=\min$ imum of $\left\{\begin{array}{c}5 \mathrm{ft} \\ 8 x \text { deck thickness } \\ 3(x-a+12 \text { in. })\end{array}\right.$

\subsection{Durability Considerations}

Design implications for improving durability of bridge decks with the use of transverse post-tensioning are discussed elsewhere (Poston et. al, 1985). The results from the durability tests of transversely posttensioned decks carried out by Poston (1985) are summarized as follows:

\subsubsection{Concrete Cover}

Although the use of transverse post-tensioning is intended to guarantee a longitudinally crack-free deck at service, there is still the 
risk of corrosion associated with the long term exposure to chlorides, which will slowly penetrate into the uncracked concrete. Durability studies by Poston (1984) indicated that the combination of a 2 in. cover and a water-cement ratio of 0.45 was adequate for corrosion protection. Because significant deviations from the specified values are expected during the construction, a minimum cover of 2.5 in. was ultimately specified in the durability tests. This value is in agreement with INDOT cover requirements.

\subsubsection{Protection of Post-tensioning}

A minimum concrete cover of 2.5 in. around all surfaces of an anchorage would provide adequate protection against corrosion. However, such minimum 2.5 in. cover over the post-tensioning ducts will likely result in less cover over the anchorage. Durability specimens with concrete cover of 2 in. over the prestressing tested by Poston (1984) had only $3 / 4$ in. cover over the top anchorage surfaces. The heavy corrosion that resulted in some of the anchorages suggested that corrective measures other than concrete cover must be used. In unbonded post-tensioning Poston et. al (1985) suggested that the anchorage must be completely sealed against moisture. The sealing material should encapsulate the anchorage, the jaws, and strand extensions. Providing physical barrier to moisture around the tendons results in an electrical isolated post-tensioning system which will be at a low risk of corrosion.

Poston et al. (1985) suggested that the external anchorages shall not be used even if protected by auxiliary protective barrier. All protected anchorage components, including strand extensions, must be surrounded by not less than $1.5 \mathrm{in}$. of concrete or mortar.

It was also suggested by Poston et al. (1985) that after stressing the tendons and sealing the anchorages, stressing pockets should be filled with a suitable chloride-free mortar with low shrinkage properties. It was 
recommended to paint the pockets with an epoxy resin bond agent to improve adhesion of the fresh mortar to the hardened concrete.

\subsubsection{Chloride Content}

The durability study tests by Poston (1984) indicate that in order to minimize the risk of corrosion, the maximum water soluble chloride content in concrete by weight of cement should be limited to $0.06 \%$.

\subsection{Post-tensioning Sequence}

Ideally, all the strands in a transversely post-tensioning deck must be stressed simultaneously to avoid losses in the strands due to elastic shortening of the deck. The situation is ideal but impractical during construction.

It was observed from the results of the parametric study presented in Chapter 4 that the restraining effects of transverse elements and boundary conditions are significantly higher at the end regions of the deck. This suggests that losses of any type should be especially minimized at such end regions. The recommended post-tensioning sequence consists of post-tensioning first in the middle regions of the deck and move towards the ends. This sequence will minimize the elastic shortening of the concrete (and then losses in the corresponding strands) at the ends. It must be noticed that the effect of jacking sequence was reported as insignificant (stress losses in the order of $4 \%$ ) in tests on transversely post-tensioned decks as reported by Ralls (1984). 


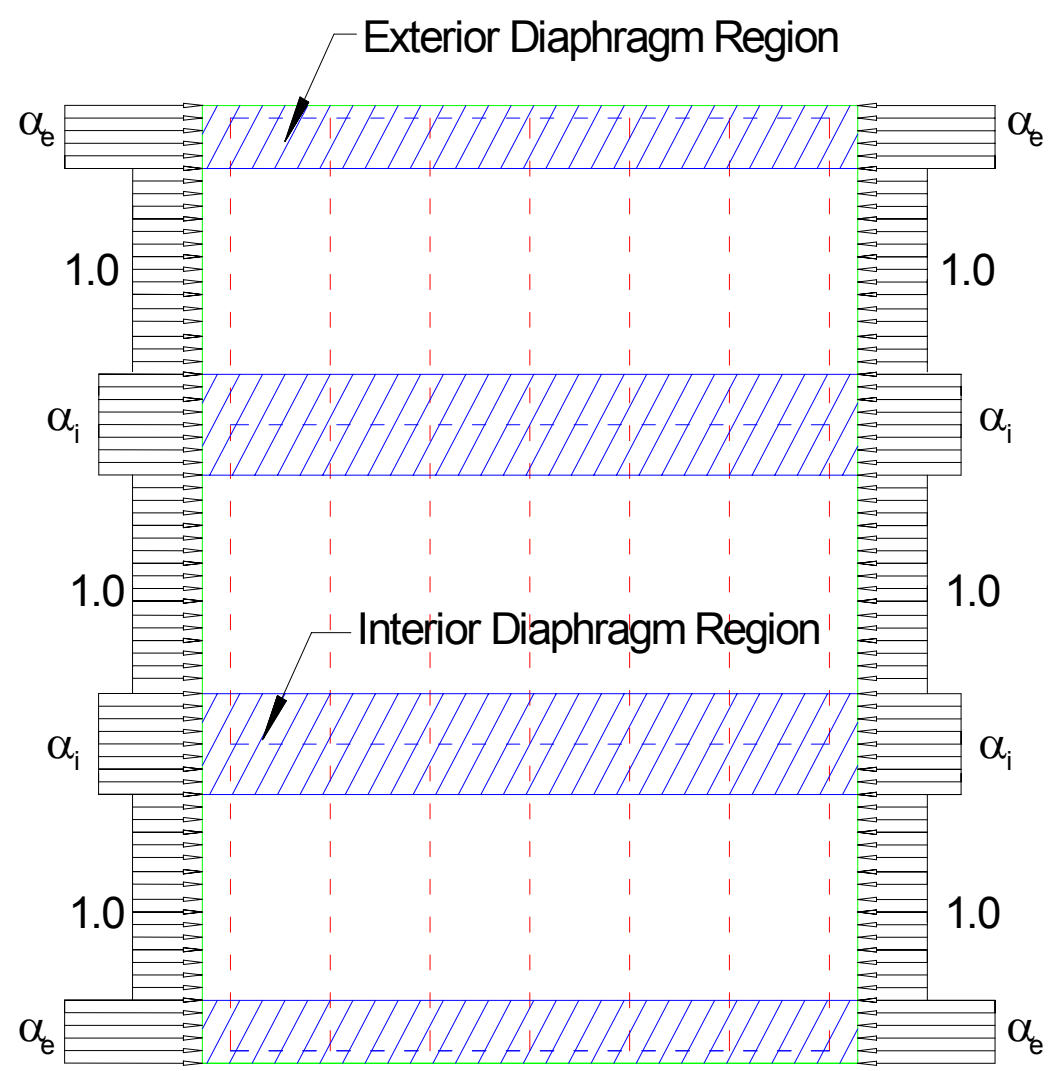

Figure 5.1 Suggested Distribution of Transverse Post-tensioning 


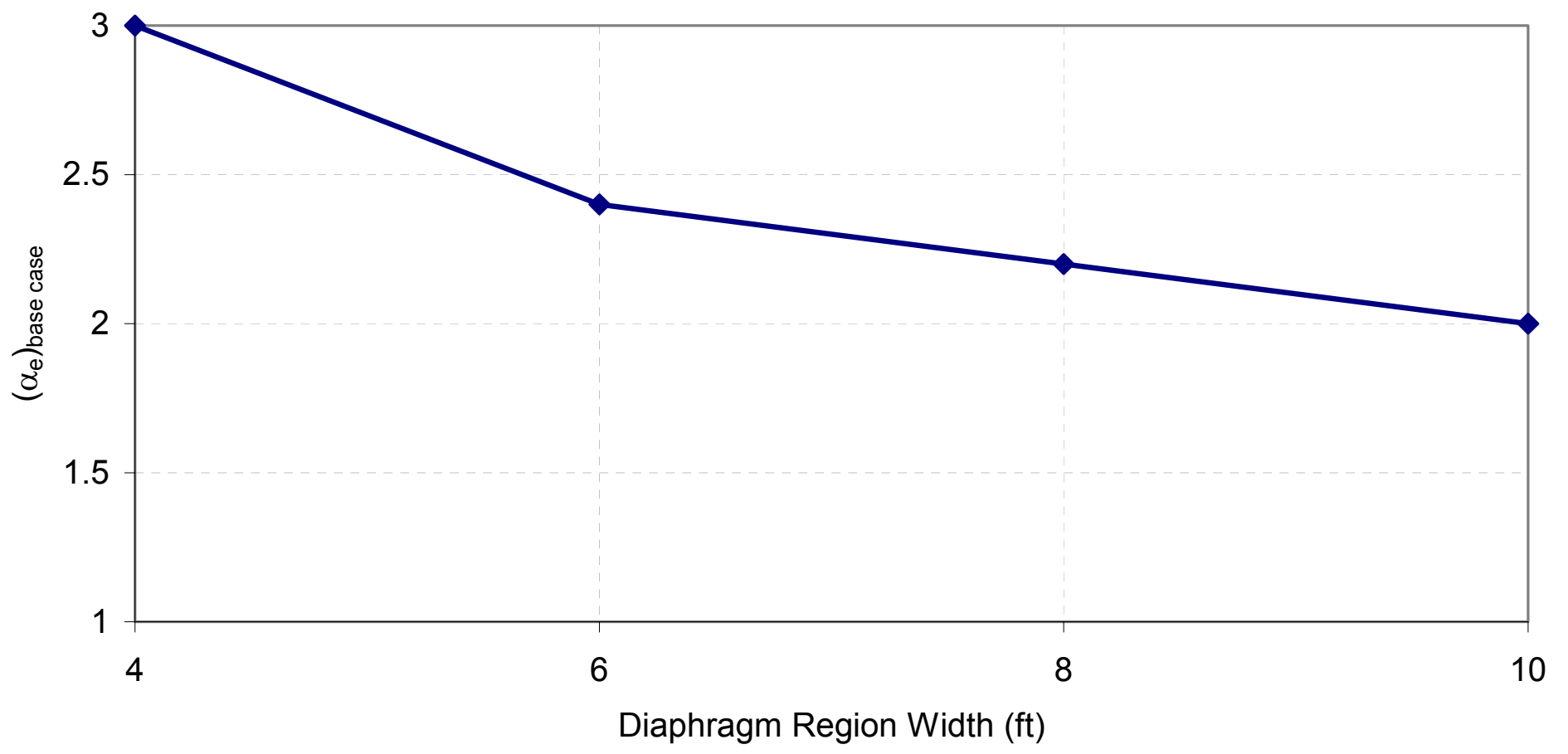

Figure 5.2 (a). Required Combination of Diaphragm Region Width and Extra-PT Force Factor to Have $\sigma_{\min }=0.8$ at Exterior Diaphragm Region. Base Case Structure 


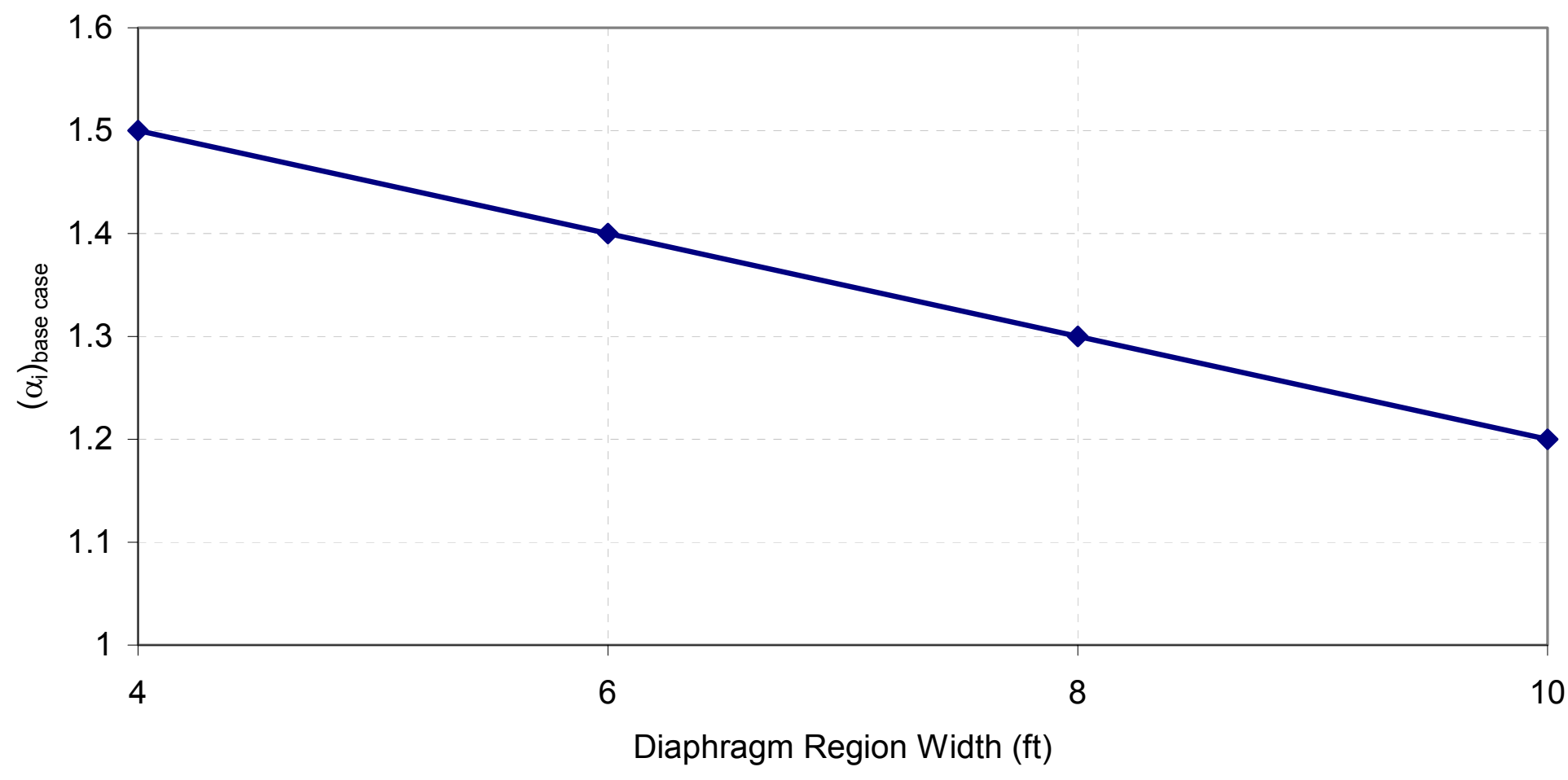

Figure 5.2 (b). Required Combination of Diaphragm Region Width and Extra-PT Force Factor to Have $\sigma_{\min }=1.0$ at Interior Diaphragm Region. Base Case Structure 


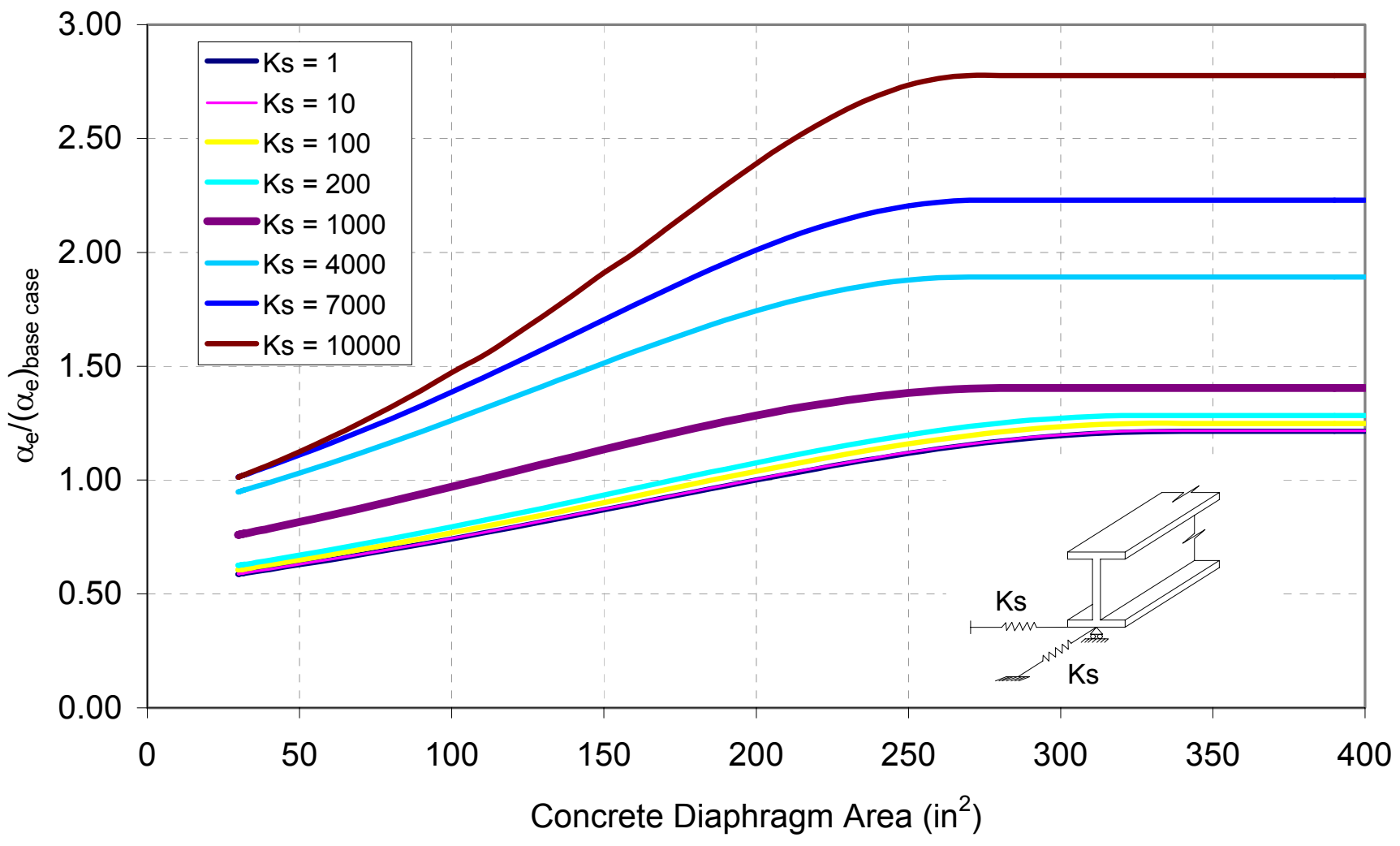

Figure 5.3 (a). Extra PosTensioning Force Factor at Exterior Diaphragm 


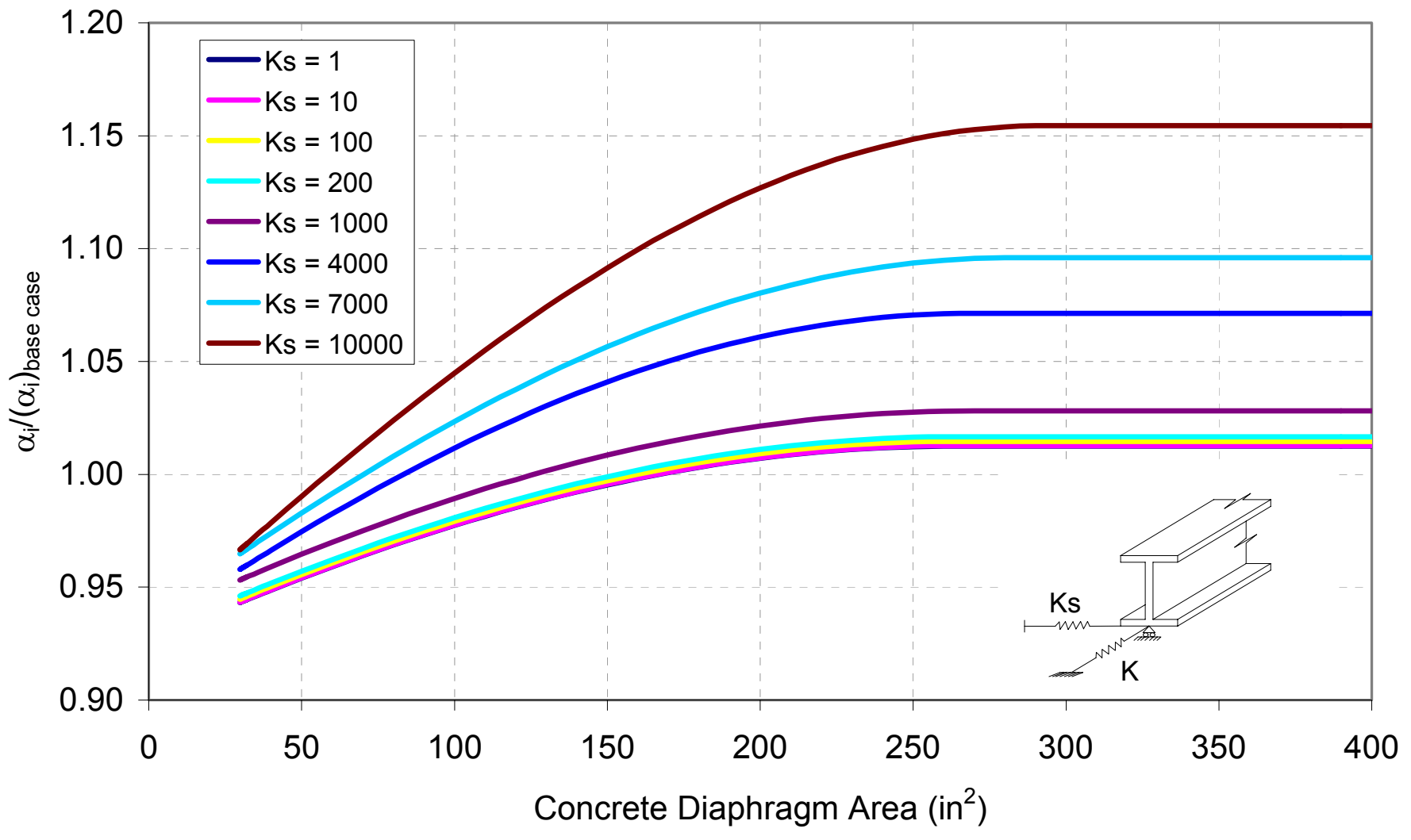

Figure 5.3 (b). Extra PosTensioning Force Factor at Interior Diaphragm 


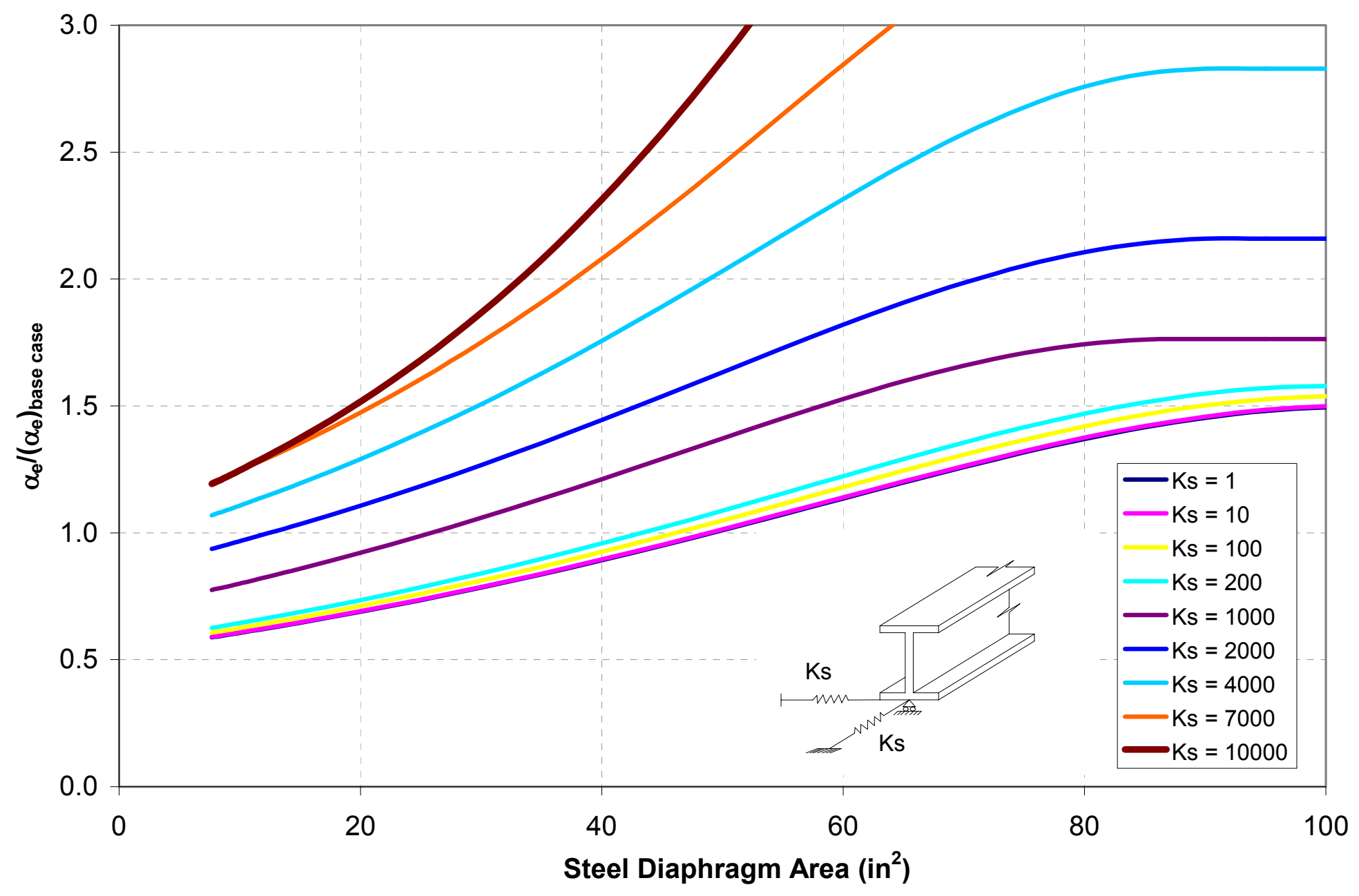

Figure 5.4 (a). Extra PosTensioning Force Factor at Exterior Diaphragm Region 


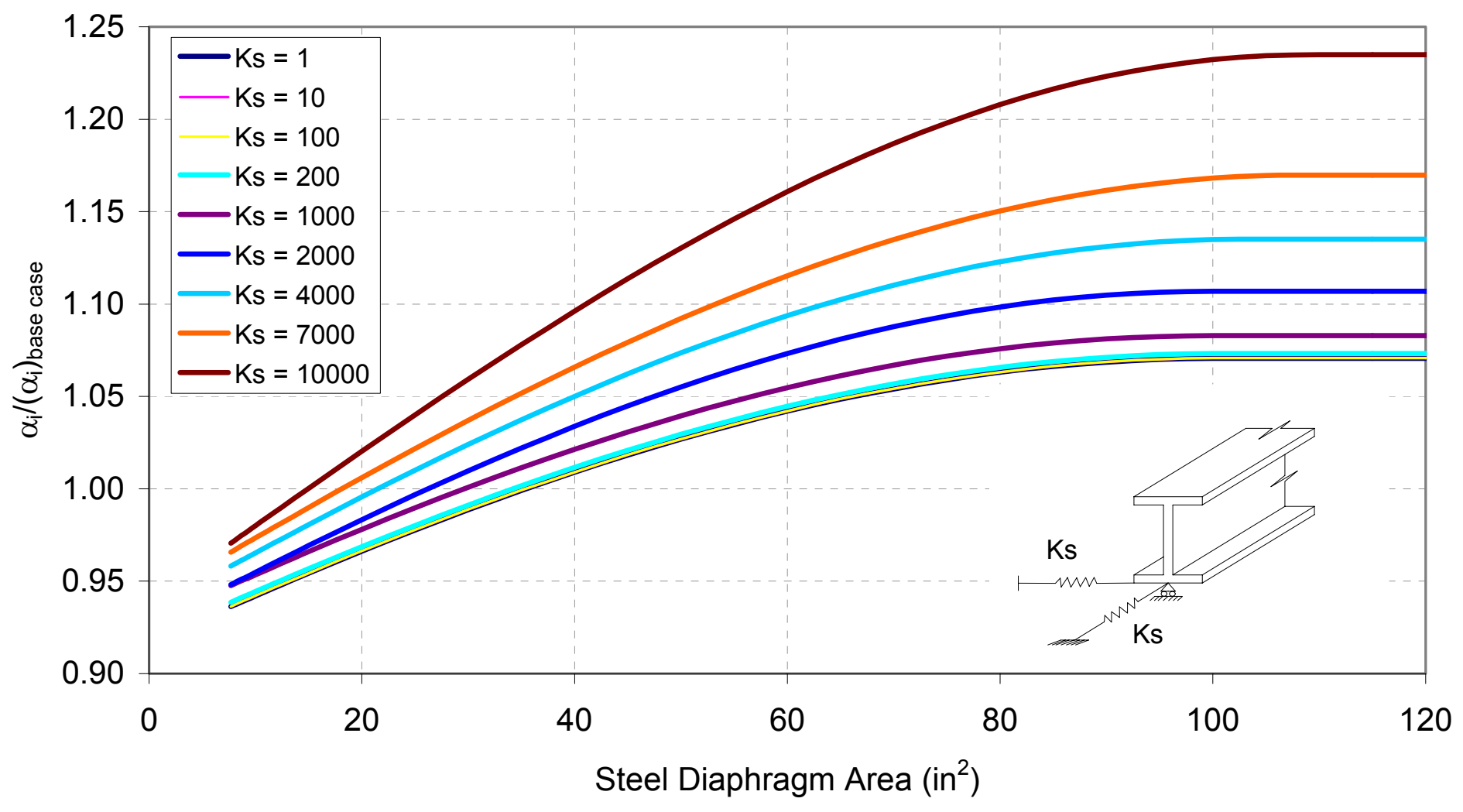

Figure 5.4 (b). Extra PosTensioning Force Factor at Interior Diaphragm Region 


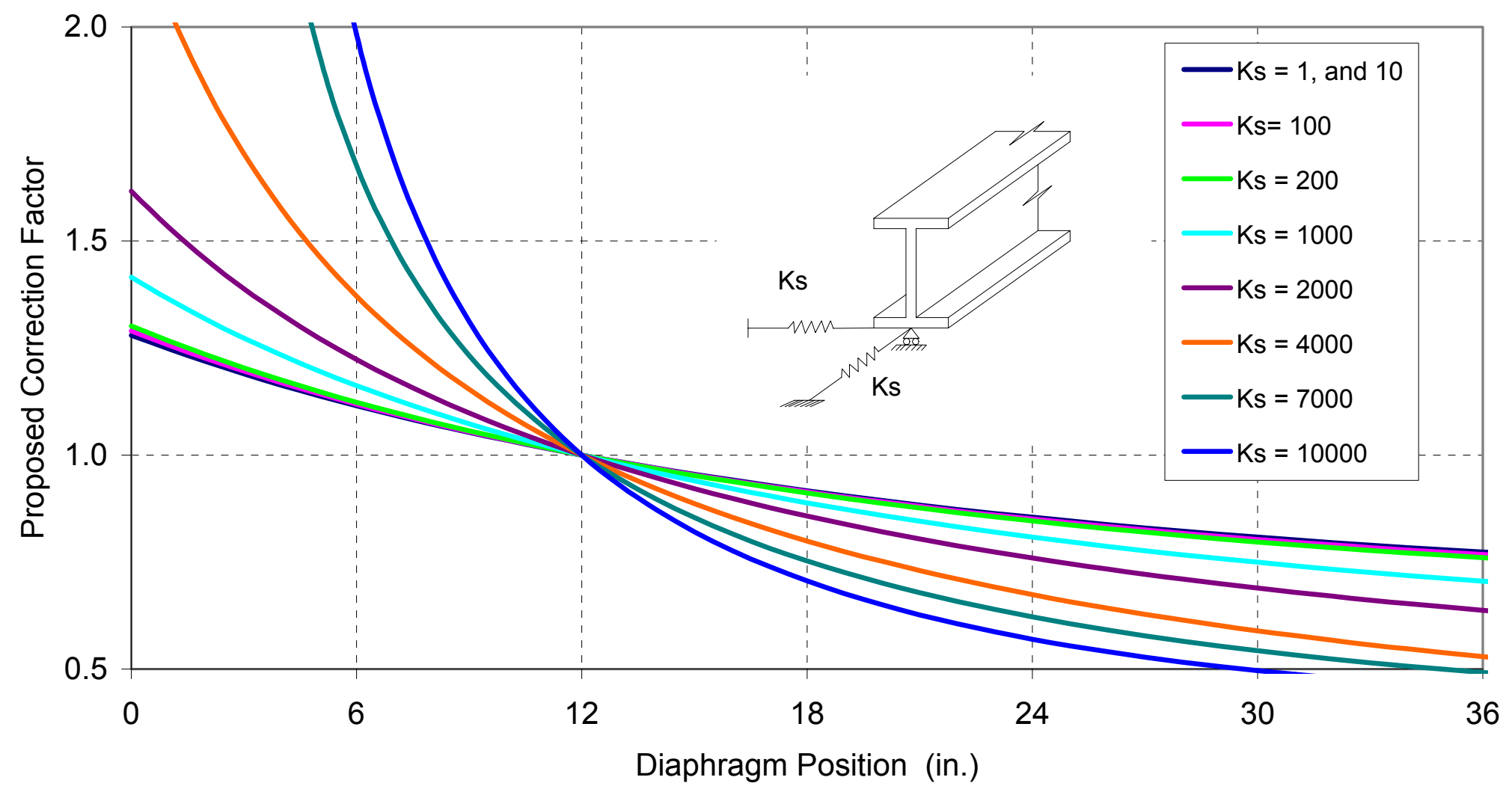

Figure 5.5. Factor Modifying $\alpha_{\mathrm{e}}$ to Account for Exterior Diaphragm Position 


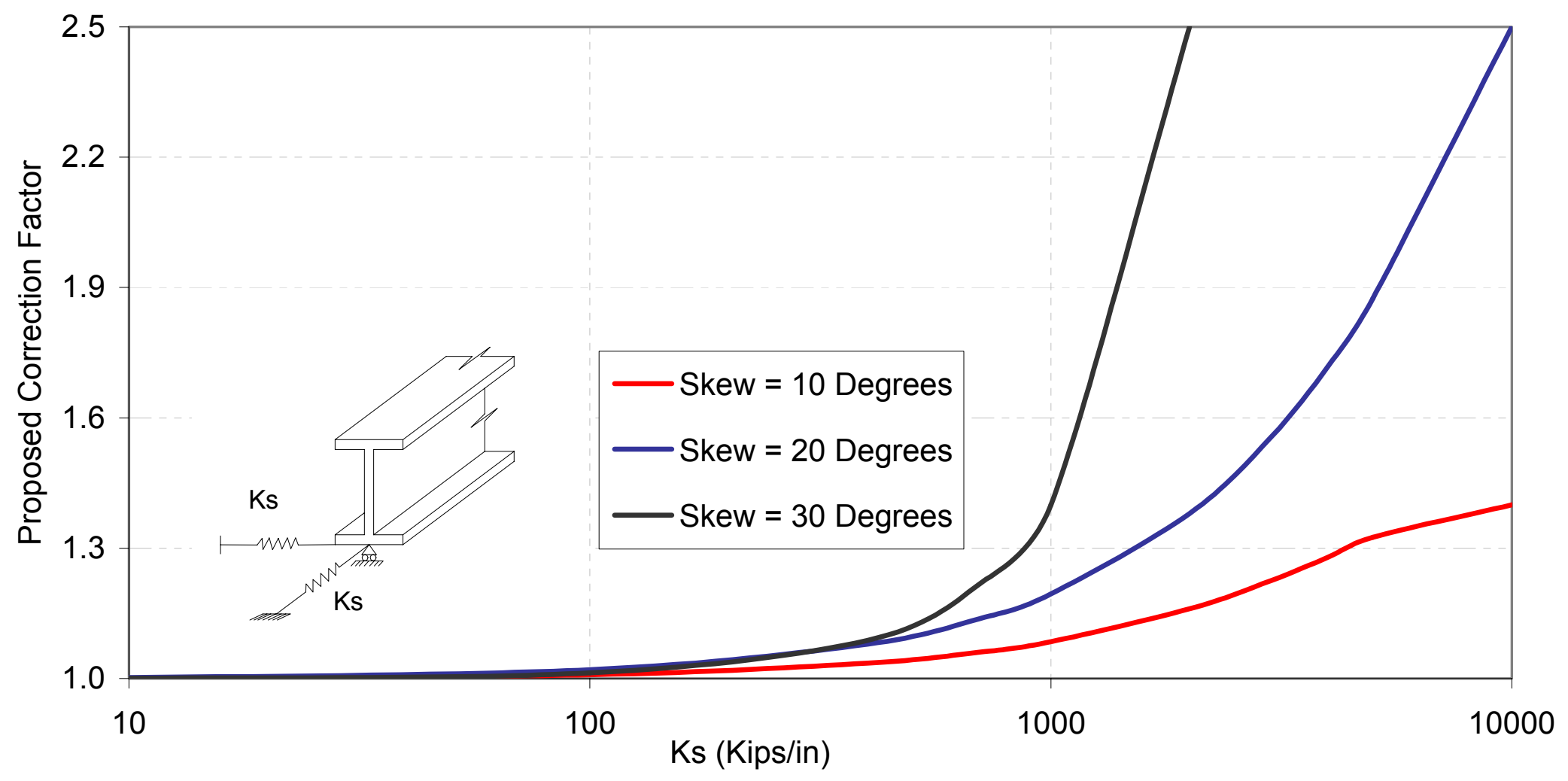

Figure 5.6 Correction Factor for Skew Angle. Exterior Diaphragm Region Only 


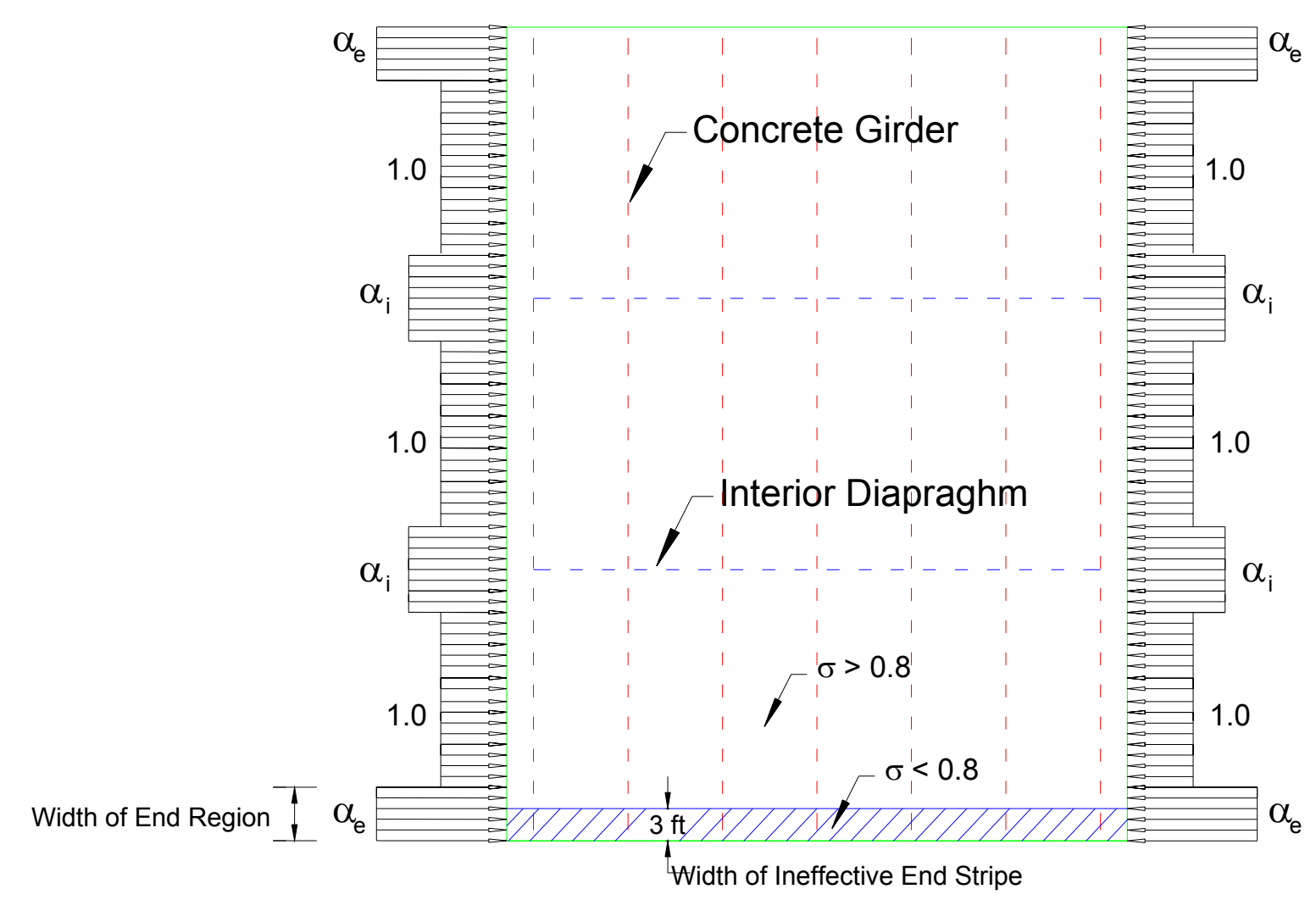

Figure 5.7 Post-tensioning Scheme for Integral-Bent-Concrete-Girder Bridges 


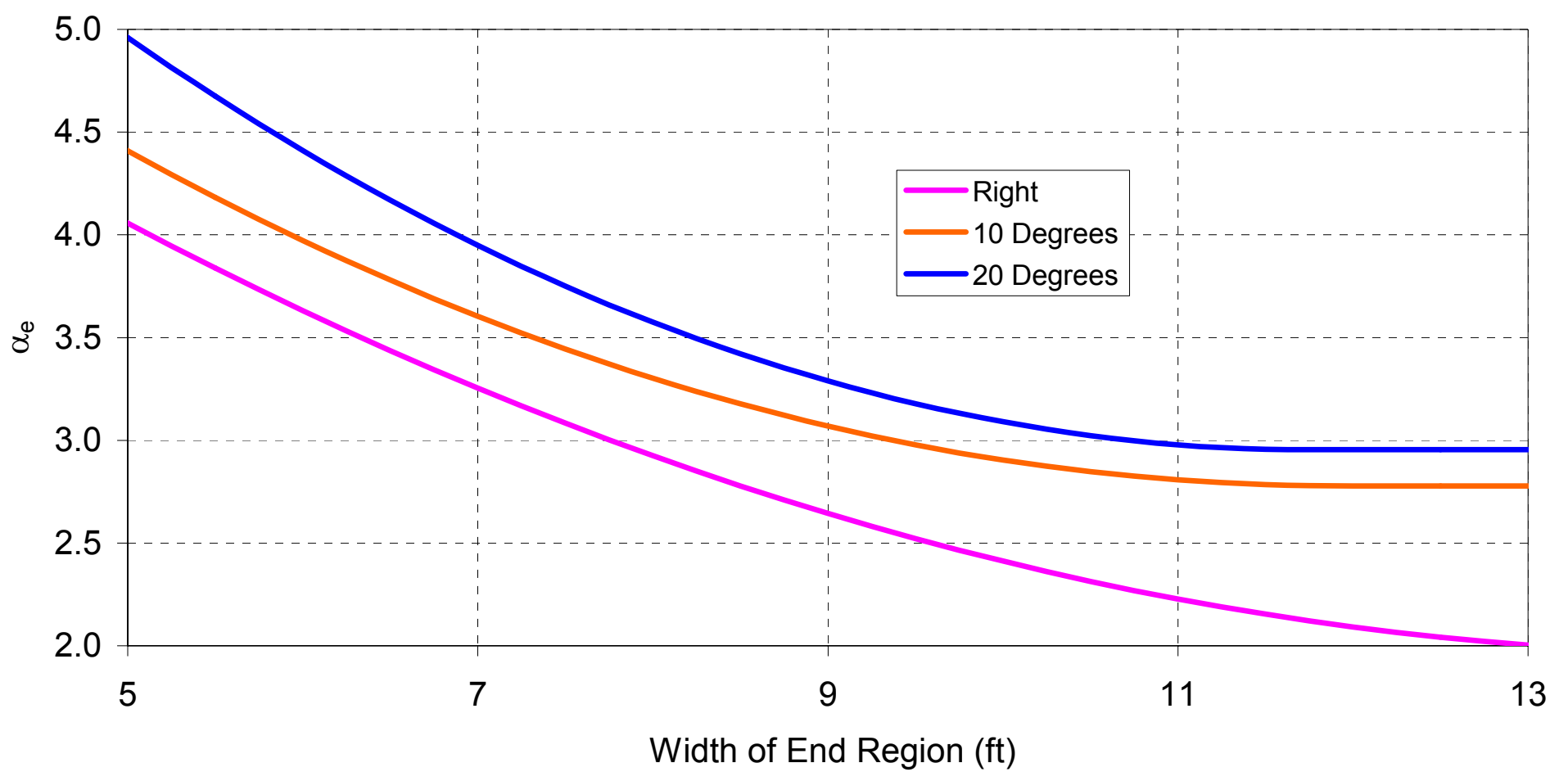

Figure 5.8- Extra Postensioning Force Factor at End Regions of Concrete Girder Integral Abutment Bridges 


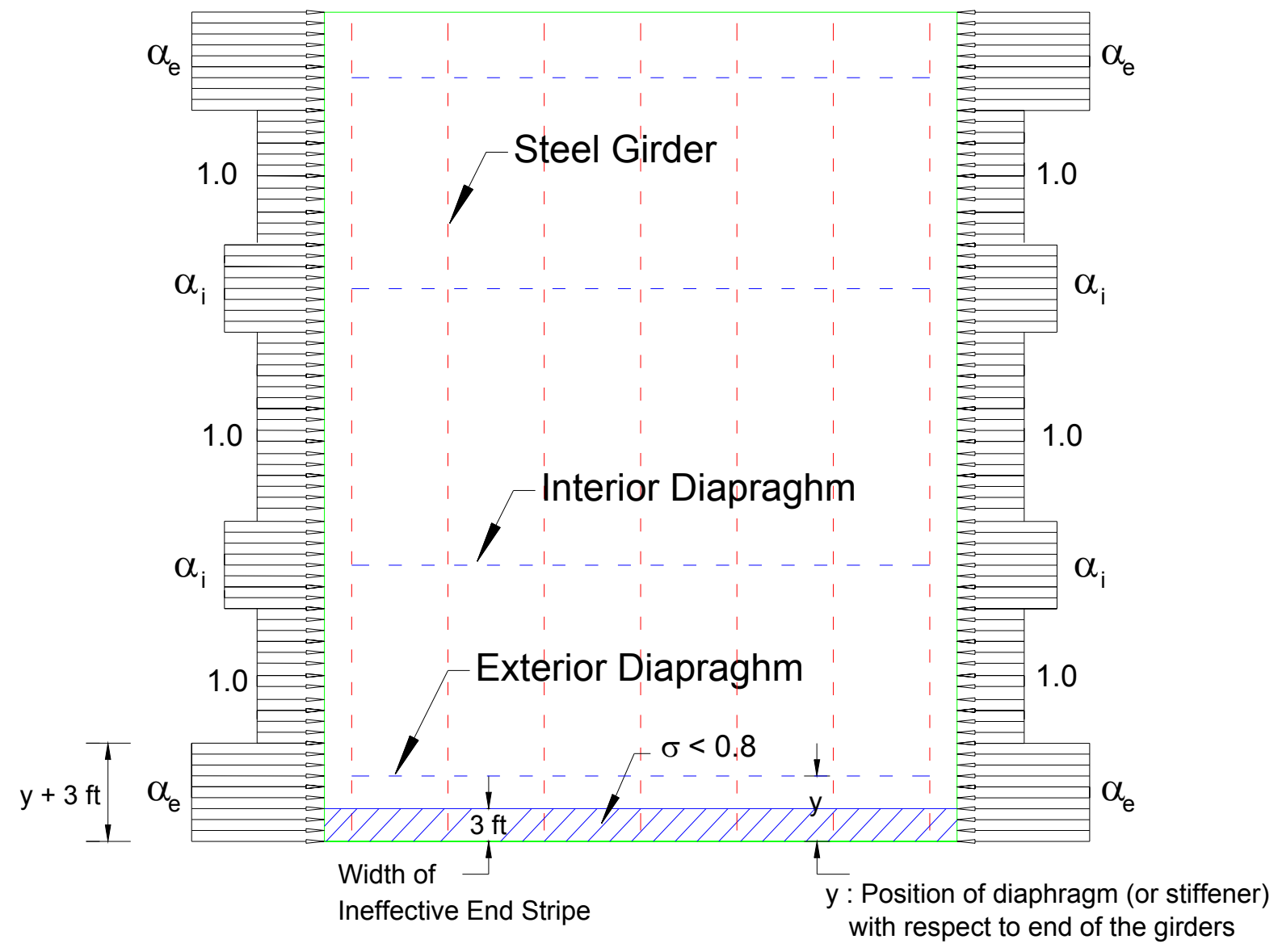

Figure 5.9 Post-tensioning Scheme for Integral-Bent-Steel-Girder Bridges 


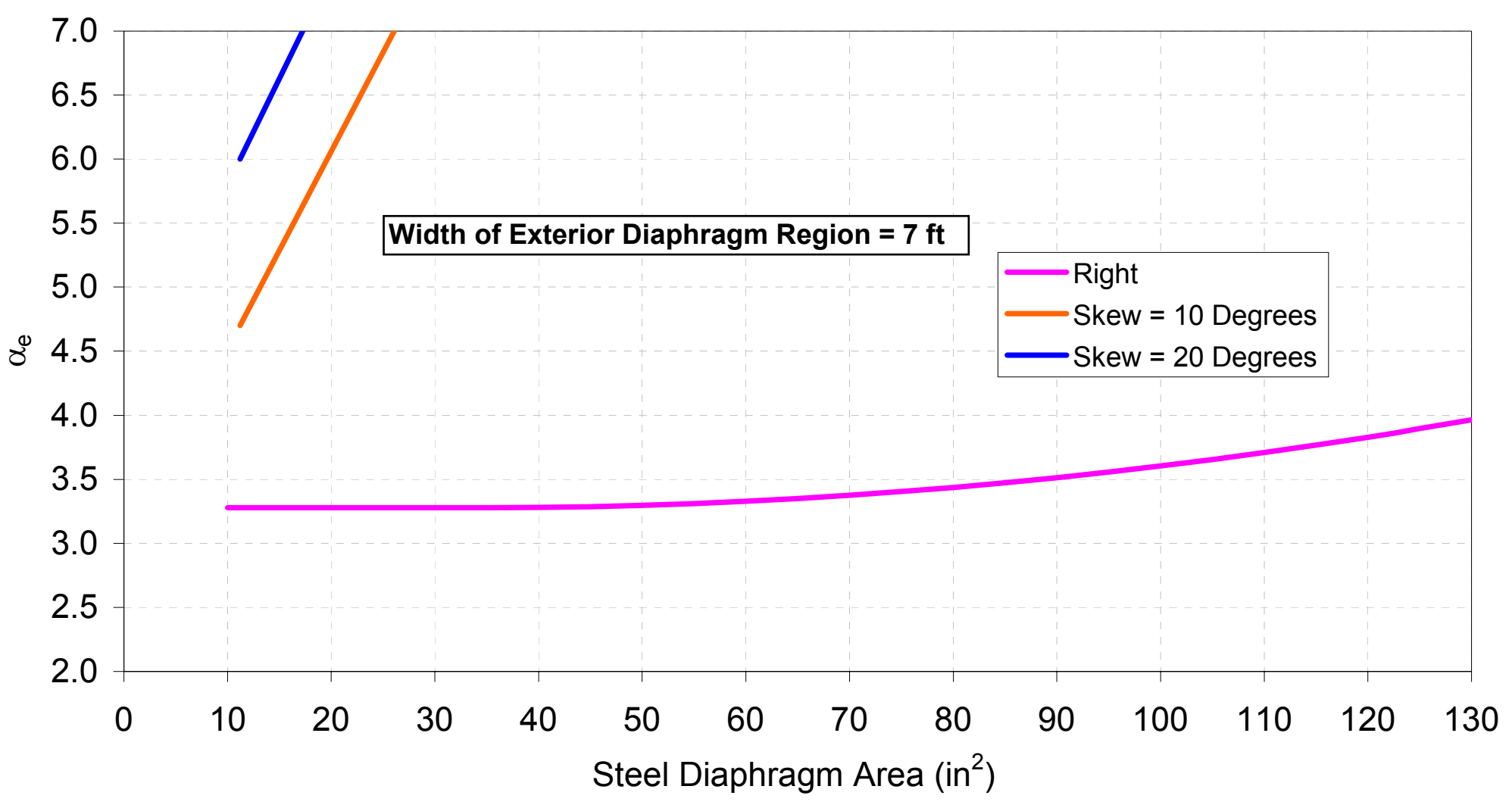

Figure 5.10 (a)- Extra-Post-tensioning Force Factor at Exterior Diaphragm Region for SteelGirder- Integral-Abutment Bridges. Exterior Diaphragm Located at $4 \mathrm{ft}$ from End of Deck 


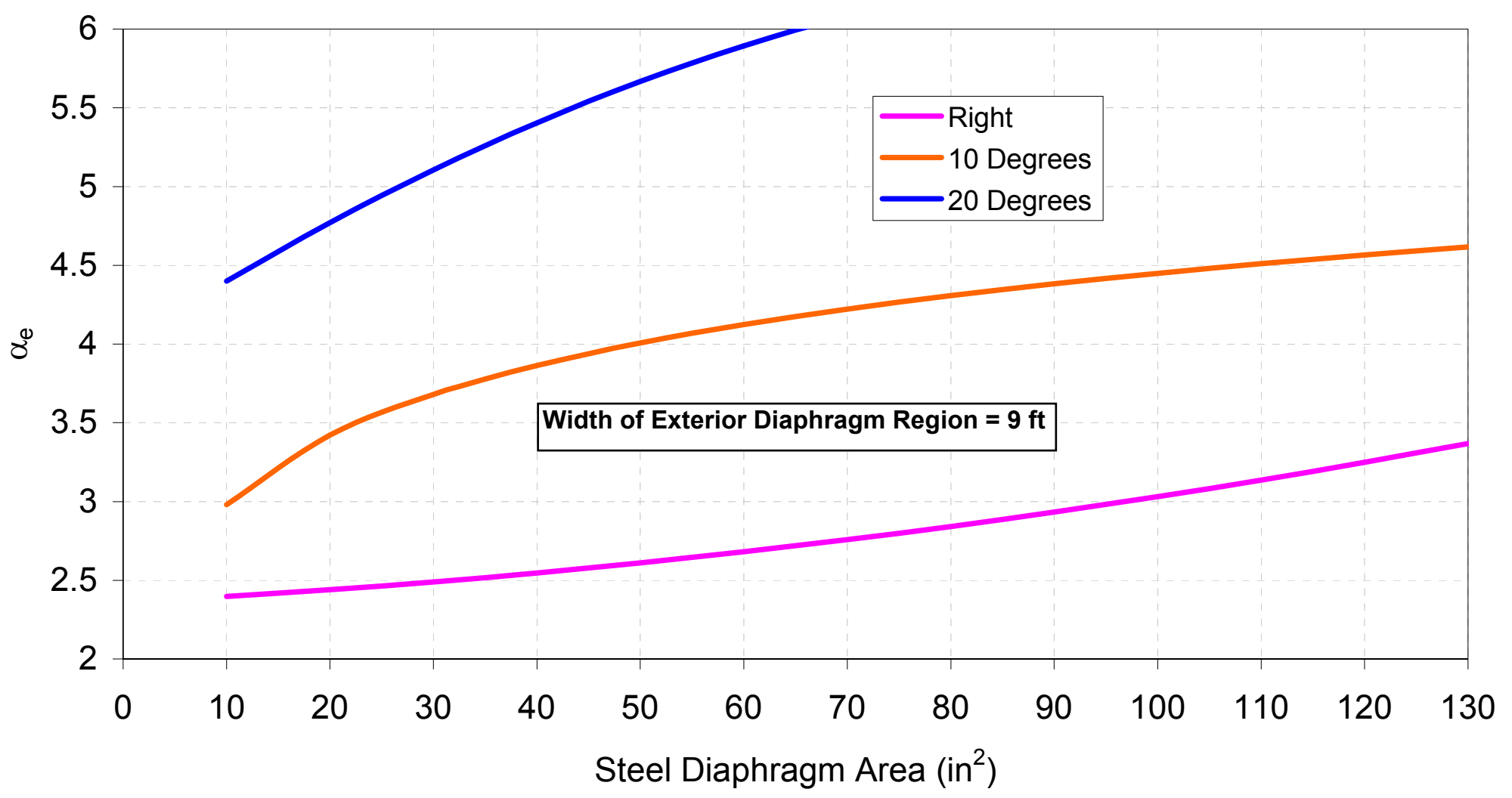

Figure 5.10(b)- Extra-Post-tensioning Force Factor at Exterior Diaphragm Region for SteelGirder-Integral-Abutment Bridges. Exterior Diaphragm Located at $6 \mathrm{ft}$ from end of Deck 


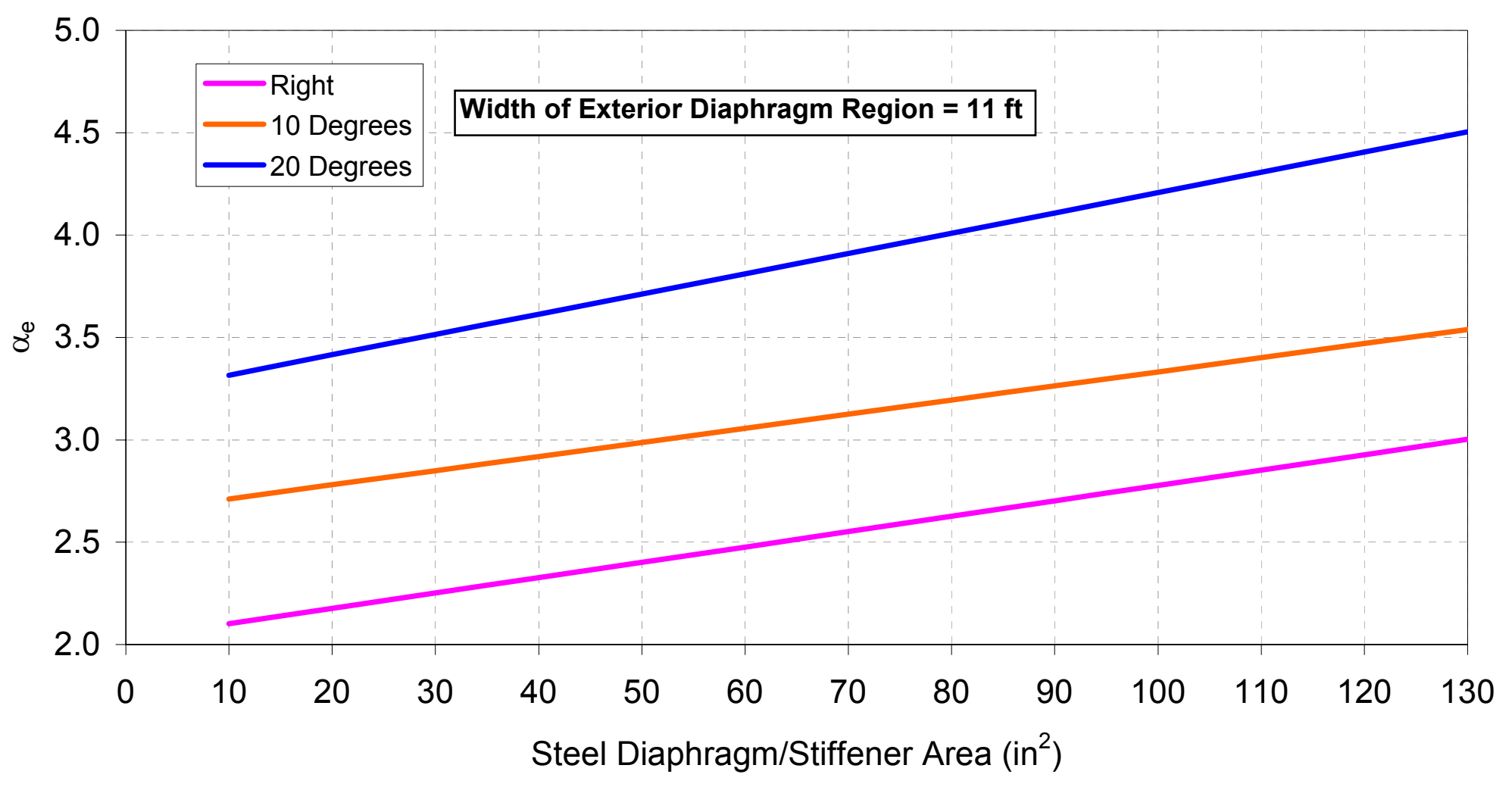

Figure 5.10(c)- Extra-Post-tensioning Force Factor at Exterior Diaphragm Region for SteelGirder-Integral-Abutment Bridges. Exterior Diaphragm Located at $8 \mathrm{ft}$ from End of Deck 


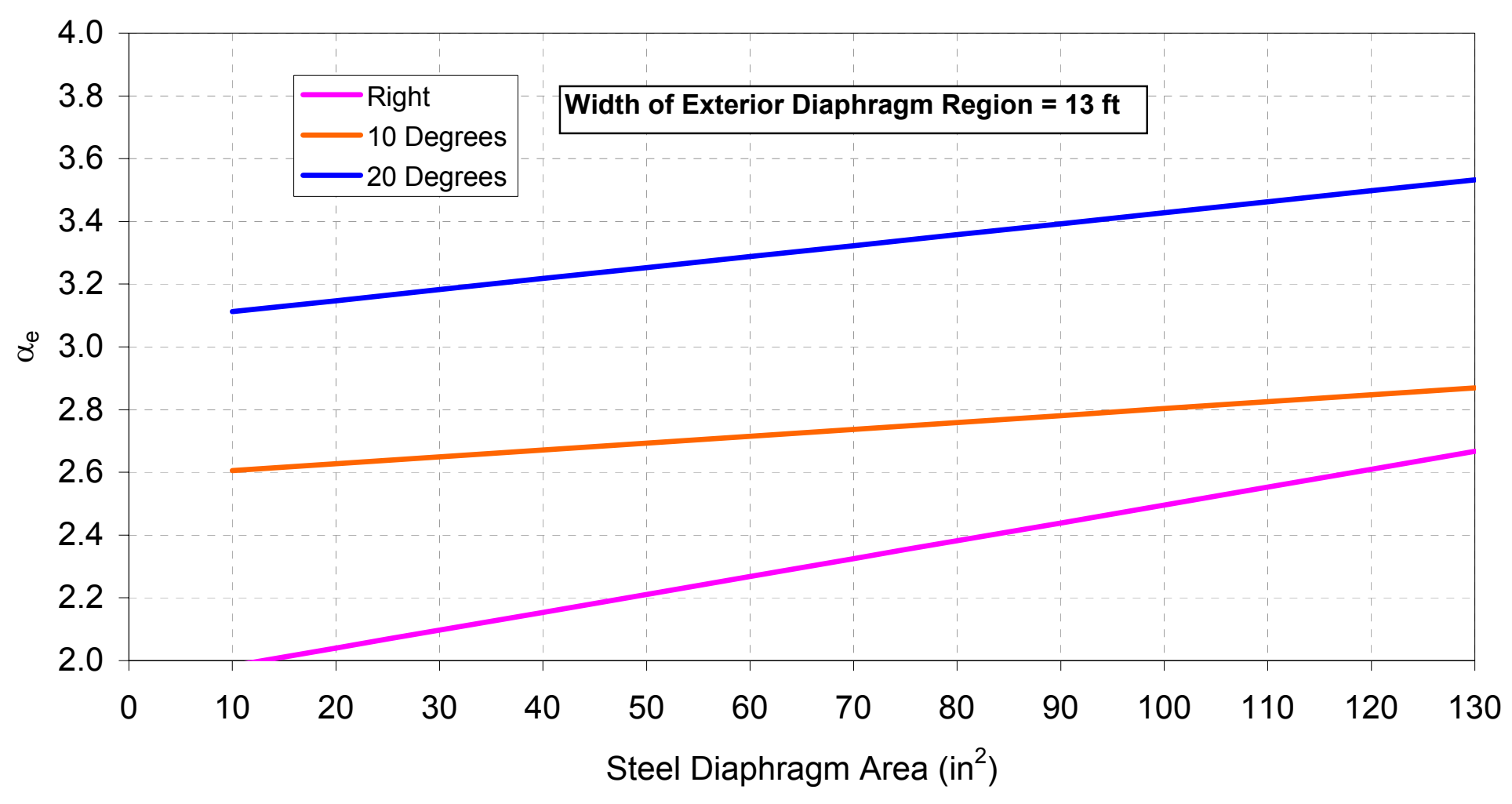

Figure 5.10 (d)- Extra-Post-tensioning Force Factor at Exterior Diaphragm Region for SteelGirder-Integral-Abutment Bridges. Exterior Diaphragm Located at $10 \mathrm{ft}$ from end of Deck 


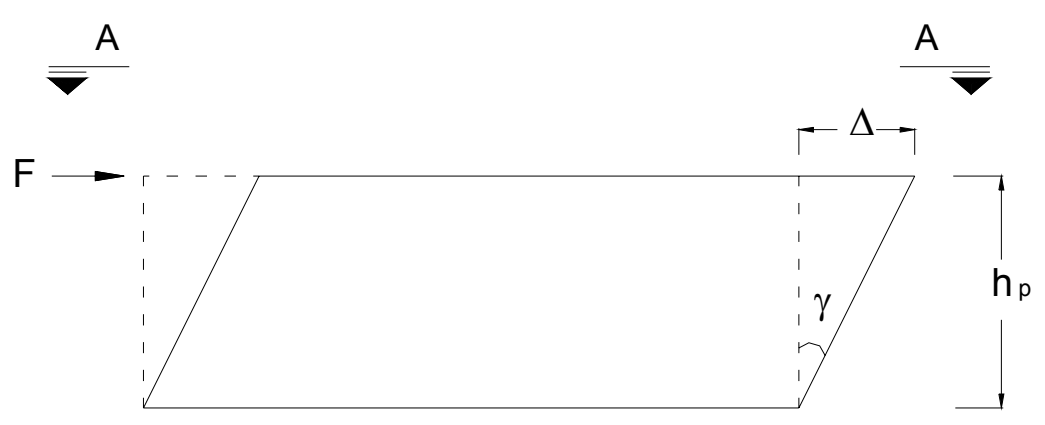

Small deformations

$\gamma=\Delta / \mathrm{h}_{\mathrm{p}}$

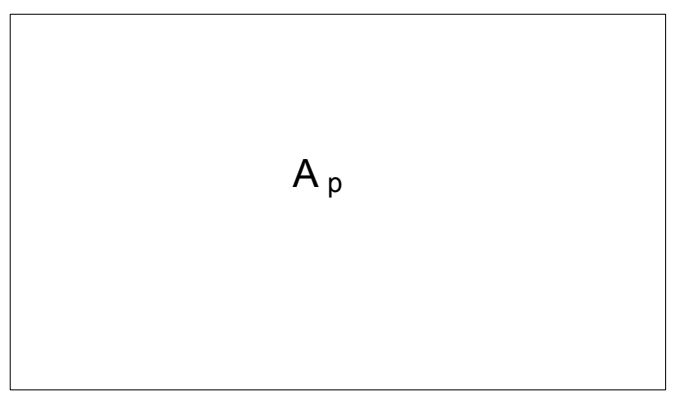

Linear elastic material

$F / A_{p}=G^{*} \gamma$

Substituting Eq (1) into Eq (2) and solving:

$F / \Delta=G * A_{p} / h_{p}$ $(=\mathrm{Ks})$

Section A-A

Figure 5.11 Derivation of Value of $\mathrm{K}_{\mathrm{s}}$ for Elastomeric Bearings 


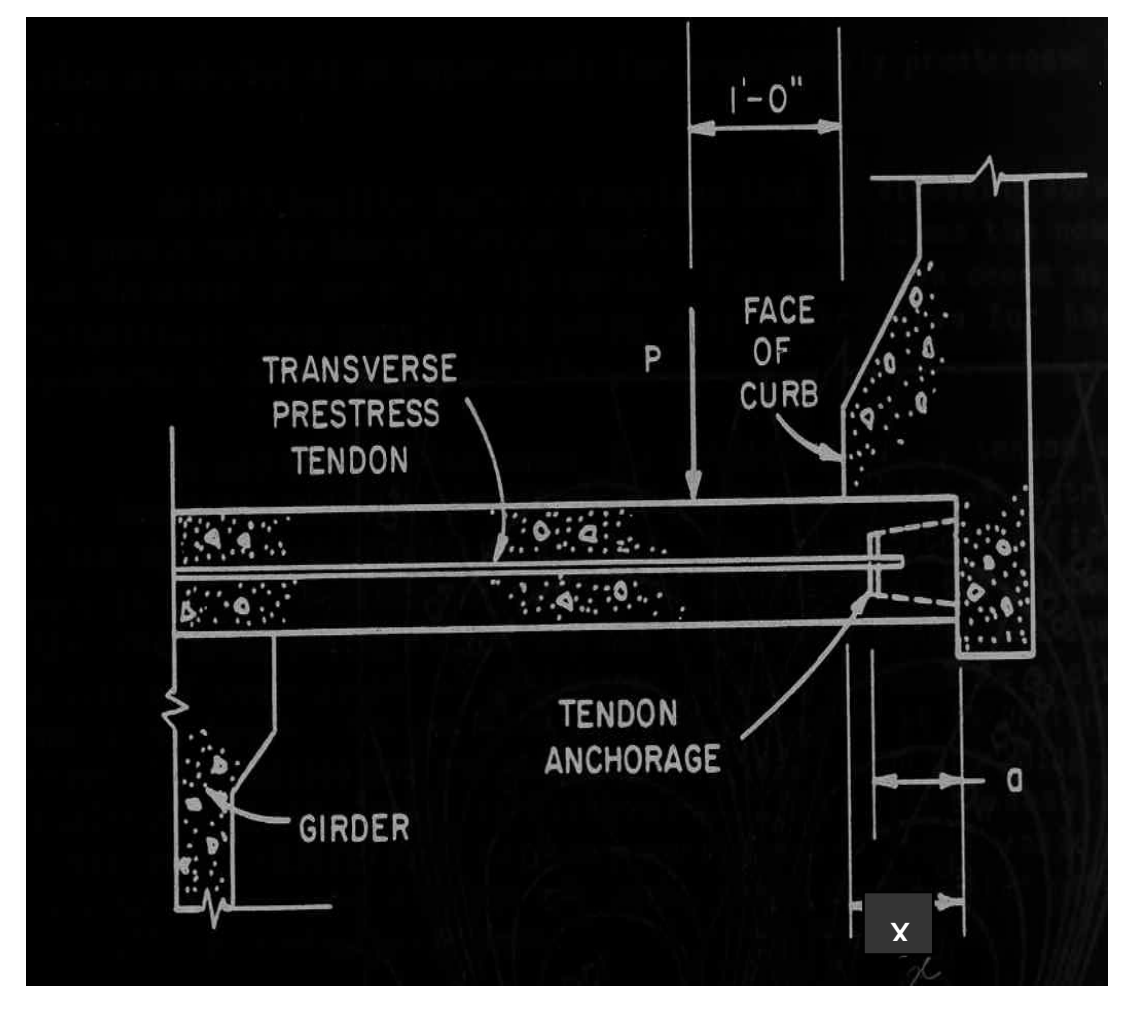

(a) Notation

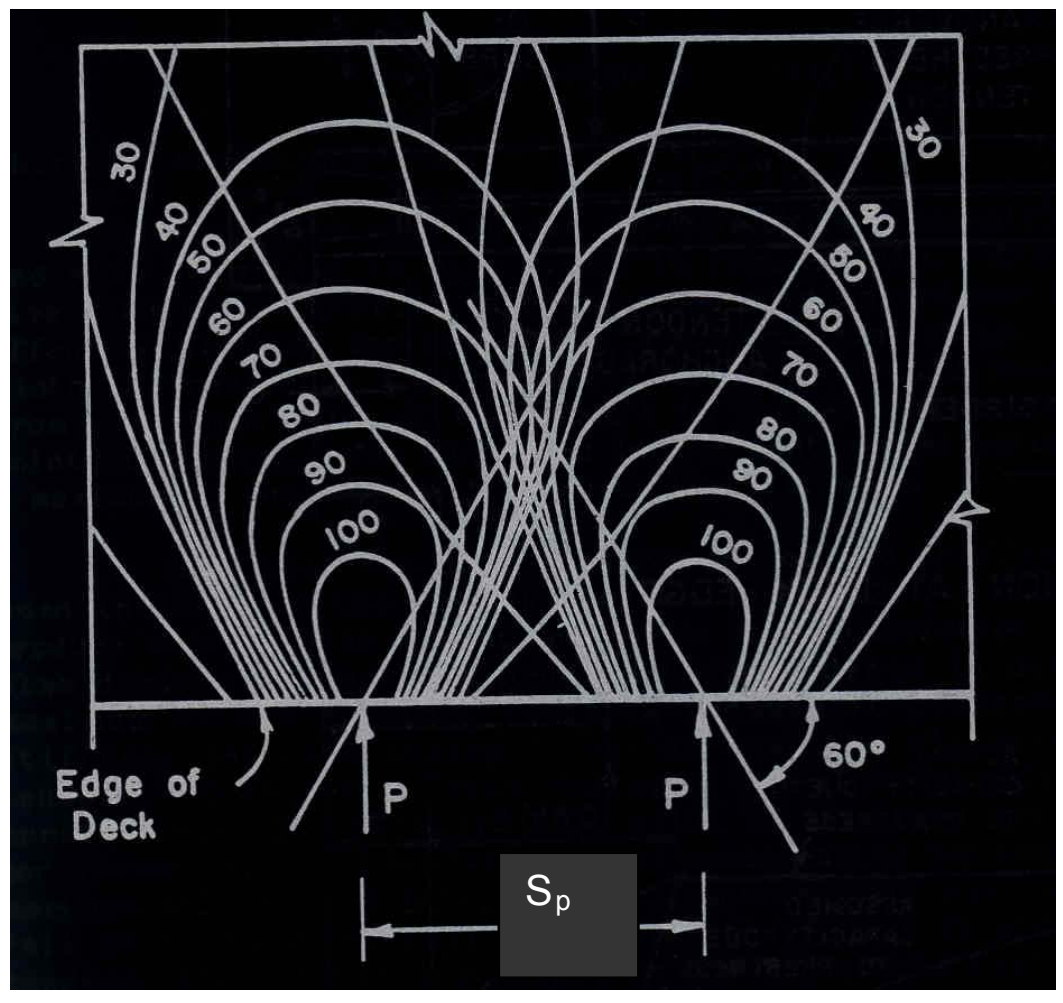

(b) Ineffective Stressed Region Between Adjacent Tendons at Edge of the Deck

Figure 5.12 Maximum Spacing of Post-tensioning Forces

(reproduced from Poston et al. (1985)) 


\section{6- Simplified Design Procedure for Use in INDOT -Detailed Description-}

A post-tensioning scheme is qualitatively shown in Figure 6.1 for a given span of a bridge superstructure. The distribution of applied transverse stresses is already normalized by the required compressive stress. In general, the boundary conditions at the girder ends are different; one end can be supported on elastomeric bearing pads or rocker bearings and, the other end integral with the abutment. Consequently, the extra-post-tensioning force factors are different also. A detailed (step-by-step) description of the simplified procedure is described in the next subsections. Some of the design aids presented in Chapter 5 will be repeated here to make the simplified design aids selfcontained. It is assumed that the girders' ends can be either nonintegral (then $K_{s}=200 \mathrm{kin} / \mathrm{in}$ is used) or integral with the abutments. Two different sets of aids are presented, the first set is applicable to deck on concrete girder bridges and the second set is applicable to deck on steel girder bridges.

\subsection{Deck on Concrete Girder Bridges, Design Aid Set 1 (Figures 6.2-6.4)}

\subsubsection{End (or Exterior Diaphragm) Region}

In order to compute $\alpha_{e}$ :

(a) If the end is integral, then select the width of the end region (i.e., the region where the extra-post-tensioning force will be applied) and use Figures 6.2.

(b) If elastomeric bearings support the girder (non-integral end), then use Figures 6.3 (a) to (c); select first the width of the exterior diaphragm region (i.e., the region where the extra-post-tensioning force will be applied) 
and then read $\left(\alpha_{e}\right)_{\text {basecase }}$ from Figure 6.3(a). Following this, read the ratio $\alpha_{e} /\left(\alpha_{e}\right)_{\text {base-case }}$ from Figure 6.3(b) based on the area of the exterior diaphragm. Finally, obtain the correction factor for exterior diaphragm position (with respect to the end of the girders) from Figure 6.3(c). The resulting value of $\alpha_{e}$ is obtained as the product of the ordinates read from Figures 6.3(a) to (c). No correction factor for skew angle is needed but if desired use the secant of the angle.

\subsubsection{Interior Diaphragm Region}

In order to compute $\alpha_{i}$ select first the interior diaphragm region width

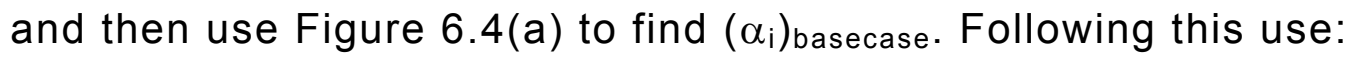

(a) Figure $6.4(\mathrm{~b})$ to find $\alpha_{i} /\left(\alpha_{i}\right)_{\text {basecase }}$ if one or both ends of the span under consideration are integral.

(b) Figure $6.4(\mathrm{c})$ to find $\alpha_{i} /\left(\alpha_{i}\right)_{\text {basecase }}$ if both ends are nonintegral.

The correction factor for skew angle is equal to the secant of the skew angle. The resulting value of $\alpha_{i}$ is obtained as the product of the ordinate read from Figure 6.4(a), the ordinate read from Figure 6.4(b) or 6.4(c) (whichever applies), and the secant of the skew angle.

\subsubsection{Intermediate Region}

At intermediate regions, (i.e., regions between consecutive diaphragm regions) the required normalized transverse stress is equal to the secant of the skew angle. 
6.2 Deck on Steel Girder Bridges, Design Aid Set 2 (Figures 6.5-6.7)

\subsubsection{End (or Exterior Diaphragm) Region}

In order to compute $\alpha_{e}$ :

(a) If the end is integral, then exterior diaphragms must be placed at not less than $6 \mathrm{ft}$ from the end of the deck. For a given position and size of exterior diaphragm use Figures 6.5 (a) to (c) to find $\alpha_{\mathrm{e}}$. Interpolation for exterior diaphragm positions not included in these Figures can be used. The exterior diaphragm region should extend three feet $(3 \mathrm{ft})$ beyond the position of the exterior diaphragm (see Figure 5.9).

(b) If rocker bearings support the girders (non-integral ends), then use Figures 6.6 (a) to (c); select first the width of the exterior diaphragm region (i.e., the region where the extra-post-tensioning force will be applied) and then read $\left(\alpha_{e}\right)_{\text {basecase }}$ from Figure 6.6(a). Following this, obtain the ratio $\alpha_{e} /\left(\alpha_{e}\right)_{\text {base-case }}$ from Figure $6.6(\mathrm{~b})$ based on the area of the exterior diaphragm. Finally, read the correction factor for exterior diaphragm position from Figure 6.6(c). The resulting value of $\alpha_{e}$ is obtained as the product of the ordinates read from Figures 6.6(a) to (c). No correction factor for skew angle is needed but if desired use the secant of the angle.

\subsubsection{Interior Diaphragm Region}

In order to compute $\alpha_{i}$ select first the width of the interior diaphragm

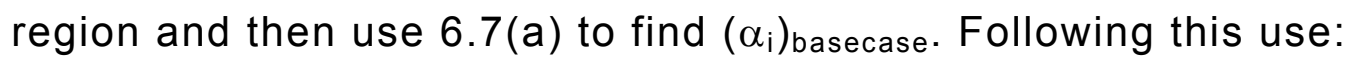

Figure $6.7(b)$ to find $\alpha_{i} /\left(\alpha_{i}\right)_{\text {basecase }}$ if one or both ends of the span under consideration are integral.. 
(b) Figure 6.7(c) to find $\alpha_{i} /\left(\alpha_{i}\right)_{\text {basecase }}$ if both ends are nonintegral.

The correction factor for skew angle is equal to the secant of the skew angle. The resulting value of $\alpha_{i}$ is obtained as the product of the ordinate read from Figure 6.7(a), the ordinate read from Figure 6.7(b) or 6.7(c) (whichever applies), and the secant of the skew angle.

\subsubsection{Intermediate Region}

At intermediate regions, (i.e., regions between consecutive diaphragm regions) the required normalized transverse stress is equal to the secant of the skew angle. 


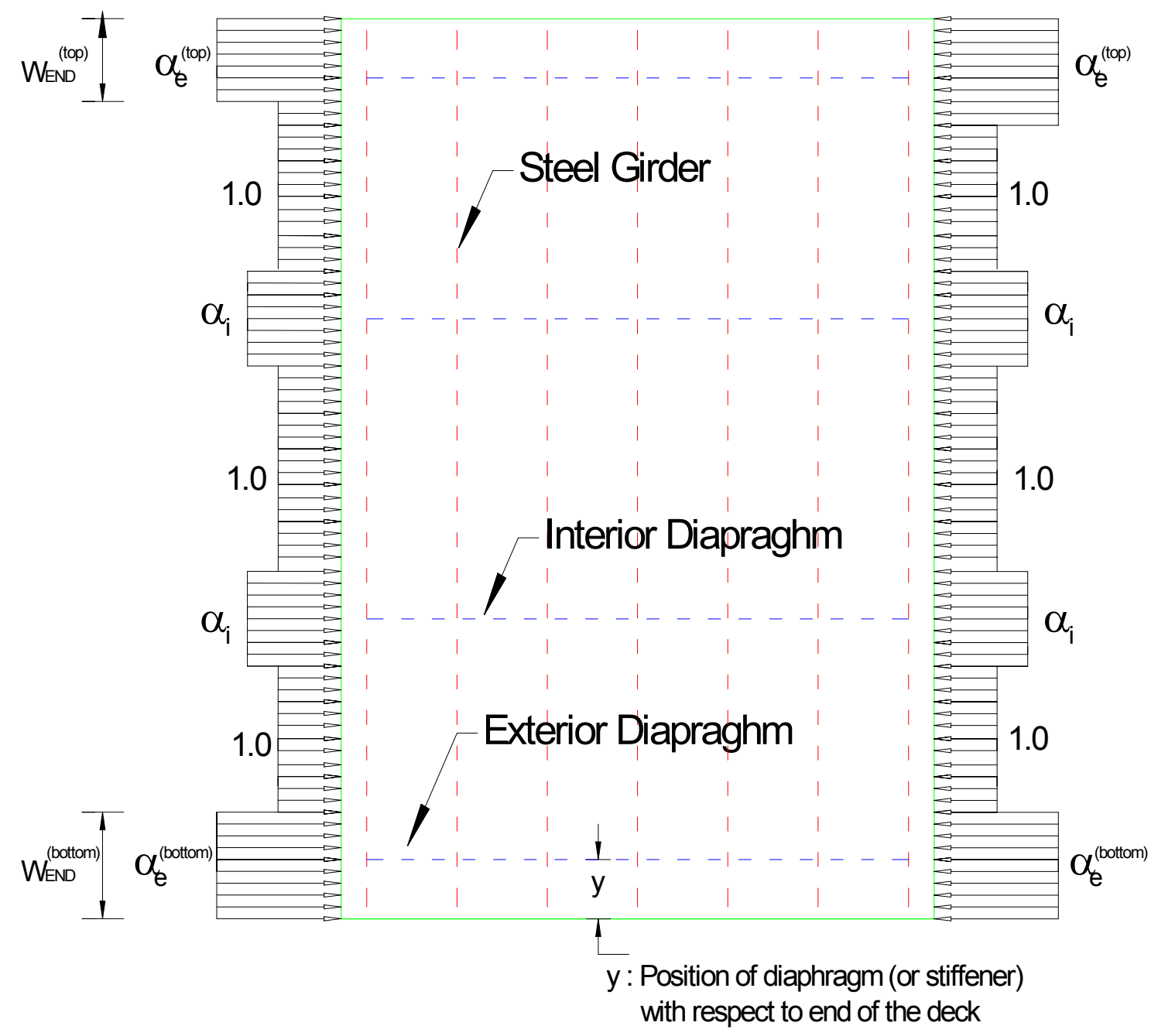

Figure 6.1 General Design Scheme 
Plot Set 1. Design Aids for Concrete Girder Bridges 


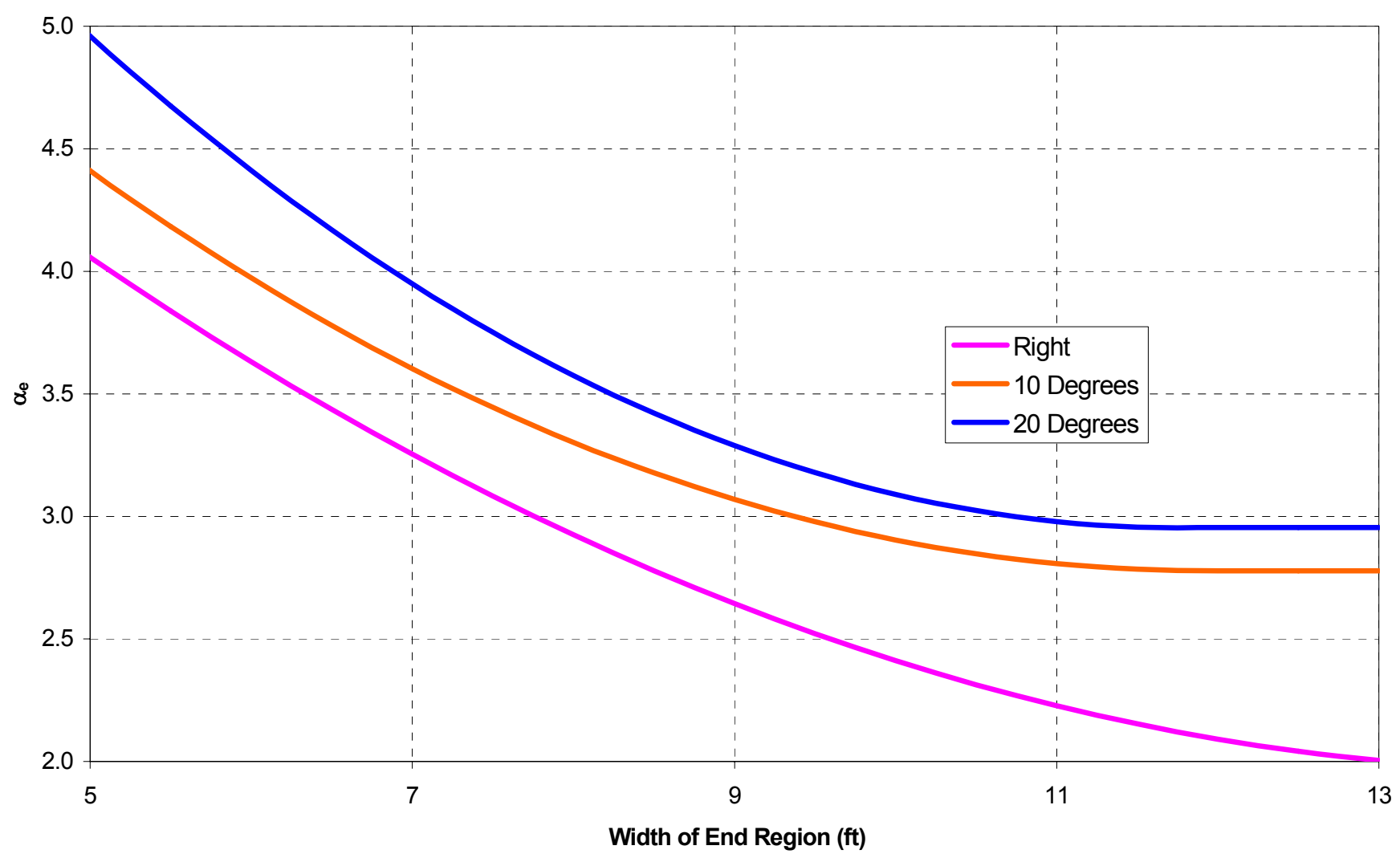

Figure 6.2 Extra Post-tensioning Force Factor for End Region. Integral End 
(a)

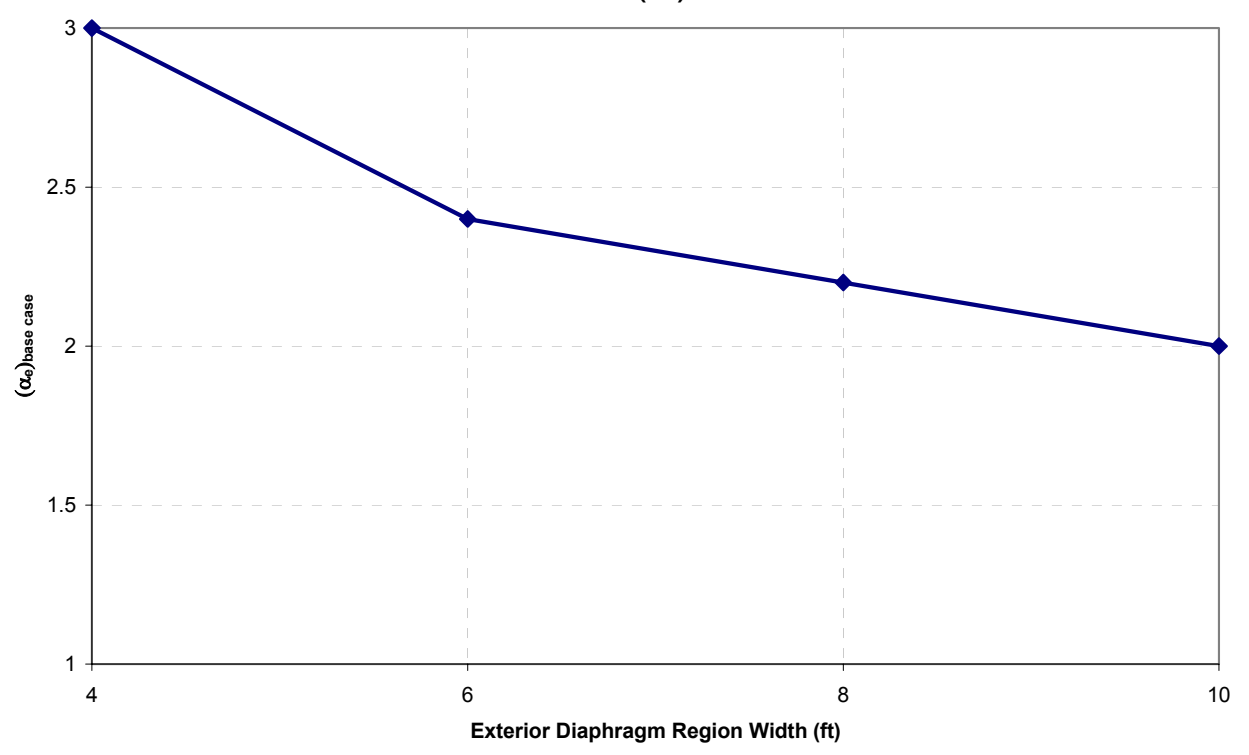

(b)

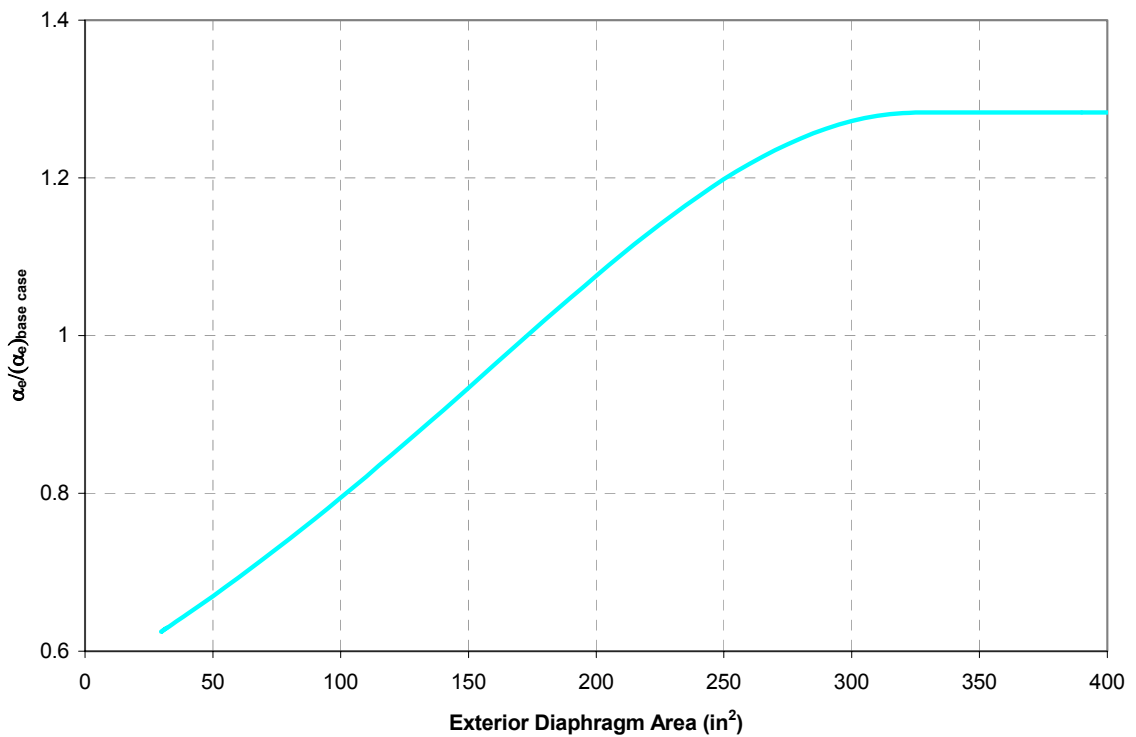

(c)

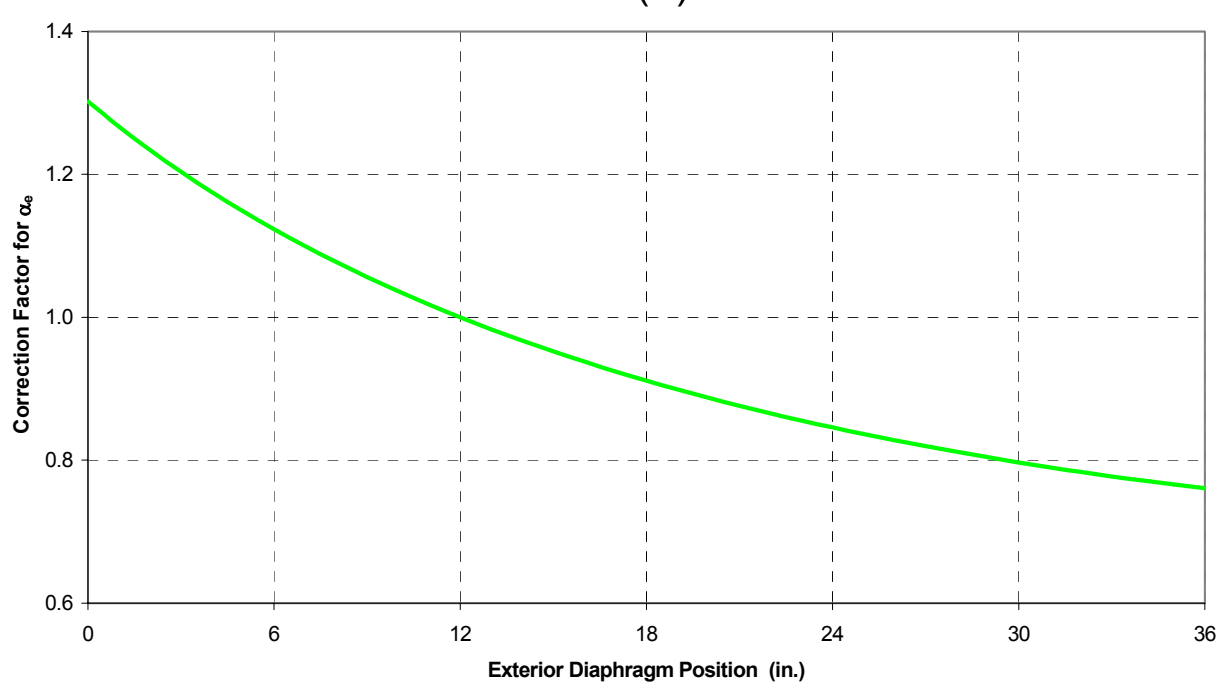

Exterior Diaphragm Position (in).

Figure 6.3 Extra Post-tensioning Force Factor for EndDiaphragm Region. Girders on Elastomeric Bearings 
(a)
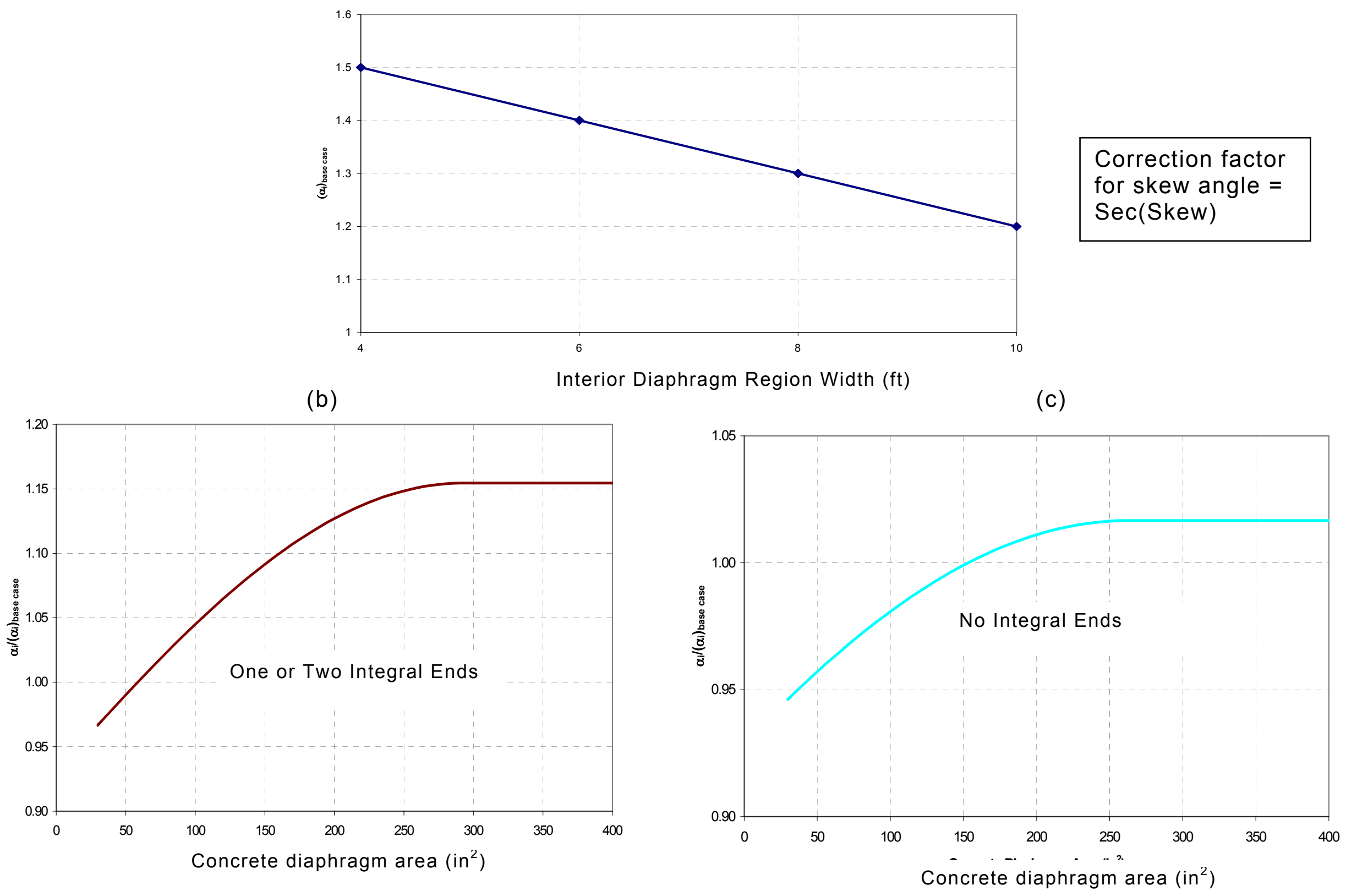

Figure 6.4 Extra Post-tensioning Force Factor for Interior Diaphragm Region:

(b) If one or both integral ends, (c) None integral ends 
Plot Set 2. Design Aids for Steel Girder Bridges 
(a) Exteriod diaphragm located at $6 \mathrm{ft}$ from end of deck

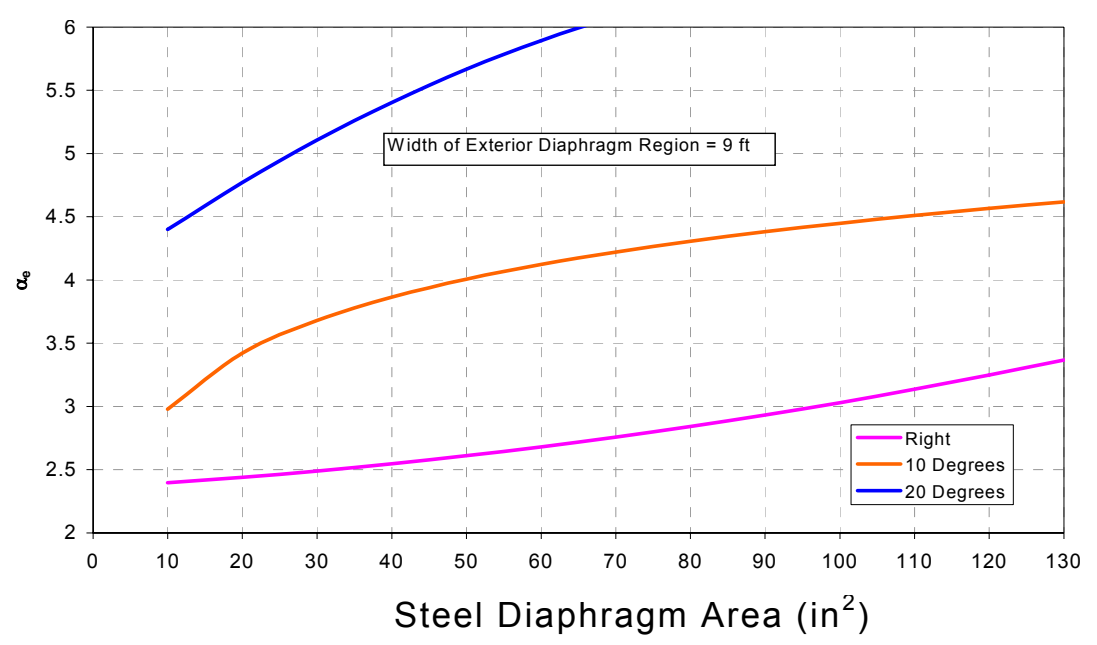

(a) Exteriod diaphragm located at $8 \mathrm{ft}$ from end of deck

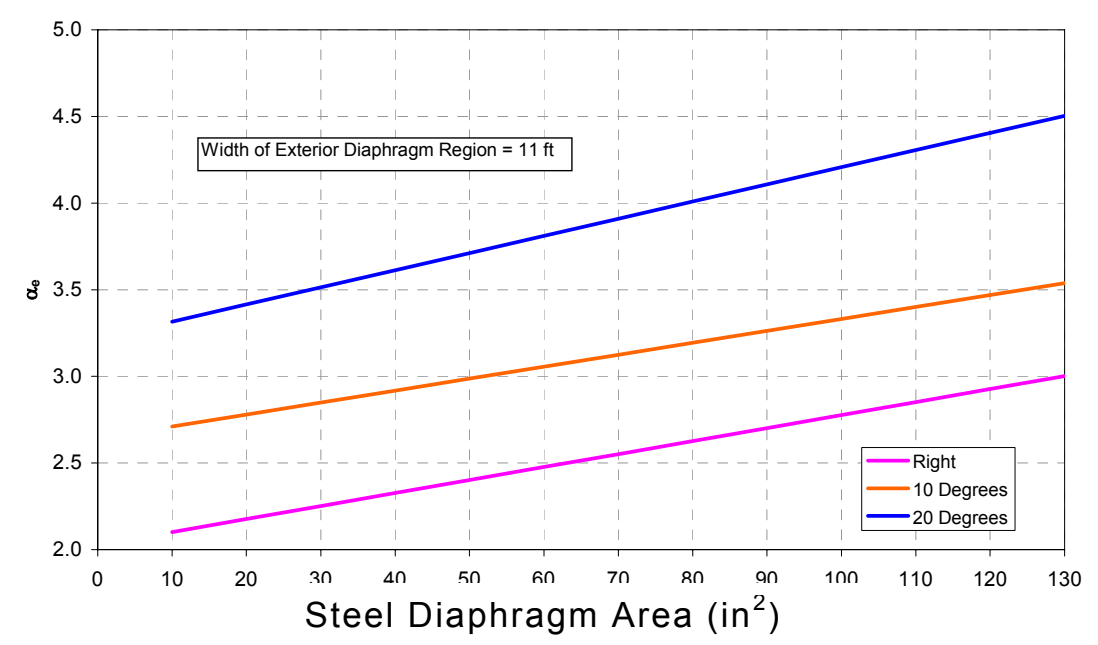

(a) Exteriod diaphragm located at $10 \mathrm{ft}$ from end of deck

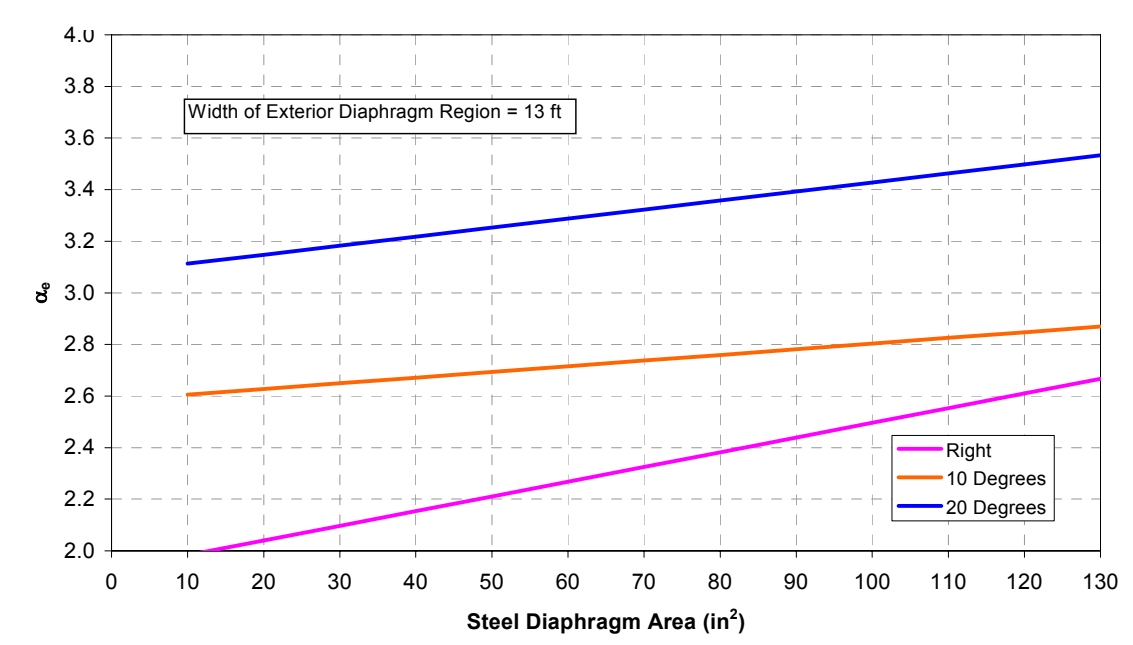

Figure 6.5 Extra Post-tensioning Force Factor for End Region. Integral End 
(a)

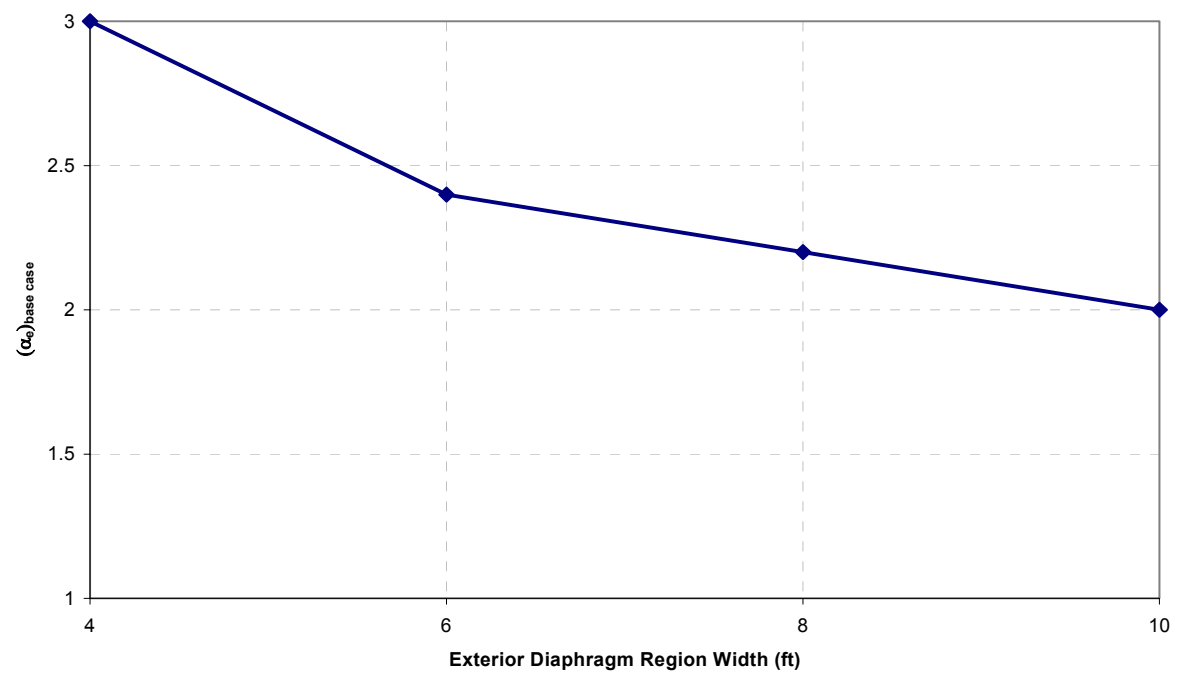

(b)

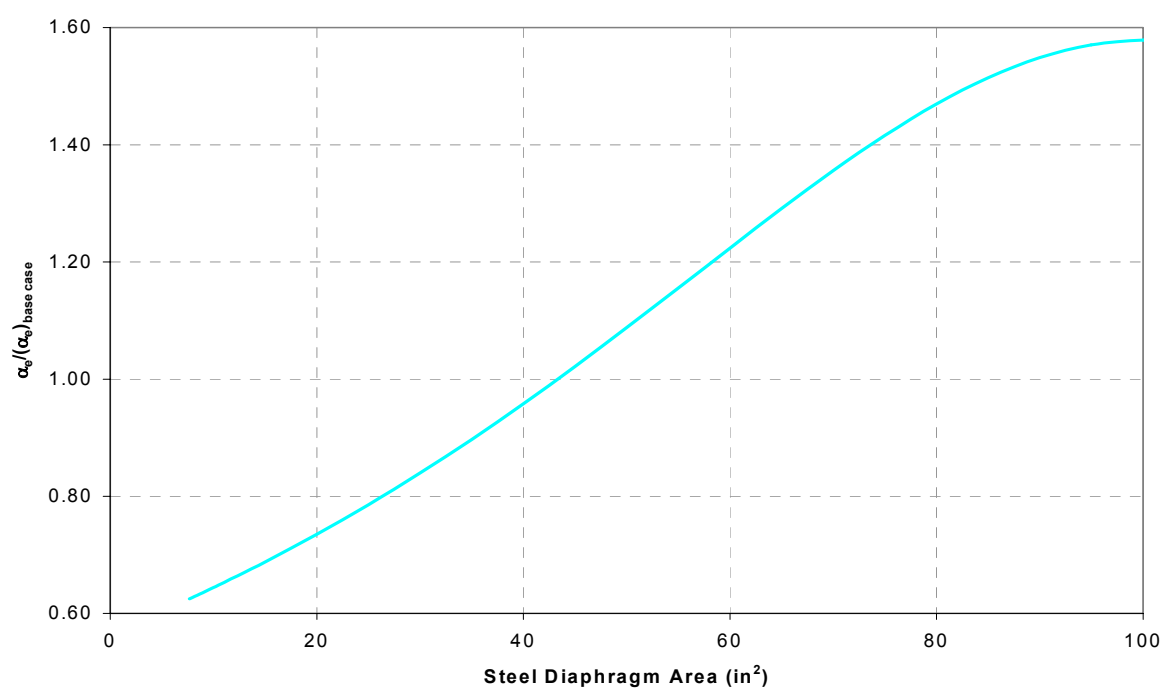

(c)

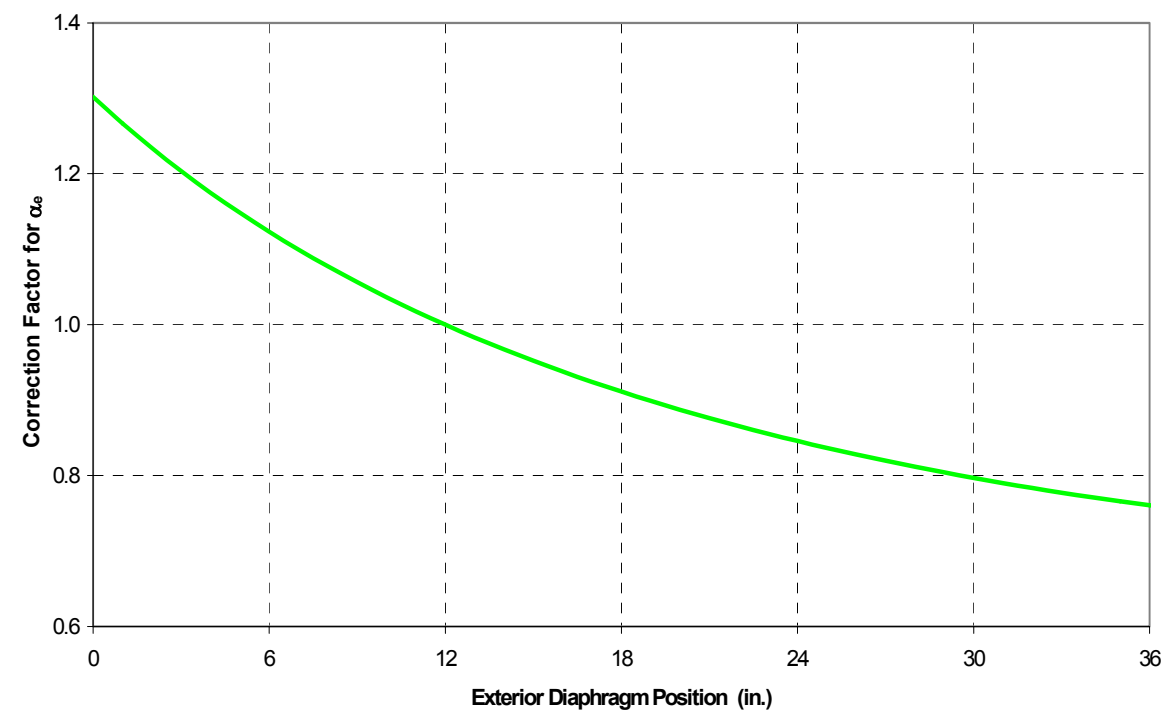

Figure 6.6 Extra Post-tensioning Force Factor for End Diaphragm Region. Girders on Flexible Steel Bearings 


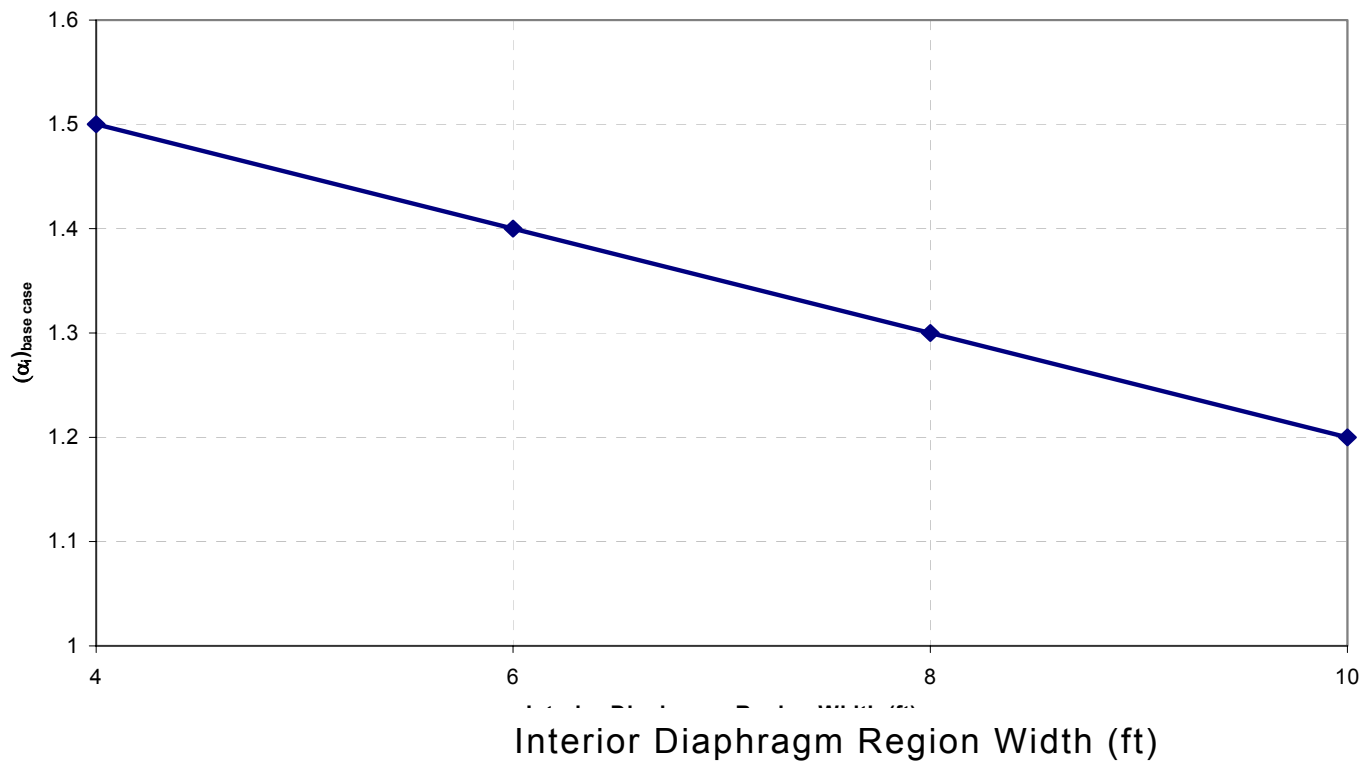

Correction factor for skew angle = Sec(Skew)
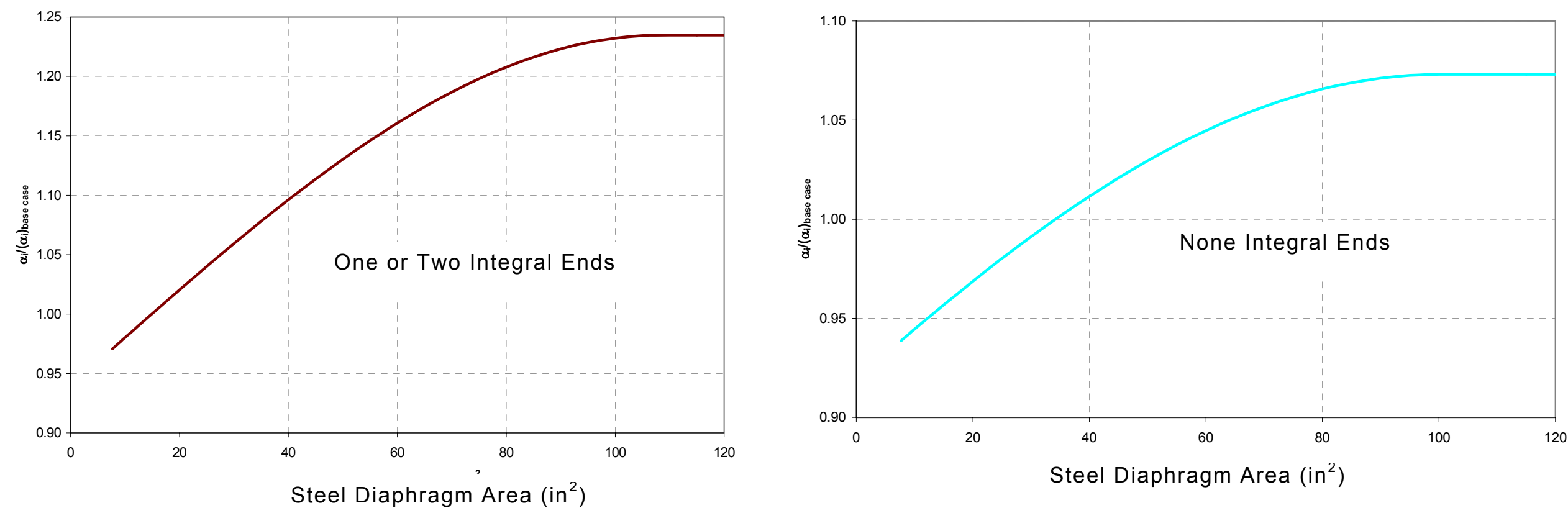

Figure 6.7 Extra Post-tensioning Force Factor for Interior Diaphragm Region:

(b) If one or both integral ends, (c) None integral ends 


\section{7- Examples and Verification of Design Guidelines}

The design of transverse post-tensioned bridge decks using the proposed simplified methodology is illustrated in this Chapter with three examples. Verification of the design specifications is carried out using 3D Type I F.E analyses with SAP2000 (see Chapter 3).

The design procedure for transversely post-tensioned decks is very similar to the procedure for reinforced concrete decks. The only departure from the conventional design procedure is the determination of the forces required to compensate for the restraining effects of: (i) axial stiffness of diaphragms, (ii) boundary conditions of the girders, (iii) diaphragm position, and (iv) skew angle. Design of the deck in the longitudinal direction is omitted, as it was outside the scope of the study. The calculation of the service loads is not rigorous in these examples because the intention is to illustrate the proposed methodology only.

\subsection{Design Example 1: Nonskew Bridge, Non-integral Girders' Ends}

Figure 7.1 shows an overall view of the bridge span to be transversely post-tensioned. Material and geometric properties of all the elements of the superstructure are also indicated.

\subsubsection{Interior Deck Span, S}

$\mathrm{S}=$ clear span $=$ girder spacing - girder flange width $=8.33-(11 / 12)=7.42 \mathrm{ft}$

\subsubsection{Service Loads}

(a) Dead Load Moment: assuming the density of the RC concrete as $0.15 \mathrm{kips} / \mathrm{ft}^{3}$, the dead moment is computed as: 
$M_{D}=0.15 \times(7 / 12) \times\left(7.42^{2} / 10\right)=0.48 \mathrm{kip}-\mathrm{ft} / \mathrm{ft}$

(b) Impact Factor:

$I=50 /(125+S)<0.3$ for $S=7.42 \mathrm{ft}, I=0.3$

(c) Live Load Moment: Assuming AASHTO HS20-44 loading, P = 16 kips

$M_{L}=(1+\mathrm{l}) \times 0.8 \times(S+2) \times P / 32=4.90 \mathrm{kip}-\mathrm{ft} / \mathrm{ft}$

(d) Total Service Moment:

$M_{T}=M_{D}+M_{L}=5.38 \mathrm{kip}-\mathrm{ft} / \mathrm{ft}$

\subsubsection{Required Force and Stress:}

Assuming that the limiting tensile stress for concrete under service load is equal to $4 \sqrt{f_{c}^{\prime}}$, the required transverse post-tensioning force, $F_{s}$, is obtained from:

$F_{s} /(12$ in. $x h)-M_{T} /\left(h^{2} / 6\right)=-4 \sqrt{f_{c}^{\prime}}$

Solving for $F_{s}: \quad F_{s}=31.6 \mathrm{kips} / \mathrm{ft}$

The required compressive stress from axial transverse post-tensioning: $\sigma_{\mathrm{T}}=31.6 /(12 \times 7)=0.38 \mathrm{ksi}$ 


\subsubsection{Normalized Distribution of Transverse Post-tensioning Force}

\section{At Exterior Diaphragm Region:}

- Select exterior diaphragm region width $=8 \mathrm{ft}$

- From Figure 6.6 (a) read: $\left(\alpha_{\mathrm{e}}\right)_{\text {basecase }}=2.2$

- With Steel Diaphragm Area $=12.5 \mathrm{in}^{2}$ read from Figure 6.6(b): $\alpha_{e} /\left(\alpha_{e}\right)_{\text {basecase }}=0.67$

- For diaphragm position $=6$ in. (see Figure 7.1), read correction factor from Figure 6.6 (c) $=1.12$

- Then; $\alpha_{e}=2.2 \times 0.67 \times 1.12=1.65$

\section{At Interior Diaphragm Regions}

- Select interior diaphragm region width $=6 \mathrm{ft}$

- From Figure 6.7(a) read: $\left(\alpha_{i}\right)_{\text {basecase }}=1.4$

- With Steel Diaphragm Area $=13.3 \mathrm{in}^{2}$ read from Figure 6.7(c): $\alpha_{i} /\left(\alpha_{i}\right)_{\text {basecase }}=0.96$

- Then; $\alpha_{i}=1.4 \times 0.96=1.34$

\section{At Intermediate regions}

- Normalized stress $=1$

\subsubsection{Distribution of Transverse Post-tensioning}

The required distribution of transverse post-tensioning force is obtained multiplying the normalized values (obtained in 7.1.4) by $F_{s}$ (or by $\sigma_{\mathrm{T}}$ if the required distribution is given terms of transverse stresses) as illustrated in Figure 7.2

\subsubsection{Check Compression Stress on Deck}

The maximum compression stress from the transverse posttensioning is approximately given by: 
$\alpha_{\mathrm{e}} \times \sigma_{\mathrm{T}}=0.63 \mathrm{ksi}$

The maximum compression stress from service load is: $\mathrm{M}_{\mathrm{T}} /\left(\mathrm{h}^{2} / 6\right)=0.66 \mathrm{ksi}$

Maximum compression $=0.63 \mathrm{ksi}+0.66 \mathrm{ksi}=1.29 \mathrm{ksi}$ which is less than an allowable compression stress, say, $0.6 \mathrm{xf}_{\mathrm{c}}{ }_{\mathrm{C}}=3.0 \mathrm{ksi}$.

\subsubsection{Resulting Transverse Stresses from Post-tensioning-Verification} of Design Aids-

A Finite Element Analysis of this structure was carried out using SAP2000. The loading consists of the transverse post-tensioning illustrated in Figure 7.2 only. A contour map of the distribution of transverse stresses normalized by the required compressive stress from post-tensioning $\left(\sigma_{\mathrm{T}}=0.38 \mathrm{ksi}\right)$ is shown in Figure 7.3. It is noticed that the minimum normalized transverse stress equals 0.84 at the end regions (also absolute minimum in the entire deck) and 1.16 at interior diaphragm regions. The normalized minimum transverse stresses, 0.85 and 1.16 , are reasonably close to the target values; 0.8 and 1.0 .

\subsection{Design Example 2: End Span of a Multi-Span Integral-Bent Steel Girder Bridge}

Figure 7.4 shows an overall view of the bridge span to be transversely post-tensioned. It is assumed that the top ends of the

girders are integral with the abutments whereas the bottom ends are supported on flexible steel bearings. Material and geometric properties of all the elements of the superstructure are also indicated.

\subsubsection{Interior Deck Span, S}

$\mathrm{S}=$ clear span $=$ girder spacing - girder flange width $=8.83-(15.75 / 12)=7.52 \mathrm{ft}$ 


\subsubsection{Service loads}

(a) Dead Load Moment: assuming the density of the RC concrete as $0.15 \mathrm{kips} / \mathrm{ft}^{3}$, the dead moment is computed as:

$M_{D}=0.15 \times(8.25 / 12) \times\left(7.52^{2} / 10\right)=0.58 \mathrm{kip}-\mathrm{ft} / \mathrm{ft}$

(b) Impact Factor:

$I=50 /(125+S)<0.3$ for $S=7.52 \mathrm{ft}, I=0.3$

(c) Live Load Moment: Assuming AASHTO HS20-44 loading, P = 16 kips:

$M_{L}=(1+I) \times 0.8 \times(S+2) \times P / 32=4.95 \mathrm{kip}-\mathrm{ft} / \mathrm{ft}$

(d) Total Service Moment:

$M_{T}=M_{D}+M_{L}=5.53 \mathrm{kip}-\mathrm{ft} / \mathrm{ft}$

\subsubsection{Required Force and Stress:}

Assuming that the limiting tensile stress under service load is equal to $4 \sqrt{\mathrm{f}_{\mathrm{c}}^{\prime}}$, the required transverse post-tensioning force, $F_{\mathrm{s}}$, is obtained from:

$F_{s} /(12$ in. $x h)-M_{T} /\left(h^{2} / 6\right)=-4 \sqrt{f_{c}^{\prime}}$

Solving for $F_{s}: \quad F_{s}=20.3 \mathrm{kips} / \mathrm{ft}$ 
Required compressive stress from transverse post-tensioning: $\sigma_{\mathrm{T}}=20.3 /(12 \times 8.25)=0.20 \mathrm{ksi}$

\subsubsection{Normalized Distribution of Transverse Post-tensioning Force}

\section{At Exterior Diaphragm Region (Bottom of Figure 7.4):}

- Select exterior diaphragm region width $=7 \mathrm{ft}$

- From Figure 6.6 (a) read: $\left(\alpha_{\mathrm{e}}\right)_{\text {basecase }}=2.3$

- With Steel Diaphragm Area $=11 \mathrm{in}^{2}$ read from Figure 6.6(b): $\alpha_{\mathrm{e}} /\left(\alpha_{\mathrm{e}}\right)_{\text {basecase }}=0.65$

- For diaphragm position $=12$ in. (see Figure 7.4 ), read correction factor from Figure 6.6 (c) $=1.0$

- Then; $\alpha_{e}{ }^{(\text {bottom })}=2.3 \times 0.65 \times 1.0=1.50$

\section{At Integral End (Top of Figure 7.4)}

- For exterior diaphragm position $=8 \mathrm{ft}$ and Steel Diaphragm Area $=11 \mathrm{in}^{2}$ read from Figure 6.5(b): $\alpha_{e}{ }^{(\text {top })}=2.1$

- The width of the exterior diaphragm region should be equal to diaphragm position $(=8 \mathrm{ft})+3 \mathrm{ft}=11 \mathrm{ft}$.

\section{At Interior Diaphragm Regions}

- Select interior diaphragm region width $=6 \mathrm{ft}$

- From Figure 6.7(a) read: $\left(\alpha_{i}\right)_{\text {basecase }}=1.4$

- With Steel Diaphragm Area $=11 \mathrm{in}^{2}$ read from Figure $6.7(b): \alpha_{i} /\left(\alpha_{i}\right)_{\text {basecase }}=0.97$

- Then; $\alpha_{i}=1.4 \times 0.96=1.36$

\section{At Intermediate Regions}

- Normalized stress $=1$ 


\subsubsection{Distribution of Transverse Post-tensioning}

The resulting required distribution of transverse post-tensioning force is obtained multiplying the normalized values (obtained in 7.2.4) by $F_{\mathrm{s}}$ (or by $\sigma_{\mathrm{T}}$ if the distribution is given terms of transverse stresses) as illustrated in Figure 7.5.

\subsubsection{Check Compression Stress on Deck}

The maximum compression stress from the transverse posttensioning is approximately given by:

$\alpha_{\mathrm{e}}{ }^{\text {(top) }} \times \sigma_{\mathrm{T}}=0.43 \mathrm{ksi}$

The maximum compression stress from service load is: $\mathrm{M}_{\mathrm{T}} /\left(\mathrm{h}^{2} / 6\right)=0.49 \mathrm{ksi}$

Maximum compression $=0.43 \mathrm{ksi}+0.49 \mathrm{ksi}=0.92 \mathrm{ksi}$ which is less than the allowable compression stress, say, $0.60 \mathrm{xf}_{\mathrm{c}}=3.0 \mathrm{ksi}$.

7.2.7 Resulting Transverse Stresses from Post-tensioning-Verification of Design Aids-

A Finite Element Analysis of this structure was carried out using SAP2000. The loading consists of the transverse post-tensioning illustrated in Figure 7.5. A contour map of the distribution of transverse stresses normalized by the required compressive stress from Posttensioning $\left(\sigma_{\mathrm{T}}=0.20 \mathrm{ksi}\right)$ is shown in Figure 7.6. It is noticed that the minimum normalized transverse stress equals 1.04 at the end diaphragm region and 1.05 at interior diaphragm regions. It is also noticed that the width of the "ineffective stripe" at the top end of the deck (i.e., region where the normalized transverse stresses are smaller than 0.8 ) has a width of about $3 \mathrm{ft}$. The normalized values of minimum stresses, 1.04 and 1.05, are reasonably (and conservatively) close to the target values, 0.8 and 1.0. On the other hand, the width of the ineffective stripe region equals the target value of $3 \mathrm{ft}$. 


\subsection{Design Example 3: End Span of a Multi-Span Integral-Bent Skewed Concrete Girder Bridge}

Figure 7.7 shows an overall view of the bridge span to be transversely post-tensioned. It is assumed one ends of the girders are integral with the abutments whereas the other ends are supported on elastomeric bearing pads. Material and geometric properties of all the elements of the superstructure are also indicated.

\subsubsection{Interior Deck Span, S}

$\mathrm{S}=$ clear span $=$ girder spacing - girder flange width $=8.0-(14 / 12)=6.83 \mathrm{ft}$

\subsubsection{Service loads}

(a) Dead Load Moment: assuming the density of the RC concrete as $0.15 \mathrm{kips} / \mathrm{ft}^{3}$, the dead moment is computed as:

$M_{D}=0.15 \times(8.25 / 12) \times\left(6.83^{2} / 10\right)=0.48 \mathrm{kip}-\mathrm{ft} / \mathrm{ft}$

(b) Impact Factor:

$I=50 /(125+S)<0.3$ for $S=6.83 \mathrm{ft}, I=0.3$

(c) Live Load Momen; Assuming AASHTO HS20-44 loading, P = 16 kips:

$M_{L}=(1+\mathrm{l}) \times 0.8 \times(S+2) \times P / 32=4.59 \mathrm{kip}-\mathrm{ft} / \mathrm{ft}$

(d) Total Service Moment: 


$$
M_{T}=M_{D}+M_{L}=5.07 \text { kip-ft/ft }
$$

\subsubsection{Required Force and Stress:}

Assuming that the limiting tensile stress under service load is equal to $4 \sqrt{f_{c}^{\prime}}$, the required transverse post-tensioning force, $F_{s}$, is obtained from:

$F_{s} /(12$ in. $x h)-M_{T} /\left(h^{2} / 6\right)=-4 \sqrt{f_{c}^{\prime}}$

Solving for $F_{s}: \quad F_{s}=16.2 \mathrm{kips} / \mathrm{ft}$

Required compressive stress from Post-tensioning:

$\sigma_{\mathrm{T}}=16.2 /(12 \times 8.25)=0.16 \mathrm{ksi}$

\subsubsection{Normalized Distribution of Transverse Post-tensioning Force}

\section{At Exterior Diaphragm Region (Bottom of Figure 7.7):}

- Select exterior diaphragm region width $=6.5 \mathrm{ft}$

- From Figure 6.3 (a) read: $\left(\alpha_{e}\right)_{\text {basecase }}=2.35$

- With Concrete Diaphragm Area $=200 \mathrm{in}^{2}$ read from

Figure $6.3(b): \alpha_{e} /\left(\alpha_{e}\right)_{\text {basecase }}=1.06$

- For diaphragm position $=36$ in. (see Figure 7.7), read Correction factor from Figure 6.3 (c) $=0.76$

- No need of correction for skew angle.

- Then; $\alpha_{e}{ }^{\text {(bottom })}=2.35 \times 1.06 \times 0.76=1.89$

\section{At Integral End (Top of Figure 7.7)}

- Select width of the end diaphragm region $=11 \mathrm{ft}$. Then for skew angle of 20 degrees, read from Figure 6.2: $\alpha_{e}{ }^{(\text {top })}=3$ 


\section{At Interior Diaphragm Regions}

- Select interior diaphragm region width $=6 \mathrm{ft}$

- From Figure 6.4(a) read: $\left(\alpha_{i}\right)_{\text {basecase }}=1.4$

- With Concrete Diaphragm Area $=200 \mathrm{in}^{2}$ read from

Figure 6.4(b): $\alpha_{i} /\left(\alpha_{i}\right)_{\text {basecase }}=1.12$

- Correction factor for skew $=\sec ($ skew $)=\sec \left(20^{\circ}\right)=1.06$

- Then; $\alpha_{i}=1.4 \times 1.12 \times 1.06=1.66$

\section{At Intermediate regions}

- Normalized stress $=\sec ($ skew $)=\sec \left(20^{\circ}\right)=1.06$

\subsubsection{Distribution of Transverse Post-tensioning}

The required distribution of transverse post-tensioning force is obtained multiplying the normalized values (obtained in 7.2.4) by $F_{s}$ (or by $\sigma_{\mathrm{T}}$ if the distribution is given terms of transverse stresses) as illustrated in Figure 7.8.

\subsubsection{Check Compression Stress on Deck}

The maximum compression stress from the transverse posttensioning is given by:

$\alpha_{\mathrm{e}}{ }^{\text {(top) }} \times \sigma_{\mathrm{T}}=0.48 \mathrm{ksi}$

The maximum compression stress from service load is: $\mathrm{M}_{\mathrm{T}} /\left(\mathrm{h}^{2} / 6\right)=0.45 \mathrm{ksi}$

Maximum compression $=0.48 \mathrm{ksi}+0.45 \mathrm{ksi}=0.93 \mathrm{ksi}$ which is less than the allowable compression stress, say, $0.45 \mathrm{x}{ }^{\prime}{ }_{c}=3.0 \mathrm{ksi}$.

\subsubsection{Resulting Transverse Stresses from Post-tensioning-Verification} of Design Aids-

A Finite Element Analysis of this structure was carried out using SAP2000. The loading consists of the transverse post-tensioning 
illustrated in Figure 7.8. A contour map of the distribution of transverse stresses normalized by the required compressive stress from Posttensioning $\left(\sigma_{\mathrm{T}}=0.16 \mathrm{ksi}\right)$ is shown in Figure 7.9 . It is noticed that the minimum normalized transverse stress equals 0.93 at the end diaphragm region and 1.05 at interior diaphragm regions. It is also noticed that the width of the "ineffective stripe" at the top end of the deck (i.e., region where the normalized transverse stresses are smaller than 0.8 ) has a width of about $3.5 \mathrm{ft}$. The normalized values of minimum stresses, 0.93 and 1.05, are reasonably (and conservatively) close to the target values, 0.8 and 1.0. On the other hand, the width of the ineffective stripe region is close to the target value of $3 \mathrm{ft}$. 


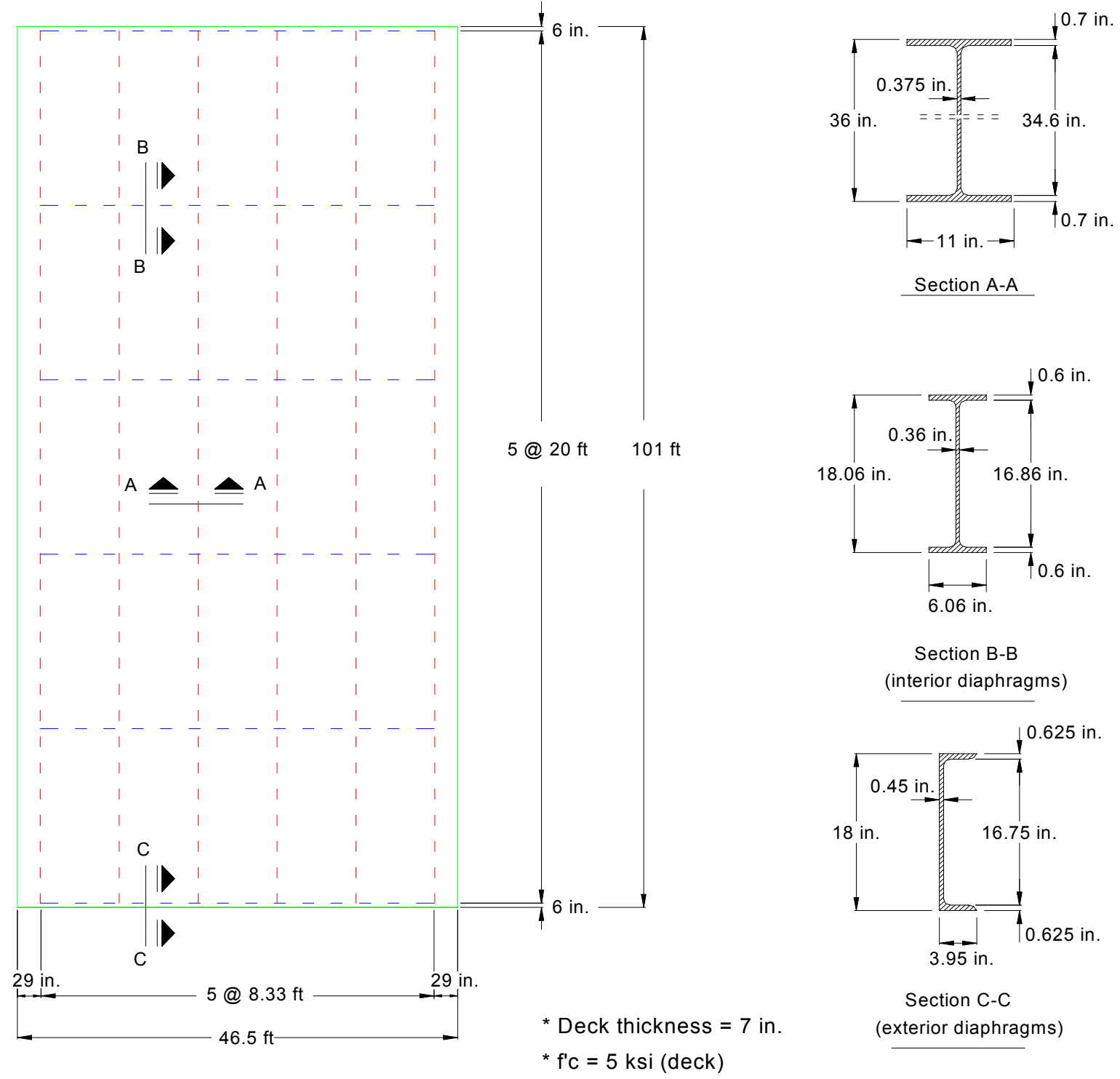

* Prestressing is symmetrical on both edges of the span.

Figure 7.1 Overall View of Bridge Span of Example 1 


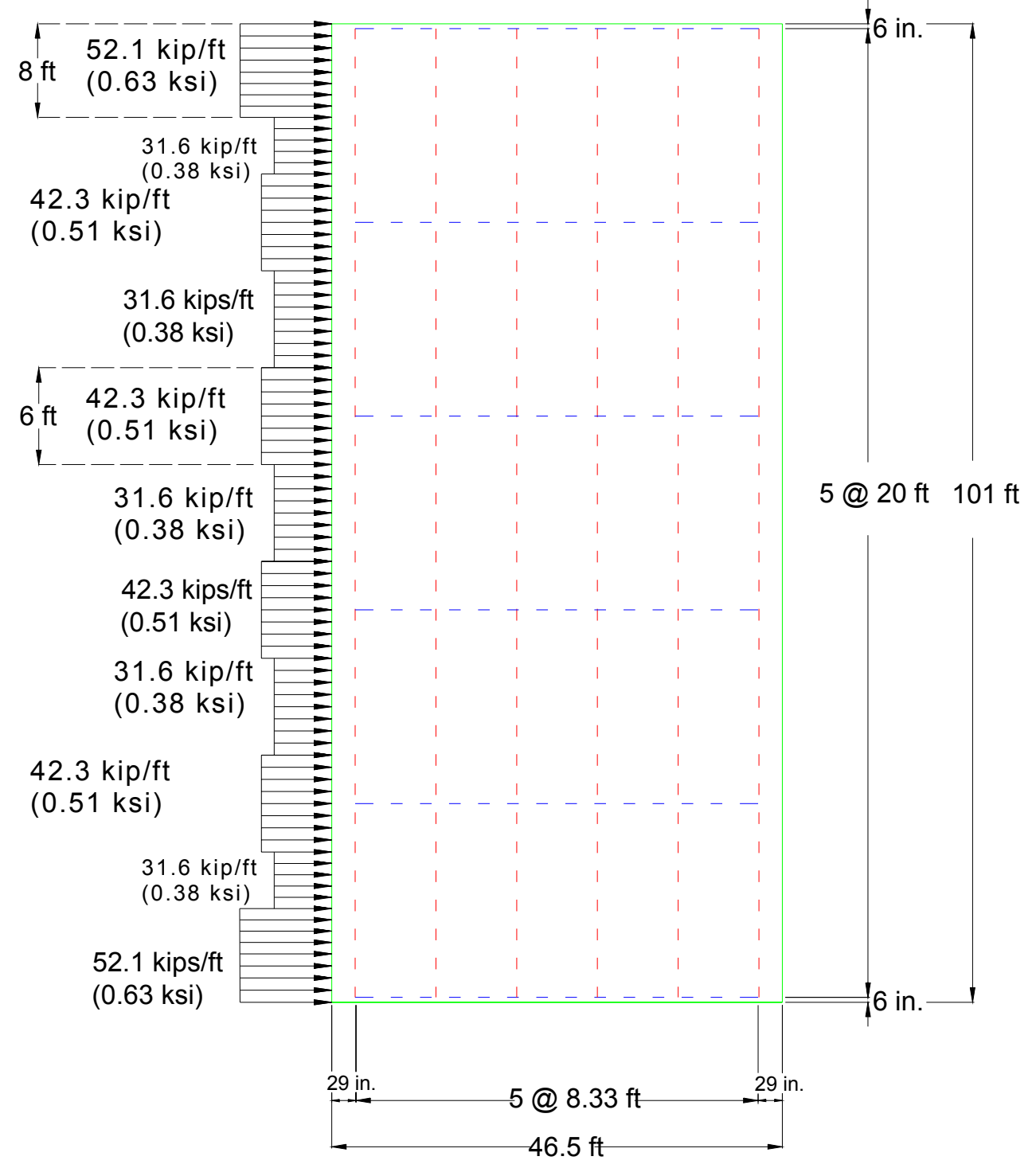

* Prestressing is symmetrical on both edges of the span.

Figure 7.2 Required Distribution of Transverse Post-tensioning for Example 1 


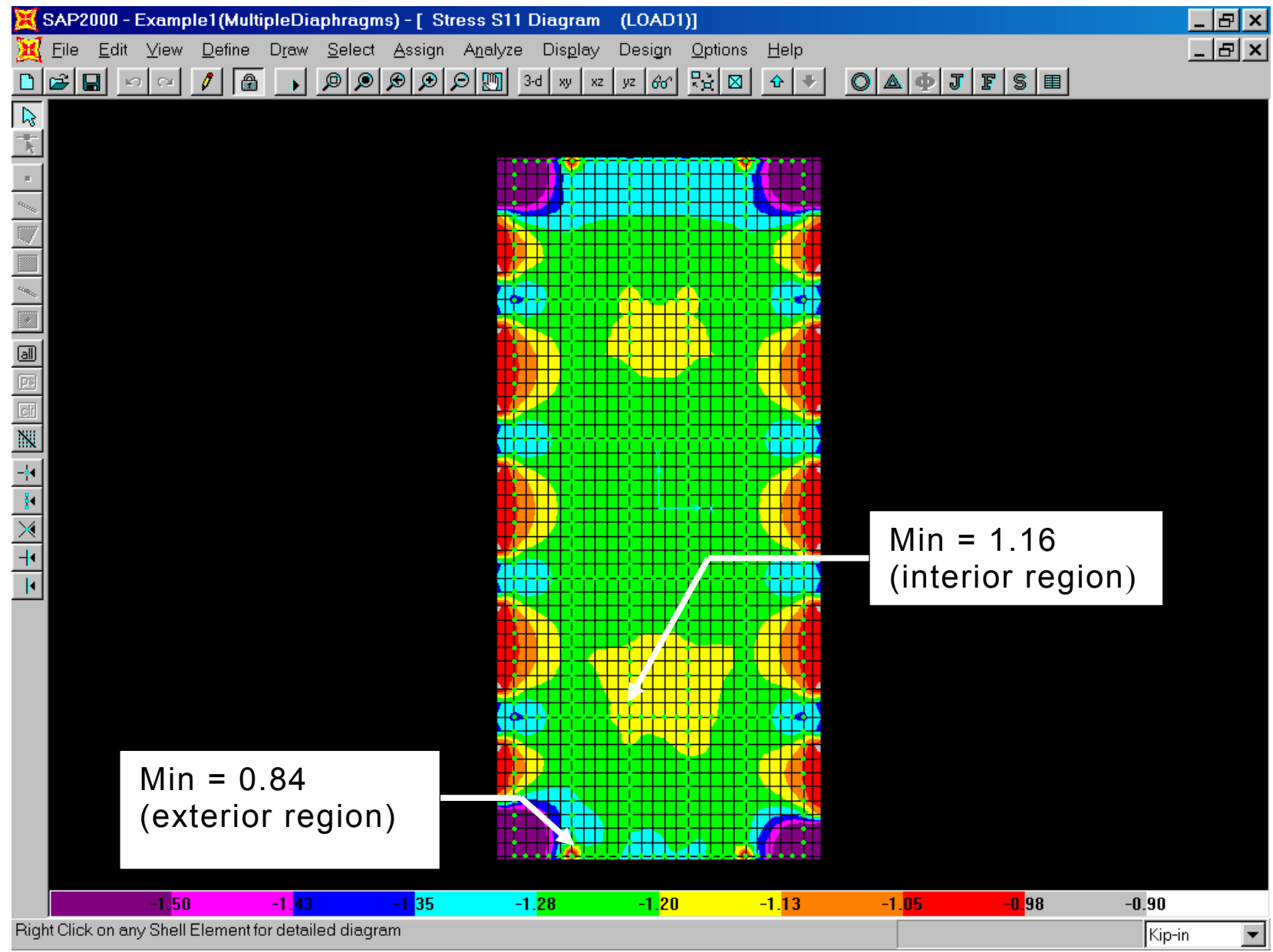

Figure 7.3 Distribution of Normalized Transverse Stresses on the Deck of Example 1 (Analysis using SAP2000) 


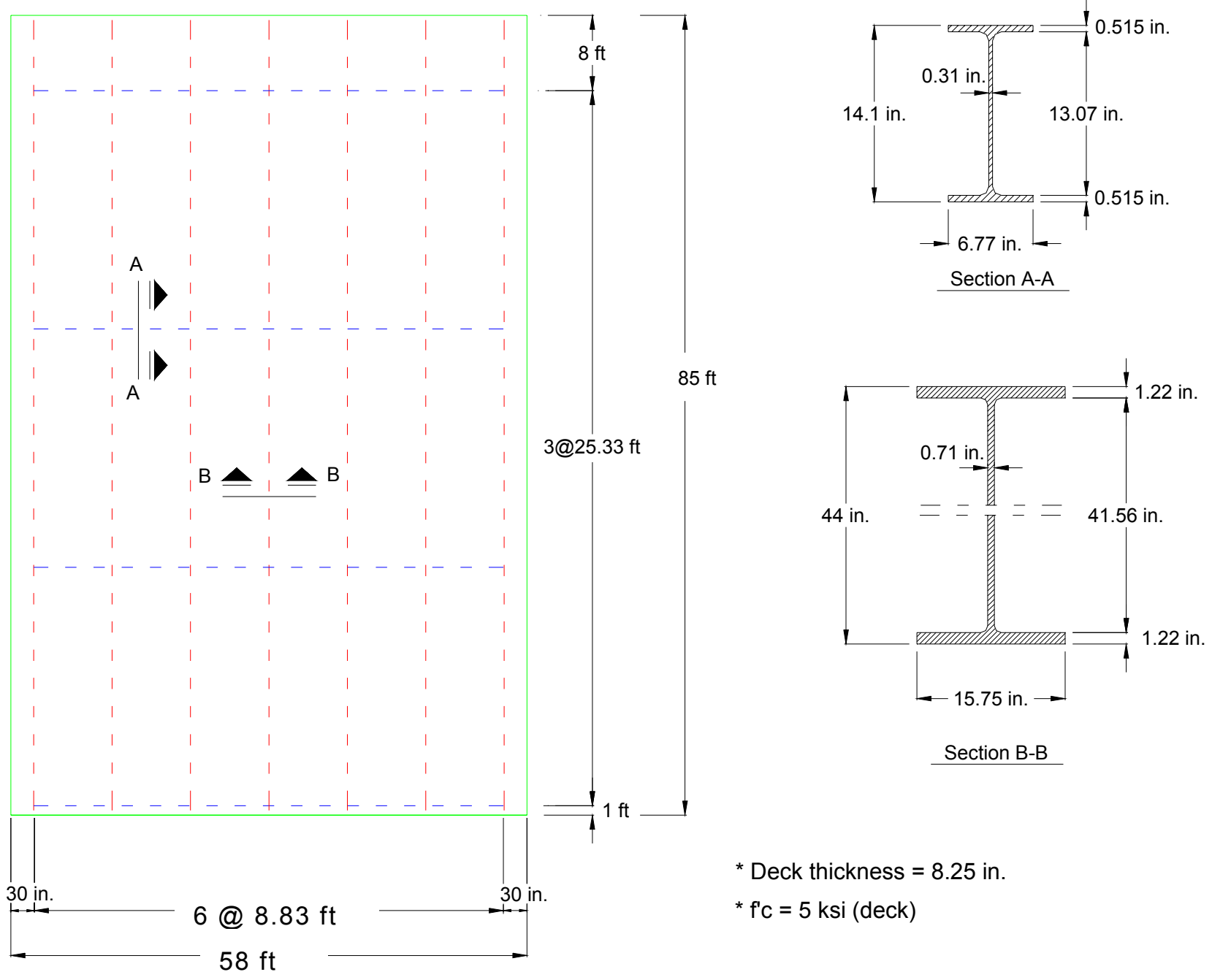

Figure 7.4 Overall View of Bridge Span of Example 2 


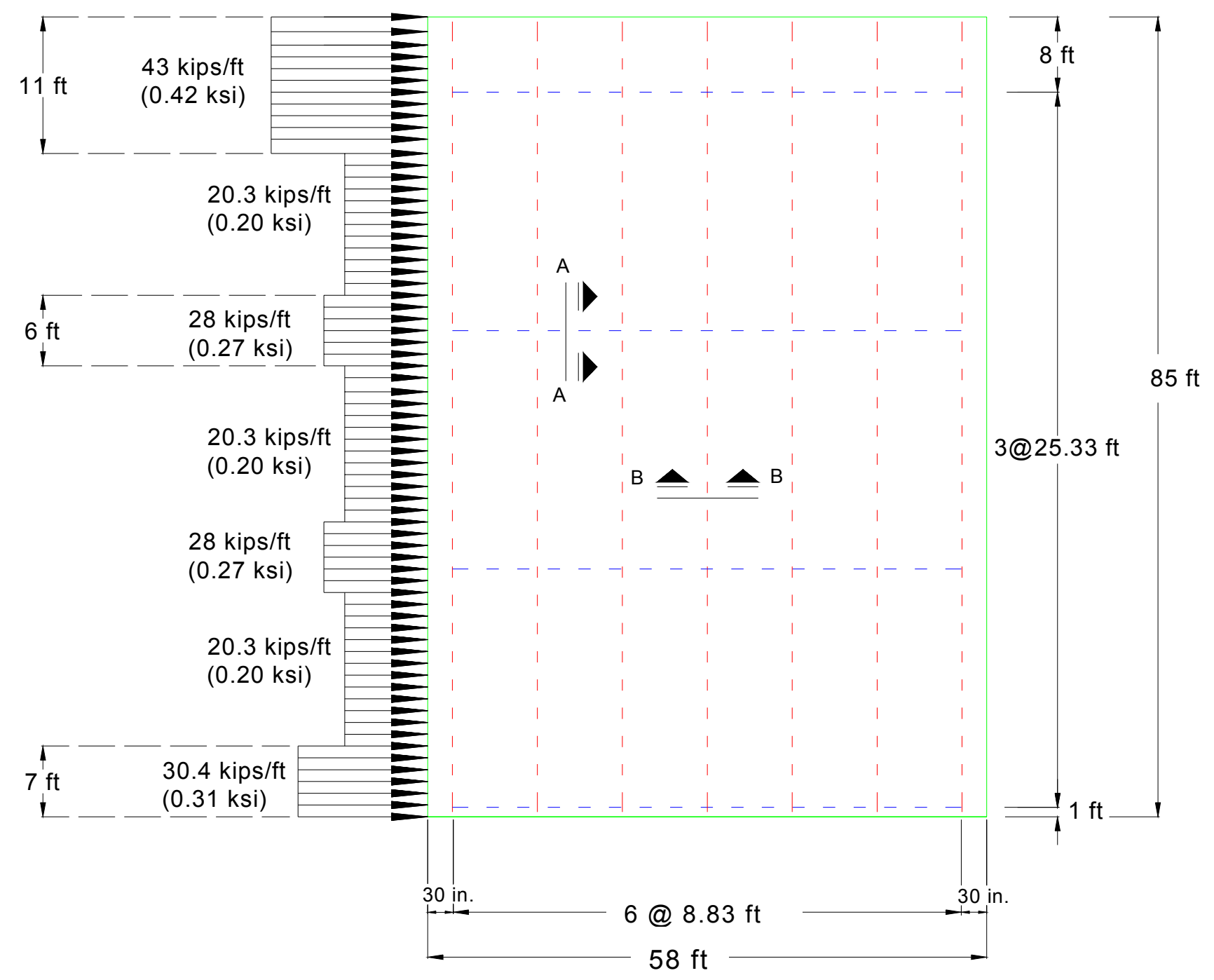

* Prestressing is symmetrical on both edges of the span.

Figure 7.5 Required Distribution of Transverse Postensioning For Example 2 


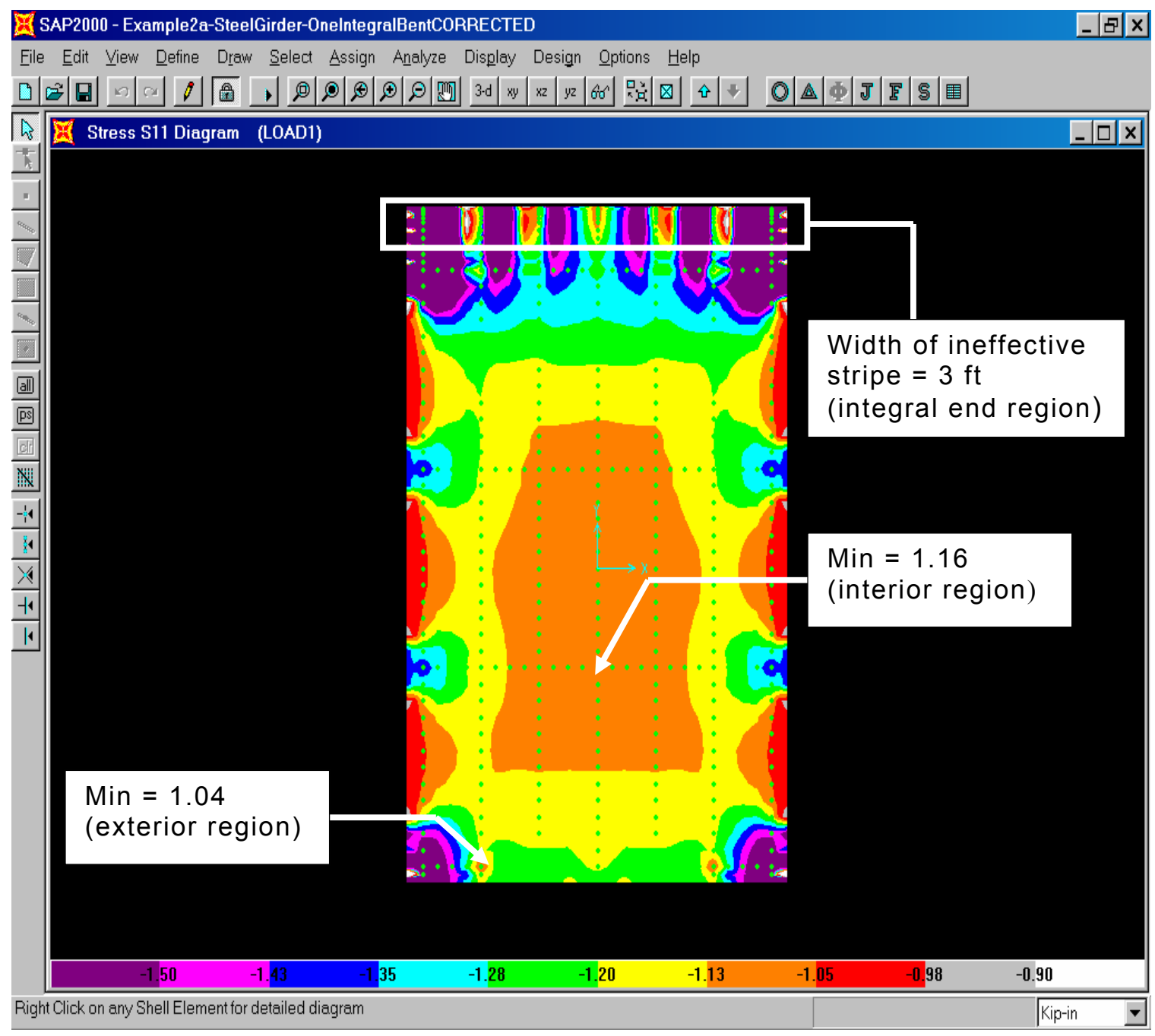

Figure 7.6 Distribution of Normalized Transverse Stresses on the Deck of Example 2 (Analysis using SAP2000) 


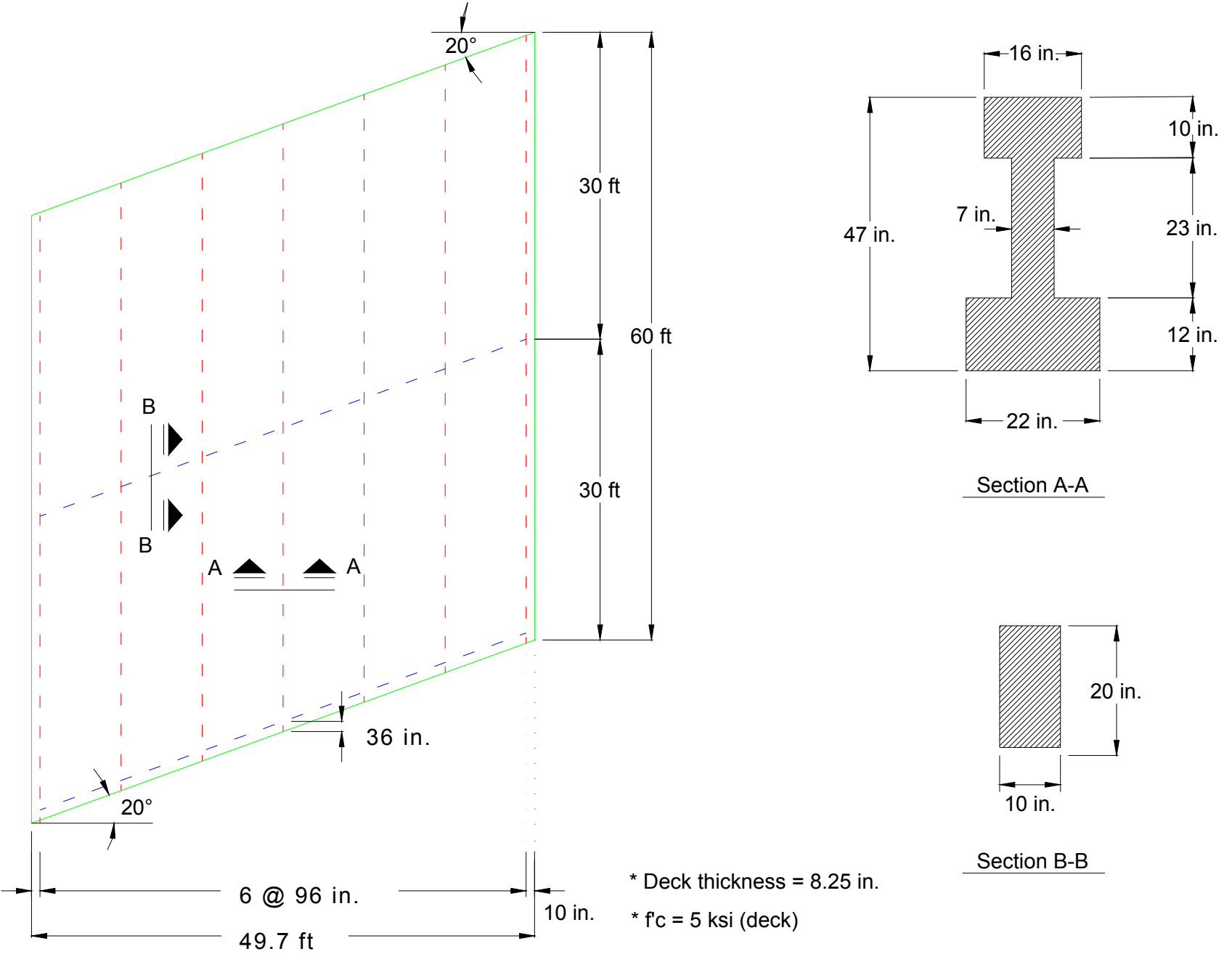

Figure 7.7 Overall View of Bridge Span of Example 3 


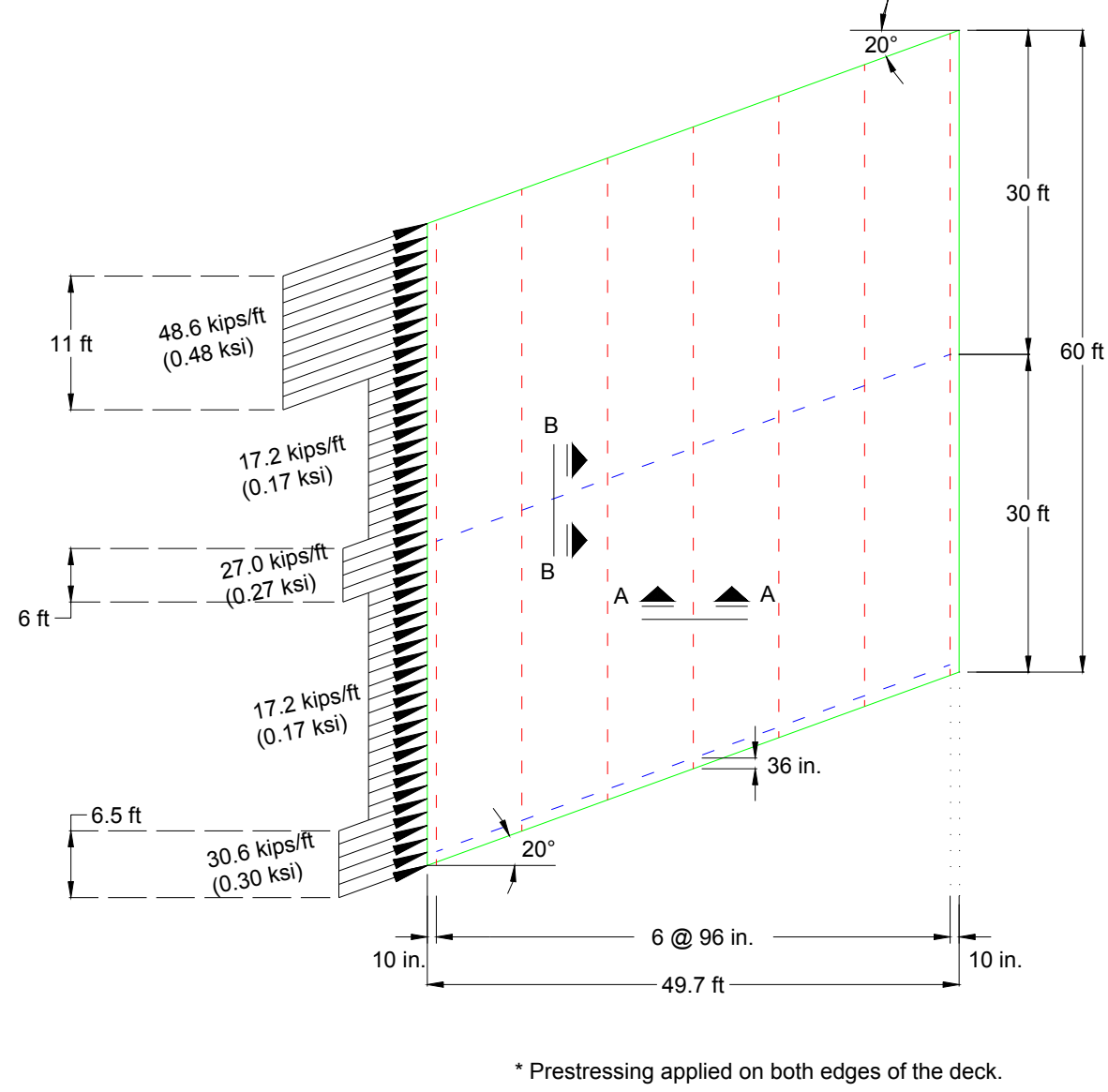

Figure 7.8 Required Distribution of Transverse Post-tensioning for Example 3 


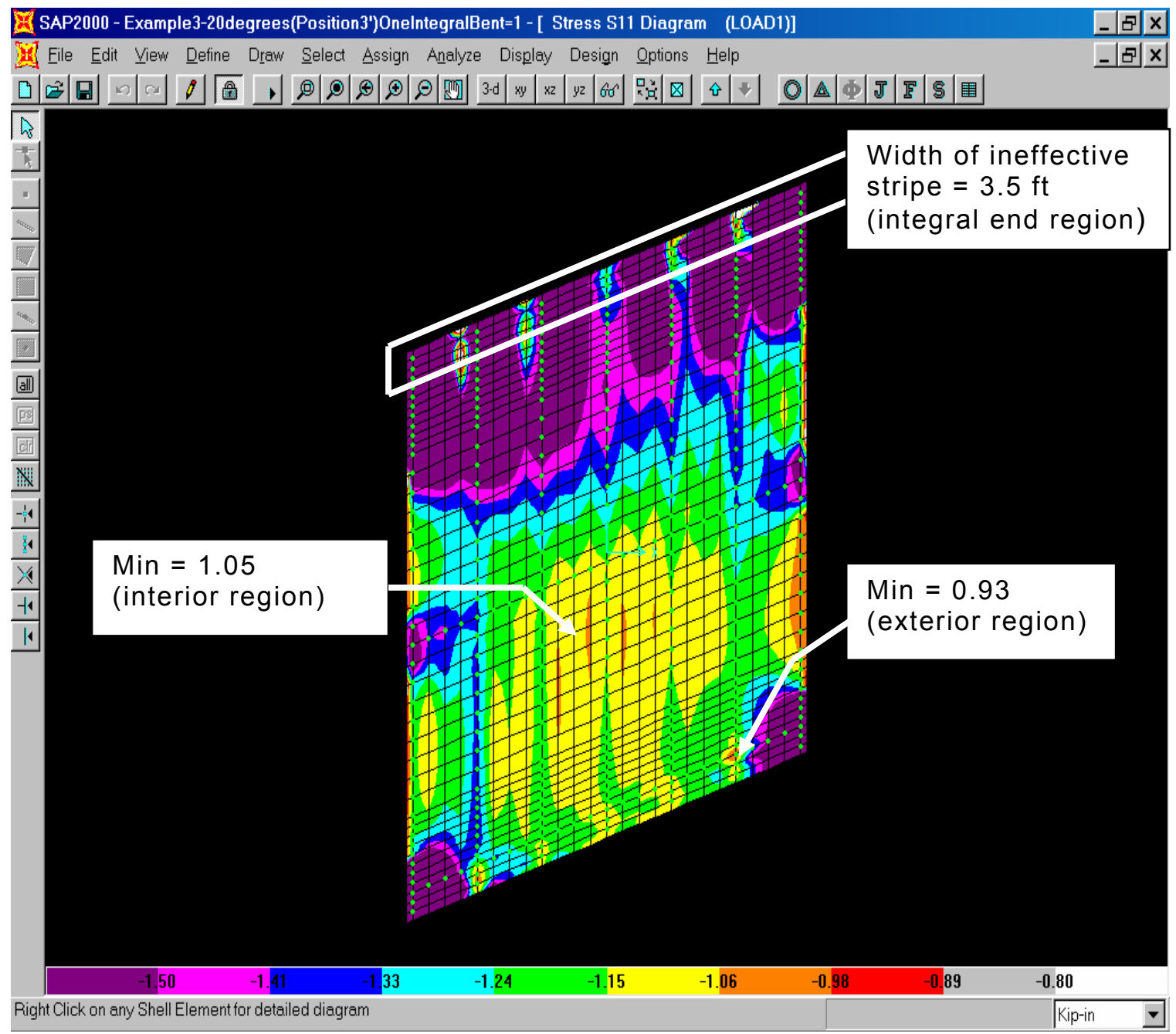

Figure 7.9 Distribution of Normalized Transverse Stresses on the Deck of Example 3 (Analysis using SAP2000) 


\section{8-Summary and Implementation}

\subsection{Summary of Study and Findings}

Premature deterioration of concrete bridge decks has been recognized as a major problem in the United States for more than three decades. The primary cause of this distress is the occurrence of corrosion of the reinforcement and freeze-thaw cycles.

This study is concerned with the application of transverse posttensioning in concrete bridge decks as an alternative procedure to delay the onset of corrosion. The intention is to improve the durability of concrete bridge decks.

The primary objective of this research was twofold:(i) evaluate the structural effects of transverse post-tensioning of bridge decks and, (ii) develop preliminary design specifications for the implementation of such methodology.

The experimental results from previous studies (Appendix B) were used to test the results from alternative modeling techniques and/or alternative Finite Element programs (Chapter 2).

Following the validation of the alternative modeling techniques, a preliminary parametric study was carried out in order to identify the variables of interest. A base case structure was defined and, subjected to transverse forces representing the post-tensioning. It was found that the distribution of transverse stresses is mainly determined by the axial stiffness of the diaphragms, and the boundary conditions of the girders. It was also found that the effect of the axial stiffness of the diaphragms is more significant when these structural members are located closer to the ends of the girders (Chapter 3 ).

After identifying the variables significantly determining the distribution of transverse stresses in the deck, a more detailed parametric study was formulated. Another base structure was defined and consecutively modified according to the set of cases described in 
the parametric study (Table 4.1). A large number of simulations using SAP2000 allowed obtaining the minimum and average transverse stress throughout the deck as a function of the variables included in the detailed parametric study (Chapter 4 ).

A post-tensioning scheme was suggested for the base case structure of Chapter 4. The recommended geometrical distribution of transverse post-tensioning was simple; a different level of post-tensioning must be used at interior diaphragm regions, exterior diaphragm regions, and intermediate regions. Design aids first developed for the base case structure only were subsequently extended to all the cases included in the detailed parametric study. Integral-end bridges were studied as a separate category. Correspondingly additional design recommendations were formulated (Chapter 5). Simplified design aids for most common bridge types in Indiana are included in Chapter 6 .

Finally, Comprehensive examples are included to (i) illustrate the use of the proposed methodology and, (ii) validate the applicability of the formulation (Chapter 7 ).

\subsection{Conclusions}

The salient conclusions from the study are:

- Different modeling schemes for a particular deck-on-girder structure subjected to transverse forces only (test model of the Texas study) were found to produce results reasonably similar to the experimental values. Average ratios of calculated to experimentally inferred stresses ranged from 1.10 to 1.15 .

- The position and size of the diaphragms was determined to play a key role in the distribution of transverse stresses induced by post-tensioning applied at the edge of the deck/slab. The influence of the diaphragm position was approximated evaluated considering a T-section having an increasing flange width as the diaphragm is placed closer to mid-span. From this model, it can 
be seen that the restraining effect of exterior diaphragms is more significant than the effect of interior diaphragms.

- The support and boundary conditions for girders and/or deck, both considered as a mechanism restricting displacements in the transverse direction, greatly restrain the distribution of the transverse stresses on the deck.

- Except for very short spans, the effect of every diaphragm in the superstructure can be taken as independent of the corresponding effect of companion diaphragms. The restraining action of a particular diaphragm is localized in a region of the deck containing such element. Prescribing different levels of posttensioning at different diaphragm regions is recommended.

- The distribution of transverse post-tensioning required can be formulated in terms of transverse forces at interior diaphragm regions, exterior diaphragm regions, and intermediate regions. Different levels of post-tensioning are needed for each region. The level of post-tensioning required at each region of the deck depends primarily on the axial stiffness of the diaphragms and the boundary conditions of the supporting girders. Because the position of the exterior diaphragms and the skew angle of the bridge also have an influence on the distribution of transverse stresses, corresponding correction factors must be introduced.

- The use of transverse post-tensioning in integral bent spans is limited in terms of efficiency. The post-tensioning is found to be ineffective in regions close to the integral support. Practically, a scheme of transverse post-tensioning to limit the size of such "ineffective region" is proposed.

- The parametric study suggests that the methodology of transverse post-tensioning is not practical for integral-end bridges (either steel or concrete) having skew angles larger than $20^{\circ}$. For 
such cases the transverse post-tensioning may induce tensile stresses on top of the deck.

- For steel-girder-integral-bent spans, the transverse posttensioning should be used only if the outermost diaphragm/stiffener is placed not less than $6 \mathrm{ft}$ away from the end of the girder. Otherwise the required transverse force may be excessive.

\subsection{Implementation}

The data required to use the proposed design guidelines include; diaphragm size and type (concrete or steel), definition of boundary conditions for the girders, position of the outermost diaphragm with respect to the ends of the girders and, deck skew angle. The user has the choice of selecting the widths of the diaphragm regions.

The most practical (and easiest) implementation of the suggested methodology consists in considering only two categories for the boundary conditions of the girders; non-integral or integral ends. The first case corresponds to girders' ends supported on either rocker or elastomeric bearings, whereas the second case corresponds to integralabutment ends. Two sets of design aids are available depending on the type of girders for the superstructure under consideration; concrete or steel. The user has the alternative of using more general deign guidelines but this requires a more precise definition of the boundary conditions for the girders. In all cases, the suggested distribution of transverse post-tensioning is such that different application levels of prestressing are required in regions containing the interior and exterior (or outermost) diaphragms.

In the case of skew decks, the proposed methodology requires placing the post-tensioning ducts oriented parallel to the skewed edge of the deck. The design specifications are limited to deck skew angles smaller $30^{\circ}$ for non-integral ends, and $20^{\circ}$ for integral ends. 
For steel-girder-integral-bent spans, transverse post-tensioning should be used only if the outermost diaphragm/stiffener is placed not less than $6 \mathrm{ft}$ away from the end of the girder.

The developed design specifications can also be applicable to slab bridges. In this case the user has to consider slab bridges as particular case of deck-on-girder bridges where the area of transverse concrete elements is zero. 


\section{9- Future Work}

Because INDOT is increasingly encouraging the use of integral abutments, a more detailed study focused solely on the possible application of transverse post-tensioning to these types of bridges is completely desirable.

A detailed study to determine the restraining effects of friction at the rocker bearings of must be carried out. In this study a value of $\mathrm{K}_{\mathrm{s}}$ $=200$ in. was assumed in the simplified design aids. Such value should be better justified by analytical/experimental studies.

The suggested design specifications are just preliminary and are not proposed for immediate use. It is recommended to first verify them test specimens aiming at evaluating the model assumptions. The experimental program should consist of testing at sufficient scale structures similar to those envisioned in the parametric study in the laboratory. Following the laboratory phase, monitoring of a pilot structure in the field is needed. The design specifications presented herein should then be modified, if necessary, according to the results from the experimental phase. 


\section{Appendix A- References}

ACl Committee 318 (2002), Building Code Requirements for Structural Concrete ( $\mathrm{ACl}$ 318-02) and Commentary (ACl 318R-02), American Concrete Institute, Printed in January 2002.

Almustafa, R. A. (1983), The Analysis of Transverse Prestressing Effects in Bridge Decks, Ph.D. Dissertation Thesis, The University of Texas at Austin, 274p.

Beeby, A. W. (1979), Corrosion of Steel Reinforcement and Crack Widths, Brazil Offshore, 1979, Rio de Janeiro, Oct. 8-12, 12p.

Beeby, A, W. (1981), Cracking, Cover, and Corrosion of Reinforcement, 1981 Annual Convention, American Concrete Institute, Dallas, Texas, Feb. 9-13, 9p.

Bishara, A. G., and Elmir, W. E. (1990), Interaction Between Cross Frames and Girders, Journal of Structural Engineering, ASCE, Vol. 116, No. 5, pp. 1319-1333.

Bishara, A. G., Liu, M. C., and El-Ali, N. D. (1993), Wheel Load Distribution on Simply Supported Skew I-Beam Composite Bridges, Journal of Structural Engineering, ASCE, Vol. 119, No. 2, pp. 399419.

Cao, L. C., and Shing, P. B. (1999), Simplified Analysis Method for Slab-on-Girder Highway Bridge Decks, Journal of Structural Engineering, ASCE, Vol. 125, No. 1, 49-59. 
Chan, T.H, and Chan, J. H. (1999), The Use of Eccentric Beam Elements in The Analysis of Slab-on-Girder Bridges, Structural Engineering and Mechanics, Vol. 8, No. 1, pp. 85-102.

Chen, T. Y., Siess, C. P., and Newmark, N. W. (1957), Studies of Slab and Beam Highway Bridges, Part IV: Moments in Simply Supported Skew I-Beam Bridges, Engineering Experimentation Station, University of Illinois, Bulletin No. 439, Vol. 54, University of Illinois, Urbana, 72pp.

Dagher, H. J., and Kulendran, S. (1992), Finite Element Modeling of Corrosion Damage in Concrete Structures, ACI Structural Journal, Vol. 89, No. 6, Nov-Dec., pp. 699-708.

Duberg, J. E., Khachaturian, N., and Fradinger, R. E. (1960), Method for Analysis of Multibeam Bridges, Journal of the Structural Division, ASCE, Vol. 86, No. ST 7.

Indiana State Highway Commission (1975), Bridge Design Manual.

Mabsout, M. E., et al. (1999), Effect of Multilanes on Wheel Load Distribution in Steel Girder Bridges, Journal of Bridge Engineering, ASCE, Vol. 4, No. 2, pp. 99-106.

Mabsout, M. E., Tarhini, K. M., and Frederick, G. R. (1997), FiniteElement Analysis of Steel Girder Highway Bridges, Journal of Bridge Engineering, ASCE, Vol. 2, No. 3, pp. 83-87.

Mora, R. A. (1983), Design and Construction of a Direct Model for the Study of Transverse Prestressing of Bridge Decks, Master of Science Thesis, The University of Texas at Austin, 63p. 
Pfeifer, D. W, and Iverson, J. K. (1985), Bearing Pads for Precast Concrete Buildings, Technical Report Summary, Precast/Prestressed Concrete Institute, PCI Journal, Vol. 30, No. 5, September/October 1985, p. 129-154.

Phipps, A. R. (1985), The Design of Transversely Bridge Decks, Master of Science Thesis, The University of Texas at Austin, 365p.

Poston, R. W. (1984), Improving Durability of Bridge Decks by Transverse Prestressing, Ph.D. Dissertation Thesis, The University of Texas at Austin, 637p.

Poston, R. W., Breen, J. E., Carrasquillo, R. L (1989), Design of Transversely Prestressed Concrete Bridge Decks, PCl Journal, Special Report, pp. 68-101.

Poston, R. W., Carrasquillo, R. L., Breen, J. E. (1987), Durability of Post-tensioned Bridge Decks, ACl Materials Journal, July-August, pp. 315-325.

Poston, R. W., Phipps, A. R., Breen, J. E., and Carrasquillo, R., L. (1985), Design Procedures for Prestressed Concrete Bridge Decks, Center of Transportation Research, Bureau of Engineering Research, The University of Texas at Austin, 175p.

Precast-Prestressed Concrete Institute (1999), PCI Design Manual, $5^{\text {th }}$ Edition. 
Ralls, M. L. (1984), Stress Distribution in a Transversely Prestressed Slab-Girder Bridge Deck, Master of Science Thesis, The University of Texas at Austin, 147p.

Randall, R. W., Phipps, A. R., Almustafa, R. A., Breen, J. E., Carrasquillo, R. L. (1988), Effects of Transverse Prestressing in Bridge Decks, Journal of Structural Engineering, ASCE, Vol. 114, No. 4, 743-764.

SAP2000, Integrated Finite Analysis and Design of Structures, Concrete Design Manual, Computers and Structures, Inc. Berkeley, California, USA.

Suzuki, K., Ohno, Y., Preparntanatorn, S., and Tamura, H. (1990), Mechanism of Steel Corrosion in Cracked Concrete, Third International Symposium on Corrosion of Reinforcement in Concrete Construction, Society of Chemical Industry, U.K, May, pp. 10-28.

Westergaard, M. H. (1930), Computation of Stresses in Bridge Slabs Due to Wheel Loads, Journal of Public Roads.

Weyers, R. E., Pyc, W., and Sprinkel, M. M.(1998), Estimating Life Service of Epoxy-Coated Reinforcing Steel, ACI Materials Journal, Vol. 95, No. 5, Sept.-Oct., pp. 546-557. 


\section{Appendix B- Literature Review}

\section{B.1 Background}

Transverse post-tensioning of bridges was first implemented as an empirical-based practice in Europe during the 60's. The main objectives (Almustafa, 1983) were:

- Maximize the length of cantilever overhangs in box-girder bridges

- Minimize the number of webs of cell-box girders

- Improve the connection between longitudinal girders

- Provide better and less congested reinforcement layout at pier locations

No consideration from the point of view of improving durability was given to transverse post-tensioning of decks until the early 70's when a twin-steel-girder expressway bridge was constructed in Dallas, Texas. The deck used both, longitudinal and transverse post-tensioning.

Analytical and experimental evidence about the behavior of transversely post-tensioned decks became available in the mid 80's when a multi-phase project (Poston et. al (1985)) was carried out at the University of Texas. This research project provided the basis for current design recommendations on transverse post-tensioning of bridge decks. Other uses of transverse post-tensioning of decks have focused on improving the punching shear strength of deck decks and the utilization of FRP as post-tensioning reinforcement.

\section{B.2 Texas Study}

The main analytical findings and design implications resulting from the research project executed at the University of Texas (Texas Study) are further discussed in the following sections. 


\section{B.2.1 Analytical Study}

The design philosophy for transverse post-tensioning consists in providing certain level of compressive stress at the top of the deck to guarantee a crack-free surface at service load level. This philosophy assumes linear elastic behavior of the deck so that the principle of superposition can be applied. Further assumptions include:

1-Isotropic and homogeneous material

2-Small deflections

3-Stress perpendicular to mid-surface of shells is taken as zero.

A series of Finite Element models of the entire superstructure, including deck, girders, and diaphragms were developed (Almustafa (1983), Poston (1984)) to study the distribution of membrane stresses in the bridge deck due to transverse post-tensioning. Membrane stresses in the direction of the post-tensioning are denoted for simplicity as transverse stresses.

The main findings from the analytical study of deck-on-girder bridges can be summarized as follows:

- Diaphragms can significantly change the distribution of the transverse stresses.

- The restraining effect of the longitudinal girders on the distribution of transverse stresses is not significant if the girders are supported on flexible supports (simply supported on neoprene pads).

- Support conditions for the girders significantly restrain the distribution of transverse stresses. 


\section{B.2.2 Experimental Evaluation of Model Bridge}

An approximately half-scale model was tested in the Texas Study (see Figure 2.1). The prototype structure consisted of an 8.25 in. thickdeck, 76-ft span, $58 \mathrm{ft}$ wide, simply supported deck-on-girder bridge.

The prototype structure had 7 standard Texas Type $C$ precast pretensioned girders spaced at $8.83 \mathrm{ft}$, two (2) exterior diaphragms compositely attached to the deck, and two (2) interior diaphragms supported by the bottom flanges of the girders. Interior diaphragms, located at third points, were removed in a second phase of the experimentation. Two types of tests were defined: the all-diaphragm case, and the end-diaphragm case (obtained after removing the interior diaphragms).

Transverse post-tensioning was applied using strands instrumented at the live-end only. In order to evaluate the relative effectiveness of using straight and draped tendons, half of the model deck was posttensioned using straight tendons only, whereas the other half used straight and draped tendons. Only half of the test model was posttensioned at a time.

Transverse stresses were inferred from strain gage readings. The gages were placed at top and bottom of the deck.

\section{B.2.2.1 Relevant findings from the experimental phase:}

- The effect of jacking sequence was found to be insignificant. Measured stress losses associated with jacking sequences were less than $4 \%$ only.

- The restraining effect of the diaphragm was limited only to certain deck region containing such elements.

- The lateral stiffness of the girders had a restraining effect on the transverse distribution of stresses that is confined to very narrow strip regions of the deck over the girders. 
- The results from the F.E. models were in reasonable agreement with the inferred mid-depth transverse stresses (less than $15 \%$ on average, Almustafa (1983)).

- A region of small compressive stresses was found between points of application of post-tensioning near the edge of the deck. The size of this region was determined to be proportional to the distance between adjacent tendons. Phipps (1985) suggested to consider such region as an equilateral triangle with sides equal to the spacing between adjacent tendons.

\section{B.2.3 Design Recommendations}

Design recommendations were formulated based on the following premises: a) the response of the superstructure at service level is linear-elastic so that the principle of superposition is applicable, b) the stresses induced by the service loads are known (from any conventional analysis). The recommendations were given to provide a desired level of compression on top of the deck through transverse post-tensioning. The desired level of compression must be enough to prevent cracking at service load levels.

In absence of restraining effects, the stress on top of the deck associated with a uniform post-tensioning force $F_{s}$ (per unit of length) is $\mathrm{F}_{\mathrm{s}} / \mathrm{t}$, where $\mathrm{t}$ is the deck thickness. Additional transverse posttensioning is required, however, to compensate for the restraining effects of the diaphragms.

For deck-on-girder bridges, no departure from the conventional design is needed provided that the maximum spacing of PT strands and minimum cover requirement are satisfied, and at least one of the following conditions is met:

a) No diaphragms are used, or 
b) The diaphragms are cast after post-tensioning, or

c) The interaction of diaphragms and longitudinal girders is eliminated before transverse post-tensioning of the deck. This could be done theoretically, for instance, by placing a steel plate between the diaphragm and the longitudinal girders before posttensioning of the deck and removing it after post-tensioning. The thickness of such plate should be equal to the elastic shortening of the deck after post-tensioning.

If one of the requirements (a) through (c) is not met, then the design recommendations depart from conventional design only in determining the amount of post-tensioning reinforcement required to compensate for the restraining effect of the diaphragms. Two possible methods were suggested:

\section{B.2.3.1 Method 1:}

Use post-tensioning reinforcement in the "diaphragm region" according to Equation (B.1):

$F_{e}=(f) \times\left(F_{s}\right)$

where:

$\mathrm{F}_{\mathrm{e}}$ : required force in the diaphragm region

$F_{s}$ : transverse prestress (force/unit of length) needed to resist the effects of imposed service loads assuming no restraining effects: coefficient depending on the skew angle

The diaphragm region is defined as a stripe having a width that extends, $x / 2$, from the center of the diaphragm (Figure B.1). The width of the diaphragm region, $x$, depends on the skew angle as follows: 
For skew angles $\theta<10^{\circ}$

$$
\begin{aligned}
& x=4 \mathrm{ft} \\
& \mathrm{f}=1.6
\end{aligned}
$$

For skew angles $\theta>10^{\circ}$

$$
\begin{aligned}
& x=4 f t+W \tan \theta \leq(L+W \tan \theta) / N \\
& f=1.2
\end{aligned}
$$

where,

$\theta$. : skew angle

W : deck width

$L$ : span length

$\mathrm{N}$ : number of diaphragm in a single span

It must be pointed out that Method 1, for the particular case of skew angle equal to zero, is the only procedure for which experimental evidence is available from the test model in the Texas Study.

\section{B2.2.3.2 Method 2:}

Apply prestressing to each diaphragm in order to provide a force level given by:

$P_{D}=C_{t} \cdot C_{k} \cdot C_{L} \cdot C_{S K} \cdot\left(1 \cdot 6 F_{S}\right)$

where:

$P_{D}$ : Post-tensioning force required to counteract the restraining effect of the diaphragm, $\mathrm{C}_{\mathrm{t}}$, : correction factor to account for deck thickness, $\mathrm{C}_{\mathrm{k}}$, : correction factor to account for diaphragm stiffness, $C_{L}$, : correction factor to account for diaphragm spacing, $\mathrm{C}_{\mathrm{sk}}$ : correction factor to account for bridge skew angle. 
The product of the previous factors is 1 for a deck thickness of 8 in., bridge skew of $0^{\circ}$, diaphragm spacing of $25 \mathrm{ft}$, and a standard concrete diaphragm in Texas (approximately $160 \mathrm{in}^{2}$ ). For that particular case, according to Equation (B.4), the diaphragm force required to approximately obtain a uniform distribution of stresses at the top of the deck is 1.6 times the transverse force needed at the edge of the deck in absence of restraining effects.

Correction factor for deck thickness, $\mathrm{C}_{\mathrm{t}}$ :

As the thickness of the deck, $t$, increases, the relative stiffness of the diaphragm becomes less significant:

$\mathrm{C}_{\mathrm{t}}=8 \mathrm{in} . / \mathrm{t}$

Correction factor for diaphragm stiffness, $\mathrm{C}_{\underline{k}}$ :

As the axial stiffness of the diaphragm, $(E A)_{D}$ (where $E, A$ are the modulus of elasticity and transverse area of the diaphragm), increases, its restraining effect becomes more significant. The following correction factor was suggested:

$\mathrm{C}_{\mathrm{K}}=(\mathrm{EA})_{\mathrm{D}} / 640,000 \mathrm{kips}$

Correction factor for diaphragm spacing, $\mathrm{C}_{\mathrm{L}}$ :

As the diaphragm spacing, $S_{D}$, increases, the associate restraint effects becomes less significant. The following correction factor was suggested:

$C_{L}=25 \mathrm{ft} / S_{D}$ 
Correction factor for bridge skew angle:

As the bridge skew angle, $\theta$, increases, the relative stiffness of the diaphragm becomes less significant. The following correction factor was suggested:

$\mathrm{C}_{\mathrm{SK}}=\cos \theta>0.75$

It must be pointed out that the specifications given in Method 2 are based on analytical studies only.

\section{B.2.4 Additional Design Recommendations}

1) Shrinkage and temperature reinforcement should still be provided as specified in current conventional design.

2) The required edge prestress force must be estimated based on a limiting concrete tensile stress at service (dead plus live load including impact) of $2 \sqrt{f_{c}^{\prime}}$ psi ( $f_{c}^{\prime}$ is in psi). This limiting value accounts for fatigue of the prestressing reinforcement in the event of cracking, and possible overloads.

3) Additional transverse mild reinforcement must be provided when using unbonded post-tensioning to control crack propagation in the event of overloads.

4) A crack-free design in the longitudinal direction must also be specified.

5) Continuous decks over discontinuous girders must be avoided. 
6) The minimum protection scheme against corrosion in the longitudinal direction at continuous supports (bent location) consists of one of the following:

a) Use epoxy coated reinforcement,

b) Post-tension the deck in the region of the support,

c) Drape post-tensioning cable in continuous girder in the top part of the deck.

7) Straight tendons should not be placed in a single row at the centroid of the deck. This provision aims to eliminate splitting failure associated with the multiple in-line anchorage zones. Two rows of tendons are preferable.

8) Maximum strand spacing for transverse post-tensioning is controlled by:

a) Prevention of shear lagging.

b) Avoidance of truckloads acting in regions of the deck between adjacent points of application of post-tensioning.

9) The practice of using draped tendons in the deck may be limited because:

- Requirement of minimum cover limits the space available for draping.

- Accidental eccentricities are more likely to occur. For the deck model tested in Texas Study, it was observed that a placement error of $1 / 4$ in. could cause design transverse moment changes of about $18 \%$.

- Labor costs are increased as a function of extra time and effort

- Friction losses are more significant. 


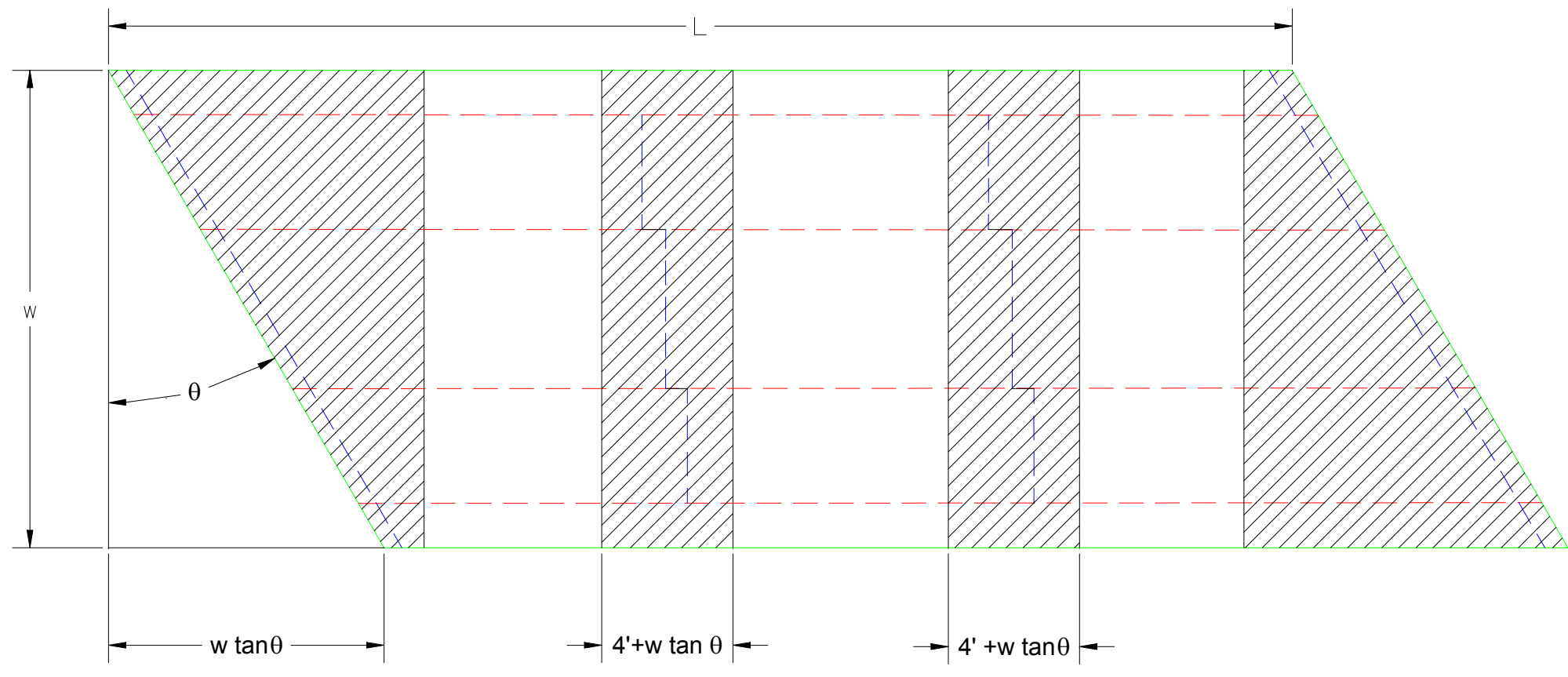

Figure B.1 Diaphragm Region in a Skewed Bridge Deck 